\title{
TRANSMISSÃO DE PREÇOS AGRÍCOLAS INTERNACIONAIS SOBRE PREÇOS AGRÍCOLAS DOMÉSTICOS: O CASO DO BRASIL
}

\author{
MARIO ANTONIO MARGARIDO \\ Bacharel em Ciências Econômicas
}

Orientador: Prof. Dr. GERALDO SANT'ANA DE CAMARGO BARROS

Tese apresentada à Escola Superior de Agricultura "Luiz de Queiroz", Universidade de São Paulo, para obtenção do título de Doutor em Ciências, Área de Concentração: Economia Aplicada.

PIRACICABA

Estado de São Paulo - Brasil

Julho -2000 


\title{
Dados Internacionais de Catalogação na Publicação (CIP) DIVISÃo DE BIBLIOTECA E DOCUMENTAÇÃo - Campus "Luiz de Queiroz"/USP
}

\author{
Margarido, Mario Antonio \\ Transmissão de preços agricolas internacionais sobre preços agrícolas domésticos: \\ caso do Brasil / Mario Antonio Margarido. - - Piracicaba, 2000. \\ $173 \mathrm{p}$. \\ Tese (doutorado) - Escola Superior de Agricultura Luiz de Queiroz, 2000. \\ Bibliografia. \\ 1. Economia doméstica 2. Economia internacional 3. Econometria 4. Estabilização \\ econômica 5. Preço agrícola 6 . Setor agrícola 7. Setor industrial 8 . Série temporal I. \\ Título
}

CDD 338.13 


\section{ERRATA}

Página 2, linha 5: onde lè-se ...Através da utilizaçăo de preços.... leia-se ....Através da utilizaçăo de políticas de preços....

Página 17, linha 9: onde lê-se ...da economia é rejeitada ..... leia-se ....da economia.

Página 21, linhas 13-14: onde lê-se ... transmitidos de forma mais instantánea.... leia-se ....transmitidos instantaneamente com mais intensidade....

Página 38, linha 9: onde lê-se .... na variável preço nivel de preço... leia-se .... na variável nivel de preço.

Página 62, linha 29: onde lê-se ..... variável aleatória... leia-se ...processo estocástico....

Página 62, linha 31: onde lê-se .... modelo.... leia-se ...método... .

Página 64: Fórmulas 5, 7 e 8, onde lê-se:

$$
y_{t}=\alpha+\beta t+\rho_{1} y_{t-1}-\sum_{j=1}^{p-1} \rho_{j+1} \nabla y_{t-j}+e_{t}
$$

leia-se:

$$
\nabla y_{t}=\alpha+\beta t+\rho_{1} y_{t-1}-\sum_{j=1}^{p-1} \rho_{j+1} \nabla y_{t-j}+e_{t}
$$

onde lê-se:

$$
y_{t}=\alpha+\beta t+\left(\rho_{1}-1\right) y_{t-1}-\sum_{j=1}^{p-1} \rho_{j+1} \nabla y_{t-j}+e_{t}
$$

leia-se:

$$
\nabla y_{t}=\alpha+\beta t+\left(\rho_{1}-1\right) y_{t-1}-\sum_{j=1}^{k-1} \rho_{j+1} \nabla y_{t-j}+e_{t}
$$

onde lê-se:

$$
y_{t}=\alpha+\beta t+\left(\rho_{1}-1\right) y_{t-1}-\sum_{j=1}^{p-1} \rho_{j+1} \nabla y_{t-j}+a_{t}-\sum_{j=1}^{g} \theta_{j} a_{i-j}
$$

leia-se:

$$
\nabla y_{t}=\alpha+\beta t+\left(\rho_{1}-1\right) y_{t-1}-\sum_{j=1}^{p-1} \rho_{j+1} \nabla y_{t-j}+a_{t}-\sum_{j=1}^{q} \theta_{j} a_{t-j}
$$

Página 67, linha 5: onde lê-se ... random walk ... leia-se ...passeio casual (random walk)...

Página 76, linha 1: onde lê-se ...ser definida como... leia-se ...ser positiva definida.

Página 81: o símbolo relativo à porcentagem deve ser suprimido da seguinte fórmula:

$$
\left(\frac{c_{21}^{2}}{c^{2}}+c_{22}^{2}\right) \cdot 100 \%
$$

Página 90, linha 19: onde lê-se ... Auto-regressivos Integrados de Médias (ARIMA) leia-se ... Autoregressivos Integrados de Médias Móveis (ARIMA) .... 
Esta Tese é dedicada ao meu pai Julio

e a minha mãe Ruth (em memória) 


\section{AGRADECIMENTOS}

Inicialmente, gostaria de agradecer ao Instituto de Economia Agricola que me liberou para o curso de doutorado e me deu as condiçōes necessárias para desenvolver a presente tese. Em seguida, destaco o auxilio financeiro da Fundação Coordenação de Aperfeiçoamento de Pessoal de Nivel Superior (CAPES), durante o periodo de realização das disciplinas do curso de Doutorado em Economia Aplicada, na Escola Superior de Agricultura Luiz de Queiroz (ESALQ) da Universidade de São Paulo (USP).

A conclusão desse trabalho somente foi possivel graças as intervenções providenciais, diretas ou indiretas, de várias pessoas com as quais tenho enorme divida de gratidão. Sendo assim, do Instituto de Economia Agricola (IEA) agradeço aos Pesquisadores José Roberto Vicente e Arthur Antonio Ghilardi, pela paciência em ler as versōes anteriores desse estudo, e fazer criticas e sugestōes para aprimoramento do trabalho. Agradeço também aos Pesquisadores Francisco Alberto Pino, pela participação no Seminário de Avaliação do Projeto de Tese e no Exame de Qualificação, e Lilian Cristina Anefalos, pelo apoio na construção de rotinas do programa SAS utilizadas neste trabalho. Destaco também o auxilio do Pesquisador Afonso Negri Neto, que na hora do "sufoco" nos ajudou prontamente.

Agradeço às bibliotecárias do IEA, Vandete Pereira do Nascimento Medeiros e Aparecida Joana da Silva, que se desdobraram para localizar e trazer publicaçōes relativas ao tema da tese, trazendo-nos prontamente obras indispensáveis para o desenvolvimento do trabalho.

Enfatizo a colaboração da minha amiga Irene Francisca Lucatto, pelo incansável trabalho de "xerocar" as diversas versōes deste estudo.

Em especial, gostaria de agradecer a amiga e Pesquisadora Maura Maria Demétrio Santiago, tanto pelo apoio técnico-científico ao longo do desenvolvimento deste estudo, bem como pelo suporte espiritual, no periodo em que foi um dos piores momento pelo qual uma pessoa pode passar, que é a perda de um ente querido.

Durante os dois anos vividos na ESALQ, outro grupo de pessoas auxiliou na realização desta tese, e agradeço ao Prof. Dr. Geraldo S. de Camargo Barros, pela orientação e escolha do tema da tese, e ao Prof. Dr. Carlos José Caetano Bacha, pelas críticas e sugestões no Seminário e no Exame de Qualificação. Agradeço também à Prof Dra. Miriam Rumenos P. Bachi, ao Prof. Dr. Joaquim Guilhoto e ao Prof. Dr. Pedro Melo, os quais contribuiram para nosso aperfeiçoamento acadêmico. Ainda com relação ao Departamento de Economia da ESALQ, agradeço também à Secretária da Pós-graduação, Maieli, pela pronta ajuda em relação às questões burocráticas, e à Ligiana, da Biblioteca da Economia, pela revisão da literatura citada. 
Agradeço também à todos os colegas e amigos do curso, principalmente à Aninha, à Suely, à Rossana, ao Moretto, ao Eduardo Leão, ao Ricardinho, ao Alexandre e ao Fabiano.

Destaque especial faço aos pais da Aninha, Sr. Pedro e Dona Virgínia, que foi uma segunda mãe durante o período que estive em Piracicaba.

Finalmente, agradeço ao amigo e mestre, Arício Xavier de Oliveira, Professor da Escola de Administração de Empresas de São Paulo (EAESP), da Fundação Getúlio Vargas (FGV), pelo apoio nos trabalhos relacionados com o tema da tese. 


\section{SUMÁRIO}

Página

LISTA DE FIGURAS

LISTA DE TABELAS

RESUMO

SUMMARY

1. - INTRODUÇÃO

2. - OBJETIVOS.

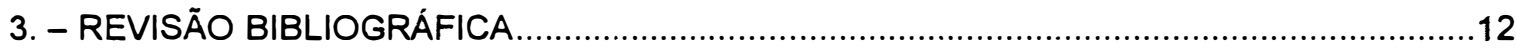

4. - MODELO TEÓRICO DE TRANSMISSÃO INTERNACIONAL DE PREÇOS AGRíCOLAS SOBRE PREÇOS AGRÍCOLAS DOMÉSTICOS ...............................................................23

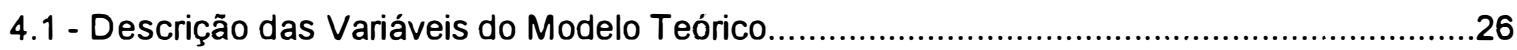

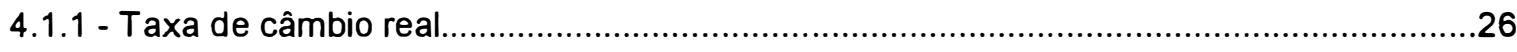

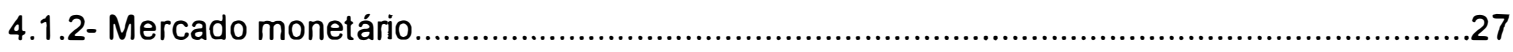

4.1.3 - Mercado agrícola

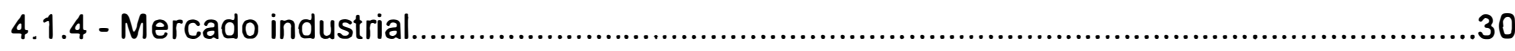

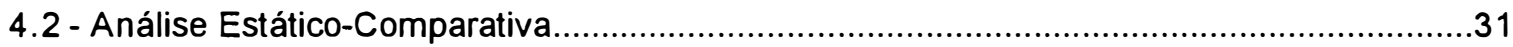

4.2.1 - Análise dos choques dos preços internacionais de produtos agrícolas sobre os preços domésticos agrícola e industrial....................................................................................34

4.2.2 - Análise dos choques no nivel de preços internacionais sobre os preços domésticos agrícola e industrial...................................................................................................

4.2.3 - Análise dos choques na oferta de moeda sobre os preços domésticos agrícola e

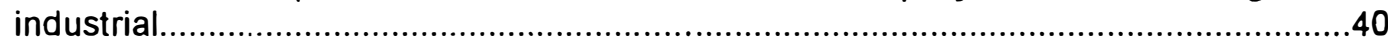

4.2.4 - Análise dos choques na taxa de câmbio sobre os preços domésticos agrícola e

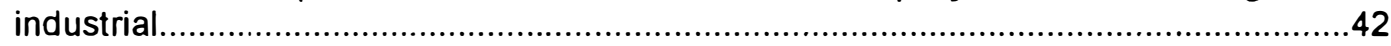

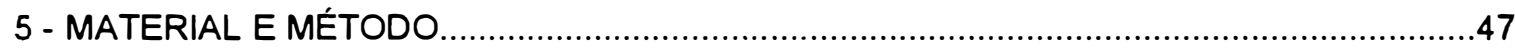

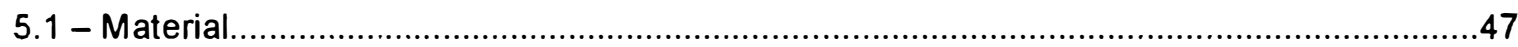


5.1.2 - Padronização dos dados. .50

5.2 - Método. 62

5.2.1 - Testes de raiz unitária 62

5.2.2 - Análise de intervenção 68

5.2.3 - Teste de raiz unitária com quebra estrutural. .71

5.2.3.1 - Modelo additive outlier (AO). .71

5.2.3.2 - Modelo innovational outlier (IO). .73

5.2.4 - Modelo Auto-regressivo Vetorial (VAR). .74

5.2.5 - Processos auto-regressivos vetoriais. . .75

5.2.6 - Teste da razão de verossimilhança. .77

5.2.7 - Função de resposta de impulso. .78

5.2.8 - Decomposição da variância dos erros de previsão. .80

5.2.9 - Modelo VAR identificável. 82

5.3 - Co-integração .83

6 - ANÁLISE DE RESULTADOS. .89

6.1 - Testes de Raiz Unitária. .90

6.1.1 - Testes de raiz unitária ADF e PP, periodo de janeiro de 1990 a junho de $1994 .$. .93

6.1.2 - Testes de raiz unitária ADF, periodo de julho de 1994 a dezembro de 1998. .101

6.1.3 - Testes de raiz unitária ADF, período de janeiro de 1990 a dezembro de 1998 106

6.1.4 - Testes de raiz unitária com quebra estrutural, periodo de janeiro de 1990 a dezembro de 1998 
6.2.1 - Teste de co-integração, período de janeiro de 1990 a junho de 1994

6.2.2 - Teste de co-integração, período de julho de 1994 a dezembro de 1998

6.2.3 - Teste de co-integração, período de janeiro de 1990 a dezembro de 1998

6.3.- Modelo vetorial de correção de erro (VEC)

6.3.1 - Modelo Auto-regressivo Vetorial (VAR) Identificável

6.3.2.- Modelo Vetorial de Correção de Erro (VEC) julho de 1994 a dezembro de1998.

6.3.2.1 - Análise da decomposição da variância dos erros de previsão.

6.3.2.2 - Análise da função de resposta de impulso

6.3.2.2.1 - Efeitos de choques em LPET sobre o bloco de variáveis domésticas

6.3.2.2.2 - Efeitos de choques em LIRMI sobre o bloco de variáveis domésticas. 148

6.3.2.2.3 - Efeitos de choques em LIFI sobre o bloco de variáveis domésticas 151

6.3.2.2.4 - Efeitos de choques em LIPPUS sobre o bloco de variáveis domésticas. 152

6.3.2.2.5 - Efeitos de choques em LTCR sobre o bloco de variáveis domésticas 154

6.3.2.2.6 - Efeitos de choques em LM2 sobre o bloco de variáveis domésticas 157

Conclusões 159

Referências Biliográfica .165

Anexo 1 172 


\section{LISTA DE FIGURAS}

Página

Figura 1 - Logaritmo do Índice Internacional de Preços de Alimentos (LIFI), Janeiro de 1990 a Dezembro de 1998.

Figura 2 - Logaritmo do Índice Internacional de Preços de Matérias-primas Agrícolas (LIRMI), Janeiro de 1990 a Dezembro de 1998.

Figura 3 - Logaritmo do Preço Internacional do Petróleo (LPET), Janeiro de 1990 a Dezembro de 1998.

Figura 4 - Logaritmo do Índice de Preços ao Produtor (LIPPUS), Estados Unidos, Janeiro de 1990 a Dezembro de 1998.

Figura 5 - Logaritmo da Oferta de Moeda (LM2), Brasil, Janeiro de 1990 a Dezembro de 1998

Figura 6 - Logaritmo da Taxa de Câmbio Real (LTCR), Brasil, Janeiro de 1990 a Dezembro de 1998.

Figura 7 - Logaritmo da Relação de Troca entre Agricultura e Indústria (LRT), Brasil, Janeiro de 1990 a Dezembro de 1998.

Figura 8: Elasticidades de função de resposta de impulso, efeitos de choques em LPET sobre LRT, LTCR e LM2. 148

Figura 9: Elasticidades de função de resposta de impulso, efeitos de choques em LIRMI sobre LRT, LTCR e LM2. 150

Figura 10: Elasticidades de função de resposta de impulso, efeitos de choques em LIFI sobre LRT, LTCR e LM2.

Figura 11: Elasticidades de função de resposta de impulso, efeitos de choques em LIPPUS sobre LRT, LTCR e LM2.

Figura 12: Elasticidades de função de resposta de impulso, efeitos de choques em LTCR sobre LRT e LM2.....

Figura 13: Elasticidades de função de resposta de impulso, efeitos de choques em LM2 sobre LRT. 


\section{LISTA DE TABELAS}

Página

TABELA 1.- İndice de Preço Internacional de Alimentos, 1990-98 .53

TABELA 2.- Indice de Preço Internacional de Matérias-primas Agricolas, 1990-98. 54

TABELA 3.- Preço Internacional do Petróleo, 1990-98. .55

TABELA 4.- İndice de Preços ao Produtor, Estados Unidos, 1990-98. .56

TABELA 5.- Taxa de Câmbio, Brasil, 1990-98. .57

TABELA 6.- Meios de Pagamento (M2), Brasil, 1990-98 .58

TABELA 7.- Índice de Preços no Atacado (disponibilidade interna), Brasil, 1990-98. .59

TABELA 8.- İndice de Preços de Produtos Agrícolas, Brasil, 1990-98. 60

TABELA 9.- İndice de Preços de Produtos Industriais, Brasil, 1990-98. 61

TABELA 10. - Determinação do número de defasagens segundo o Critério de Informação de Schwarz (SBC) para executar o teste de raiz unitária do tipo ADF e PP para as variáveis LIFI, LIRMI, LPET, LIPPUS, LM2, LTCR e LRT, Janeiro de 1990 a Junho de 1994 95

TABELA 11. - Resultados dos Testes de Raiz Unitária Dickey-Fuller Aumentado (ADF) ${ }^{1}$ para as variáveis LIFI, LIRMI, LPET, LIPPUS, LM2 e LRT, Janeiro de 1990 a Junho de 1994. .99

TABELA 12. - Resultados dos Testes de Raiz Unitária Phillips-Perron (PP) ${ }^{1}$ para as variáveis LIFI, LIRMI, LPET, LIPPUS, LM2 e LRT, Janeiro de 1990 a Junho de 1994...100

TABELA 13.- Estimativas dos Parâmetros do Teste de Raiz Unitária ADF com Variáveis de Intervenção do tipo Pulse, para a Variável LTCR, Janeiro de 1990 a Junho de 1994. 100

TABELA 14. - Determinação do número de defasagens segundo o Critério de Informação de Schwarz (SBC) para executar o teste de raiz unitária do tipo ADF para as variáveis LIFI, LIRMI, LPET, LIPPUS, LM2, LTCR e LRT, Julho de 1994 a Dezembro de 1998 
TABELA 15. - Resultados dos Testes de Raiz Unitária Dickey-Fuller Aumentado (ADF) ${ }^{1}$ para as variáveis LIFI, LIRMI, LPET, LIPPUS, LM2 e LRT, Julho de 1994 a Dezembro de 1998. .104

TABELA 16. - Resultados dos Testes de Raiz Unitária Phillips-Perron (PP) ${ }^{1}$ para as variáveis LIFI, LIRMI, LPET, LIPPUS, LM2 e LRT, Julho de 1994 a Dezembro de 1998. .105

TABELA 17.- Estimativas dos Parâmetros do Teste de Raiz Unitária ADF com Variáveis de Intervenção do tipo Pulse, para a Variável LTCR, Julho de 1994 a Dezembro de 1998. 106

TABELA 18. - Determinação do número de defasagens segundo o Critério de Informação de Schwarz (SBC) para executar o teste de raiz unitária do tipo ADF e PP para as variáveis LIFI, LIRMI, LPET, LIPPUS e LRT, Janeiro de 1990 a Dezembro de 1998 108

TABELA 19. - Resultados dos Testes de Raiz Unitária Dickey-Fuller Aumentado (ADF) ${ }^{1}$ para as variáveis LIFI, LIRMI, LPET, LIPPUS e LRT Janeiro de 1990 a Dezembro de 1998. 110

TABELA 20. - Resultados dos Testes de Raiz Unitária Phillips-Perron (PP) ${ }^{1}$ para as variáveis LIFI, LIRMI, LPET, LIPPUS e LRT Janeiro de 1990 a Dezembro de 1998.......111

TABELA 21.- Estimativas dos Parâmetros do Modelo de Regressão com Variável de Intervenção e do Teste de Raiz Unitária Dickey-Fuller Aumentado para a Variável LM2, Modelo Additive Outlier (AO) caso 3, Janeiro de 1990 a Dezembro de 1998. 113

TABELA 22.- Estimativas dos Parâmetros do Teste de Raiz Unitária ADF com Variáveis de Intervenção do tipo Pulse, para a Variável LTCR, Janeiro de 1990 a Dezembro de 1998

TABELA 23.- Critério de Informação de Akaike para o Modelo Auto-regressivo Vetorial (VAR), variáveis LPET, LIRMI, LIFI, LIPPUS, LTCR, LM2 e LRT, Janeiro de 1990 a Junho de 1994.

TABELA 24.- Resultados do Teste de Co-integração de Johansen, variáveis LRT, LPET, LIRMI, LIFI, LIPPUS, LTCR e LM2, Janeiro de 1990 a Junho de 1994 .119

TABELA 25.- Coeficientes da primeira equação de co-integração normalizada, variáveis LPET, LIRMI, LIFI, LIPPUS, LTCR, LM2 e LRT, Janeiro de 1990 a Junho de $1994 \ldots . . .121$

TABELA 26.- Critério de Informação de Akaike para o Modelo Auto-regressivo Vetorial (VAR), variáveis LPET, LIRMI, LIFI, LIPPUS, LTCR, LM2 e LRT, Julho de 1994 a dezembro de 1998.

TABELA 27.- Resultados do Teste de Co-integração de Johansen, variáveis LPET, LIRMI, LIFI, LIPPUS, LTCR, LM2 e LRT, Julho de 1994 a Dezembro de 1998. 123

TABELA 28.- Coeficientes da primeira equação de co-integração normalizada, variáveis LPET, LIRMI, LIFI, LIPPUS, LTCR, LM2 e LRT, Julho de 1994 a Dezembro de 1998 
TABELA 29.- Critério de Informação de Akaike para o Modelo Auto-regressivo Vetorial (VAR), variáveis LPET, LIRMI, LIFI, LIPPUS, LTCR, LM2 e LRT, Janeiro de 1990 a Dezembro de 1998. .125

TABELA 30.- Resultados do Teste de Co-integração de Johansen, variáveis LPET, LIRMI, LIFI, LIPPUS, LTCR, LM2 e LRT, Janeiro de 1990 a Dezembro de 1998. 126

TABELA 31.- Coeficientes da primeira equação de co-integração normalizada, variáveis LPET, LIRMI, LIFI, LIPPUS, LTCR, LM2 e LRT, Janeiro de 1990 a Dezembro de 1998.

TABELA 32.- Estimativas dos coeficientes da matriz $A_{0}$ 131

TABELA 33.- Coeficientes das equações de co-integração e do modelo Vetorial de Correção de Erro (VEC), variáveis LPET, LIRMI, LIFI, LIPPUS, LTCR, LM2 e LRT, Julho de 1994 a Dezembro de 1998. 133

TABELA 34.- Resultados da Decomposição da Variância dos Erros de Previsão em Porcentagem para as variáveis LPET, LIRMI. LIFI, LIPPUS, LTCR, LM2 e LRT, Julho de 1994 a Dezembro de 1998. 140

TABELA 35.- Resultados da Decomposição da Variância dos Erros de Previsão em Porcentagem para as variáveis LPET, LIRMI. LIFI, LIPPUS, LTCR, LM2 e LRT, Julho de 1994 a Dezembro de 1998. 141

TABELA 36.- Resultados da Decomposição da Variância dos Erros de Previsão em Porcentagem para as variáveis LPET, LIRMI. LIFI, LIPPUS, LTCR, LM2 e LRT Julho de 1994 a Dezembro de 1998. .142

TABELA 37.- Resultados da Decomposição da Variância dos Erros de Previsão em Porcentagem para as variáveis LPET, LIRMI. LIFI, LIPPUS, LTCR, LM2 e LRT Julho de 1994 a Dezembro de 1998. .143

TABELA 38.- Resultados da Decomposição da Variância dos Erros de Previsão em Porcentagem para as variáveis LPET, LIRMI. LIFI, LIPPUS, LTCR, LM2 e LRT Julho de 1994 a Dezembro de 1998. .144

TABELA 39.- Resultados da Decomposição da Variância dos Erros de Previsão em Porcentagem para as variáveis LPET, LIRMI. LIFI, LIPPUS, LTCR, LM2 e LRT Julho de 1994 a Dezembro de 1998. 145

TABELA 40.- Resultados da Decomposição da Variância dos Erros de Previsão em Porcentagem para as variáveis LPET, LIRMI. LIFI, LIPPUS, LTCR, LM2 e LRT Julho de 1994 a Dezembro de 1998. 


\section{LISTA DE QUADROS}

Páginas

QUADRO 1.- Comparativo dos autores aqui comentados 16

QUADRO 2: Descrição resumida do modelo teórico 31

QUADRO 3 - Elasticidades dos preços domésticos com respeito a choques nos preços internacionais de produtos agrícolas sob diferentes hipóteses de transmissão. 34

QUADRO 4 - Elasticidades dos preços domésticos com respeito a choques no nivel de preços internacionais sob diferentes hipóteses de transmissão.

QUADRO 5 - Elasticidades dos preços domésticos com respeito a choques na oferta de moeda sob diferentes hipóteses de transmissão. .40

QUADRO 6 - Elasticidades dos preços domésticos com respeito a choques na taxa de câmbio sob diferentes hipóteses de transmissão. 


\title{
TRANSMISSÃO DE PREÇOS AGRICOLAS INTERNACIONAIS SOBRE PREÇOS AGRICOLAS DOMÉSTICOS: O CASO DO BRASIL
}

\author{
Autor: MARIO ANTONIO MARGARIDO
}

Orientador: PROF. DR. GERALDO SANT'ANA DE CAMARGO BARROS

\section{RESUMO}

Este trabalho analisou os efeitos que choques em variáveis macroeconômicas externas e domésticas tem sobre o comportamento do indice de relação de troca entre o setor agrícola e industrial no Brasil para o período de janeiro de 1990 até dezembro de 1998. O modelo utiliza a teoria de equilibrio parcial que considera ações individuais e conjuntas nos preços dos produtos agricolas domésticos e internacionais. A principal hipótese é que o processo de abertura econômica iniciada em 1990, conjuntamente com a estabilização dos preços domésticos em julho de 1994 proporcionada pela implementação do Plano Real, tornaram os preços agrícolas internos mais sensiveis às variações de preços ocorridas no mercado internacional de produtos agrícolas. Essa hipótese foi estudada utilizando-se testes de raiz unitária convencionais do tipo Dickey-Fuller Aumentado (ADF) e Phillips-Perron (PP) e com quebra estrutural, testes de cointegração de Johansen e modelo Vetorial de Correção de Erro (VEC). Os resultados mostraram que o conjunto de variáveis externas exercem maior influência sobre 0 comportamento dos preços agrícolas no Brasil comparativamente às variáveis domésticas conforme obtido em estudos anteriores BARROS(1990) e PONGIBOVE (1996). Em relação aos preços industriais verificou-se que existe equilibrio entre os efeitos decorrentes de variações nas variáveis internas e externas. Também, os preços internacionais do petróleo perderam importância sobre o comportamento dos preços agricolas domésticos no Brasil na década de 90 relativamente aos anos 80 conforme observado em trabalhos já realizados englobando os anos 80. Finalmente, as funções de resposta de impulso mostraram que diante de choques não antecipados o periodo mais crítico de ajuste dos mercados correspondem aos seis primeiros meses após a incidência desses choques. 


\section{TRANSMISSION OF INTERNATIONAL AGRICULTURAL PRICES ON DOMESTIC AGRICULTURAL PRICES: THE CASE OF BRAZIL}

Author: Mario Antonio Margarido

Adviser: Prof. Dr. Geraldo Sant'Ana of Camargo Barros

\section{SUMMARY}

This study analyzes the effects that shocks on macroeconomic external and domestic variables have on the behavior of the relationship between the agricultural and industrial brazilian sectors from January 1990 to December 1998. The theoretical framework uses partial equilibrium theory that considers individual and joint action of domestic and international prices. The main hypothesis is that the internal agriculture prices has turned more sensitive to the international price changes because of the economic opening process that had begun in 1990, and also to the stabilization of the domestic prices in July 1994, when the Plano Real has started. This study checks this hypothesis by using tests of unit root you stipulate of the type Augmented Dickey-Fuller (ADF) and Phillips-Perron (PP) and with structural break, tests of cointegration of Johansen and Vector Error Correction Model (VECM). The results showed that the group of external variables exercises larger influence on the agricultural prices in Brazil than the domestic variables as obtained in previous studies from BARROS (1990) and PONGIBOVE (1996). However, there is an equilibrium on the industrial prices with the variations in the internal and external variables. Also, the international prices of the petroleum showed less significance on the changes of the domestic agricultural prices in Brazil in the nineties relatively to the eighties as already observed in several paper. Finally, when impulse response function faces unknown shocks the most critical adjustment period in the markets corresponds to the first six months after the incidence of those shocks. 


\section{1 - INTRODUÇÃO}

O setor agrícola é o que apresenta maior grau de sensibilidade diante de choques de oferta e de demanda em razão de suas especificidades. No caso de choques de oferta, fatores de ordem climática, tais como geada, excesso de chuvas, incidência de pragas, etc. , podem contribuir para a alteração da quantidade ofertada de produtos agrícolas, e conseqüentemente, ter reflexos sobre o nível de preços da economia. Pelo lado da demanda, os preços do setor agrícola também são influenciados pelas mudanças dos rumos da política econômica, tais como alterações nas alíquotas de importações, taxa de câmbio, política monetária, etc.

Outro aspecto importante do setor são as dificuldades para se distinguir o que são instrumentos de política econômica exclusivamente interna e dissociá-los de fatores ligados a questões externas.

Além disso, a ampliação do comércio mundial decorrente, do próprio processo de globalização, conduziu ao surgimento de novos concorrentes em setores antes dominados por poucos países, tendo como resultado o acirramento da tensão já existente entre eles, sendo que os países já estabelecidos em determinados mercados de produtos não tem conseguido resistir à invasão de seus mercados domésticos por novos competidores.

No caso da agricultura, o exemplo mais marcante é a disputa envolvendo os Estados Unidos (EUA) e a União Européia (UE). A competição entre esses dois gigantes econômicos resultou em conflito que conduziu ao desordenamento do mercado internacional de produtos agricolas, em razão dos efeitos viesados produzidos por suas respectivas políticas de subsídios, tanto ao nível da produção, como também para a exportação de produtos agropecuários. Historicamente, até os anos 60 , os EUA ocupavam posição hegemônica em relação os comércio intemacional de produtos agrícolas, enquanto que a Europa se caracterizava por ser deficiente na produção de alimentos, fato esse que a tornava extremamente dependente das importações de alimentos, principalmente dos EUA. Essa situação começou a mudar com medidas tomadas já nos anos 50 , com o processo de unificação da Europa, a qual passou a adotar uma política agrícola conjunta, denominada de Política Agrícola Comum (PAC) ${ }^{1}$.

\footnotetext{
'Uma análise sobre o tratado que estabeleceu os objetivos pertinentes à formação da Uniâo Européia (Tratado de Roma), da sua Política Agrícola Comum (PAC) e sua respectiva Política Comercial Comum
} 
Basicamente, a questão agrícola da UE apresentou três fases distintas. Nos anos 60 , a UE se caracterizava por ser importadora líquida de alimentos, passando ao longo do tempo a ser auto-suficiente, inclusive com produção de excedentes para exportação, chegando na década de oitenta com excesso de produção e uma complicada gestão de mecanismos da PAC para controle dos excessos de estoques. Através da utilização de preços; tanto ao nível interno (mecanismo dos Direitos Niveladores) quanto externo (Restituiçōes às Exportações) ${ }^{2}$, a UE contribuia para distorcer os preços mundiais da produtos agrícolas. No mercado doméstico, dado que os preços internos eram superiores aos preços internacionais, a UE elevava os preços dos produtos agrícolas de países terceiros que se dirigiam para seu mercado interno, igualando-os aos preços dos produtos domésticos, ou seja, retirava a competitividade dos produtos agrícolas importados, taxando-os até o ponto em que seu preço ficasse igual ao do produto agrícola produzido no interior da UE, prejudicando dessa forma os países exportadores desses produtos. Em relação ao comércio externo, a política de restituições das exportações de produtos agrícolas, na verdade um tipo de subsídio, era um prêmio para os exportadores da UE, uma vez que, como mencionado anteriormente, os preços internos da UE eram normalmente mais elevados que os preços mundiais, dessa forma, através da concessão de bônus variáveis a UE estimulava a exportação de seus produtos agrícolas para países terceiros. O resultado final da aplicação desses dois tipos de instrumentos pela UE nos anos 80 era uma restrição de acesso de produtos agrícolas estrangeiros em seu mercado doméstico e, ao mesmo tempo, uma elevação artificial da oferta de produtos agrícolas no mercado internacional, contribuindo dessa maneira para deprimir os preços de alimentos e matérias-primas agrícolas em termos mundiais.

O quadro delineado acima é confirmado por BARROS (1990b, p.2), o qual coloca que os "preços internacionais das mercadorias agrícolas, após o boom do início dos anos 70 , moderaram-se até 1977, para em seguida iniciar um processo de crescimento até 1980. A partir de então observa-se queda vertiginosa, só interrompida em 1986. Tomando-se o caso dos alimentos como ilustração, verifica-se que seu preço em dólares aumentou cerca de 40,0\% de 1976 a 1980 e decresceu cerca de $25,0 \%$ nos cinco anos seguintes. No caso de matériasprimas agrícolas também se observa substancial oscilação de preço no período. Mudanças dessas magnitudes têm impactos substanciais tanto sobre economias desenvolvidas e em desenvolvimento, mascarando mesmo as vantagens comparativas que cada qual apresenta”.

(PCC) em relação a paises terceiros, pode ser encontrada em THORSTENSEN (1993) e MARGARIDO; FREITAS FILHO; BIRAL (1992b).

2 Detalhes sobre o funcionamento do mecanismo de Direitos Niveladores e de Restituiçōes às Exportaçőes podem ser encontrados em CARVALHO e SILVA (1995), MARGARIDO; CAMBON JUNIOR (1995) e BERGMANN; BAUDIN (1989) e COMUNIDADE ECONÔMICA EUROPÉIA (1989). 
Como resultado dessas transformações, houve tendência para uma internacionalização mais incisiva do capital, além da emergência de novas forças econômicas nesse novo cenário mundial que se esboçava. Contudo, apesar dos avanços do comércio mundial, surgiram dificuldades inerentes a esse processo, uma vez que o maior grau de exposição dos países ao comércio internacional toma as economias nacionais mais vulneráveis às políticas intemas (políticas fiscal e monetária) e externa (política comercial) dos demais países.

Nesse quadro, efeitos das políticas macroeconômicas sobre os preços relativos envolvendo produtos tradeables e domésticos, tem sido objeto de diversos estudos. Entretanto, a análise dos mecanismos pelos quais as políticas macroeconômicas afetam os preços setoriais é dificultada pela heterogeneidade dos setores produtivos, pois a grande maioria dos produtos tem seus preços atrelados às evoluções dos preços de insumos de origem tanto doméstica como externa.

Numa economia aberta, os preços dos produtos considerados tradeables são determinados pelos seus respectivos preços internacionais, taxa de câmbio nominal e tarifas. Em contrapartida, os preços dos produtos domésticos são determinados pelas condições de demanda e oferta domésticas, que por sua vez, são influenciadas pelas decisões no âmbito governamental. Por outro lado, muitas das decisões econômicas dependem dos preços relativos entre os setores tradeable e nontradeable as quais utilizam como referência a taxa de câmbio real. De acordo com MUNDLAK, CAVALLO e DOMENECH (1990, p.55), análises utilizando "taxa de câmbio real geralmente agregam toda a produção dentro de dois setores, tradeables e nontradeables. Esta agregação simplifica a discussão e ajuda a compreender alguns temas importantes, mas a sua relevância empíica é limitada: não há nenhum produto que possa ser classificado puramente como tradeable ou nontradeablen, sendo que, o seu relacionamento estrutural dependerá do grau de abertura da economia. Além disso, na prática essas dificuldades são ampliadas pela existência e vigência dos acordos comerciais e contratuais.

Contrastando com os anos 70 s e 80 s, nos anos 90 s o mercado internacional de alimentos e de matérias-primas agrícolas apresentou um comportamento relativamente mais estável. Analisando-se a evolução do índice internacional de preços de alimentos e do índice internacional de preços de matérias-primas agrícolas, para o período de janeiro de 1990 a dezembro de 1998, verifica-se que nos dois mercados os preços sofreram poucas variações, até julho de 1994. A partir desta data, os preços de alimentos e matérias-primas agrícolas iniciaram um processo ascendente, derivado do crescimento da economia mundial, que somente foi interrompido com a crise financeira dos países do sudeste asiático, em 1997 (Figuras 1 e 2). A crise asiática, iniciada em julho de 1997, teve forte impacto sobre a economia japonesa, e a crise da Rússia, em agosto de 1998, provocou pesadas perdas para os credores 
de diversos paises, com destaque para a Alemanha. Como resposta à possibilidade de crise, 0 Brasil e o Fundo Monetário Internacional (FMI) iniciaram e concretizaram negociações para a concessão de um empréstimo da ordem de US\$ 41,5 bilhões. "Esse aporte de recursos só foi possível devido ao temor do governo dos Estados Unidos de ver comprometida a continuidade de sua força no mercado latino-americano caso o Brasil mergulhasse em uma crise mais profunda arrastando outros países do continente" (CARVALHO e SILVA, 2000, p.260).

Tanto 0 indice internacional de preços de alimentos, quanto 0 indice internacional de preços de matérias-primas agrícolas, começaram a declinar aproximadamente três meses antes da eclosão da crise financeira de julho de 1997. Possivelmente este comportamento já estaria refletindo as mudanças das expectativas dos investidores financeiros sobre desempenho económico e financeiro da região asiática, sendo que, no caso do índice internacional de preços de matérias-primas agrícolas, esse efeito foi mais acentuado, tendo os preços desses insumos apresentado forte queda a partir de abril de 1997.

Com à economia norte-americana, apesar da crise asiática em 1997 e da crise de outros países emergentes em 1998 e no início de 1999, o indice de preços, para o período de janeiro de 1990 a dezembro de 1999, apresentou tendência ascendente, mas sem bruscas alterações de trajetória, refletindo dessa forma o longo e sustentado processo de crescimento, que teve início em 1984, com o fim da recessão mundial iniciada em 1979 e relacionada com o segundo choque do petróleo e com o choque nas taxas de juros em nivel internacional (Figura 4).

Contrariamente ao que aconteceu na década de 70 , onde os preços internacionais do petróleo apresentaram expressivas altas, como em 1973 e em 1979, levando a economia mundial a uma profunda recessão, nos anos 90 o preço internacional do petróleo apresentou pequenas flutuações (Figura 3). Observa-se que essa evolução esteja relacionada com o fato de que, após os dois choques do petróleo, diversos países investiram em pesquisas para alterar suas matrizes energéticas e desenvolver fontes energéticas alternativas, visando reduzir a dependência em relação ao petróleo. Além disso, as mudanças políticas ocorridas no cenário internacional, com o aumento da importância econômica e política dos Estados Unidos e a derrocada do comunismo em 1990, exerceram forte pressão sobre os paises exportadores de petróleo. Mais recentemente, apesar do preço do petróleo chegar na casa dos US $\$ 30,00$ em fevereiro de 2000 , observa-se que seus efeitos sobre a economia mundial não estão sendo tão intensos, comparativamente ao que ocorreu quando o preço do petróleo chegou a esse mesmo patamar em 1973. 
Apesar do Brasil ter papel de destaque na produção de produtos agropecuários, e pertencer ao Grupo de Cairns $^{3}$, sua capacidade na determinaçăo de preços de produtos agrícolas de exportação é relativamente pequena comparativamente aos grandes produtores agrícolas, como Estados Unidos e União Européia. Assim, como exemplo, verifica-se que apesar do Brasil ser o maior exportador mundial de suco de laranja concentrado congelado, os preços do suco são determinados basicamente pelas condições de oferta e demanda prevalecentes no mercado dos Estados Unidos. Em outras palavras, os preços domésticos da maioria dos produtos agrícolas exportáveis ${ }^{4}$ estão a reboque de acontecimentos do mercado internacional, sendo que as variaçőes nos preços recebidos pelos produtores eståo diretamente relacionadas às variaçőes de preços exógenas.

Outro aspecto a ser realçado é a sensibilidade dos preços internos de produtos agricolas brasileiros, relativamente às variações de preços externos, que provavelmente foi acentuada tanto pelo processo de globalizaçåo como também pela abertura econômica a partir de 1990, registrada pelo governo Collor. LOPES (1992) calculou as taxas de proteção nominal e efetiva para o Brasil, em termos regionais, para algodão (fibra curta), algodão (fibra longa), soja, milho, arroz de sequeiro e trigo para o periodo 1990-1992. Com exceção do trigo produzido no sul do pais, todos os demais produtos apresentaram sinal negativo em relação às suas respectivas taxas de proteção, tanto nominal, quanto efetiva. Verifica-se assim, que a partir de 1990, com a abertura comercial, o setor agrícola brasileiro ficou mais vulnerável frente à competição internacional, ou seja, os preços agrícolas domésticos passaram a sofrer maior nível de exposição às flutuações de preços agrícolas externos.

Além disso, o aumento da abertura econômica, relacionada com a busca da estabilidade de preços e com a implementação do Plano Real em julho de 1994, acarretou maior concorrência entre os produtos domésticos e estrangeiros e foi um dos instrumentos utilizados para segurar a elevação dos preços domésticos.

Nesse quadro, apesar das acentuada instabilidade observada na evolução das principais variáveis econômicas no Brasil, na década de 90 verifica-se a presença de dois

\footnotetext{
${ }^{3}$ O Grupo de Cairns é composto por treze países, que possuem considerável importância na produção e comercialização internacional de produtos agrícolas: Brasil, Argentina, Austrália, Canadá, Chile, Colômbia, Filipinas, Hungria, Indonésia, Malásia, Nova Zelândia, Tailândia e Uruguai. Estima-se que esse grupo seja responsável por $25,0 \%$ do comércio mundial de produtos agrícolas; no entanto, seu poder para fixação de preços de produtos agrícolas no mercado internacional é relativamente pequeno, uma vez que a composição desse grupo é muito heterogênea em termos de posicionamento político no cenário internacional, dado que, alguns países preferem uma posição de alinhamento com os Estado Unidos no que refere-se as negociaçōes sobre agricultura no âmbito da Organização Mundial do Comércio (OMC), enquanto outros, defendem uma posiçăo independente dos EUA.

${ }^{4}$ Os preços dos produtos agrícolas nontradeables também podem ser afetados por variaçōes dos preços internacionais dos produtos agrícolas, só que de forma indireta. O aumento do preço internacional dos tradeables pode induzir os agricultores a substituirem a produçăo de produtos domésticos pela de
} 
períodos muito distintos. O primeiro, vai de janeiro de 1990 até junho de 1994, marcado pela grande elevação e instabilidade de preços na economia, o segundo, a partir de julho de $1994 \mathrm{e}$ implementação do Plano Real, caracterizado pela redução acentuada da taxa de crescimento dos preços e mudança brusca da trajetória da inflação, configurando dessa forma, uma quebra estrutural na evolução dos preços na economia brasileira.

Assim, no periodo posterior a janeiro de 1990, com o crescente grau de inserção da economia brasileira no comércio mundial, e com as duas distintas trajetórias da evolução dos preços, o comportamento de variáveis macroeconômicas internacionais e os choques externos e internos seguramente apresentaram impactos diferenciados na economia brasileira, tanto entre os setores agrícola e industrial, bem como entre os sub-períodos de 1990 a meados de 1994, relativamente a meados de 1994 até dezembro de 1998.

Este trabalho consta de sete capítulos, incluindo introdução e conclusões.

No segundo capitulo são delineados os objetivos e as expectativas em relação ao comportamento das variáveis diante de choques não antecipados.

O terceiro capítulo apresenta o modelo teórico utilizado como base neste estudo e as respectivas inter-relações entre as variáveis utilizadas.

No quarto capítulo, são apresentados e sintetizadas as conclusões de trabalhos empíricos que abordaram o tema relacionado com respostas de variáveis diante de choques econômicos.

O quinto capítulo subdivide-se em duas partes. Na primeira, são apresentadas as variáveis a serem utilizadas e suas respectivas fontes. Na segunda, são apresentados os métodos econométricos utilizados tanto no contexto univariado, quanto multivariado.

No sexto capítulo são apresentados e analisados os resultados obtidos a partir da estimação dos modelos econométricos.

produtos de exportação. Assim, pode haver retração da oferta de nontradeables no mercado doméstico conduziindo a um aumento do preço do produto nontradeable no mercado interno. 


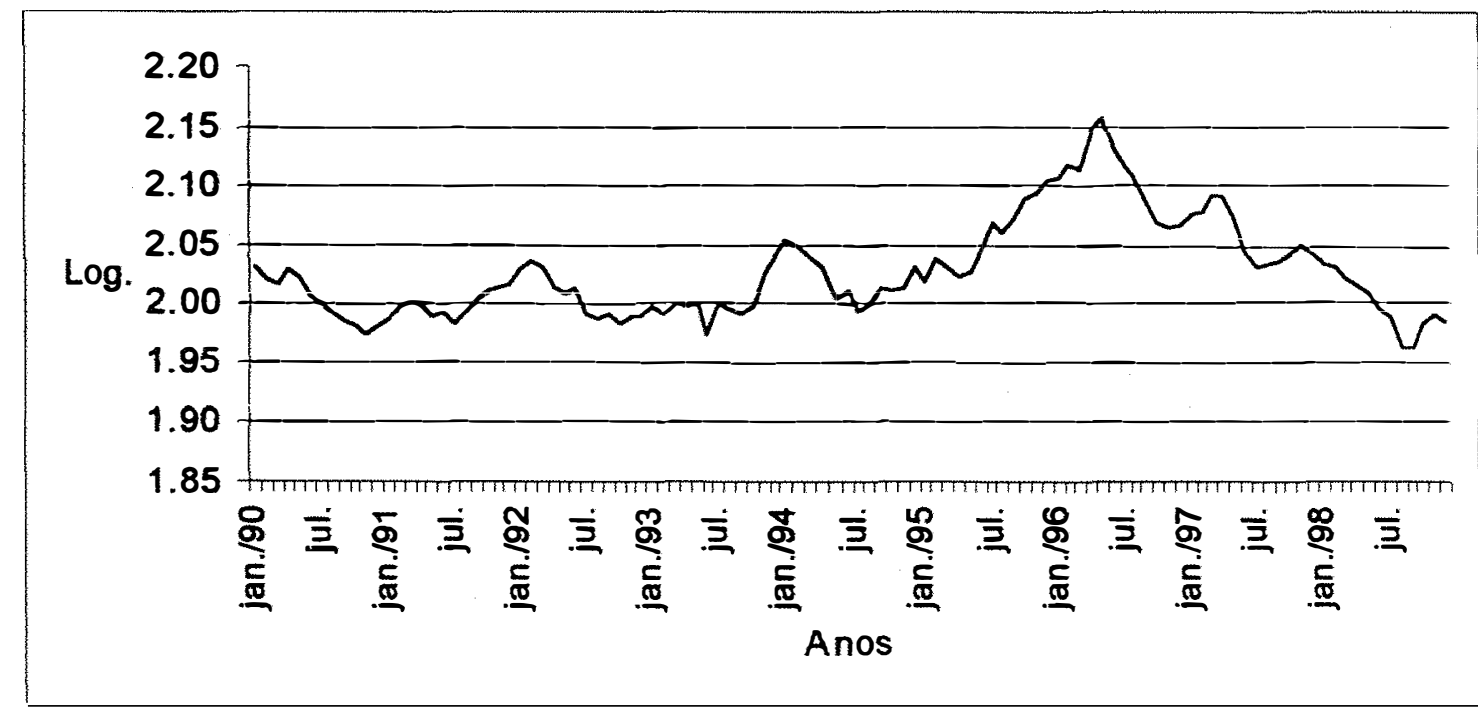

Figura 1 - Logaritmo do Indice Internacional de Preços de Alimentos (LIFI), Janeiro de 1990 a Dezembro de 1998.

Fonte: Dados Básicos da International Financial Statistics (1990/1999).

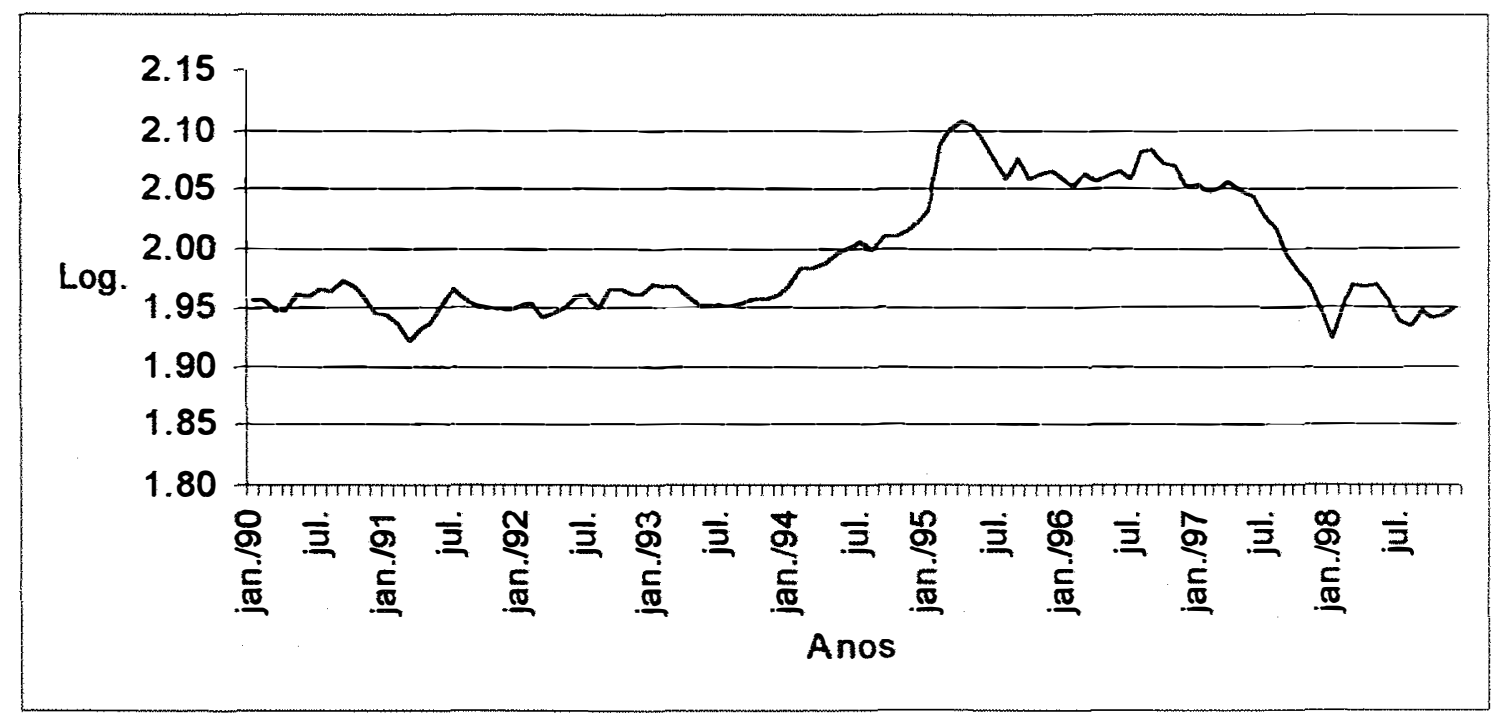

Figura 2 - Logaritmo do índice Internacional de Preços de Matérias-primas Agrícolas (LIRMI), Janeiro de 1990 a Dezembro de 1998.

Fonte: Dados Básicos da International Financial Statistics (1990/1999). 


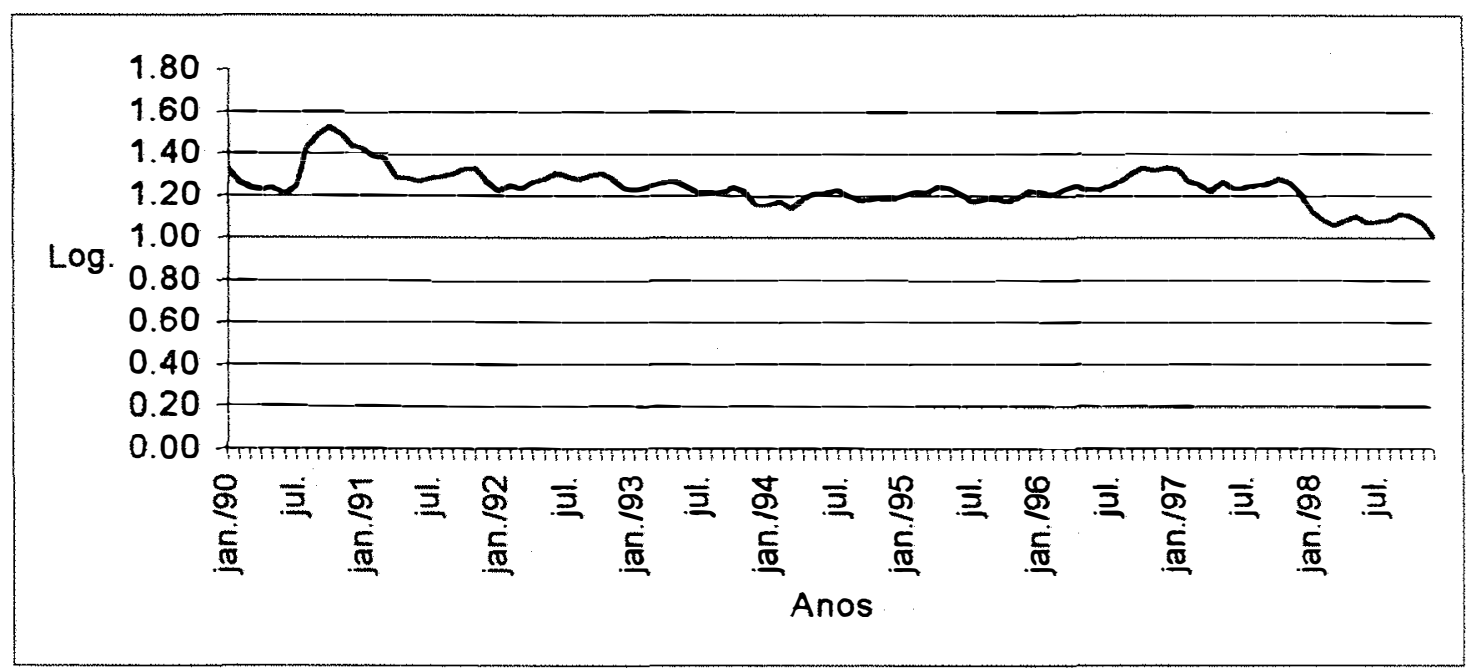

Figura 3 - Logaritmo do Preço Internacional do Petróleo (LPET), Janeiro de 1990 a Dezembro de 1998.

Fonte: Dados Básicos da Conjuntura Econômica (1991/1999).

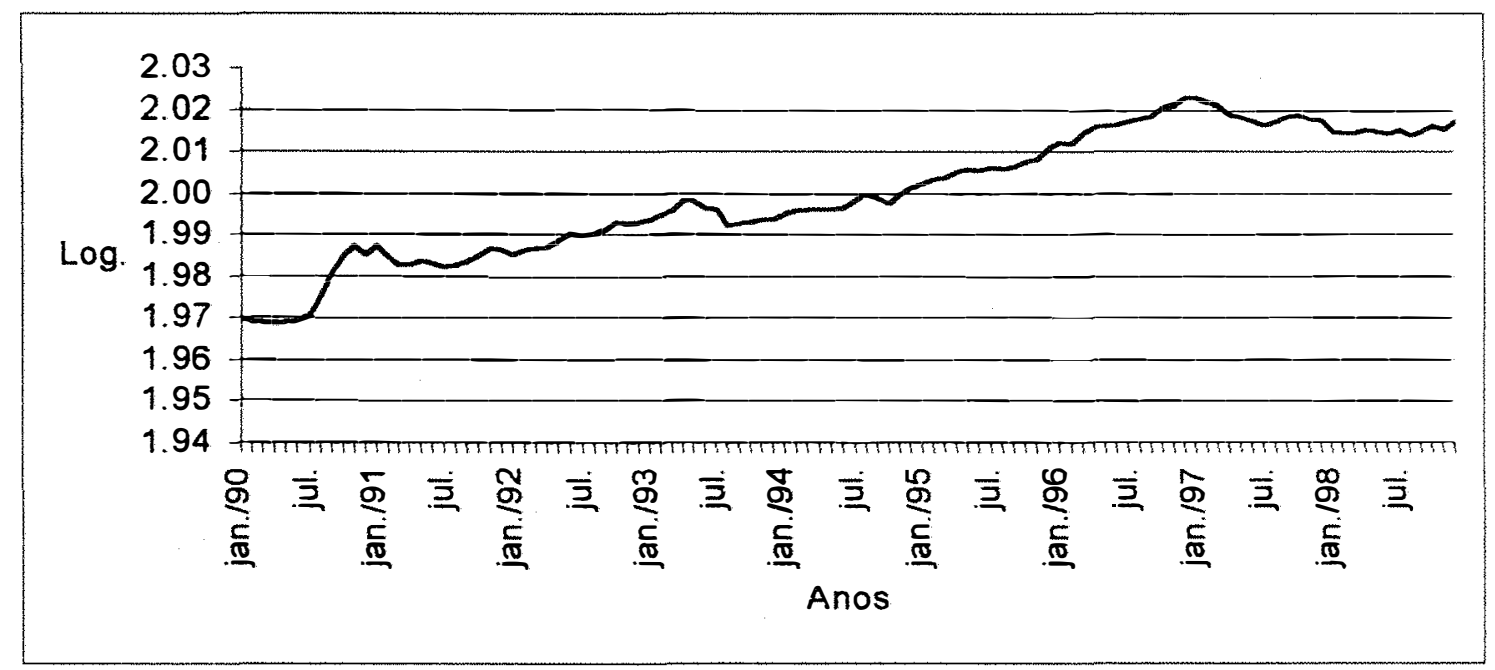

Figura 4 - Logaritmo do Índice de Preços ao Produtor (LIPPUS), Estados Unidos, Janeiro de 1990 a Dezembro de 1998.

Fonte: Dados Básicos do U.S. Department of Labor, Bureau of Labor. 


\section{2 - OBJETIVOS}

O objetivo geral deste estudo consiste em analisar os impactos de choques de oferta, de demanda e de natureza macroeconômica, tanto extemas como intemas sobre os preços relativos dos setores agrícola e industrial no Brasil, no período de 1990 a 1998.

Especificamente, o objetivo inicial é verificar se variações em variáveis macroeconômicas extemas, tais como, indice internacional de preços de alimentos, indice intemacional de preços de matérias-primas agrícolas, índice de preços ao produtor nos Estados Unidos, preço intemacional do óleo crú (US\$/barril) e em variáveis intemas, como taxa de câmbio real e a quantidade ofertada de moeda na economia, transmitem-se ao comportamento do índice de relação de troca entre preços agrícolas e industriais no Brasil.

Em seguida, pretende-se medir o grau do impacto causado por mudanças nas variáveis acima citadas sobre o índice de preços agrícolas no Brasil, ou seja, quantificar essa relação.

Para atingir os objetivos propostos, são utilizados testes de raiz unitária convencionais do tipo Dickey-Fuller Aumentado (ADF), Phillips-Perron (PP), além de testes de raiz unitária para detectar quebras estruturais propostos por PERRON (1989 e 1994) e FRANSES e HALDRUP (1993) para a determinação da correta ordem de integração das variáveis. São utilizados, também, Modelos Auto-regressivos Vetoriais (VAR) e/ou modelos Vetoriais de Correção de Erro (VEC) para obter as relações entre as séries, bem como suas respectivas estruturas de defasagens.

Estudos semelhantes, já realizados, abordaram o período anterior a 1990 e procuraram verificar os efeitos de variáveis extemas sobre os preços agrícolas no Brasil, mas numa situação em que o grau de abertura da economia era muito menor. Assim, espera-se que nos anos 90 os preços agrícolas no Brasil tenham se tomado mais sensíveis às variações dos preços agrícolas no mercado intemacional, com a maior inserção da economia brasileira no processo de globalização, e com a estabilização de preços após 1994, principalmente, a partir de meados de 1994 com a implementação do Plano Real.

Quanto ao comportamento das variáveis abordadas neste estudo, tem-se a seguir alguns aspectos esperados, relacionado-os com resultados obtidos em trabalhos realizados anteriomente. 
No caso da variável preço intemacional do petróleo, espera-se que elevações dessa variável, ou seja, um choque de custo (oferta), conduza a uma queda na relação de troca entre o setor agrícola e industrial no Brasil, devido ao fato de que os preços industriais geralmente são mais sensiveis diante de variaçōes nos preços do petróleo, um dos principais insumos utilizados na produção industrial, e com grande impacto sobre os custos do setor. Essa questão relativa ao grau de sensibilidade dos preços agrícolas e industriais diante de choques nos preços intemacionais do petróleo foi quantificada por BARROS (1990), o qual, utilizando o modelo Vetorial Auto-regressivo (VAR) constatou que, no período de 1973 a 1987, um aumento de $10,0 \%$ nos preços do petróleo no mercado mundial conduzia a uma elevação imediata de $2,2 \%$ nos preços das matérias-primas agrícolas no mercado intemacional e de $10,0 \%$ no índice de preços em nível de atacado nos Estados Unidos. Essa elevação nos preços intemacionais do petróleo refletia-se sobre os preços domésticos no Brasil, sendo que os preços industriais cresciam cerca de $5,1 \%$, enquanto que os preços agrícolas apresentavam pequena variação, em tomo de $\mathbf{0 , 0 2 \%}$ apenas, inferindo-se que no curto prazo há uma deterioração da relação de troca agricultura/indústria.

Quanto aos choques nas variáveis índice intemacional de preços de matérias-primas agrícolas e índice intemacional de preços de alimentos, espera-se que resultem na elevação da relação de troca agricultura indústria. Considerando-se a pequena participação do intercâmbio brasileiro no comércio mundial, admite-se que a oferta de importaçōes e a demanda por exportações são infinitamente preço-elásticas, ou com elevada elasticidade. Portanto, esperase que o comportamento da demanda internacional por matérias-primas agrícolas e por alimentos seja o principal deteminante na evolução dos preços agrícolas domésticos; assim, tem-se a expectativa de uma relação direta entre os preços intemacionais desses insumos e produtos e a relação de troca agricultura/indústria no Brasil.

Dada a magnitude da economia dos Estados Unidos (EUA) bem como sua importância no comércio mundial, espera-se que a elevação do índice de preços domésticos americano esteja diretamente relacionado com a demanda intemacional de insumos e produtos. Tem-se em conta que as importaçōes de um país dependem do ciclo econômico em que se encontra a sua economia doméstica, uma economia aquecida implica no aumento de importaçőes, principalmente de matérias-primas e produtos semi-elaborados. Nesse quadro, o nível de preços nos EUA representaria uma proxy da utilização da capacidade instalada do país, e como resultado, espera-se que uma elevação nos preços americanos tenha efeito direto sobre a relação de troca agricultura e indústria no Brasil.

No que se refere à variações na taxa de câmbio, espera-se que desvalorizações reais tendam a reduzir a relação de troca entre o setor agrícola e industrial, pelo menos no curto prazo, uma vez que a produção agrícola caracteriza-se pelo fato de apresentar um caráter 
sazonal mais definido do que a produção industrial. Sendo assim, choques originados na taxa de câmbio real não tenderiam a ser transferidos para os preços dos produtos agrícolas num curto horizonte temporal, devido suas características produtivas, o que não acontece com os produtos industriais, onde a produção, na maioria das vezes, é menos dependente da questão sazonal.

MODIANO (1985) elaborou um modelo para medir o impacto de choques no caso da economia brasileira. Segundo esse autor, uma desvalorização cambial real de 10,0\% condiciona um aumento direto de cerca de $3,5 \%$ sobre os preços industriais e uma elevação de apenas $1,2 \%$ no caso dos preços agrícolas. Portanto, a expectativa é de que ocorra uma relação inversa entre variaçōes na taxa de câmbio real e relação de troca, pelo menos no curto prazo.

Finalmente, diante de choques na oferta de moeda, a expectativa é que seus efeitos sejam diretos sobre a relação de troca entre agricultura e indústria, e espera-se que aumentos na oferta monetária levem à elevação dessa relação e beneficiem o setor agrícola, conforme modelo desenvolvido por FRANKEL (1986) e que será detalhado ao longo do presente trabalho. 


\section{3 - REVISÃO BIBLIOGRÁFICA}

A análise se iniciará pela relação entre a política monetária e os preços agrícolas. De maneira geral, no caso de uma economia fechada, existe uma relação direta entre variações na oferta monetária e os preços agrícolas, tanto dos produtos agrícolas exportáveis, quanto dos produtos comercializados apenas internamente, pois variações na oferta de moeda influenciam a relação de troca entre agricultura e indústria, sendo que a magnitude de seu impacto depende do nivel de flexibilidade dos preços. Os preços agrícolas caracterizam-se por apresentar maior flexibilidade, pois estão sujeitos às condições de oferta e demanda, enquanto que os preços industriais apresentam maior grau de rigidez em virtude de só reagirem a variações nos custos, como por exemplo, elevação nos preços de matérias-primas e de salários, ou seja, estão sujeitos às condições de mark up.

O primeiro trabalho a analisar os efeitos que a política monetária tem sobre os preços da commodities agrícolas foi desenvolvido por FRANKEL (1986) o qual, fez uma adaptação do modelo de ultrapassagem (overshooting) de DORNBUSCH (1976), relativo ao mercado cambial, que enfatiza a diferença entre os preços em moeda estrangeira que podem variar instantaneamente, isto é, esses preços são livres para se ajustar rapidamente de acordo com as mudanças nas condições de oferta e demanda, enquanto que os preços em moeda doméstica apresentam maior grau de rigidez. Basicamente, o mecanismo de ultrapassagem dos preços das commodities agrícolas descrito por FRANKEL (1986) assume que um aumento não antecipado da oferta de moeda na economia, no primeiro momento, conduz a um crescimento nominal na oferta de moeda, e também, uma elevação de mesma magnitude na oferta real de moeda, pois nesse primeiro momento, em função de sua própria rigidez, os preços industriais não reagem imediatamente, resultando em queda na taxa de juros como decorrência do aumento real da oferta de moeda. Portanto, o efeito de um aumento inesperado na oferta de moeda é uma redução das taxas de juros, desestimulando os investimentos em ativos monetários, ou seja, há fuga dos investidores dos ativos monetários para as commodities agrícolas. Esse repentino aumento da demanda por commodities agrícolas resulta numa elevação acentuada dos preços das commodities agrícolas no curto prazo, isto é, ocorre um overshooting dos preços desses produtos. Esse aumento dos preços das commodities altera as 
expectativas de inflação futura. A partir disso, o índice de preços começa a se elevar e, no longo prazo, tende a reduzir a oferta real de moeda da economia, aumentando as taxas de juros e causando uma migração dos investidores das commodities agrícolas para as aplicações financeiras. Nas palavras de FRANKEL (1986, p. 344) "um aumento esperado da taxa de inflação devido, por exemplo, a um aumento da oferta monetária desloca os investidores do mercado financeiro para o mercado de commodities. Como conseqüência do aumento da demanda por commodities, a expectativa em relação à inflação futura tem um efeito positivo sobre os preços das commodities no presente. De outra forma, um aumento na taxa de juros nominal em resposta à expectativa de aumento da inflação (isto é, um aumento na taxa de juros real) devido, por exemplo, a um decréscimo do nivel da oferta de moeda ou uma contração da política fiscal resulta no deslocamento dos investidores do mercado de commodities para o mercado de títulos. Esse processo tem um efeito negativo sobre os preços das commodities".

Comparativamente ao modelo desenvolvido por FRANKEL (1986), o modelo aqui utilizado tem uma trajetória de transmissão de informações diferente em relação ao primeiro. Enquanto que, no modelo de FRANKEL (1986) uma variação na oferta monetária afeta a taxa de juros alterando a rentabilidade dos ativos financeiros para baixo e deslocando a demanda para as commodities agrícolas e conseqüentemente elevando os seus respectivos preços, no caso do modelo desenvolvido por PONGIBOVE (1996), um aumento da oferta monetária conduz a uma elevação do nível de renda e como resultado eleva a demanda por bens agrícolas e industriais elevando os seus respectivos preços, conforme pode ser acompanhado através das equações (9), (14) e (18), dado que este modelo não leva em consideração o papel da taxa de juros.

Visando sofisticar esse tipo de análise, ou seja, a relação entre o setor agrícola e as demais variáveis macroeconômicas, passou-se a incorporar além das variáveis de âmbito intemo, tais como, política monetária e inflação, variáveis relacionadas com as condições intemacionais como por exemplo a taxa de câmbio ${ }^{5}$ e as condições do comércio mundial de produtos agrícolas e suas matérias-primas.

Um dos trabalhos pioneiros a analisar a influência da variável taxa de câmbio conjugado com as questões relativas ao comércio internacional sobre o comportamento dos preços agrícolas foi desenvolvido por SCHUH (1974). Esse autor analisou os efeitos da sobrevalorização do dólar sobre o processo de ajustamento da agricultura norte americana na

\footnotetext{
${ }^{5}$ De acordo com ZINI (1993, p. 17), a "taxa de câmbio é um dos preços relativos básicos das economias de mercado, e a sua importância advém do fato de intermediar todas as transaçōes entre a economia doméstica e o resto do mundo. Os modelos analíticos de equilibrio geral permitem definir que a taxa de câmbio é adequada quando reflete a competitividade externa do país, bem como a confiança sobre alguns fatores macroeconômicos fundamentais".
} 
década de 50, fato esse que resultou na transferência de grande parte dos benefícios das mudanças tecnológicas obtidas pelos produtores rurais para os consumidores.

Historicamente, em relação ao Brasil, a política cambial sempre exerceu um papel preponderante sobre o setor agrícola, seja como fonte de recursos para financiar o processo de industrialização via Substituição de Importações ao discriminar contra o setor agrícola na década de 50 , passando-se pelos anos 60 , onde na sua segunda metade, a Substituição de Importações deixa de ser prioridade e a política comercial volta-se para a promoção das exportações, sendo que, o acontecimento mais importante foi a mudança na política cambial através da introdução do sistema de minidesvalorizaçōes, a qual passou a adotar a teoria da paridade do poder de compra, ou seja, os reajustes cambiais levavam em conta não somente a inflação doméstica, mas também, a inflação externa de modo a manter a competitividade dos produtos brasileiros de exportação, chegando-se nos anos 90 , com a segmentação do mercado de câmbio em comercial, flutuante e paralelo e a ampliação da abertura da economia patrocinada pelo Governo Collor, além do abandono, de certa forma, da teoria da paridade do poder de compra para a determinação da taxa de câmbio, até chegar a estabilização econômica sob a égide do Plano Real em julho de 1994.

Em relação ao Plano Real, deve-se observar que, na verdade, o processo de estabilização teve início em $1993^{6}$ e foi segmentado em três fases. A primeira em 1993 consistiu na criação do Fundo Social de Emergência (FSE) e a criação do Imposto Provisório sobre Movimentação Financeira (IPMF), que objetivavam realizar um ajuste nas contas do setor público. A segunda fase, considerada a mais criativa, e considerada heterodoxa, começou no final de fevereiro de 1994 com a criação da Unidade Real de Valor (URV). A introdução da URV objetivava quebrar a inércia inflacionária via a amarração de todos os preços da economia através de um indexador único, ou seja, um indexador que fosse capaz de alinhar todos os preços relativos da economia, sendo que a URV durou até junho de 1994. A terceira etapa foi a transformação da URV numa nova moeda, o Real, a partir de julho de 1994. Desta data em diante todos os preços da economia que estavam anteriormente cotados em URV foram convertidos para real na razão de que uma URV eqüivalia a um real (ou um dólar) e igual a 2.750 cruzeiros reais.

Especificamente em relação ao câmbio, adotou-se, inicialmente, uma política de cunho praticamente liberal, uma vez que a taxa de câmbio não foi fixada de maneira rígida, isto é, na relação de um real para um dólar. "Em vez disso, o Banco Central anunciou que venderia dólares por um Real, mas deixou a taxa de compra flutuando livremente no mercado. Essa taxa

\footnotetext{
${ }^{6}$ No entanto, deve-se observar que as condiçōes macroeconômicas para a implementação de um futuro plano de estabilização começaram a se delinear em 1992, pois nesse período, as reservas cambiais vinham se ampliando.
} 
(i.e., a taxa pela qual os exportadores vendem seus dólares) caiu para $R \$ 0,91$ em julho e $R \$$ 0,86 em agosto, representando uma apreciação da moeda local (na fase dois, uma URV valia cerca de um dólar)". (SACHS e ZINI, 1995, p.41). Logo após, o Govemo adotou uma política monetána contracionista, mantendo as taxas internas acima daquelas praticadas no mercado intemacional, visando com essa medida atrair o capital extemo para compensar uma possível redução do superávit da balança comercial em decorréncia da valorização cambial e equilibrar 0 Balanço de Pagamentos. Com essas medidas foi possível controlar a inflação e atravessar 1996 com relativa tranqüilidade, a qual, só viria a ser perturbada em outubro de 1997 com a crise das bolsas no sudeste asiático, fato esse que obrigou o Govemo a elevar ainda mais os juros internos para evitar a fuga de capitais e, ao mesmo tempo, inibir o investimento intemo, reduzindo dessa forma o nível de renda e emprego, de modo a provocar um desaquecimento da economia e a conseqüente redução das importações e atenuar o persistente déficit na balança comercial.

A partir do modelo matemático de overshooting desenvolvido por FRANKEL (1986) mostrando como variações na política monetária são transmitidas mais que proporcionalmente aos preços do setor agrícola, pelo menos no curto prazo, e também, do trabalho de SCHUH (1974) incorporando o impacto tanto de variáveis domésticas, como também, extemas, sobre os preços agrícolas intemos, diversos estudos procuraram quantificar essa relação através da utilização de modelos econométricos. Uma síntese desses estudos encontra-se no Quadro 1. 


\begin{tabular}{|c|c|c|c|c|c|}
\hline 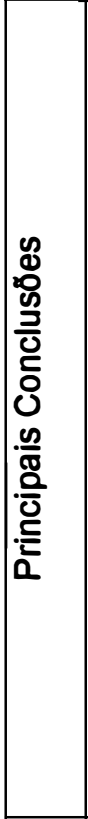 & 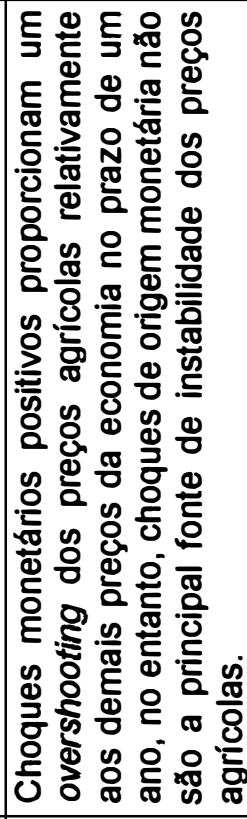 & 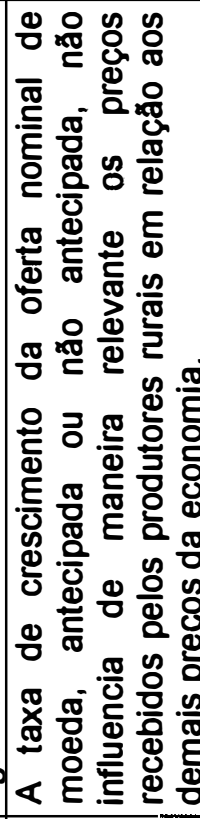 & 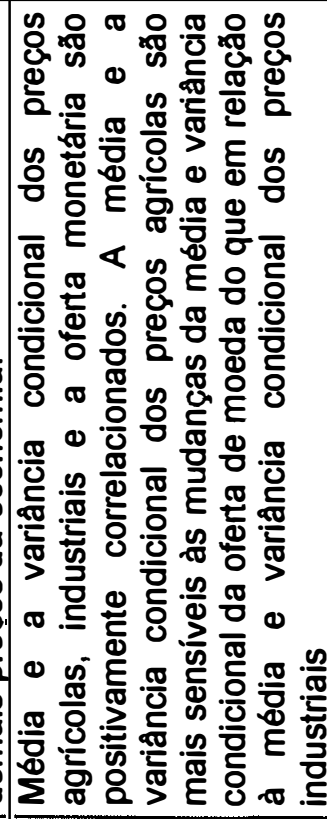 & 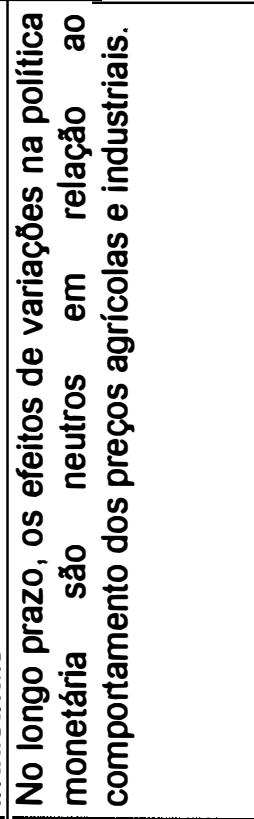 & 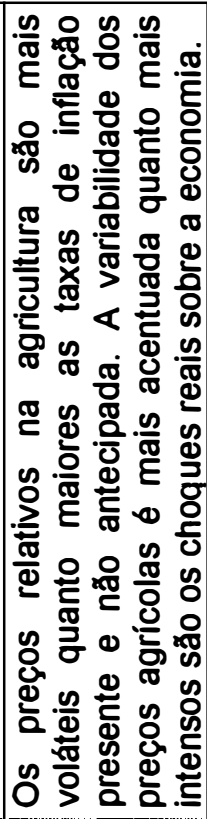 \\
\hline 矛 & 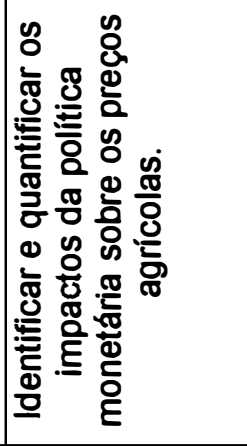 & 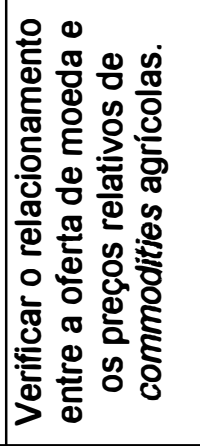 & 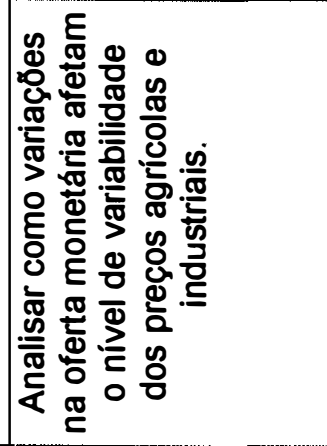 & 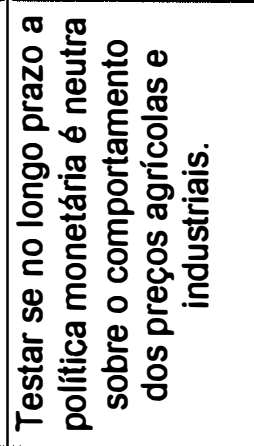 & 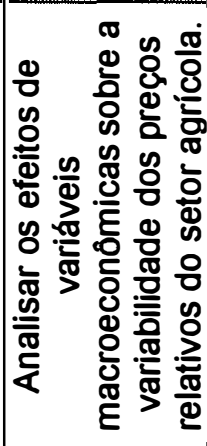 \\
\hline 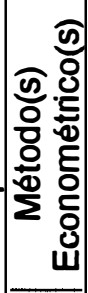 & 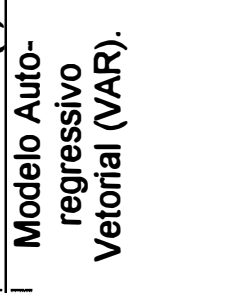 & 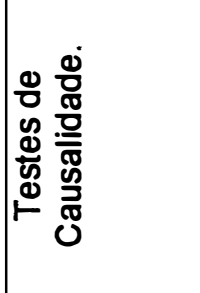 & 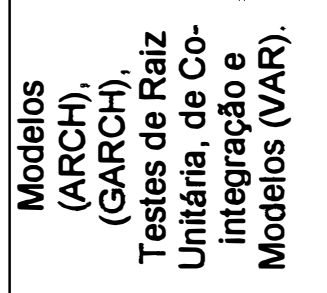 & 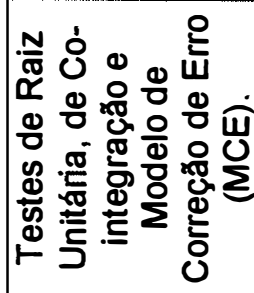 & 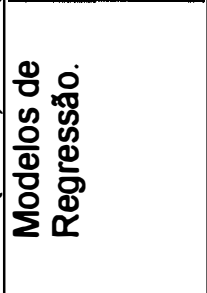 \\
\hline 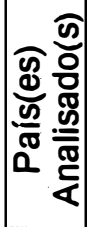 & 음 & 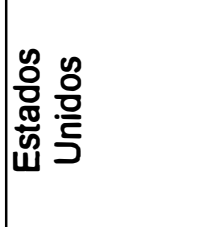 & 象 & 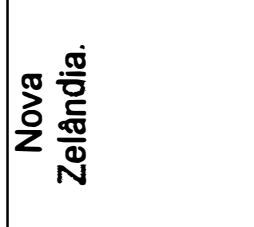 & 我 \\
\hline 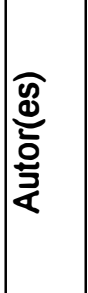 & 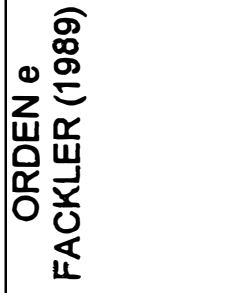 & 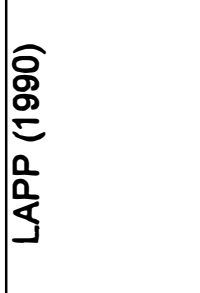 & 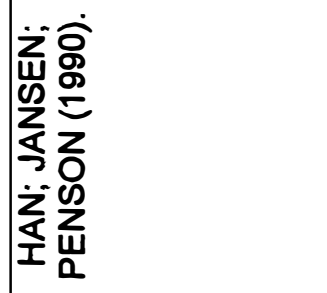 & 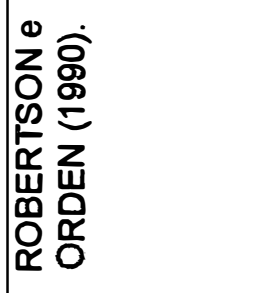 & 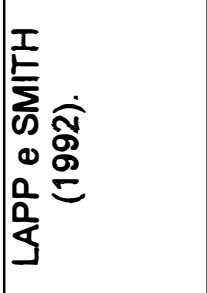 \\
\hline
\end{tabular}




\begin{tabular}{|c|c|c|c|c|}
\hline 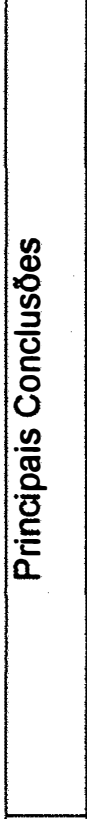 & 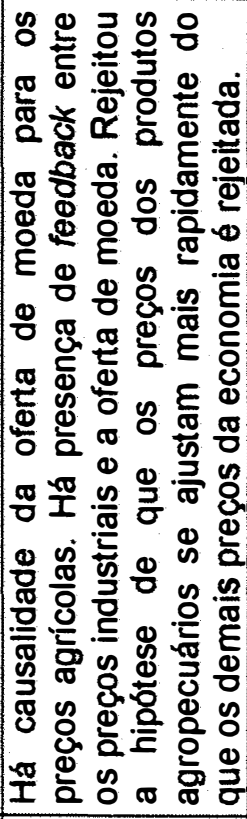 & 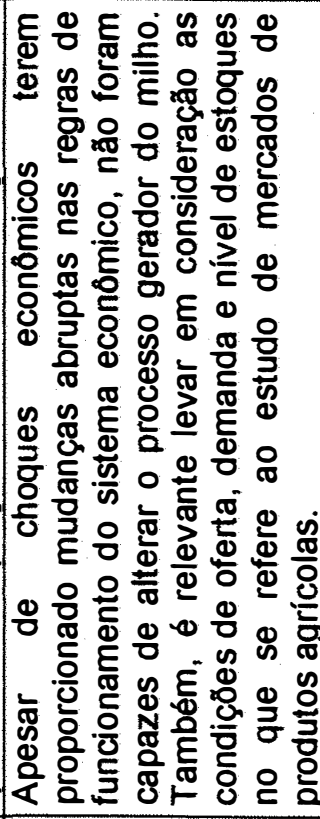 & 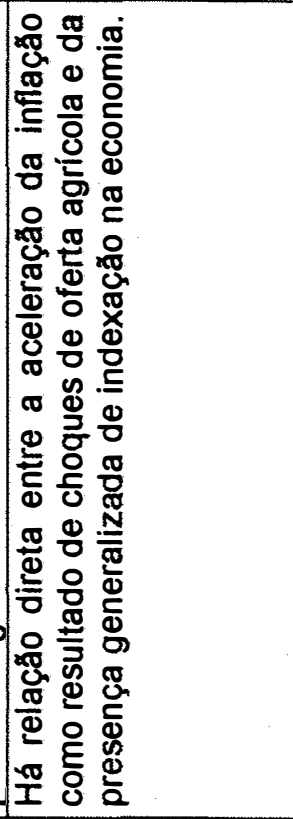 & 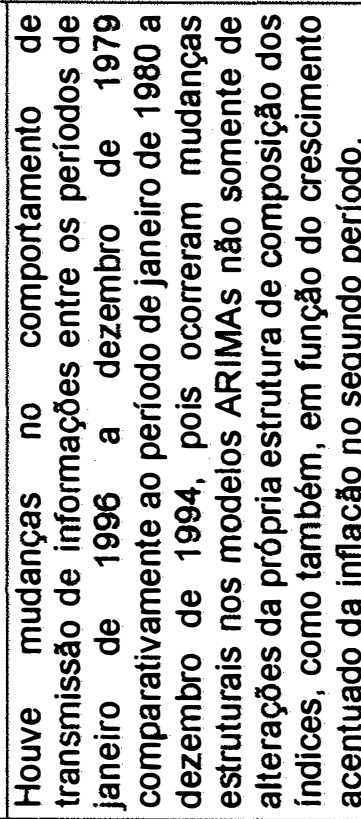 \\
\hline 焉 & 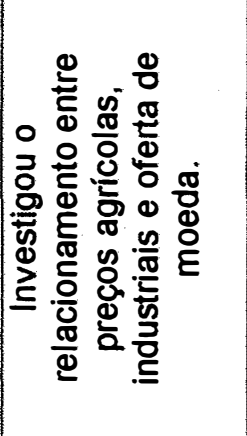 & 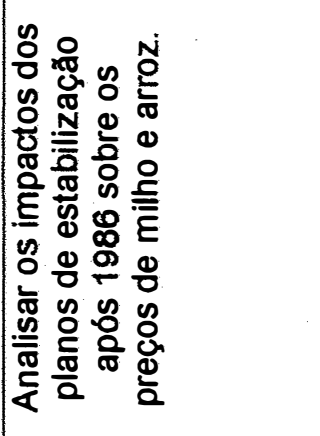 & 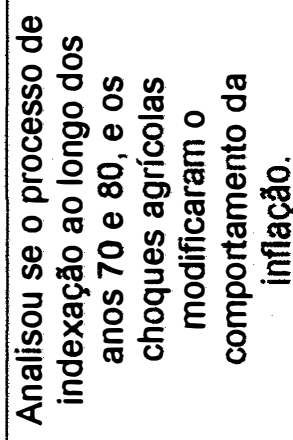 & 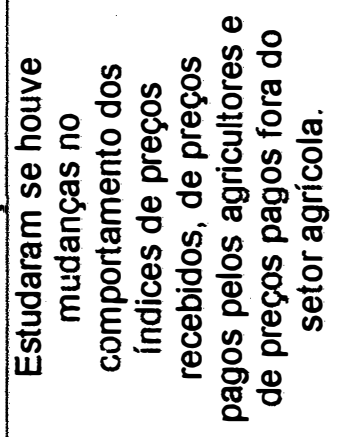 \\
\hline 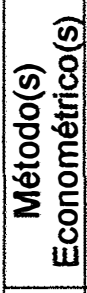 & $\frac{\dot{\hat{\alpha}}}{\sum_{0}^{\alpha}}$ & 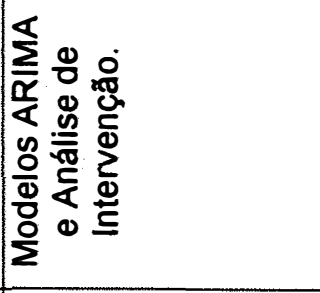 & 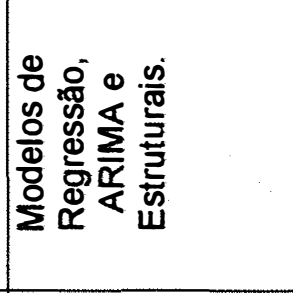 & 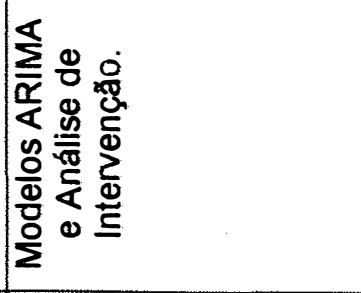 \\
\hline 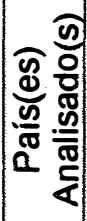 & & 离 & $\mid \begin{array}{c}\overline{\bar{c}} \\
\frac{\pi}{\tilde{\omega}} \\
\frac{\pi}{n}\end{array}$ & 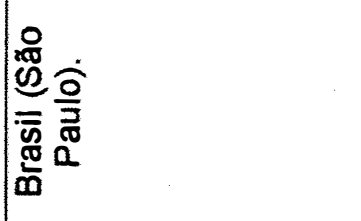 \\
\hline$\frac{\widehat{c}}{\frac{0}{6}}$ & 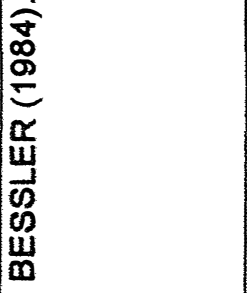 & 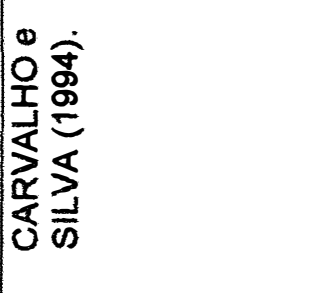 & 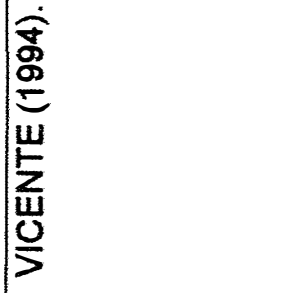 & 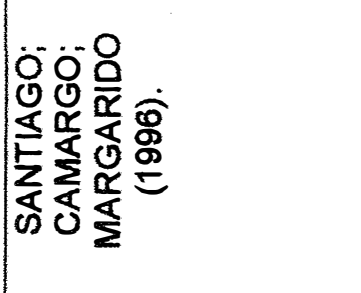 \\
\hline
\end{tabular}




\begin{tabular}{|c|c|c|c|c|}
\hline 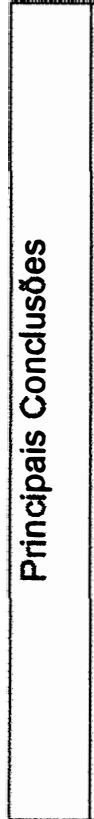 & 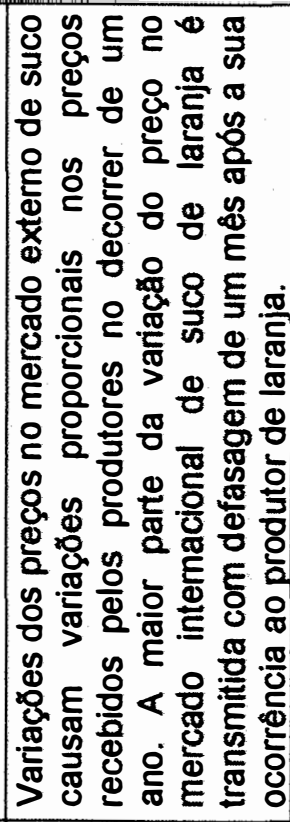 & 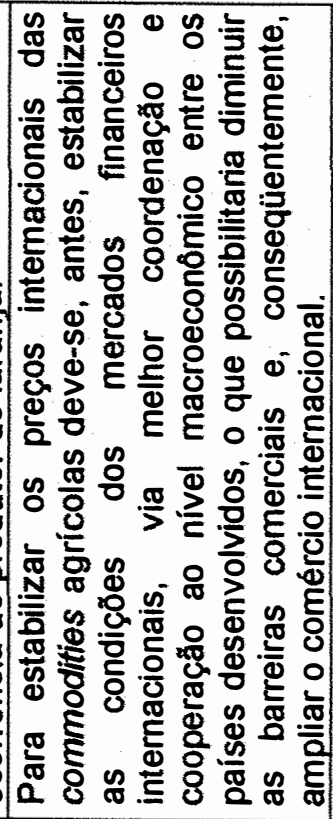 & 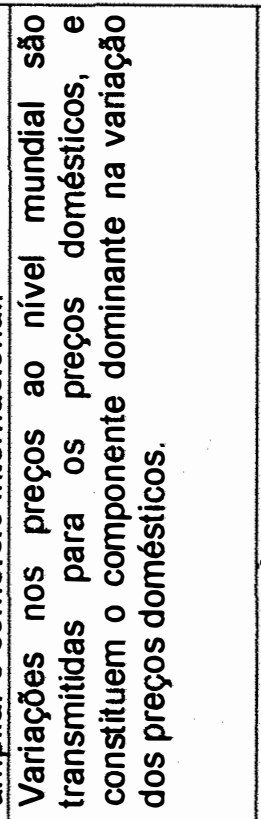 & 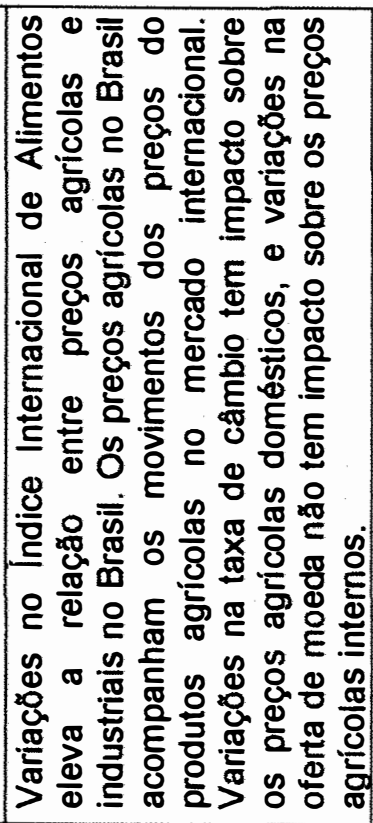 \\
\hline $\begin{array}{l}\frac{0}{0} \\
\frac{0}{0} \\
\frac{0}{0} \\
\frac{0}{0} \\
0\end{array}$ & 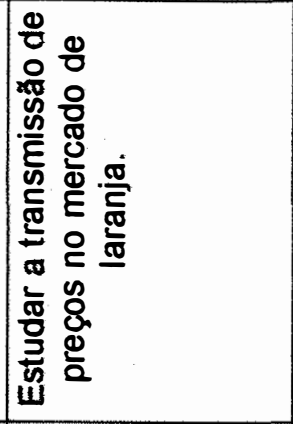 & 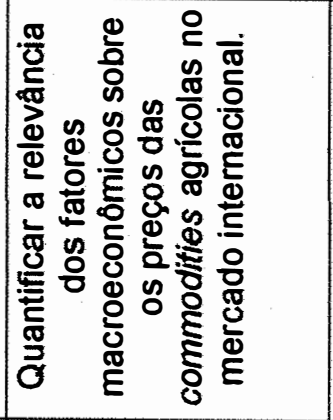 & 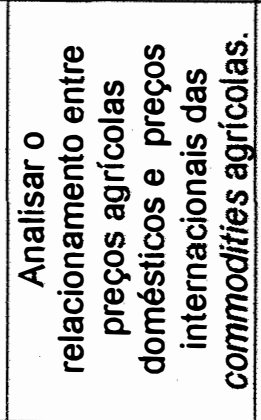 & 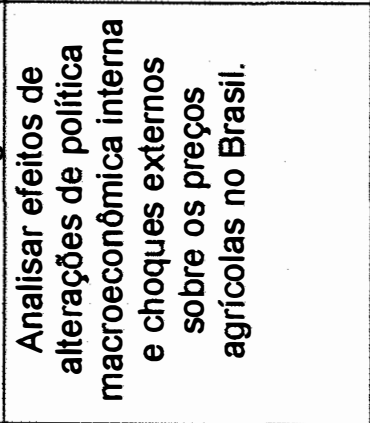 \\
\hline 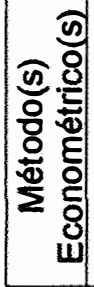 & 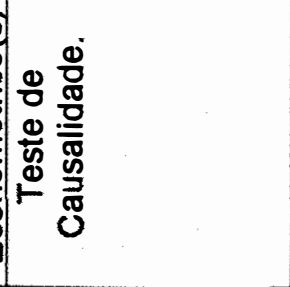 & 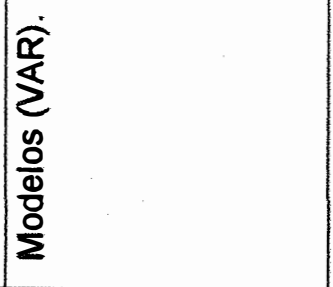 & 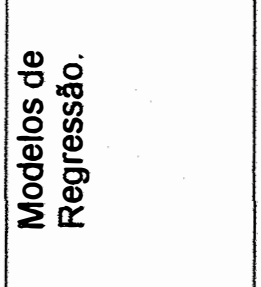 & $\begin{array}{l}\frac{1}{\alpha} \\
\sum \\
\frac{\alpha}{0} \\
\frac{0}{0} \\
\frac{0}{2}\end{array}$ \\
\hline 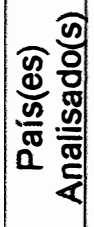 & 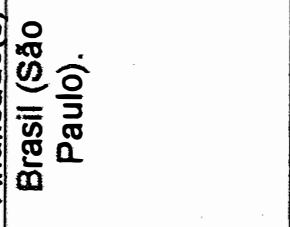 & 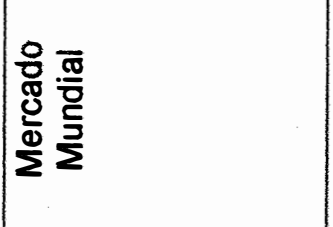 & 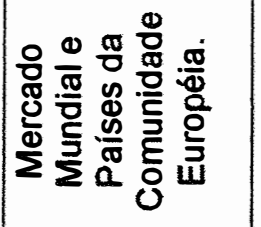 & 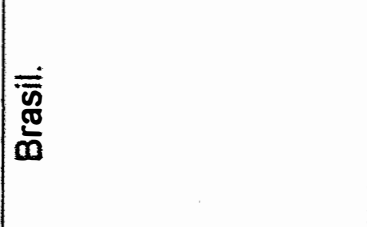 \\
\hline$\frac{\widehat{c}}{\frac{0}{2}}$ & 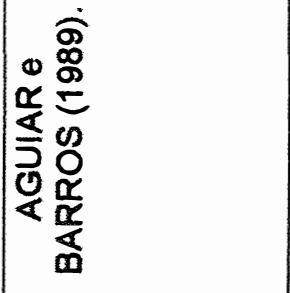 & 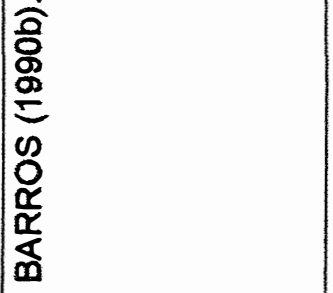 & 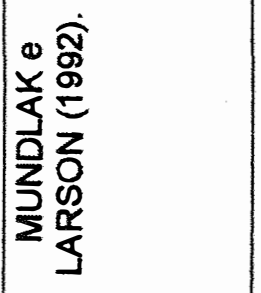 & 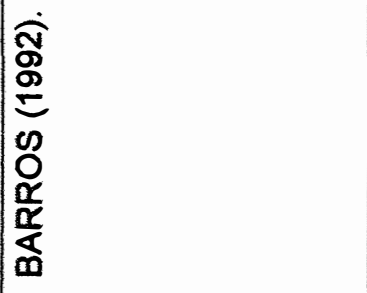 \\
\hline
\end{tabular}




\begin{tabular}{|c|c|c|c|c|}
\hline 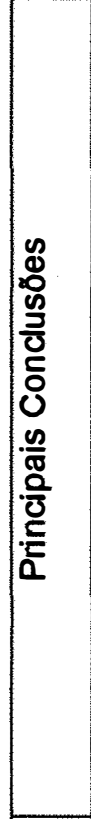 & 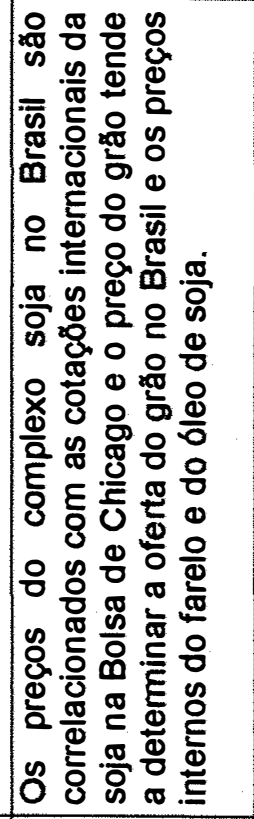 & 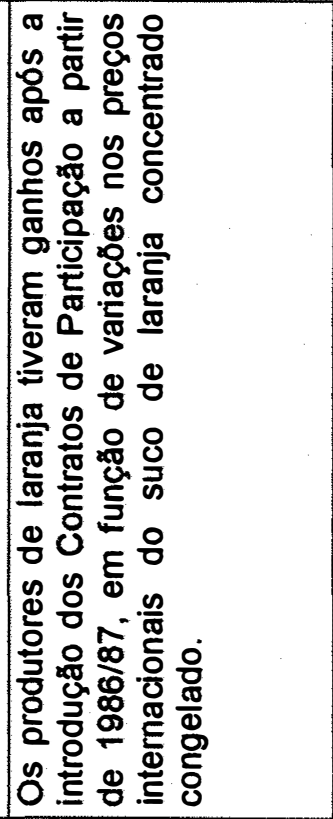 & 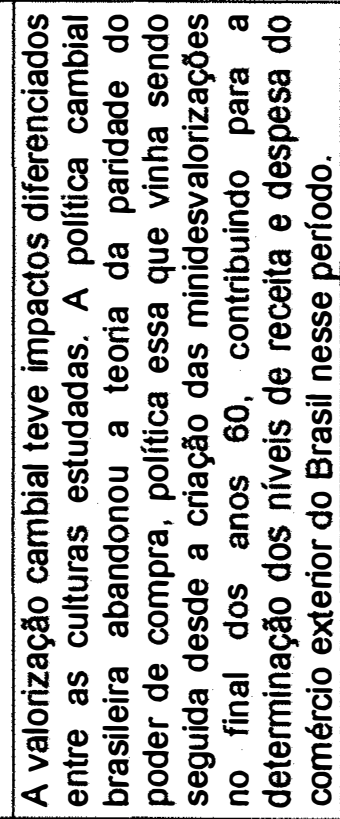 & 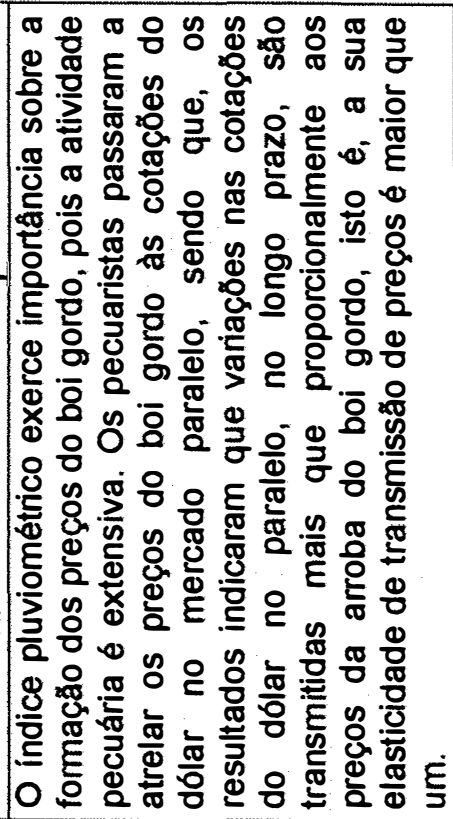 \\
\hline $\begin{array}{l}\frac{0}{0} \\
\frac{0}{0} \\
\frac{0}{0} \\
0\end{array}$ & 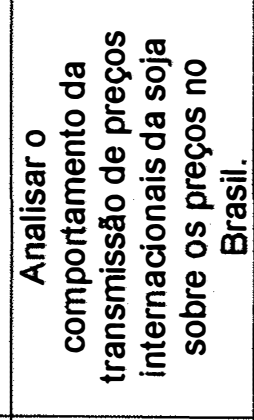 & 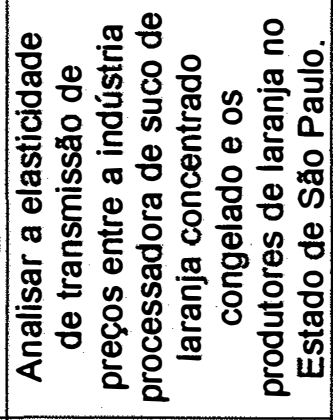 & 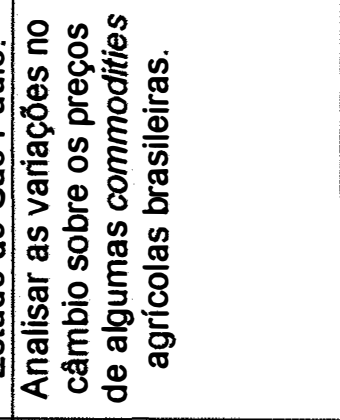 & 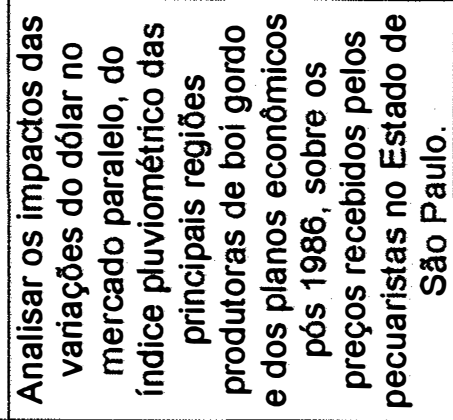 \\
\hline 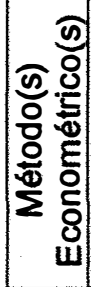 & 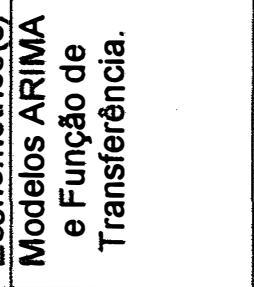 & 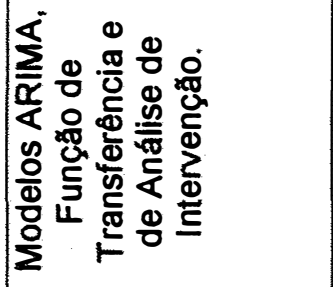 & 㺃 & 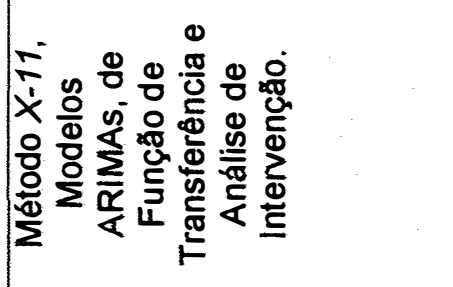 \\
\hline 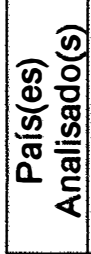 & & 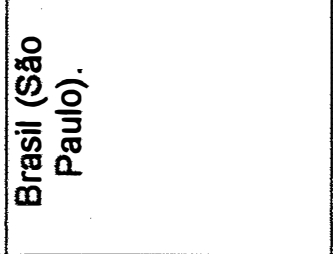 & 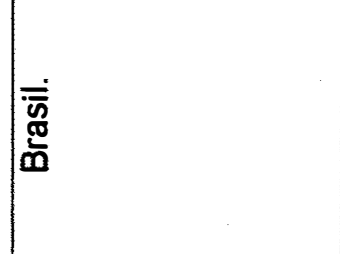 & 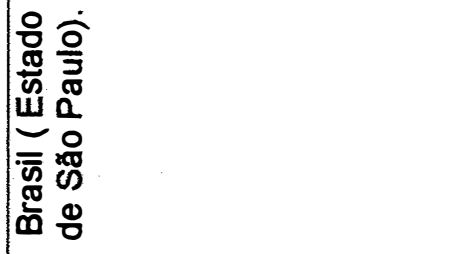 \\
\hline$\frac{\mathscr{c}}{\frac{0}{5}}$ & 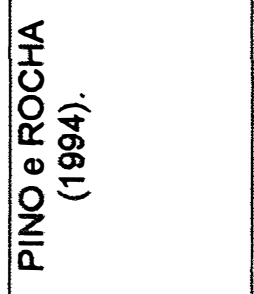 & $\frac{0}{\frac{0}{\alpha \alpha}}$ & 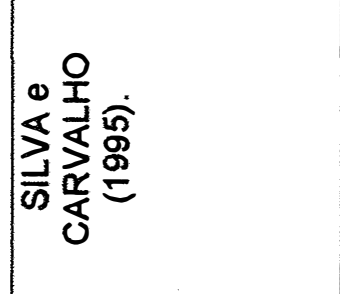 & 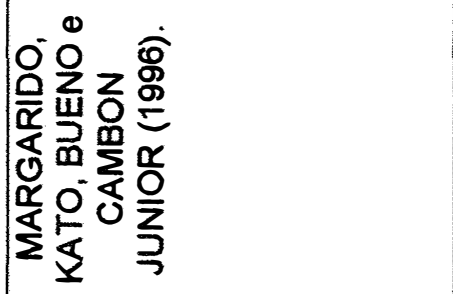 \\
\hline
\end{tabular}




\begin{tabular}{|c|c|c|c|}
\hline 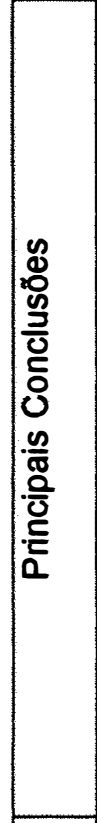 & 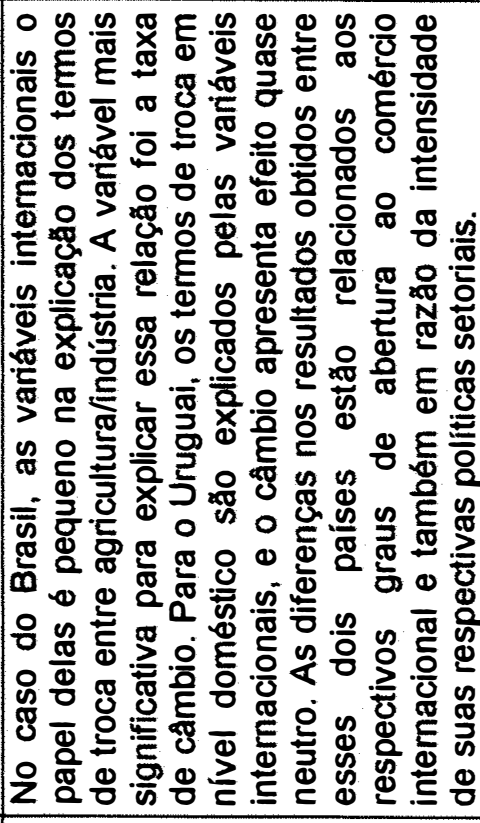 & 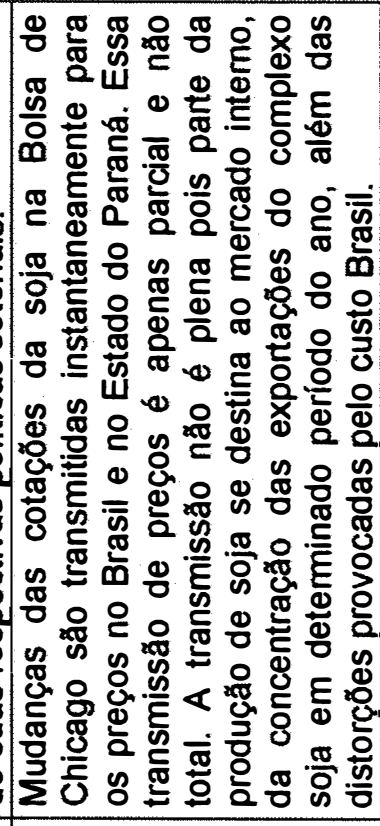 & 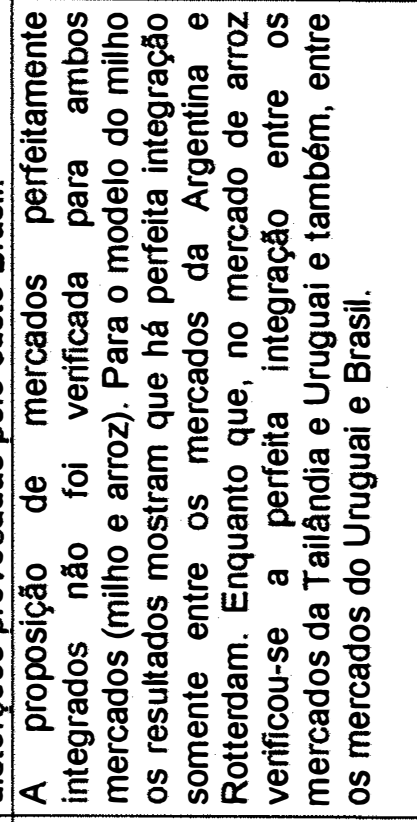 \\
\hline 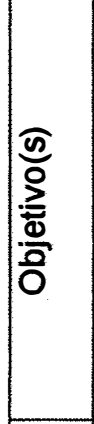 & 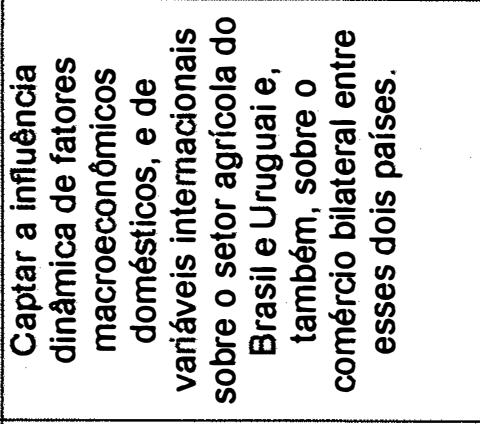 & 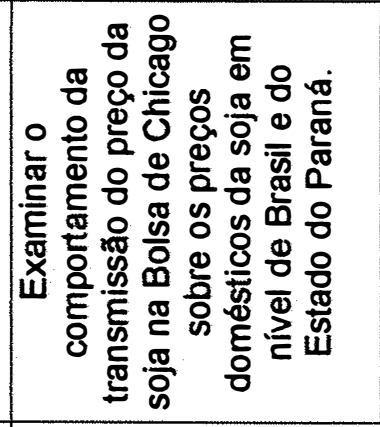 & 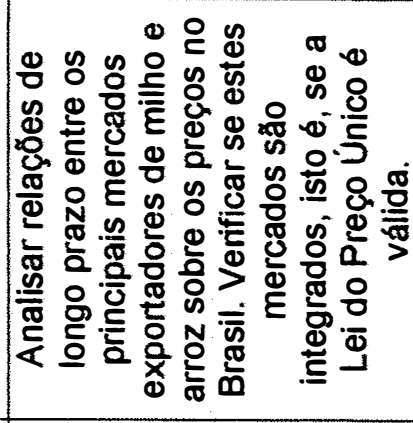 \\
\hline 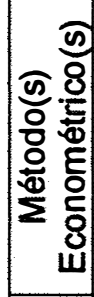 & 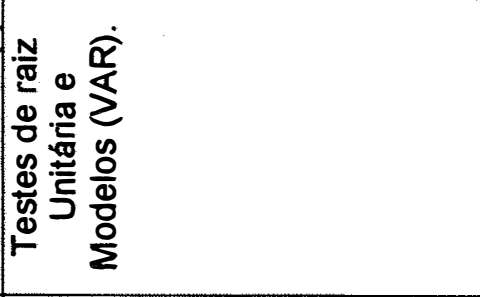 & 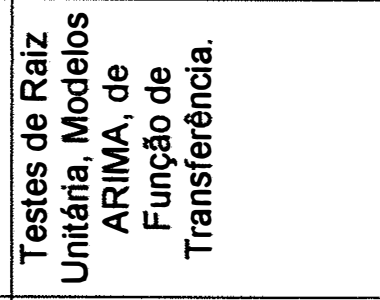 & 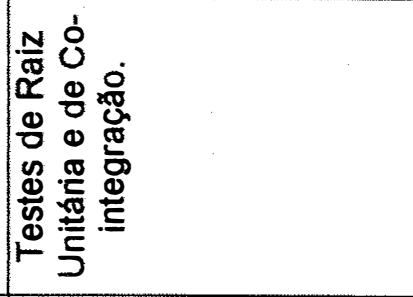 \\
\hline 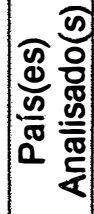 & 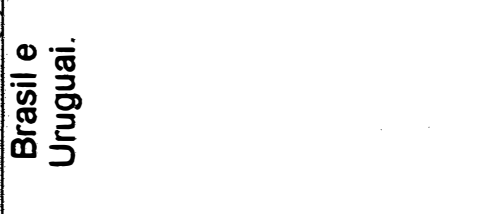 & 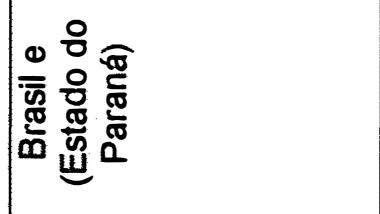 & $\mid \begin{array}{c}\overline{\bar{c}} \\
\frac{\bar{\pi}}{\bar{\infty}}\end{array}$ \\
\hline & $\underbrace{m}_{0}$ & 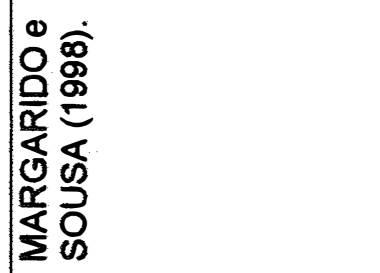 & 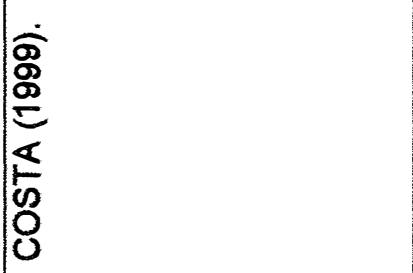 \\
\hline
\end{tabular}




\begin{tabular}{|c|c|}
\hline 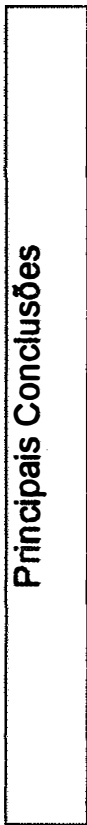 & 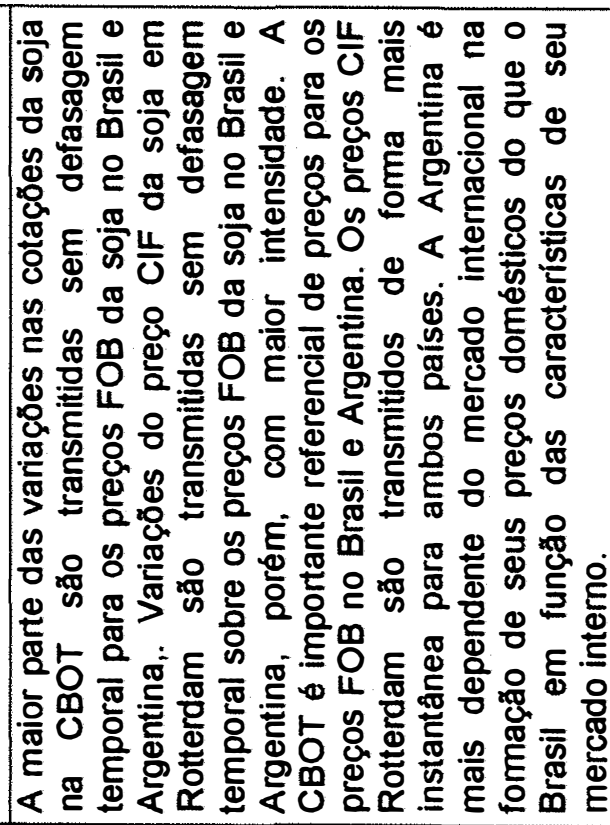 \\
\hline 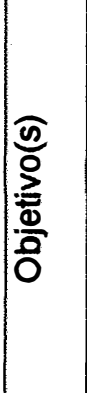 & 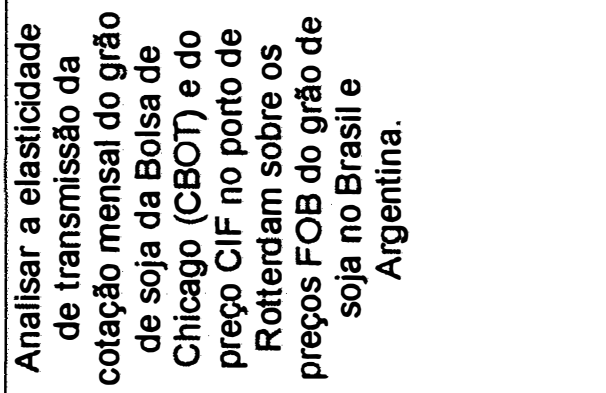 \\
\hline 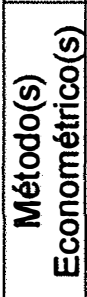 & 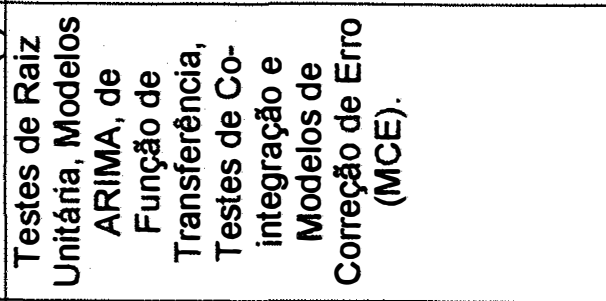 \\
\hline 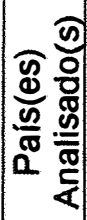 & 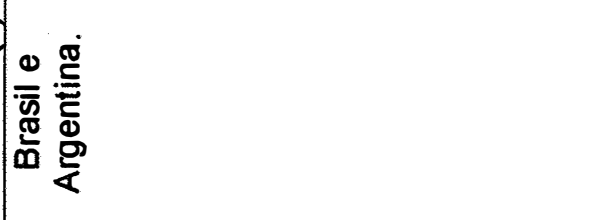 \\
\hline 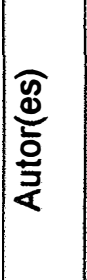 & 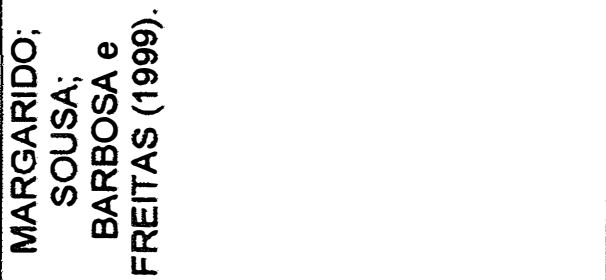 \\
\hline
\end{tabular}




\section{4 - MODELO TEÓRICO DE TRANSMISSÃo INTERNACIONAL DE PREÇOS AGRÍCOLAS SOBRE PREÇOS AGRÍCOLAS DOMÉSTICOS}

O modelo térico utilizado caracteriza-se por ser estático e adequado para o caso de uma economia aberta contendo apenas dois setores, quais sejam agricultura e indústria e tem como base o trabalho desenvolvido por PONGIBOVE (1996), que por sua vez, inspirou-se em BARROS (1990a), o qual teve como referência básica os trabalhos de SAYAD (1979), MODIANO (1985) e BARBOSA (1987).

Em relação ao modelo desenvolvido por PONGIBOVE (1996) este estudo procurou utilizar variáveis que espelham de maneira mais fidedigna a realidade. Enquanto PONGIBOVE (1996) utilizou o nível de preços nos EUA para representar o grau de atrelamento da taxa de câmbio nominal no Brasil, neste caso, preferiu-se utilizar a taxa de câmbio real para exercer a mesma função, pois para o exportador em termos de tomada de decisão o que importa é a taxa de câmbio real, a qual leva em consideração além do valor da taxa de câmbio nominal, o nível de preços intemacionais e domésticos, e não a taxa de câmbio nominal.

Já o papel do nível de preços domésticos nos EUA foi utilizado aqui para captar o comportamento da demanda intemacional, dado que os EUA são a economia hegemônica. Mais precisamente, uma vez que, os EUA representam a mais importante economia em termos individuais (na linguagem de economia intemacional os EUA são considerados um país grande), então suas ações tem reflexos diretos sobre o comportamento dos demais países e consequentemente sobre a demanda mundial.

Outra modificação foi a inclusão da variável M2 para representar a oferta de moeda ao invés de M1: a justificativa para este procedimento reside no fato de que, no período de 1990 até junho de 1994, a economia brasileira apresentou um quadro com elevada instabilidade do nivel de preços. Diante de um quadro de inflação crônica, a utilização de M1 poderia apresentar resultados viesados.

Também, é necessário realçar que, enquanto o trabalho desenvolvido por PONGIBOVE (1996) abrangeu um período em que a economia brasileira apresentava elevado nível de indexação por parte dos agentes econômicos exatamente em função da instabilidade de preços proporcionada pelo processo inflacionário crônico no Brasil, neste estudo, o período de análise está dividido em duas fases distintas. A primeira que vai de janeiro de 1990 até junho de 1994 
caracterizou-se por apresentar forte instabilidade de preços, enquanto que, a segunda, a qual iniciou-se a partir de julho de 1994, com a implementação do Plano Real, estende-se até dezembro de 1998, sendo que, esta segunda fase caracterizou-se pela estabilidade dos preços domésticos, além do desmantelamento dos mecanismos de indexação envolvendo preços e salários. Logo, este estudo também diferencia-se dos demais pelo fato de analisar um período de ausência de indexação na economia brasileira.

O modelo econômico elaborado por PONGIBOVE (1996) diferencia-se do modelo apresentado em BARROS (1990a) por acrescentar "na determinação do preço doméstico do bem agrícola comercializável a possibilidade que este preço possa refletir com algumas distorçőes o seu correspondente preço internacional". Isto quer dizer que a existência de restrições impostas ao funcionamento do mercado internacional de produtos agrícolas, como por exemplo a presença de tarifas sobre importações, ou então de subsidios às exportações, não permite que o preço doméstico de um bem tradable (ou comercializável) no mercado externo possa acompanhar o seu respectivo preço internacional, pelo menos no curto prazo, invalidando dessa forma a Lei do Preço Único.

De forma resumida, como delineado em MUNDLAK e LARSON (1992), a Lei do Preço Único $^{7}$ estabelece que se pode escrever o preço doméstico do produto agrícola comercializável como função do preço internacional da commodity agrícola, da taxa de câmbio e da política comercial adotada pelo país. Algebricamente, esse modelo pode ser representado como:

$$
P_{i t}=P^{*}{ }_{i t} E_{0 t} S_{i t}
$$

sendo: $P_{i t}=$ preço doméstico do produto $i$ no período $t, P_{i t}^{*}=$ preço mundial do produto $i$ no período $t, E_{0 t}=$ taxa de câmbio nominal no período $t$, e $S_{i t}=\left(1+\tau_{i t}\right)$, onde $S_{i t}$ é a política comercial implementada em relação ao produto i no período te $\tau$ é a taxa utilizada pela política comercial. Quando essa taxa é positiva, isso implica na imposiçăo de uma tarifa para o produto $i$ importado ou subsídio para o setor exportador, e quando seu valor é negativo isso quer dizer que o governo desembolsa recursos para estimular a importação do produto $i$, ou seja esse produto é subsidiado pelo governo, ou então, há taxação sobre os produtos exportados.

Outro aspecto importante desse referencial teórico é que o termo $S_{i t}$ incorpora não somente os instrumentos clássicos de política comercial, tais como a imposição de tarifas e a concessão de subsídios, mas também elementos de política comercial considerados heterodoxos como, por exemplo, restriçőes quantitativas de importações. Essa teoria ão leva

\footnotetext{
${ }^{7}$ Para KRUGMAN e OBSTFELD (1997), apesar da Paridade do Poder de Compra (PPP) ser semelhante à Lei do Preço Único, há diferença entre ambas. Enquanto a primeira aplica-se a produtos específicos, a segunda refere-se ao nivel geral de preços, o qual reflete os preços de todos os produtos que compöe uma determinada cesta de bens de referência. No entanto, se a Lei do Preço Único é válida para todos os produtos dessa cesta de referência, então a Lei do Preço Único iguala-se à PPP.
} 
em consideração diferenças qualitativas entre os produtos nem custos de transporte, armazenagem, bem como insumos domésticos nontradeables. Em relação à taxa de câmbio esse arcabouço teórico pressupõe que a taxa de câmbio está em equilíbrio, ou seja, o câmbio não está subvalorizado nem sobrevalonizado, logo a diferença entre as taxas de inflação doméstica e internacional é inteiramente refletida no termo $E$. Para capturar possíveis desvios, em funçăo de variáveis não introduzidas no modelo, adiciona-se um termo de disturbância $(U)$ na equação ${ }^{8}$.

Portanto, na ausência de intervenção por parte do governo ou de alguma outra forma de restriçăo sobre o mercado, como por exemplo a existência de contratos, espera-se que os preços internos do produto agrícola doméstico comercializável acompanhem as variações dos preços externos, isto é, que prevaleça o lei do preço único. Entretanto, especificamente no caso do setor agrícola verifica-se que, em função de suas próprias características, esse setor normalmente está sob considerável nível de intervenção pública, a qual resulta no diferencial entre os preços agrícolas praticados internamente e externamente.

Escrevendo-se a equação (1) na forma logaritmica, obtém-se:

$$
p_{i t}=p^{*}{ }_{i t}+e_{t}+s_{i t}+u_{i t}
$$

onde $u \sim \| D^{9}\left(\mu, \sigma^{2}\right)$ e $E(e u)=E(s u)=E\left(\rho^{\star} u\right)=0$, ou seja u não é correlacionado com nenhuma das variáveis do modelo.

O modelo mais simples de transmissão de preço proposto por MUNDLAK e LARSON (1992) parte do princípio de que o preço doméstico de determinado produto é função de seu respectivo preço mundial, da taxa de câmbio nominal e do termo de disturbância, logo deve-se estimar o seguinte modelo:

$$
p_{i t}=\alpha+\gamma p_{i t}^{*}+\beta e_{t}+\varepsilon_{i t}
$$

sendo que as hipóteses em relação aos parâmetros são: $0 \leq \gamma \leq 1 \mathrm{e} 0 \leq \beta \leq 1$. O coeficiente $\gamma$ é a elasticidade do preço doméstico em relação ao comércio intemacional, ou seja é a sua elasticidade de transmissão de preço. Quando seu valor é igual a um isto significa que variações no preço internacional são plenamente transmitidas ao preço doméstico. Por outro lado, quando o valor de $\gamma$ é igual a zero, isso implica que variações do preço internacional não conduzem a qualquer tipo de resposta do preço doméstico; nesse caso a economia do país é completamente fechada. $O$ caso mais comum é o valor de $\gamma$ permanecer entre zero e um,

\footnotetext{
${ }^{8}$ A completa apresentação e discussão do modelo tendo como base a Lei do Preço Único encontra-se em MUNDLAK e LARSON (1992).

${ }^{9}$ Independente e Identicamente Distribuido (IID).
} 
refletindo, dessa forma, a respectiva política comercial adotada pelo país ou algum outro tipo de restrição imposta ao mercado.

\section{1 - Descrição das Variáveis do Modelo Teórico}

\subsection{1 - Taxa de cámbio real}

Conforme a Teoria da Paridade do Poder de Compra (Purchasing-power parity, PPP) 0 índice da taxa de câmbio real é representado pela relação entre um indice de preço extemo ( $P$ ) e um índice de preço doméstico $(P)$, sendo ambos considerados em uma mesma moeda, isto é:

$$
E_{t}=E_{0 t} \frac{P_{t}^{*}}{P_{t}}
$$

onde $E_{a t}$ é a taxa de câmbio nominal (no caso do Brasil R\$/US\$). Logo, a PPP é o mecanismo pelo qual os preços domésticos estão ligados à taxa de câmbio.

Ao se tomar o logaritmo da taxa de câmbio real, tem-se:

$$
e_{t}=e_{0 t}+p_{t}^{*}-p_{t}+u_{t}
$$

onde: $e_{t}=$ logaritmo da taxa de câmbio real; $e_{o t}=$ logaritmo da taxa de câmbio nominal; $p_{t}{ }^{*}=$ logaritmo do índice de preço internacional; $p_{t}=$ logaritmo do índice de preço doméstico, e $u_{t}=$ desvio da PPP no período $t$, ou seja esse termo capta os desvios da taxa de câmbio real no curto prazo decorrentes de algum tipo de choque, tais como, choques de oferta que alteram a produtividade dos fatores de produção, ou choques de demanda.

No longo prazo a tendência é de que os preços domésticos igualem-se aos respectivos preços internacionais, sendo assim, o termo de disturbância na equação 5 toma-se igual a zero.

Supondo que o parâmetro $\gamma$, representa o fator de correção ou velocidade de ajustamento da variação da taxa de câmbio nominal relativamente ao diferencial entre a inflação extema e interna, e também, supondo-se que $0 \leq \gamma \leq 1$, então, a equação (5) pode ser escrita da seguinte forma:

$$
e=e_{0}+\gamma\left(p-p^{*}\right), 0 \leq \gamma \leq 1
$$

Caso o valor de $\gamma$ seja igual a 1, então a transmissão da taxa de câmbio em relação à variação do diferencial entre o nível de preço intemacional e doméstico será perfeita, e conseqüentemente a teoria da paridade do poder de compra toma-se válida, pois variações nos preços externos são plenamente repassadas aos preços domésticos. Quando for igual a zero 
não há transmissão, uma vez que variações nos preços intemacionais não tem qualquer efeito sobre o nivel dos preços domésticos, isto é, a transmissão de preços extemos sobre os preços domésticos é nula. Portanto, o parâmetro $\gamma$ mostra não somente o grau de resposta dos preços domésticos às variações dos preços extemos, como também o nivel de competitividade de seus produtos tradeables no mercado internacional. Quando a taxa de câmbio é reduzida, isto implica que os bens estrangeiros são baratos relativamente aos bens produzidos internamente, enquanto que os bens produzidos intemamente são caros relativamente aos bens produzidos no exterior. Se a taxa de câmbio for elevada, esta relação inverte-se, pois agora, os bens estrangeiros são relativamente caros e os domésticos, relativamente baratos.

MUNDLAK e LARSON (1992) também chamam a atenção para a questão da correta medida da influência da taxa de câmbio na análise do modelo, pois a variabilidade da elasticidade da taxa de câmbio está diretamente relacionada com a sua volatilidade, que, por sua vez, é função direta da inflação, e também do regime cambial adotado.

\subsection{2-Mercado monetário}

O equilibrio no mercado monetário ocorre onde a demanda de moeda iguala-se à sua oferta. Tendo-se como ponto de partida a Teoria Quantitativa da Moeda, tem-se a seguinte expressão:

$$
M x V=P x Y
$$

onde, $M$ é a oferta nominal de moeda, $V$ é a velocidade renda da circulação da moeda, $P$ é 0 nivel de preços da economia e $Y$ é o nível de renda real da economia. As hipóteses adotadas nesse caso são de que a velocidade renda da circulação da moeda é constante e que a demanda real de moeda depende somente da renda real. Rearrumando os temos de (7), temse:

$$
\left(\frac{M}{P}\right)^{d}=k \times Y
$$

sendo que $k=\frac{1}{V}$ é o inverso da velocidade renda da circulação da moeda. Logo, a demanda por saldos monetários reais $\left(\frac{M}{P}\right)^{d}$, é igual a oferta real de moeda $\frac{M}{P}$, e como conseqüência - montante dos saldos monetários reais demandados é proporcional à renda nominal. Aplicando-se o logaritmo em (8) obtém-se:

$$
m_{0}=k_{0}+y
$$


onde, $m_{0}$ é a oferta real de moeda, $k_{0}$ é uma constante e y é o nivel de renda real. Portanto, esse modelo simplificado objetiva captar o efeito da liqüidez da economia através da relação entre renda e moeda. Visando simplificar a análise, este modelo não leva em consideração a demanda especulativa de moeda, isto é, não incorpora o papel da taxa de juros sobre a determinação da demanda de moeda.

\subsection{3 - Mercado agrícola}

Nesse modelo, admite-se que o setor agrícola doméstico produz somente dois tipos de produtos, denominados comercializáveis (c), ou seja aqueles que são transacionados no mercado internacional e os não comercializáveis $(b)$, isto é aqueles que são comercializados exclusivamente no mercado interno. O preço agrícola total é igual a $\left(\boldsymbol{p}_{a}\right)$, enquanto que 0 produto agrícola total é $\left(q_{\mathrm{a}}\right)$. Em termos matemáticos tem-se:

$$
\begin{aligned}
& p_{a}=\mu p_{b}+(1-\mu) p_{c} \\
& q_{a}=\mu q_{b}+(1-\mu) q_{c}
\end{aligned}
$$

onde, $\rho_{b}$ é o preço do bem não comercializável e $q_{b}$ é a quantidade produzida do bem não comercializável, $\rho_{c}$ representa o preço do bem comercializável e $q_{c}$ é a quantidade produzida do bem comercializável, e $\mu$ é a parcela (ou percentagem) da produção e do preço agrícola total destinada aos produtos não comercializáveis e $(1-\mu)$ a parcela dos comercializáveis, sendo que o seu valor varia entre zero e um. Portanto, esse modelo pressupõe idêntica contribuição dos produtos comercializáveis para o preço total e a produção total do produto agrícola.

A formação do preço do produto agrícola vai depender das características próprias desse bem. Para o produto agrícola comercializável, o preço é determinado exógenamente, ou seja, no caso do produto tradeable o país é tomador de preços no mercado internacional, logo o seu preço doméstico $\left(\rho_{c}\right)$ é função direta do preço desse produto no mercado externo $\left(\rho_{c}^{*}\right)$ e da taxa de câmbio (e). Matematicamente tem-se:

$$
p_{c}=\lambda\left(p_{c}^{*}+e\right), \quad 0 \leq \lambda \leq 1
$$

o parâmetro $\lambda$ representa a velocidade de ajustamento do preço doméstico do produto comercializável frente às variações no preço do bem comercializável no mercado mundial e da taxa de câmbio. Diante de algum tipo de restrição no mercado, como por exemplo a presença de impostos e/ou subsídios sobre as exportações desse produto, 0 valor de $\lambda$ pode diferir de um. A introdução desse fator $\lambda$ é que distingue o modelo desenvolvido por PONGIBOVE (1996) do trabalho apresentado por BARROS (1990a). 
Ainda com relação ao produto agrícola comercializável (c), o modelo incorpora a suposição simplificadora de que este é produzido utilizando somente um insumo, o qual é derivado do setor industrial e denominado (D). Portanto, a quantidade ofertada do produto agrícola comercializável $\left(q_{c s}\right)$ é função direta de seu próprio preço $\left(p_{c}\right)$ e indireta do preço do bem nontradeable $\left(\rho_{b}\right)$ que exerce concorre diretamente com o bem tradeable e do preço do produto industrial $\left(p_{i}\right)$ que é utilizado como insumo na produção do bem tradeable, ou seja:

$$
q_{c s}=c_{0}-c_{1} p_{b}+c_{2} p_{c}-c_{3} p_{i}
$$

sendo que: $c_{1}-c_{2}+c_{3}=0$ e $0<c_{j}<1, j=1,2,3$.

Em função de suas próprias características, o preço do produto agrícola não comercializável $\left(\rho_{b}\right)$ é determinado em regime de concorrência perfeita ${ }^{10}$, ou seja, pelas condições de oferta e demanda prevalecentes nesse mercado. Pelo lado da demanda tem-se:

$$
q_{b d}=\theta_{b}+y-p_{b}
$$

onde, $q_{b d}$ é a quantidade demanda do produto agrícola não comercializável, y é a renda do consumidor e $p_{b}$ é o preço do bem agrícola não comercializável. A hipótese aqui é de que uma proporção fixa da renda do consumidor é dispendida em cada bem, isto é, trabalha-se com funções utilidade do tipo potência, sendo que $\theta_{b}$ representa o logaritmo da fração da renda gasta nesse produto, enquanto que os coeficientes relativcs às variáveis y e $p_{b}$ são iguais a um.

Em relação à quantidade ofertada do produto agrícola não comercializável $\left(q_{b s}\right)$ tem-se algo semelhante ao do produto agrícola tradeable, isto é:

$$
q_{b s}=b_{0}+b_{1} p_{b}-b_{2} p_{c}-b_{3} p_{i}
$$

onde a quantidade ofertada do produto agricola nontradeable $\left(q_{b} s\right)$ é função direta de seu próprio preço $\left(p_{b}\right)$ e inversa do preço do produto agrícola comercializável $\left(p_{c}\right)$ e do preço do único insumo industrial utilizado na produção do bem agricola não comercializável $\left(p_{i}\right)$, além disso tem-se que $b_{1}-b_{2}-b_{3}=0$ e $0<b_{j}<1, j=1,2,3$.

\footnotetext{
${ }^{10}$ Dado que o modelo pressupōe que o setor agrícola atua num regime de concorrência perfeita e com pleno emprego, isto implica que este setor pode ser modelado como uma economia clássica. Portanto, uma vez que os agricultores não podem fixar o preço de seus respectivos produtos em função do grande número de produtores e também, pelo fato do produto ser homogẻneo, o preço é determinado pelo próprio mercado. No caso do modelo clássico, o emprego de equilibrio é determinado apenas no mercado de trabalho, independentemente das condiçð̋es da demanda agregada da economia. Como o preço participa multiplicativamente das funçōes oferta e demanda de trabalho, o salário nominal variará pelo mesmo
} 


\subsection{4 - Mercado industrial}

A formação do preço do produto industrial utilizado como insumo na produção tanto do bem comercializável, quanto não comercializável pode ser dividida em dois segmentos. No primeiro é estabelecido o custo do insumo importado $\left(\rho_{w}\right)$ que por sua vez é função direta da taxa de câmbio (e) e do preço desse insumo no mercado internacional $(p)$ conforme mostra a seguinte expressão:

$$
p_{w}=\left(e+p^{*}\right)
$$

No segundo segmento detemina-se a fixação de uma certa margem ( $\pi$ ) incidente sobre os insumos agrícolas. Aglutinando-se os dois segmentos obtém-se a expressão completa que determina o preço do bem industrial:

$$
p_{i}=\beta_{0}+\beta_{1} \pi p_{a}+\left(1-\beta_{1}\right)\left(e+p^{*}\right)
$$

onde os parâmetros $\pi$ e $\beta_{1}$ são ambos maiores que zero e menor que um.

Analisando-se mais detalhadamente, o "fator $\pi$ é então uma medida de transmissão dos preços industriais aos agrícolas (seja porque estes são considerados bens-salários e/ou matérias-primas da indústria, particularmente no primeiro caso é uma medida de transmissão dos custos industriais aos salários)". (PONGIBOVE, 1996, p. 24).

A construção da equação de demanda para o produto industrial é semelhante a do produto agrícola não comercializável, isto é:

$$
q_{i d}=\theta_{i}+y-p_{i}
$$

onde: $q_{i d}$ é a quantidade demandada do bem industrial, a qual é função direta de uma parcela da renda $(y)$ representada pelo parâmetro $\theta_{i}$ e inversa do seu próprio preço.

Para finalizar esse item, resta adicionar duas equações, uma para quantidade $(y)^{11}$ e 0 outra para preço $(p)$, para determinar qual a respectiva participação do setor agrícola e do setor industrial na economia do país. Para o caso da quantidade agregada tem-se a seguinte equação:

$$
y=\delta q_{a}+(1-\delta) q_{i}
$$

Para os preços agregados obtém-se:

$$
p=\delta p_{a}+(1-\delta) p_{i}
$$

sendo que $\delta$ representa a fração (ou percentual) do produto agrícola em relação ao produto agregado da economia.

montante que o nível de preço, mas o emprego permanecerá constante, assim como o custo real da mãode-obra. 
Resumidamente, esse modelo contém treze equações, doze variáveis endógenas e quatro variáveis exógenas (QUADRO 2).

QUADRO 2: Descrição resumida do modelo teórico.

\begin{tabular}{|c|c|}
\hline Variáveis endógenas & Equaçōes \\
\hline 1) $e=$ taxa de câmbio real & $\begin{array}{c}(5),(12),(16) \\
e(17)\end{array}$ \\
\hline 2) $\rho=$ preço agregado da economia & (5) e (20) \\
\hline 3) $y=$ produto agregado da economia & $\begin{array}{l}(9),(14),(18) \\
\text { e }(19)\end{array}$ \\
\hline $\begin{aligned} \text { 4) } q_{b}= & \text { quantidade ofertada e demandada do produto agrícola não } \\
& \text { comercializável (nontradeable) }\end{aligned}$ & $\begin{array}{l}(11),(14) \mathrm{e} \\
(15)\end{array}$ \\
\hline 5) $p_{b}=$ preço do produto agrícola não comercializável & $\begin{array}{l}(10),(13) \\
(14) \text { e }(15)\end{array}$ \\
\hline 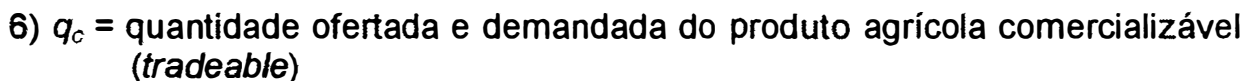 & (11) e (13) \\
\hline 7) $p_{c}=$ preço do produto agrícola comercializável & $\begin{array}{l}(10),(12) \\
(13) \text { e }(15)\end{array}$ \\
\hline 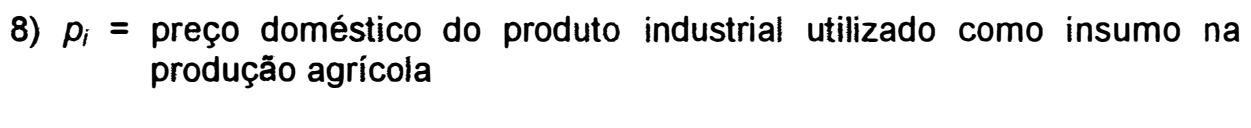 & $\begin{array}{c}(13),(15) \\
(17),(18) \mathrm{e} \\
(20)\end{array}$ \\
\hline 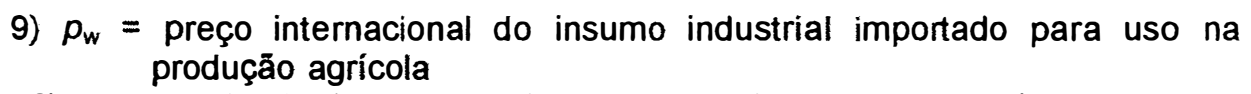 & (16) \\
\hline $\begin{array}{l}\text { 10) } q_{i}=\text { quantidade demanda do insumo industrial pelo setor agrícola } \\
\text { 11) } p_{a}=\text { preço do produto agricola }\end{array}$ & $\begin{array}{c}(18) \text { e }(19) \\
(10),(17) \text { e } \\
(20)\end{array}$ \\
\hline 12) $q_{a}=$ quantidade ofertada do produto agrícola total & (11) e (19) \\
\hline Variáveis exógenas & Equações \\
\hline 1) $p=$ nivel de preço externo & $\begin{array}{l}(5),(16) \mathrm{e} \\
(17)\end{array}$ \\
\hline 2) $e_{0}=$ taxa de câmbio nominal & $(5)$ \\
\hline 3) $m_{0}=$ oferta monetária & (9) \\
\hline 4) $p_{c}=$ preço internacional do produto agrícola comerciali & $(12)$ \\
\hline
\end{tabular}

Fonte: Elaborado pelo autor.

\section{2 - Análise Estático-Comparativa}

Como o objetivo desse estudo foi analisar o comportamento dos preços agrícolas e industriais diante de alterações em variáveis macroeconômicas, tanto domésticas, quanto externas, torna-se necessário construir as formas reduzidas para as variáveis preços agrícolas $\left(p_{a}\right)$ e preços industriais $\left(p_{i}\right)$.

"O termo y representa o Produto Interno Bruto (PIB) da economia. 
Partido-se do equilíbrio do mercado do produto agrícola não comercializável (equações 14 e 15) é possivel obter uma expressão para $\rho_{b}$. A partir dessa nova expressão, juntamente com as equaçőes 9 e 10, chega-se a uma equação para $p_{a}$ :

$$
p_{a}=\alpha_{0}+\alpha_{1} p_{i}+\alpha_{3} m_{0}+\alpha_{2} p_{c}
$$

onde:

$$
\begin{aligned}
& \alpha_{0}=\left[\left(\frac{\mu}{b_{1}+1}\right)\right]\left(\theta_{b}-b_{0}-k_{0}\right) ; \\
& \alpha_{1}=\frac{\mu b_{3}}{\left(b_{1}+1\right)} \\
& \alpha_{2}=\frac{\left[(1-\mu)\left(b_{1}+1\right)+\mu b_{2}\right]}{\left(b_{1}+1\right)} \\
& \text { e } \alpha_{3}=\frac{\mu}{\left(b_{1}+1\right)}
\end{aligned}
$$

Os parâmetros devem obedecer à restrição $0<\alpha_{j}<1, j=1,2,3$ e $\alpha_{1}+\alpha_{2}+\alpha_{3}=1$, indicando que variações dos preços do produto industrial, do produto comercializável e da oferta monetária, numa dada proporção, implicam em alteração do preço do produto agrícola não comercializável em igual magnitude. Outros aspectos importantes são que $\alpha_{1}<\alpha_{3}$ e a relação dos paråmetros $\alpha_{1}$ e $\alpha_{3} \operatorname{com} \alpha_{2}$ é indeterminada.

Para obter-se a forma reduzida de $p_{a}$ é necessário combinar as equações (5), (12), (17), (20) e (21), o que resulta em:

$$
\begin{aligned}
& p_{a}=\alpha_{0}\left[\left(1-\left(1-\beta_{1}\right) \gamma(1-\delta)\right] \phi^{-1}+\beta_{0}\left[\alpha_{1}+\alpha_{2} \lambda \gamma(1-\delta)\right] \phi^{-1}\right. \\
& \left\{\left[\alpha_{1}+\alpha_{2} \lambda \gamma(1-\delta)\right]\left(1-\beta_{1}\right)+\left[1-\left(1-\beta_{1}\right) \gamma(1-\delta)\right] \lambda \alpha_{2}\right\} e_{0} \phi^{-1}+ \\
& \left\{\left[\alpha_{1}+\alpha_{2} \lambda \gamma(1-\delta)\right]\left(1-\beta_{1}\right)(1-\gamma)-\left[1-\left(1-\beta_{1}\right) \gamma(1-\delta)\right] \lambda \gamma \alpha_{2}\right\} p^{*} \phi^{-1}+ \\
& {\left[1-\left(1-\beta_{1}\right) \gamma(1-\delta)\right] \lambda \alpha_{2} p_{c}^{*} \phi^{-1}+\left[1-\left(1-\beta_{1}\right) \gamma(1-\delta)\right] \alpha_{3} m_{0} \phi^{-1}}
\end{aligned}
$$

sendo que

$$
\phi=\left(1-\alpha_{2} \lambda \gamma \delta\right)\left[1-\left(1-\beta_{1}\right) \gamma(1-\delta)\right]-\left[\beta_{1} \pi+\left(1-\beta_{1}\right) \gamma \delta\right]\left[\alpha_{1}+\alpha_{2} \lambda \gamma(1-\delta)\right]
$$

A forma reduzida para $p_{i}$ tem como base as equações (20) e (21) e assume o seguinte formato: 


$$
\begin{aligned}
& p_{i}=\beta_{0}\left(1-\alpha_{2} \lambda \gamma \delta\right) \phi^{-1}+\left[\beta_{1} \pi+\left(1-\beta_{1}\right) \gamma \delta\right] \alpha_{0} \phi^{-1}+ \\
& {\left[\beta_{1} \pi+\left(1-\beta_{1}\right) \gamma \delta\right] \alpha_{2} \lambda \dot{p}_{0}^{*} \phi^{-1}+} \\
& \left\{\left[\beta_{1} \pi+\left(1-\beta_{1}\right) \gamma \delta\right] \alpha_{2} \lambda+\left(1-\beta_{1}\right)\left(1-\alpha_{2} \lambda \gamma \delta\right)\right\} e_{0} \phi^{-1}+ \\
& \left\{\left(1-\alpha_{2} \lambda \gamma \delta\right)\left(1-\beta_{1}\right)(1-\gamma)-\left[\beta_{1} \pi+\left(1-\beta_{1}\right) \gamma \delta\right] \alpha_{2} \lambda \gamma\right\} p^{*} \phi^{-1}+ \\
& {\left[\beta_{1} \pi+\left(1-\beta_{1}\right) \gamma \delta\right] \alpha_{3} m_{0} \phi^{-1}}
\end{aligned}
$$

Em termos econômicos, os numeradores das equações (22) e (23) podem ser interpretados como choques proporcionados pelas variáveis exógenas sobre os preços agrícolas e industrial intemos, enquanto que o denominador revela o efeito multiplicador dos choques exógenos.

Um aspecto relevante em relação a especificação desse modelo teórico reside no fato de que se toma possivel realizar a análise sob diferentes hipóteses de transmissão “do câmbio ao diferencial de preços domésticos e extemos (coeficiente $\gamma$ ); dos custos industriais às mudanças de preços agrícolas (seja através dos salários industriais ou dos custos das matérias-primas agrícola) (coeficiente $\pi$ ); do preço do bem agrícola comercializável $\left(p_{c}\right)$ ao seu correspondente preço intemacional $\left(p_{c}^{*}\right)$ (coeficiente $\left.\lambda\right)^{n}$ (PONGIBOVE, 1996, p. 26). Quando o respectivo coeficiente de transmissão for igual a um, isto quer dizer que a transmissão é perfeita e caracteriza uma situação de longo prazo, e quando for igual a zero não há transmissão, configurando aspectos relacionados com o curto prazo, ou seja, em função da presença de alguma distorção imposta pelo mercado, os preços não conseguem convergir para o equilíbrio no curto prazo.

O próximo passo consiste em analisar o comportamento das elasticidades dos preços agrícolas domésticos $\mathrm{e}$ industriais relativamente a choques proporcionados pelos preços intemacionais de produtos agrícolas, do nivel de preços dos Estados Unidos, na oferta monetária e da taxa de câmbio, utilizando os extremos das diferentes hipóteses de transmissão, isto é, considera-se somente as hipóteses de que os coeficientes de transmissão assumam os valores zero ou um. A justificativa para adotar somente os valores extremos dos coeficientes de transmissão decorre do fato de que, ao assumir valor igual a um, ou de transmissão plena, representam uma situação de longo prazo, enquanto que, ao assumir valor igual a zero (ausência completa de transmissão), isto configuram uma situação de curto prazo. 


\subsection{1 - Análise dos choques dos preços internacionais de produtos agrícolas sobre os preços domésticos agricola e industrial}

O Quadro 3 apresenta os resultados que os choques da variável preço internacional dos produtos agrícolas têm sobre as elasticidades dos preços agrícolas domésticos e preços industriais.

QUADRO 3 - Elasticidades dos preços domésticos com respeito a choques nos preços internacionais de produtos agrícolas sob diferentes hipóteses de transmissão

\begin{tabular}{ccccc}
\hline & \multicolumn{2}{c}{ Transmissão } & \multicolumn{2}{c}{ Elasticidades } \\
\hline Caso & Indexadores & $\frac{\alpha_{2}}{\alpha_{3}}$ & $E_{\mathrm{i}}$ & $\mathrm{E}_{\mathrm{a}}-\mathrm{E}_{\mathrm{i}}$ \\
\hline 1 & $\gamma=\pi=\lambda=1$ & 0 & $\frac{\alpha_{2}}{\alpha_{3}}$ & 0 \\
2 & $\gamma=\pi=\lambda=0$ & $\alpha_{2}$ & 0 & 0 \\
3 & $\gamma=\pi=0 \quad \lambda=1$ & 0 & 0 & $\alpha_{2}$ \\
4 & $\gamma=\pi=1 \lambda=0$ & 0 & 0 & 0 \\
5 & $\gamma=\lambda=0 \pi=1$ & $\frac{\alpha_{2}\left[1-\left(1-\beta_{1}\right)(1-\delta)\right]}{\Delta}$ & $\frac{\alpha_{2} \delta\left(1-\beta_{1}\right)}{\Delta}$ & $\frac{\alpha_{2} \beta_{1}}{\Delta}$ \\
6 & $\gamma=\lambda=1 \quad \pi=0$ & 0 & 0 \\
7 & $\pi=\lambda=0 \quad \gamma=1$ & $\frac{\alpha_{2}}{\left(1-\alpha_{1} \beta_{1}\right)}$ & $\frac{\alpha_{2} \beta_{1}}{\left(1-\alpha_{1} \beta_{1}\right)}$ & $\frac{\alpha_{2}\left(1-\beta_{1}\right)}{\left(1-\alpha_{1} \beta_{1}\right)}$
\end{tabular}

onde: $E_{a}=$ Elasticidade do preço agrícola doméstico, $E_{i}=$ Elasticidade do preço industrial doméstico e $\Delta=\left\{\alpha_{3} \delta+\beta_{1}\left[1-\delta\left(1-\alpha_{1}\right)\right]\right\}$.

Fonte: PONGIBOVE (1996).

Diante da inexistência de transmissão de preço do produto agrícola doméstico comercializável $(\lambda=0)$, como acontece nos casos $2,4,5$ e 7 , choques no seu correspondente preço internacional, não se transmitem para o seu preço interno diretarnente, sobre o próprio preço do produto agrícola, nem indiretamente, via preço do produto industrial utilizado como insumo na produção do produto agrícola exportável, pois nesses quatro casos as elasticidades dos produtos agrícola e industrial são iguais a zero, indicando que esses dois preços não são contaminados por choques exógenos.

Quando há perfeita transmissão de preços do produto agrícola doméstico exportável em relação ao seu próprio preço internacional $(\lambda=1)$, aos custos do produto industrial utilizado 
na produção do produto agrícola $(\pi=1)$ e ao nível de preço doméstico relativamente ao preço internacional, igual ao apresentado no caso 1, um choque originado exogenamente no preço do produto agrícola tradeable é transmitido igualmente sobre os preços domésticos, com magnitude igual a $\alpha_{2}$, sendo que seu efeito multiplicador é igual a $\frac{1}{\alpha_{3}}$, dado que $\alpha_{3}<1$. Portanto, choques de caráter exógeno tem efeitos iguais sobre as elasticidades do preço agrícola doméstico do produto exportável e do produto industrial, não alterando dessa forma os preços relativos entre os setores agrícola e industrial.

Quando somente o preço do produto agrícola doméstico exportável é perfeitamente indexado ao seu respectivo preço internacional, enquanto os indexadores relacionados com a taxa de câmbio e com os custos industriais são nulos (caso 3), a elasticidade do preço agrícola doméstico é igual a $\alpha_{2} \mathrm{e}$ a elasticidade do preço industrial é igual a zero. Portanto, $\alpha_{2}$ representa a magnitude da mudança dos preços relativos em função desses choques agrícolas externos, sendo que somente o preço agrícola se altera, dado que esse choque não transmite-se para o preço industrial, uma vez que $\pi=0$.

Ao se adotar a perfeita transmissão do preço do produto agrícola tradeable e da taxa de câmbio (caso 6), enquanto que os custos industriais permanecem rígidos a flutuações do preço agrícola internacional, obtém-se valores positivos para $E_{a}$ e $E_{i}$, só que nesse caso tem-se que $E_{a}>E_{i}$ e novamente há alteração nos termos de troca entre agricultura e indústria em favor da primeira. Segundo PONGIBOVE (1996, p. 28) o "fato de $E_{i}$ ser positiva ainda que $\pi$ seja zero, explica-se pelos efeitos do choque em $\dot{\rho}_{c}^{*}$ sobre $\rho_{a}$ através do nível geral de preços da economia e da taxa de câmbio".

No caso 8, adota-se a hipótese de perfeita transmissão para o preço do produto industrial doméstico em relação ao preço agrícola interno e do preço do bem agrícola doméstico comercializável ao seu respectivo preço externo, enquanto que não há transmissão da taxa de câmbio relativamente ao diferencial de preços doméstico e externo. Como resultado dessa hipótese as duas elasticidades são positivas, no entanto $E_{a}>E_{i}$ em função do fato de que os efeitos dos choques agrícolas externos sobre $\rho_{a}$ ser igual a $\alpha_{2}$ e sobre $p_{i}$ corresponder a $\alpha_{2} \beta_{1}$ resultando em um efeito idêntico sobre ambos setores, ou seja nesse caso não há alteração dos termos de troca entre esses dois setores pois o efeito multiplicador é o mesmo tanto para o setor agrícola, quanto o industrial. 


\subsection{2 - Análise dos choques no nível de preços internacionais sobre os preços domésticos agrícola $e$ industrial}

Assim como ocorreu no caso anterior, serão considerados oito casos diferentes de transmissảo relativamente à taxa de câmbio, preço doméstico do produto agrícola exportável e custos industriais doméstico. Sendo que nesse caso a variável exógena a ser considerada é o nível de preços ao produtor dos Estados Unidos, o qual é considerado como uma proxy do nível intemacional de preços. A justificativa para utilizar o nível de preços ao produtor nos EUA para representar o nível de preços mundial reside no fato de que individualmente os EUA são os maiores exportadores e importadores de produtos $^{12}$, além do que todos os demais paises seguem a reboque em relação às decisões de política econômica tomadas pelo governo dos EUA. Por exemplo, a alteraçăo da taxa de juros nos EUA tem reflexos diretos sobre todas as demais economias do planeta. Também, é necessário frisar que a única economia que apresentou crescimento contínuo e sustentado na década de 90 foram os Estados Unidos. Por último, não se pode esquecer que o preço da maioria das commodities agrícolas e não agrícolas tem seu preço formado nas Bolsas dos Estados Unidos.

O Quadro 4 apresenta os oito casos de transmissão a serem analisados diante de choques no nível internacional de preços $\left(p^{\circ}\right)$ sobre a relação dos termos de troca envolvendo os setores agrícolas e industrial domésticos.

\footnotetext{
12 Com exceção de 1990, no período de 1991 a 1998, conforme FOCUS (1990/1998), os EUA permaneceram como país líder no comércio internacional de produtos, tanto em relação às exportaçōes, quanto importaçōes em termos de valores. Na média, no período de 1990 até 1998, a participação percentual das exportações dos EUA em valores no total do comércio mundial correspondeu a $12,13 \%$, enquanto que as importaçōes representaram $15,31 \%$. Ao se adicionar o setor de serviços, estes valores elevam-se ainda mais.
} 
QUADRO 4 - Elasticidades dos preços domésticos com respeito a choques no nível de preços internacionais sob diferentes hipóteses de transmissão

\begin{tabular}{ccccc}
\hline & Transmissảo & & \multicolumn{1}{c}{ Elasticidades } & \\
\hline Caso & Indexadores & $\mathrm{E}_{\mathrm{a}}$ & $\mathrm{E}_{\mathrm{i}}$ & $\mathrm{E}_{\mathrm{a}}-\mathrm{E}_{\mathrm{i}}$ \\
\hline 1 & $\gamma=\pi=\lambda=1$ & $-\frac{\alpha_{2}}{\alpha_{3}}$ & $-\frac{\alpha_{2}}{\alpha_{3}}$ & 0 \\
2 & $\gamma=\pi=\lambda=0$ & $\alpha_{1}\left(1-\beta_{1}\right)$ & $\left(1-\beta_{1}\right)$ & $\left(\alpha_{1}-1\right)\left(1-\beta_{1}\right)$ \\
3 & $\gamma=\pi=0 \quad \lambda=1$ & $\alpha_{1}\left(1-\beta_{1}\right)$ & $\left(1-\beta_{1}\right)$ & $\left(\alpha_{1}-1\right)\left(1-\beta_{1}\right)$ \\
4 & $\gamma=\pi=1 \quad \lambda=0$ & 0 & 0 & 0 \\
5 & $\gamma=\lambda=0 \pi=1$ & $\frac{\alpha_{1}\left(1-\beta_{1}\right)}{\left(1-\alpha_{1} \beta_{1}\right)}$ & $\frac{\left(1-\beta_{1}\right)}{\left(1-\alpha_{1} \beta_{1}\right)}$ & $\frac{\left(1-\beta_{1}\right)\left(\alpha_{1}-1\right)}{\left(1-\alpha_{1} \beta_{1}\right)}$ \\
6 & $\gamma=\lambda=1 \quad \pi=0$ & $\frac{\alpha_{2}\left[1-\left(1-\beta_{1}\right)(1-\delta)\right]}{\Delta}$ & $\frac{\alpha_{2} \delta\left(1-\beta_{1}\right)}{\Delta}$ & $\frac{\alpha_{2} \beta_{1}}{\Delta}$ \\
7 & $\pi=\lambda=0 \quad \gamma=1$ & 0 & 0 & 0 \\
8 & $\pi=\lambda=1 \quad \gamma=0$ & $\frac{\alpha_{1}\left(1-\beta_{1}\right)}{\left(1-\alpha_{1} \beta_{1}\right)}$ & $\frac{\left(1-\beta_{1}\right)}{\left(1-\alpha_{1} \beta_{1}\right)}$ & $\frac{\left(1-\beta_{1}\right)\left(\alpha_{1}-1\right)}{\left(1-\alpha_{1} \beta_{1}\right)}$
\end{tabular}

onde: $E_{a}=$ Elasticidade do preço agrícola doméstico, $E_{i}=$ Elasticidade do preço industrial doméstico e $\Delta=\left\{\alpha_{3} \delta+\beta_{1}\left[1-\delta\left(1-\alpha_{1}\right)\right]\right\}$.

Fonte: PONGIBOVE (1996).

Visando obter melhor compreensão de como variações no nível internacional de preços afetam o comportamento dos preços agrícolas doméstico e industrial a partir da equações 19 e 20, PONGIBOVE (1996) realizou a análise relativa a esse tipo de choque sem levar em consideração o seu respectivo efeito multiplicador.

O efeito direto de variações do nível internacional de preços $(p)$ sobre os preços agrícolas domésticos $\left(p_{a}\right)$ descontado o seu efeito multiplicador pode ser dividido em três casos. "a) $-\alpha_{2} \lambda \gamma$, através do atrelamento do câmbio ao diferencial de preços extemos $\mathrm{e}$ domésticos e da relação dos preços agrícolas doméstico e internacional através do câmbio; b) $\alpha_{1}\left(1-\beta_{1}\right)$, indiretamente através do efeito de $p_{i}$ e deste, diretamente, sobre $\left.p_{a} ; \mathrm{c}\right)$ $-\alpha_{1} \gamma\left(1-\beta_{1}\right)$, indiretamente através do efeito sobre o câmbio, deste sobre $p_{i}$ e deste último preço, diretamente, sobre $p_{a}$. Assim, o efeito direto do choque em $p^{*}$ sobre $p_{a}$ (a) tem sinal oposto ao choque inicial e depende dos indexadores $\lambda$ e $\gamma$, enquanto que a soma dos efeitos via $p_{i}$ tem o mesmo sinal que o do choque e depende somente do indexador $\gamma^{n}$. (PONGIBOVE, 1996, p.29). 
Por outro lado, os efeitos diretos de choques de $p^{*}$ sobre $p_{i}$, desconsiderando-se o seu respectivo efeito multiplicador, são: a) $\left(1-\beta_{1}\right)(1-\gamma)$ via impacto direto de $p$ nos custos da indústria; b) $-\alpha_{2} \lambda \gamma \beta_{1} \pi$, através do efeito de $p^{*}$ sobre a taxa de câmbio que se transmite para o preço agrícola comercializável e deste sobre o preço agrícola agregado e deste último sobre os custos industriais; c) $-\alpha_{2} \lambda \gamma \delta \delta\left(1-\beta_{1}\right)$, pelo seu efeito via $p_{a}$ sobre o nível geral de preços da economia o qual tem reflexos sobre os custos das indústrias. Portanto, o impacto do caso (a) possuí o mesmo sinal do choque e depende somente da magnitude do indexador $\gamma$. Já para os outros dois casos, os reflexos via taxa de câmbio, dependerão dos três indexadores e terá sinal contrário ao do choque na variável preço nível de preço internacional.

Analisando-se caso por caso tem-se os seguintes resultados:

a) Caso 1: há perfeita transmissão nas três variáveis em questão, sendo assim choques no nivel internacional de preços são repassados igualmente para todos os demais preços nominais domésticos, tendo comportamento semelhante ao de choques originados na variável preços agrícolas internacionais, porém com sinal oposto ao desse último choque. Portanto, no caso 1, tanto a elasticidade preço do setor agrícola, quanto do industrial são iguais, fato esse que implica no resultado de que não ocorrem modificações nos preços relativos domésticos em função de choques no nivel de preços extemos;

b) Caso 2: quando adota-se a hipótese de completa ausência de transmissão em todas as variáveis, um choque elevando o nível de preço internacional tem reflexos sobre $p_{i}$ numa magnitude igual a $\left(1-\beta_{1}\right)$ e sobre $p_{a}$ com valor igual a $\alpha_{1}\left(1-\beta_{1}\right)$, o qual pode ser dividido em duas partes, sendo que parte do choque sobre o nivel intemacional de preços transmite-se diretamente sobre $p_{a}$ através do componente $\alpha_{1}$ e outra parte provém indiretamente de $p_{i}$ através de $\left(1-\beta_{1}\right)$. Outra característica relevante desse caso, refere-se ao fato de que os preços domésticos agrícola e industrial alteram-se na mesma direção do choque exógeno, porém com magnitudes diferentes, resultando em mudanças na relação de trocas entre esses dois setores;

c) Caso 3: obtém-se resultado semelhante ao do caso anterior, pois o parâmetro $\lambda$ não é afetado pelo choque no nivel internacional de preços, desde que ambos $\pi$ e $\gamma$ assumam valor igual a zero, como acontece nesse caso;

d) Casos 4 e 7: os preços domésticos estão isolados de choques no nível internacional de preços, uma vez que as diversas combinaçōes relacionadas as hipóteses sobre as magnitudes dos indexadores anulam-se, tanto ao nivel de efeitos diretos, quanto indiretos via alteração da taxa de câmbio sobre os preços nacionais; 
e) Casos 5 e 8: Nesses dois casos foram obtidos resultados semelhantes àqueles dos casos 2 e 3 , sendo que a única diferença foi a inclusão do efeito multiplicador (denominador igual a $\left.\left(1-\alpha_{1} \beta_{1}\right)\right)$. Outro aspecto relevante em relação a esses dois casos reside no fato de que choques no nível internacional de preços são transferidos aos preços domésticos diretamente através dos preços industriais, não ocorrendo efeito via taxa de câmbio. As respectivas elasticidades do setor agrícola e industrial são ambas positivas e maiores que as apresentadas nos casos 2 e 3 . Finalmente, observa-se que os efeitos de choques exógenos no nível intemacional de preços tem reflexos mais intensos sobre 0 setor industrial do que em relação ao segmento agrícola;

f) Caso 6: os resultados mostram que os efeitos diretos e via câmbio competem entre si, o que conduz a elasticidades negativas para os dois setores, no entanto ao se levar em consideração seus respectivos valores absolutos verifica-se que a elasticidade do setor industrial é maior relativamente à elasticidade obtida para o setor agrícola $\left(E_{i}>E_{a}\right)$. 


\subsection{3 - Análise dos choques na oferta de moeda sobre os preços domésticos agrícola e industrial}

Nesse item serão analisados os efeitos que choques originados através da política monetária tem sobre os preços agrícolas e industriais (Quadro 5).

QUADRO 5 - Elasticidades dos preços domésticos com respeito a choques na oferta de moeda sob diferentes hipóteses de transmissão

\begin{tabular}{|c|c|c|c|c|}
\hline \multicolumn{2}{|c|}{ Transmissāo } & \multicolumn{3}{|c|}{ Elasticidades } \\
\hline Caso & Indexadores & $E_{a}$ & $\overline{E_{i}}$ & $E_{a}-E_{i}$ \\
\hline 1 & $\gamma=\pi=\lambda=1$ & 1 & 1 & 0 \\
\hline 2 & $\gamma=\pi=\lambda=0$ & $\alpha_{3}$ & 0 & $\alpha_{3}$ \\
\hline 3 & $\gamma=\pi=0 \lambda=1$ & $\alpha_{3}$ & 0 & $\alpha_{3}$ \\
\hline \multirow[t]{2}{*}{4} & $\gamma=\pi=1 \lambda=0$ & $\alpha_{3}$ & $\alpha_{3}$ & 0 \\
\hline & & $\left(1-\alpha_{1}\right)$ & $\left(1-\alpha_{1}\right)$ & \\
\hline \multirow[t]{2}{*}{5} & $\gamma=\lambda=0 \pi=1$ & $\alpha_{3}$ & $\alpha_{3} \beta_{1}$ & $\alpha_{3}\left(1-\beta_{1}\right)$ \\
\hline & & $\left(1-\alpha_{1} \beta_{1}\right)$ & $\left(1-\alpha_{1} \beta_{1}\right)$ & $\left(1-\alpha_{1} \beta_{1}\right)$ \\
\hline \multirow[t]{2}{*}{6} & $\gamma=\lambda=1 \pi=0$ & $\alpha_{3}\left[1-\left(1-\beta_{1}\right)(1-\delta)\right]$ & $\alpha_{3} \delta\left(1-\beta_{1}\right)$ & $\alpha_{3} \beta_{1}$ \\
\hline & & $\Delta$ & $\Delta$ & $\Delta$ \\
\hline \multirow[t]{2}{*}{7} & $\pi=\lambda=0 \quad \gamma=1$ & $\alpha_{3}\left[1-(1-\delta)\left(1-\beta_{1}\right)\right]$ & $\left(1-\beta_{1}\right) \alpha_{3} \delta$ & $\alpha_{3} \beta_{1}$ \\
\hline & & $\Omega$ & $\Omega$ & $\Omega$ \\
\hline \multirow[t]{2}{*}{8} & $\pi=\lambda=1 \gamma=0$ & $\alpha_{3}$ & $\alpha_{3} \beta_{1}$ & $\alpha_{3}\left(1-\beta_{1}\right)$ \\
\hline & & $\left(1-\alpha_{1} \beta_{1}\right)$ & $\left(1-\alpha_{1} \beta_{1}\right)$ & $\left(1-\alpha_{1} \beta_{1}\right)$ \\
\hline
\end{tabular}

onde: $E_{a}=$ Elasticidade do preço agrícola doméstico, $E_{i}=$ Elasticidade do preço industrial doméstico, $\Delta=\left\{\alpha_{3} \delta+\beta_{1}\left[1-\delta\left(1-\alpha_{1}\right)\right]\right\}$ e $\Omega=\left\{1-\left[1-\beta_{1}\right]\left[1-\delta\left(1-\alpha_{1}\right)\right]\right\}$.

Fonte: PONGIBOVE (1996).

Discriminando-se cada caso em relação aos efeitos dos choques monetários sobre as elasticidades dos preços agrícolas e industriais para as diversas hipóteses de transmissåo temse os seguintes resultados:

a) Caso 1: havendo perfeita transmissão em relação aos três indexadores, verificou-se que alterações na oferta monetária afetam os preços agrícolas e industriais na mesma proporção, ou seja não há modificação nas relações de troca entre agricultura e indústria;

b) Caso 2: a completa ausência de transmissão implịca que choques na oferta de moeda transmite-se exclusivamente para os preços agrícolas através de alterações na demanda 
de produtos agrícolas (equação 19). A elasticidade do preços agrícolas às variações na oferta de moeda é inelástica, ou seja é menos que proporcional, mas com mesmo sinal;

c) Caso 3: obteve-se o mesmo resultado do caso anterior, uma vez que o valor do indexador $\lambda$ não interfere em relação aos resultados de choques na oferta de moeda sobre os preços agrícolas e industriais, no entanto como no caso acima, há alteração nos preços relativos em função desses choques, dado que os preços agrícolas respondem menos que proporcionalmente a esses choques, caracterizando dessa forma uma situação inelástica. Outro ponto a ser realçado é que a resposta dos preços agrícolas aos choques monetários tem sinal igual ao desse último;

d) Caso 4: choques na oferta de moeda são repassados na mesma proporção, tanto para 0 preços agrícolas, quanto industriais, logo não ocorre alteração dos preços relativos. Tomando-se como base de comparação os casos anteriores, nesse caso, além do impacto direto dos choques monetários sobre os preços analisados, adiciona-se ainda um efeito multiplicador o qual é dado pelo denominador $\left(1-\alpha_{1} \beta_{1}\right)$ que é menor que um. Portanto, em função da presença desse multiplicador, verifica-se que as elasticidades nesse caso são maiores que as do caso anterior;

e) Caso 5: um choque monetário é transmitido em diferentes graus para os preços agrícolas e industriais, causando modificações na relação de troca entre esses dois setores. Os efeitos de um choque na oferta de moeda sobre os preços agrícolas são idênticos aos do caso 4, entretanto ao se levar em consideração seus efeitos sobre os preços da indústria, verifica-se que sua transmissão é maior comparativamente ao caso anterior. A magnitude do multiplicador é a mesma, seja para os preços agrícolas e industriais, contudo possuem um efeito mais amplo se comparado ao do caso 4 . De maneira agregada, ou seja levando-se em consideração o efeito total, isto é o somatório dos efeitos diretos e indiretos, os impactos sobre a elasticidade dos preços agrícolas relativamente àquela dos preços industriais é mais acentuada, demonstrando dessa forma o fato de que choques na variável oferta de moeda conduzem a alterações nos preços relativos da economia;

f) Casos 6 e 7: os resultados são iguais "evidenciando que se, tal como é comum às duas hipóteses de transmissão destes casos, acontece que $\gamma=1$ e $\pi=0$, o valor de $\lambda$ não afeta 0 resultado obtido. Nestas duas hipóteses expressam-se os efeitos do choque sobre os preços industriais através dos impactos sobre o nivel geral de preços e a taxa de câmbio. Sobre os preços agrícolas acontece que tem sinais opostos o efeito direto evidenciado por $\alpha_{3}$ e os restantes impactos dados por $\alpha_{3}\left(1-\beta_{1}\right)(1-\delta)$. Nestas condições $E_{a}$ é maior que $E_{i}$ sendo que ambas são positivas. Haverá, caso ocorrer um choque de moeda, mudanças nos preços relativos". (PONGIBOVE, 1996, p. 32); 
g) Caso 8: independentemente do valor assumido pelo parâmetro $\lambda$ ser igual a um ou zero, que é exatamente o que distingue o caso 8 do caso 5 , e dado que nesses dois casos os valores såo os mesmos seja para $\pi=1$, seja para $\gamma=0$, os resultados obtidos aqui são idênticos àqueles delineados no caso 5.

\subsection{4 - Análise dos choques na taxa de câmbio sobre os preços domésticos agricola e industrial}

Em relação ao efeito proporcionado por choques na taxa câmbio sobre as elasticidades dos preços agrícolas e industriais, novamente PONGIBOVE (1996) realizou a análise tendo como base as equações para os preços agricolas e industriais na forma reduzida (19 e 20), sem levar em consideração os respectivos efeitos multiplicadores (Quadro 6). Segundo esse autor, verificou-se que choques na taxa de câmbio segmentam-se em dois tipos de efeitos sobre cada um dos preços domésticos analisados. 
QUADRO 6 - Elasticidades dos preços domésticos com respeito a choques na taxa de câmbio sob diferentes hipóteses de transmissão

\begin{tabular}{ccccc}
\hline \multicolumn{2}{c}{ Transmissão } & \multicolumn{3}{c}{ Elasticidades } \\
\hline Caso & Indexadores & $E_{\mathrm{a}}$ & $\mathrm{E}_{\mathrm{i}}$ & $\mathrm{E}_{\mathrm{a}}-\mathrm{E}_{\mathrm{i}}$ \\
\hline 1 & $\gamma=\pi=\lambda=1$ & $\frac{\left[\alpha_{1}\left(1-\beta_{1}\right)+\alpha_{2}\right]}{\Psi}$ & $\frac{\left[\left(1-\beta_{1}\right)+\alpha_{2} \beta_{1}\right]}{\Psi}$ & $\frac{\left(1-\beta_{1}\right)\left(\alpha_{1}-1+\alpha_{2}\right)}{\Psi}$ \\
2 & $\gamma=\pi=\lambda=0$ & $\alpha_{1}\left(1-\beta_{1}\right)$ & $\left(1-\beta_{1}\right)$ & $\left(\alpha_{1}-1\right)\left(1-\beta_{1}\right)$ \\
3 & $\gamma=\pi=0 \lambda=1$ & $\alpha_{2}+\alpha_{1}\left(1-\beta_{1}\right)$ & $\left(1-\beta_{1}\right)$ & $\alpha_{2}+\left(\alpha_{1}-1\right)\left(1-\beta_{1}\right)$ \\
4 & $\gamma=\pi=1 \lambda=0$ & $\frac{\alpha_{1}\left(1-\beta_{1}\right)}{\Gamma}$ & $\frac{\left(1-\beta_{1}\right)}{\Gamma}$ & $\frac{\left(\alpha_{1}-1\right)\left(1-\beta_{1}\right)}{\Gamma}$ \\
5 & $\gamma=\lambda=0 \pi=1$ & $\frac{\alpha_{1}\left(1-\beta_{1}\right)}{\left(1-\alpha_{1} \beta_{1}\right)}$ & $\frac{\left(1-\beta_{1}\right)}{\left(1-\alpha_{1} \beta_{1}\right)}$ & $\frac{\left(\alpha_{1}-1\right)\left(1-\beta_{1}\right)}{\left(1-\alpha_{1} \beta_{1}\right)}$ \\
6 & $\gamma=\lambda=1 \pi=0$ & $\frac{\left[\alpha_{1}\left(1-\beta_{1}\right)+\alpha_{2}\right]}{\Delta}$ & $\frac{\left(1-\beta_{1}\right)}{\Delta}$ & $\frac{\left[\alpha_{2}-\left(1-\beta_{1}\right)\left(1-\alpha_{1}\right)\right]}{\Delta}$ \\
7 & $\pi=\lambda=0 \gamma=1$ & $\frac{\alpha_{1}\left(1-\beta_{1}\right)}{\Omega}$ & $\frac{\left(1-\beta_{1}\right)}{\Omega}$ & $\frac{\left(\alpha_{1}-1\right)\left(1-\beta_{1}\right)}{\Omega}$ \\
8 & $\pi=\lambda=1 \gamma=0$ & $\frac{\left[\alpha_{1}\left(1-\beta_{1}\right)+\alpha_{2}\right]}{\left(1-\alpha_{1} \beta_{1}\right)}$ & $\frac{\left[\left(1-\beta_{1}\right)+\alpha_{2} \beta_{1}\right]}{\left(1-\alpha_{1} \beta_{1}\right)}$ & $\frac{-\alpha_{2}\left(1-\beta_{1}\right)}{\left(1-\alpha_{1} \beta_{1}\right)}$
\end{tabular}

onde: $E_{a}=$ Elasticidade do preço agrícola doméstico, $E_{i}=$ Elasticidade do preço industrial doméstico,

$\Psi=\alpha_{3}\left[1-\left(1-\beta_{1}\right)(1-\delta), \Gamma=\left(1-\alpha_{1}\right)\left[1-\left(1-\beta_{1}\right)(1-\delta)\right]\right.$,

$\Delta=\left\{\alpha_{3} \delta+\beta_{1}\left[1-\delta\left(1-\alpha_{1}\right)\right]\right\}$ e $\Omega=\left\{1-\left[1-\beta_{1}\right]\left[1-\delta\left(1-\alpha_{1}\right)\right]\right\}$.

Fonte: PONGIBOVE (1996).

Descontado os efeitos multiplicadores dos choques na taxa de câmbio sobre os preços domésticos agrícolas, tem-se basicamente duas situações a serem analisadas: 1) $\lambda \alpha_{2}, 0$ qual representa o grau de relacionamento entre o preço doméstico do produto agrícola exportável e conseqüentemente do preço agrícola doméstico agregado com o preço agrícola internacional; 2) $\alpha_{1}\left(1-\beta_{1}\right) \circ$ qual condiciona de maneira indireta o efeito da taxa de câmbio sobre os preços da indústria, via custos do produtos industriais importados, e deste último diretamente sobre os custos de produção da agricultura. Esses dois efeitos derivados de choques na taxa de câmbio sobre os preços agrícolas domésticos possuem sinal igual ao do choque cambial, a diferença entre ambos é no caso (1) onde o seu efeito está diretamente relacionado somente com o indexador $\gamma$, enquanto que o efeito relacionado com o caso (2) independe do valor dos três indexadores. 
Os efeitos de um choque cambial sobre os preços industriais, sem levar em consideração o seu respectivo efeito multiplicador são os seguintes: 1) $\left(1-\beta_{1}\right)$, nessa situação a cadeia de transmissão do choque cambial ocorre diretamente através do próprio mercado cambial, uma vez que ao intemalizar o insumo intemacional importado a empresa residente precisa converter o preço externo desse insumo em moeda corrente local, fato esse que tem reflexos imediatos sobre os custos de produção do bem industrial doméstico; 2) $-\alpha_{2} \lambda \beta_{1} \pi$, nesse caso a corrente de transmissão de choques cambiais sobre os preços domésticos industriais ocorre via efeito da variação cambial sobre o preço interno do bem agrícola tradeable, que por sua vez reflete-se sobre o nivel de preço agrícola agregado e deste para os custos industriais. Outras duas características em relação aos choques cambiais sobre o comportamento dos preços industriais é que para ambos casos a variação nos preços da indústria tem mesmo sinal do choque da taxa de cambio, ou seja os reflexos nos custos industriais tem a mesma direção do choque cambial, a diferença é que no caso (1) os efeitos de choques na taxa de câmbio não dependem do valor de qualquer dos três indexadores, enquanto que no caso (2) o efeito desses choques dependem dos valores assumidos pelos parâmetros relacionados com os indexadores relativos a transmissão dos preços industriais aos preços do setor agrícola representado por $\pi$ e pelo parâmetro $\lambda$ o qual representa 0 grau de transmissão dos preços agrícolas domésticos exportáveis em relação aos seus respectivos preços vigentes no mercado mundial.

Analisando-se as diferentes hipóteses quanto ao nível de transmissão dos parâmetros $\gamma, \lambda$ e $\pi$ e o correspondente comportamento dos preços agrícolas domésticos e industriais frente a choques na taxa de câmbio tem-se novamente oito casos:

a) Caso 1: isoladamente, ou seja desconsiderando-se o efeito multiplicador, verificou-se que choques na variável taxa de câmbio são transmitidos tanto para os preços do setor agrícola, quanto industrial via os dois mecanismos analisados acima. No entanto, ao realizar-se a análise tendo em conta os respectivos efeitos multiplicadores, conclui-se que os impactos são mais intensos relativamente àqueles sem a incorporação dos multiplicadores, amplificando dessa forma o choque inicial. As elasticidades apresentam sinal positivo para ambos setores. Outro ponto importante é que apesar dos preços agrícolas e industriais variarem na mesma direção do choque na taxa de câmbio, ainda assim, ocorre alteração na relação de troca entre esses dois setores, dado que a faixa de variação dos preços agrícolas é menor comparativamente a dos preços da indústria;

b) Caso 2: contrariamente ao que acontece no caso 1, onde há plena transmissão, no caso 2 há completa ausêneia de transmissão. Segundo PONGIBOVE (1996, p. 34) "só são relevantes os efeitos dos choques que independem dos indexadores. Isto é, segundo 
discutido anteriormente, $\left(1-\beta_{1}\right)$ sobre $p_{i}$ e $\alpha_{1}\left(1-\beta_{1}\right)$ sobre os preços agrícolas. Não existe efeito multiplicador e ambas elasticidades são positivas. Porém, $E_{a}$ é menor que $E_{i}$ de maneira tal que um choque na taxa de câmbio modifica os preços relativos";

c) Caso 3: é semelhante ao caso anterior, sendo que a única diferença reside no valor adotado para o parâmetro $\lambda$, choques na taxa de câmbio conduzem a resultados semelhantes no comportamento dos preços industriais em relação ao caso 2. Ainda comparativamente ao segundo caso, choques exógenos proporcionados por variações cambiais impactam os preços agrícolas domésticos de forma mais intensa, pois adiciona-se o elemento $\alpha_{2}$ ao seu numerador (Quadro 5). Continuando a comparação com o caso 2, verifica-se que no caso 3 é adicionado um efeito multiplicador no que se refere aos preços agrícolas. Outro ponto que chama a atenção é o fato de as elasticidades para os preços agrícolas e industrial serem positivas, porém não é possivel avaliar qual delas é maior, sendo assim não é factivel determinar qual a direção tomada pelos preços relativos diante de um choque cambial;

d) Casos 4 e 7: em relação aos efeitos diretos de choques na taxa de câmbio sobre os preços agricolas domésticos e industriais, os casos 4 e 7 tem comportamento igual àquele descrito para o caso 2, uma vez que o numerador é o mesmo para os três casos. A diferença reside exatamente no fato de que comparativamente ao caso 2, os casos 4 e 7 possuem a presença de um efeito multiplicador, que no entanto é diferente para cada caso, ou seja 0 denominador do caso 4 não é o mesmo do caso 7 (Quadro 5). Portanto, nesses dois casos as elasticidades são positivas, sendo que a elasticidade do setor agrícola é menor se comparada com a elasticidade do setor industrial levando a alteração nos termos de troca entre os dois setores ;

e) Caso 5: os efeitos diretos de variações na taxa cambial conduz a resultados iguais àqueles prevalecentes no caso 2 , porém nesse caso há um efeito multiplicador que induz as elasticidades do setor agrícola e industrial serem mais elevadas que as do caso 2. Apesar das duas elasticidades serem positivas, verifica-se que a elasticidade do setor industrial é maior que a do setor agrícola, ou seja o primeiro setor apresenta maior grau de sensibilidade relativamente a choques na taxa de câmbio do que o segundo;

f) Caso 6: conforme já analisado anteriormente, choques cambiais afetam os preços agrícolas de duas maneiras, seja diretamente, ou então via os preços industriais. Já para os preços da indústria o efeito de variaçð̃es na taxa de câmbio apresentam somente efeito direto sobre o primeiro. Novamente, como aconteceu nos casos anteriores, além do efeito direto, no caso 6 deve-se levar em consideração o efeito multiplicador. Como resultado, conclui-se 
que ambas elasticidades são positivas, no entanto é impossivel estipular qual delas é a mais elevada;

9) Caso 8: além dos efeitos diretos que alterações na taxa de câmbio tem sobre os preços agricolas e industriais, nesse caso adiciona-se um efeito multiplicador. Como resultado final, verifica-se que as duas elasticidades são positivas, sendo que a elasticidade do setor agricola é superior àquela do setor industrial, indicando que o primeiro é mais sensível às variações cambiais do que o segundo e que nesse caso há modificações nos termos de troca entre agricultura e indústria. 


\section{5 - MATERIAL E MÉTODO}

\section{1 - Material}

Visando analisar a relação existente entre os preços agrícolas no Brasil com variáveis internas e externas, serăo utilizadas basicamente nove séries temporais com dados mensais.

Como variáveis internas em nível de Brasil serão utilizados os Índices de Preços Agrícolas em nível de Atacado (IPAgr) ${ }^{13}$, Índice de Preços Industriais em nível de Atacado total $\left(\right.$ IPI) ${ }^{14}$, Taxa de Câmbio (TC), índice Preços em nível de Atacado (IPA) e Oferta de Moeda (M2). Essas cinco séries foram obtidas junto aos vários números da revista Conjuntura Econômica da Fundação Getúlio Vargas.

Em nível externo, serão utilizadas quatro séries econômicas, quais sejam: o Indice Internacional de Preço de Alimentos (IFI), Índice Internacional de Preço de Matérias-primas Agrícolas (IRMI), Índice de Preços ao Produtor nos Estados Unidos (IPPUS) e o Preço Internacional do Petróleo (PET). As duas primeiras séries tiveram como fonte de referência a publicação Intemational Financial Statistics do Fundo Monetário Internacional (FMI), enquanto que a série relativa ao Índice de Preço ao Produtor nos Estados Unidos teve como fonte básica - U.S. Department of Labor, Bureau of Labor Statistics, enquanto que a série relativa aos Preços Internacionais do Petróleo foi obtida junto a revista Conjuntura Económica.

Esse estudo seguirá o caminho traçado por BARROS (1990a), o qual ao invés de utilizar Índice de Preços em nível de Produtor Agricola, utilizou o Índice de Preços Agrícolas em nivel de Atacado para medir os efeitos que impactos externos tem sobre os preços domésticos, pois esse é o procedimento mais utilizado na literatura econômica segundo esse autor, o qual

\footnotetext{
${ }^{13}$ Neste estudo foi utilizado o índice de preços agrícolas em nivel de atacado (oferta global). Mais precisamente, o indice total ou agregado, dado que, a Fundação Getúlio Vargas publica também os índices agrícolas no atacado de maneira desagregada englobando oito categorias, quais sejam: 1) legumes e frutas, 2) cereais e grảos, 3) fibras vegetais, 4) oleaginosas, 5) raizes e tubérculos, 6) animais e derivados, 7) lavouras para exportação e 8) outros.

${ }_{14}$ Assim como aconteceu com o índice de preços agrícolas, o índice de preços industriais aqui utilizado refere-se ao preços industriais em nivel de atacado total, pois a Fundação Getúlio Vargas além de publicar um índice total, também publica os índices de preços industriais por setor.
} 
argumenta que, apesar dos efeitos sobre preços em nível de produtor ser de grande interesse, a estimação de modelos com essa variável exigiria o desenvolvimento de um modelo teórico mais detalhado, o que está fora do dos objetivos propostos por esse estudo. Mais especificamente, será utilizado o Índice de Preços por Atacado - oferta global, os quais são levantados pela Fundação Getúlio Vargas (FGV) e publicados na revista Conjuntura Económica.

Em relação ao Indice Preços tanto em nível de Brasil, quanto dos Estados Unidos, a opção foi utilizar o Índice de Preços em nível de Atacado no Brasil e o Índice de Preços ao Produtor para os Estados Unidos ${ }^{15}$. Segundo ZINI (1993, p. 32), a principal razão para se utilizar o índice de preços no atacado ao invés de um índice de preço ao consumidor, deve-se ao fato de que o primeiro "reflete os preços praticados pelos produtores e acompanha principalmente os preços de produtos industriais e de produtos agrícolas de grande safra (exportáveis). O IPA, portanto, mostra a evolução dos preços de bens que podem ser caracterizados como comercializáveis com o resto do mundo (tradeables)". Sendo assim, a competitividade dos produtos exportáveis de um pais é medida pela diferença entre a inflação doméstica e externa. Ainda segundo ZINI (1993, p. 32) o principal problema em se utilizar 0 índice de preços ao consumidor de diferentes países é que "esses índices incluem vários bens e serviços que estão à margem do comércio intemacional (bens não-comercializáveis), e, portanto, não devem ser incluídos nas comparações de competitividade de uma economia”.

A utilização do Índice de Preços ao Produtor nos Estados Unidos deve-se basicamente a dois fatores. Em primeiro lugar, dada a pressuposição de país pequeno, esse índice reflete os custos das matérias-primas no mercado internacional, as quais são importadas pelo setor industrial doméstico. Além do que, esse indice procura captar o grau de atrelamento da taxa de câmbio no Brasil em relação à taxa inflacionária norte-americana, prevalecendo dessa forma a teoria da paridade do poder de compra.

Quanto à taxa de câmbio a opção recaiu sobre a taxa de câmbio comercial (média aritmética mensal), pois é essa taxa que reflete os fluxos da balança comercial do país em relação ao seu respectivo comércio com os demais países. Mais especificamente, segundo FREITAS FILHO et al. (1993, p. 73) o "mercado oficial ou comercial, aparentemente trabalha com taxas livres, mas com fluxos totalmente controlados, ou seja, somente com transações permitidas pelo Governo (tarifas, guias de exportação, etc.) ${ }^{n}$. Ainda, conforme FREITAS FILHO et al. (1993, p. 73) quando "as exportações excedem, em valor, as importações tem-se um superávit. Sendo esse mercado controlado, não há a contrapartida de demanda pelos saldos positivos de dólares, havendo necessariamente uma sobra. O comprador dessa sobra, ao final,

\footnotetext{
${ }^{15}$ É necessário observar que o antigo índice de preços em nivel de atacado nos Estados Unidos foi substituído pelo índice de preços ao produtor.
} 
será sempre o BACEN, único comprador no País a ter livre seus fluxos de capital, comprando esses dólares excedentes. Em decorrência, essa sobra é que dita a taxa de câmbio desse mercado: se o saldo não é comprado, a taxa cai (valorização cambial) até o ponto que ela fica tão cara para os exportadores e tão barata para os importadores que ou o sistema tende a nivelar-se ou o BACEN interfere, comprando, pois há legislação que penaliza o banco comercial que retiver dólares. A taxa pela qual o BACEN efetua a compra do saldo é a que prevalece como taxa de câmbio oficial ou comercial. Essa prática, por outro lado, enseja meios para o BACEN estimular/desestimular exportaçőes ou importações, pois é ele quem determina, atuando monopolisticamente, como único agente comprador e deixando que as operações se desenvolvam até atingir o nível que lhe interessa".

Visando reduzir o número de variáveis utilizadas na análise, e também, pelo fato de que em termos econômicos toma-se mais interessante trabalhar com a taxa de câmbio real ao invés da taxa de câmbio nominal, neste estudo optou-se em utilizar a primeira, a qual é representada pela taxa de câmbio nominal multiplicada pela relação dos índices de preços externo e doméstico. Sendo que, a variável relativa à taxa de câmbio real foi denominada de (TCR).

Apesar da variável M1 (papel moeda em poder do público + depósitos à vista) ao invés de outro agregado monetário ser a mais utilizada entre os vários trabalhos consultados, neste estudo foi utilizada a variável M2 (M1 + Títulos Federais). Normalmente, a principal restrição em relação ao uso de $M 1$, especialmente no caso do Brasil, está relacionado ao fato de que o país enfrentou um prolongado e persistente problema inflacionário, o qual tomou-se ainda mais acirrado na década de 80 e nos primeiros anos da década de 90 (pelo menos até junho de 1994, período que antecedeu a implementação do Plano Real em julho de 1994), onde na tentativa de estabilizar os preços da economia, o governo implementou diversos planos econômicos de cunho heterodoxo.

Como o período analisado por este trabalho, o qual inicia-se em 1990 e estende-se até 1998 (com um total de 108 observações), apresenta dois períodos distintos, um com elevada inflação (de janeiro de 1990 até junho de 1994, com 54 observações, correspondendo a 50,0\% do total das observações utilizadas) e outro com menores taxas de inflação (de julho de 1994 até dezembro de 1998, também com 54 observações representando os outros $50,0 \%$ do total de observações), optou-se em utilizar como agregado monetário M2 ao invés de M1 pelo seguinte motivo: o primeiro período caracterizou-se pela acentuada instabilidade do nível de preços, pois o IGP-DI apresentou uma variação percentual de 2.739,7 em 1990; 414,7 em 1991; 991,4 em 1992; 2.103,7 em 1993 e 4.406,8 em 1994. Além disso, apesar da implementação do Plano Real em julho de 1994, ainda assim, a inflação nesse ano pode ser considerada relativamente alta, uma vez que, o IGP-DI variou em tomo de $67,5 \%$, ampliando dessa forma 0 período com inflação elevada de janeiro de 1990 até dezembro de 1994 e conseqüentemente 
incrementando em termos percentuais o número de observações para o primeiro período, passando de $50,0 \%$ para 55,56\%, e em contrapartida, reduzindo o número de observações em termos percentuais no período marcado pela estabilidade de preços para apenas $44,44 \%$ (período de janeiro de 1995 até dezembro de 1998). Além do que, dado que a economia brasileira enfrentou um prolongado processo inflacionário, toma-se muito difícil apagar rapidamente esse fato da memória dos diversos agentes econômicos.

Finalmente, assim como, no caso da taxa de câmbio, objetivando restringir o número de variáveis a serem analisadas dentro do modelo, ao invés de se trabalhar com os índices de preços agrícolas e índices de preços industriais no Brasil separadamente, optou-se em construir um índice de relação de troca entre esses dois setores e esta variável foi denominada de (RT).

\subsection{2 - Padronização dos dados}

Como esse estudo utiliza diversas séries econômicas, foi necessário realizar algumas transformações para padronizá-las. Especificamente em relação às séries de tempo envolvendo indices de preços, tanto intemacionais, quanto domésticos, objetivou-se deixar todas com 0 mesmo período base. 0 período base adotado nesse trabalho para todas as variáveis relacionadas com índices de preços foi agosto de 1994 igual a cem.

Para aquelas variáveis que utilizam-se de unidades monetárias, a unidade padrão adotada nesse estudo caminhou no sentido de transformar os valores de todas as séries temporais domésticas para reais (R\$) e das séries extemas para dólar (US\$).

A série do Índice Internacional de Preços de Alimentos (IFI) apresentava dois períodos base distintos, fato esse que exigiu medidas para corrigir essa distorção. No intervalo de janeiro de 1990 até novembro de 1993 essa variável tinha como período base 1985 igual a cem, enquanto que a partir de dezembro de 1993 até dezembro de 1998 o período base utilizado foi 1990 igual a cem. O procedimento utilizado nesse caso residiu, inicialmente, em modificar 0 período base do primeiro intervalo, transportando os valores que tinham como período base 1985 igual a cem para 1990 igual a cem, para deixá-los com a mesma base do segundo intervalo. Obtida a série toda com o mesmo período base (1990 igual a cem), o próximo passo foi modificar novamente o período base, transportando todas as observações da série para agosto de 1994 igual a cem, ou seja, dividiu-se toda série pelo valor do respectivo índice de agosto de 1994 e multiplicou-se cada resultado obtido a partir dessa divisão por cem (Tabela 1).

Para a série do Índice Internacional de Preço de Matérias-primas Agrícolas (IRMI) 0 procedimento foi o mestro utilizado no caso anterior, dado que os períodos base para esses dois indices são iguais (Tabela 2). 
A variável Preço Internacional do Petróleo utilizada corresponde aos preços dos derivados petróleo (preços do óleo crú) em dólares por barril (US\$/b) no emirado árabe de Dubai, Golfo Pérsico principal regiảo produtora de petróleo do mundo (Tabela 3).

Em relação à variável Índice de Preços ao Produtor nos Estados Unidos (IPPUS), no período de janeiro de 1990 até dezembro de 1998 o período base considerado era 1982 igual a cem. Sendo assim, para transportar toda a série para o período base agosto de 1994 igual a cem, toda a série foi dividida pelo valor do índice correspondente a agosto de 1994 e a seguir foi multiplicada por cem (Tabela 4).

Para a variável Taxa de Câmbio (TC) houve a necessidade de se harmonizar as unidades monetárias, pois de janeiro de 1990 até agosto de 1993 a taxa de câmbio estava definida como sendo a relação entre Cruzeiros por Dólar (Cr\$/US\$), mudando para Cruzeiros Reais por Dólar (CR\$/US\$) no período de setembro de 1993 até junho de 1994, quando novamente a unidade monetária foi modificada para Reais por Dólar (R\$/US\$) a partir de agosto de 1994 em diante. Visando obter todos os valores dessa série em Reais por Dólar, o primeiro passo consistiu em transformar os valores que se encontravam em Cruzeiros por Dólar em Cruzeiros Reais por Dólar, ou seja dividiu-se esses valores por mil para se obter a relação Cruzeiros Reais por Dólar. A seguir, para deixar todas as observações em Reais por Dólar, todos os valores que se encontravam em Cruzeiros Reais por Dólar foram divididos por CR\$ 2.750,00 (Tabela 5).

Procedimento semelhante ao que aconteceu com a variável descrita no parágrafo anterior necessitou ser empregado para a variável Oferta de Moeda (M2), pois essa série também apresentava diferentes unidades monetárias ao longo do período analisado. De janeiro de 1990 até dezembro do mesmo ano os dados encontravam-se em bilhões de cruzeiros. $A$ partir de janeiro de 1991 até dezembro de 1992 os dados originais encontravam-se em milhões de cruzeiros reais. Posteriormente a essa data, e até o final dessa série em dezembro de 1998, as observações encontravam-se em milhões de reais. Objetivando transformar todos os valores da variável M2 em milhões de reais, as observações que encontravam-se em bilhões de cruzeiros foram divididas por mil, obtendo-se dessa forma os respectivos valores em milhões de cruzeiros reais. A seguir, a parte da série que estava em milhões de cruzeiros reais foi dividida por CR $\$ 2.750,00$ para se obter toda a série em termos de milhões de reais (Tabela 6).

A série do Índice de Preços no Atacado no Brasil (IPA), assim como as demais séries de índices de preços, também apresentava diferentes bases ao longo do período analisado. Sendo assim, para deixar toda a série com a base agosto de 1994 igual a cem foram necessárias algumas transformações. No período compreendido entre janeiro de 1990 até janeiro de 1991, a base utilizada foi dezembro de 1989 igual a cem. Já para o período de tempo abrangendo fevereiro de 1991 até setembro de 1992 a base utilizada passou a ser dezembro de 
1992 igual a cem. Após setembro de 1992 o período base a ser adotado foi agosto de 1994 igual a cem. Para deixar toda a série do IPA com base agosto de 1994 igual a cem, 0 procedimento inicial foi transportar as observações que tinham como período base dezembro de 1989 igual a cem para a base dezembro de 1992 igual a cem. A seguir, a parte da série que encontrava-se com a base dezembro de 1992 igual a cem foi dividida pelo valor do índice referente a agosto de 1994 e multiplicada por cem para deixar toda a série com a base agosto de 1994 igual a cem (Tabela 7).

Quanto à variável Índice de Preços Agrícolas em nível de Atacado para o Brasil (IPAgr), o período base inicial era dezembro de 1989 igual a cem. Esse período base começa em janeiro de 1990 e estende-se até dezembro de 1991. A partir desta data em diante o período base utilizado é dezembro de 1992 igual a cem, sendo que esse período base é válido até julho de 1993. A seguir, o período base é novamente modificado para agosto de 1994 igual a cem, mantendo-se com essa base até o final da série. Como no caso anterior, os valores que tinham como base dezembro de 1989 igual a cem foram transportados para o período base dezembro de 1992 igual a cem. Percorrida essa etapa, o próximo passo foi transformar as observações que encontravam-se com a base dezembro de 1992 igual a cem para a base agosto de 1994 igual a cem. Para realizar tal transformação, os valores que tinham como período base dezembro de 1992 igual a cem foram divididos pelo valor do índice referente a agosto de 1994 e a seguir esses valores foram multiplicados por cem para se obter como resultado final toda a série do IPAgr em termos do período base agosto de 1994 igual a cem (Tabela 8).

Inicialmente, o Índice de Preços Industriais em nível de Atacado para o Brasil (IPI) utilizou como período base dezembro de 1989 igual a cem, sendo que essa base imperou até dezembro de 1991. A partir de então até julho de 1993 a base adotada passou a ser dezembro de 1992 igual a cem. De agosto de 1993 até o final do período analisado a base passou a ser agosto de 1994 igual a cem. Visando obter toda a série do IPI com a base agosto de 1994 igual a cem, foram necessários alguns procedimentos. Primeiramente, os valores que tinham como base dezembro de 1989 igual a cem foram convertidos para o período base dezembro de 1992 igual a cem. A seguir, todos os valores com base dezembro de 1992 igual a cem foram divididos pelo valor do índice de agosto de 1994 igual a cem e multiplicados por cem, obtendose dessa maneira toda a série com o período base agosto de 1994 igual a cem (Tabela 9).

Outra observação em relação às variáveis utilizadas nesse trabalho diz respeito ao fato de que todas serão utilizadas na forma logarítmica, de modo que os próprios valores dos coeficientes fornecem diretamente as suas respectivas elasticidades. 
TABELA 1.- Índice de Preço Internacional de Alimentos, 1990-98.

(Base Ago. $94=100$ )

\begin{tabular}{lcccccc}
\hline Ano & Jan. & Fev. & Mar. & Abr. & Maio & Jun. \\
\hline 1990 & 107,68 & 104,98 & 104,05 & 106,84 & 105,35 & 101,63 \\
1991 & 96,97 & 99,49 & 100,51 & 99,49 & 97,81 & 98,74 \\
1992 & 107,22 & 108,71 & 107,59 & 103,03 & 102,00 & 103,03 \\
1993 & 99,86 & 98,37 & 99,95 & 99,49 & 100,14 & 93,99 \\
1994 & 112,98 & 112,27 & 109,96 & 107,44 & 101,01 & 102,82 \\
1995 & 104,43 & 109,26 & 107,55 & 105,43 & 106,34 & 110,66 \\
1996 & 128,17 & 130,99 & 129,98 & 140,14 & 143,56 & 135,21 \\
1997 & 119,22 & 119,92 & 123,54 & 123,24 & 118,01 & 110,36 \\
1998 & 108,35 & 107,55 & 105,23 & 103,82 & 102,41 & 99,30 \\
\hline Ano & Jul. & Ago. & Set. & Out. & Nov. & Dez. \\
\hline 1990 & 100,14 & 98,00 & 96,50 & 95,76 & 94,36 & 95,48 \\
1991 & 95,95 & 98,74 & 100,98 & 102,84 & 103,12 & 103,77 \\
1992 & 98,18 & 97,16 & 98,18 & 96,32 & 97,81 & 97,81 \\
1993 & 100,14 & 98,93 & 98,37 & 99,58 & 106,57 & 110,16 \\
1994 & 98,79 & 100,00 & 103,32 & 102,52 & 103,52 & 107,55 \\
1995 & 117,40 & 115,09 & 118,01 & 122,94 & 124,25 & 126,96 \\
1996 & 130,38 & 128,17 & 122,13 & 117,10 & 116,30 & 116,90 \\
1997 & 107,65 & 108,15 & 108,65 & 110,36 & 112,58 & 110,36 \\
1998 & 97,69 & 92,05 & 91,75 & 96,08 & 98,09 & 96,45 \\
\hline
\end{tabular}

Fonte: Dados básicos da International Financial Statistics (1990/1999). 
TABELA 2.- Indice de Preço Internacional de Matérias-primas Agrícolas, 1990-98.

(Base Ago. $94=100$ )

\begin{tabular}{lcccccc}
\hline Ano & Jan. & Fev. & Mar. & Abr. & Maio & Jun. \\
\hline 1990 & 90,84 & 90,51 & 89,01 & 88,75 & 91,55 & 91,16 \\
1991 & 87,90 & 86,66 & 83,53 & 85,69 & 86,66 & 89,86 \\
1992 & 89,66 & 90,25 & 87,45 & 88,36 & 89,86 & 91,03 \\
1993 & 93,45 & 93,18 & 92,79 & 91,03 & 89,66 & 89,86 \\
1994 & 93,20 & 96,46 & 96,19 & 97,46 & 99,37 & 100,36 \\
1995 & 108,07 & 122,30 & 126,47 & 128,38 & 126,84 & 122,39 \\
1996 & 114,32 & 112,96 & 115,50 & 113,87 & 114,96 & 116,59 \\
1997 & 113,69 & 111,79 & 112,15 & 113,87 & 111,79 & 110,70 \\
1998 & 83,95 & 89,66 & 93,65 & 93,20 & 93,38 & 90,75 \\
\hline Ano & Jul. & Ago. & Set. & Out. & Nov. & Dez. \\
\hline 1990 & 92,27 & 91,95 & 93,77 & 92,79 & 90,97 & 88,36 \\
1991 & 92,34 & 90,51 & 89,86 & 89,14 & 89,40 & 89,01 \\
1992 & 91,36 & 89,47 & 92,47 & 92,66 & 91,36 & 91,55 \\
1993 & 89,66 & 89,60 & 90,25 & 90,71 & 90,64 & 91,75 \\
1994 & 101,36 & 100,00 & 102,18 & 102,36 & 103,26 & 105,35 \\
1995 & 117,41 & 114,32 & 119,13 & 114,42 & 115,50 & 116,14 \\
1996 & 114,87 & 120,67 & 121,40 & 118,22 & 117,32 & 112,96 \\
1997 & 106,44 & 104,08 & 99,00 & 95,83 & 93,47 & 89,12 \\
1998 & 87,13 & 86,22 & 88,67 & 87,49 & 87,94 & 89,30 \\
\hline
\end{tabular}

Fonte: Dados básicos da International Financial Statistics (1990/1999). 
TABELA 3.- Preço Internacional do Petróleo, 1990-98.

(US\$ / barril)

\begin{tabular}{lcccccc}
\hline Ano & Jan. & Fev. & Mar. & Abr. & Maio & Jun. \\
\hline 1990 & 21,41 & 18,65 & 17,48 & 16,98 & 17,50 & 16,24 \\
1991 & 26,42 & 24,16 & 24,07 & 19,28 & 19,22 & 18,61 \\
1992 & 16,83 & 17,68 & 17,10 & 18,36 & 19,05 & 20,39 \\
1993 & 16,95 & 17,38 & 18,00 & 18,56 & 18,58 & 17,37 \\
1994 & 14,36 & 15,11 & 13,90 & 15,32 & 16,34 & 16,54 \\
1995 & 16,08 & 16,64 & 16,49 & 17,65 & 17,24 & 16,24 \\
1996 & 16,57 & 16,06 & 17,09 & 17,77 & 16,99 & 17,00 \\
1997 & 21,28 & 18,70 & 18,10 & 16,60 & 18,60 & 17,30 \\
1998 & 13,50 & 12,30 & 11,50 & 12,20 & 12,80 & 11,80 \\
\hline Ano & Jul. & Ago. & Set. & Out. & Nov. & Dez. \\
\hline 1990 & 17,73 & 27,42 & 31,06 & 33,81 & 31,14 & 27,39 \\
1991 & 19,37 & 19,68 & 20,20 & 21,32 & 21,44 & 18,65 \\
1992 & 19,55 & 18,94 & 19,78 & 20,42 & 19,21 & 17,44 \\
1993 & 16,36 & 16,49 & 16,43 & 17,36 & 16,48 & 14,32 \\
1994 & 16,91 & 15,73 & 15,08 & 15,30 & 15,53 & 15,39 \\
1995 & 14,97 & 15,37 & 15,53 & 14,92 & 15,56 & 16,81 \\
1996 & 17,79 & 18,70 & 20,35 & 21,71 & 20,87 & 21,65 \\
1997 & 17,40 & 17,70 & 18,00 & 19,20 & 18,50 & 16,30 \\
1998 & 12,10 & 12,30 & 13,10 & 12,80 & 11,80 & 10,10 \\
\hline
\end{tabular}

Fonte: Dados básicos da Conjuntura Econômica (1991/1999) . 
TABELA 4.- Índice de Preços ao Produtor, Estados Unidos, 1990-98.

(Base Ago. $94=100$ )

\begin{tabular}{|c|c|c|c|c|c|c|}
\hline Ano & Jan. & Fev. & Mar. & Abr. & Maio & Jun. \\
\hline 1990 & 93,26 & 93,19 & 93,11 & 93,03 & 93,11 & 93,19 \\
\hline 1991 & 97,15 & 96,51 & 96,12 & 96,12 & 96,35 & 96,20 \\
\hline 1992 & 96,67 & 96,91 & 96,99 & 97,07 & 97,39 & 97,78 \\
\hline 1993 & 98,57 & 98,81 & 99,05 & 99,60 & 99,60 & 99,21 \\
\hline 1994 & 98,89 & 99,05 & 99,13 & 99,13 & 99,13 & 99,21 \\
\hline 1995 & 100,55 & 100,79 & 100,87 & 101,19 & 101,35 & 101,27 \\
\hline 1996 & 102,85 & 102,77 & 103,41 & 103,72 & 103,80 & 103,88 \\
\hline 1997 & 105,39 & 105,15 & 104,99 & 104,52 & 104,28 & 104,04 \\
\hline 1998 & 103,49 & 103,41 & 103,41 & 103,57 & 103,49 & 103,33 \\
\hline Ano & Jul. & Ago. & Set. & Out. & Nov. & Dez. \\
\hline 1990 & 93,42 & 94,45 & 95,64 & 96,59 & 97,15 & 96,67 \\
\hline 1991 & 95,96 & 96,12 & 96,28 & 96,59 & 96,99 & 96,91 \\
\hline 1992 & 97,70 & 97,78 & 98,02 & 98,42 & 98,34 & 98,42 \\
\hline 1993 & 99,13 & 98,18 & 98,34 & 98,42 & 98,57 & 98,57 \\
\hline 1994 & 99,60 & 100,00 & 99,76 & 99,45 & 99,92 & 100,32 \\
\hline 1995 & 101,43 & 101,35 & 101,51 & 101,74 & 101,90 & 102,54 \\
\hline 1996 & 104,04 & 104,20 & 104,36 & 104,83 & 104,99 & 105,39 \\
\hline 1997 & 103,80 & 104,04 & 104,36 & 104,44 & 104,20 & 104,12 \\
\hline 1998 & 103,57 & 103,25 & 103,49 & 103,80 & 103,57 & 104,04 \\
\hline
\end{tabular}

Fonte: Dados básicos do U.S. Department of Labor, Bureau of Labor Statistics. 
TABELA 5.- Taxa de Câmbio ${ }^{1}$, Brasil, 1990-98.

(R\$/US\$ comercial) $)^{2}$

\begin{tabular}{lcccccc}
\hline Ano & Jan. & Fev. & Mar. & Abr. & Maio & Jun. \\
\hline 1990 & $5,2047 \mathrm{E}-06$ & $8,6040 \mathrm{E}-06$ & $1,3709 \mathrm{E}-05$ & $1,7415 \mathrm{E}-05$ & $1,8993 \mathrm{E}-05$ & $2,0769 \mathrm{E}-05$ \\
1991 & $7,0251 \mathrm{E}-05$ & $8,0639 \mathrm{E}-05$ & $8,3667 \mathrm{E}-05$ & $9,1700 \mathrm{E}-05$ & $9,9264 \mathrm{E}-05$ & $1,0832 \mathrm{E}-04$ \\
1992 & $4,3541 \mathrm{E}-04$ & $5,3769 \mathrm{E}-04$ & $6,5982 \mathrm{E}-04$ & $7,9921 \mathrm{E}-04$ & $9,5587 \mathrm{E}-04$ & $1,1454 \mathrm{E}-03$ \\
1993 & $5,1124 \mathrm{E}-03$ & $6,4977 \mathrm{E}-03$ & $8,1706 \mathrm{E}-03$ & $1,0447 \mathrm{E}-02$ & $1,3469 \mathrm{E}-02$ & $1,7493 \mathrm{E}-02$ \\
1994 & 0,1421 & 0,2003 & 0,2793 & 0,4035 & 0,5765 & 0,8350 \\
1995 & 0,8470 & 0,8410 & 0,8890 & 0,9080 & 0,8970 & 0,9140 \\
1996 & 0,9745 & 0,9811 & 0,9861 & 0,9902 & 0,9953 & 1,0013 \\
1997 & 1,0427 & 1,0489 & 1,0570 & 1,0611 & 1,0683 & 1,0746 \\
1998 & 1,1198 & 1,1274 & 1,1338 & 1,1411 & 1,1480 & 1,1547 \\
\hline Ano & Jul. & Ag0. & Set. & Out. & Nov. & Dez. \\
\hline 1990 & $2,4188 \mathrm{E}-05$ & $2,6093 \mathrm{E}-05$ & $2,7469 \mathrm{E}-05$ & $3,4605 \mathrm{E}-05$ & $4,4776 \mathrm{E}-05$ & $5,6213 \mathrm{E}-05$ \\
1991 & $1,1961 \mathrm{E}-04$ & $1,3501 \mathrm{E}-04$ & $1,5598 \mathrm{E}-04$ & $2,1231 \mathrm{E}-04$ & $2,6922 \mathrm{E}-04$ & $3,4832 \mathrm{E}-04$ \\
1992 & $1,3924 \mathrm{E}-03$ & $1,6990 \mathrm{E}-03$ & $2,0987 \mathrm{E}-03$ & $2,6236 \mathrm{E}-03$ & $3,2897 \mathrm{E}-03$ & $4,0549 \mathrm{E}-03$ \\
1993 & $2,2827 \mathrm{E}-02$ & $3,0087 \mathrm{E}-02$ & 0,0404 & 0,0550 & 0,0748 & 0,1016 \\
1994 & 0,9330 & 0,8990 & 0,8650 & 0,8460 & 0,8420 & 0,8500 \\
1995 & 0,9290 & 0,9420 & 0,9530 & 0,9600 & 0,9640 & 0,9680 \\
1996 & 1,0069 & 1,0134 & 1,0193 & 1,0251 & 1,0304 & 1,0373 \\
1997 & 1,0807 & 1,0880 & 1,0937 & 1,1000 & 1,1072 & 1,1138 \\
1998 & 1,1615 & 1,1717 & 1,1809 & 1,1885 & 1,1941 & 1,2055 \\
\hline
\end{tabular}

Tédia aritmética mensal.

${ }^{2}$ Alguns dados estăo expressos em notação científica, isto é: os números apresentados à esquerda com três casas decimais, devem ser multiplicados por 10 elevado à potência indicada à direita da letra $E$. Fonte: Dados básicos da Conjuntura Económica (1991/1999). 
TABELA 6.- Meios de Pagamento (M2) ${ }^{1}$, Brasil, 1990-98.

(em milhões de R\$) ${ }^{2}$

\begin{tabular}{lcccccc}
\hline Ano & Jan. & Fev. & Mar. & Abr. & Maio & Jun. \\
\hline 1990 & 0,47 & 0,77 & 0,60 & 0,85 & 1,05 & 0,95 \\
1991 & 2,28 & 2,61 & 3,00 & 3,14 & 3,45 & 3,85 \\
1992 & 18,65 & 24,30 & 32,15 & 40,99 & 52,73 & 66,91 \\
1993 & 294,91 & 395,27 & 500,73 & 628,73 & 792,00 & 1020,00 \\
1994 & 10044,00 & 14422,00 & 19107,00 & 28836,00 & 42135,00 & 66553,00 \\
1995 & 68410,00 & 71911,00 & 68032,00 & 68882,00 & 69421,00 & 73929,00 \\
1996 & 108711,00 & 114161,00 & 118272,00 & 122995,00 & 130054,00 & 134122,00 \\
1997 & 173471,00 & 178170,00 & 181210,00 & 184319,00 & 185783,00 & 188052,00 \\
1998 & 200508,00 & 207151,00 & 216853,00 & 221464,00 & 226334,00 & 230531,00 \\
\hline Ano & Jul. & Ago. & Set. & Out. & Nov. & Dez. \\
\hline 1990 & 1,06 & 1,15 & 1,24 & 1,36 & 1,59 & 1,92 \\
1991 & 4,22 & 5,11 & 6,04 & 7,39 & 9,61 & 13,98 \\
1992 & 82,18 & 104,73 & 122,18 & 151,27 & 198,91 & 237,45 \\
1993 & 1373,00 & 1864,00 & 2430,00 & 3341,00 & 4774,00 & 6809,00 \\
1994 & 70093,00 & 71623,00 & 69882,00 & 70874,00 & 70727,00 & 72846,00 \\
1995 & 81778,00 & 88888,00 & 91834,00 & 93213,00 & 100649,00 & 107157,00 \\
1996 & 140463,00 & 144362,00 & 148837,00 & 150274,00 & 157201,00 & 166687,00 \\
1997 & 193023,00 & 194586,00 & 199456,00 & 199992,00 & 195549,00 & 202433,00 \\
1998 & 237623,00 & 238172,00 & 224630,00 & 227424,00 & 241071,00 & 252102,00 \\
\hline M2 $=$ M1+ Títulos Federais. & & & & & \\
2 Saldos em fim de período. & & & & &
\end{tabular}

Fonte: Dados básicos da Conjuntura Econômica (1991/1999). 
TABELA 7.- Índice de Preços no Atacado (disponibilidade interna), Brasil, 1990-98.

(Base Ago. $94=100$ )

\begin{tabular}{lcccccc}
\hline Ano & Jan. & Fev. & Mar. & Abr. & Maio & Jun. \\
\hline 1990 & 0,00054 & 0,00094 & 0,00170 & 0,00187 & 0,00206 & 0,00221 \\
1991 & 0,00580 & 0,00706 & 0,00758 & 0,00827 & 0,00872 & 0,00949 \\
1992 & 0,03506 & 0,04399 & 0,05264 & 0,06201 & 0,07518 & 0,09089 \\
1993 & 0,43821 & 0,55315 & 0,70846 & 0,90908 & 1,20049 & 1,56427 \\
1994 & 15,78524 & 22,60919 & 32,47811 & 45,53431 & 63,05135 & 91,73972 \\
1995 & 107,94100 & 108,56700 & 109,74100 & 111,92300 & 109,65200 & 111,34700 \\
1996 & 115,33400 & 115,87900 & 115,79800 & 116,27100 & 117,82500 & 118,93100 \\
1997 & 125,10400 & 125,52700 & 127,51900 & 128,19500 & 128,36900 & 128,67900 \\
1998 & 133,63200 & 133,43200 & 133,60100 & 133,22100 & 133,39800 & 133,62200 \\
\hline Ano & Jul. & Ago. & Set. & Out. & Nov. & Dez. \\
\hline 1990 & 0,00246 & 0,00278 & 0,00309 & 0,00354 & 0,00420 & 0,00482 \\
1991 & 0,01067 & 0,01233 & 0,01420 & 0,01808 & 0,02270 & 0,02758 \\
1992 & 0,11105 & 0,14148 & 0,17992 & 0,22459 & 0,27945 & 0,34589 \\
1993 & 2,06930 & 2,75919 & 3,78708 & 5,11361 & 6,98119 & 9,47494 \\
1994 & 95,78544 & 100,00000 & 101,78900 & 104,54800 & 106,82400 & 107,00600 \\
1995 & 113,84600 & 115,81800 & 113,01100 & 112,85400 & 114,54000 & 113,84600 \\
1996 & 120,56800 & 120,50900 & 121,00300 & 121,29000 & 121,58400 & 123,05300 \\
1997 & 128,56000 & 128,36700 & 129,54900 & 130,08600 & 131,48800 & 132,63100 \\
1998 & 132,81300 & 132,76600 & 132,85000 & 132,60200 & 132,33400 & 134,64000 \\
\hline
\end{tabular}

Fonte: Dados básicos da Conjuntura Econômica (1991/1999). 
TABELA 8.- Indice de Preços de Produtos Agrícolas ${ }^{1}$, Brasil, 1990-98.

(Base Ago. $94=100$ )

\begin{tabular}{lcccccc}
\hline Ano & Jan. & Fev. & Mar. & Abr. & Maio & Jun. \\
\hline 1990 & 0,0003 & 0,0005 & 0,0009 & 0,0010 & 0,0016 & 0,0018 \\
1991 & 0,0045 & 0,0058 & 0,0071 & 0,0086 & 0,0091 & 0,0095 \\
1992 & 0,0270 & 0,0335 & 0,0382 & 0,0429 & 0,0499 & 0,0596 \\
1993 & 0,3181 & 0,3873 & 0,5037 & 0,6253 & 0,8503 & 1,0915 \\
1994 & 10,2162 & 14,8804 & 22,1629 & 30,3367 & 41,9355 & 62,1372 \\
1995 & 111,3920 & 111,6450 & 114,1340 & 116,2780 & 107,3960 & 107,9880 \\
1996 & 108,1470 & 109,6790 & 109,7850 & 110,3170 & 114,3680 & 116,7010 \\
1997 & 127,7620 & 128,1660 & 133,9970 & 135,0600 & 135,1650 & 135,3160 \\
1998 & 146,5250 & 145,6130 & 145,9110 & 144,8960 & 145,1230 & 145,3350 \\
\hline Ano & Jul. & Ago. & Set. & Out. & Nov. & Dez. \\
\hline 1990 & 0,0021 & 0,0024 & 0,0026 & 0,0030 & 0,0034 & 0,0037 \\
1991 & 0,0103 & 0,0116 & 0,0129 & 0,0163 & 0,0189 & 0,0212 \\
1992 & 0,0732 & 0,0959 & 0,1297 & 0,1634 & 0,2025 & 0,2472 \\
1993 & 1,4643 & 1,9590 & 2,8724 & 3,7821 & 5,1535 & 7,0182 \\
1994 & 88,2171 & 100,0000 & 105,2090 & 111,5130 & 113,7470 & 110,5300 \\
1995 & 111,6400 & 116,8180 & 105,6300 & 103,1250 & 107,1880 & 104,3230 \\
1996 & 121,2690 & 120,0180 & 120,7140 & 121,0960 & 121,1200 & 122,3760 \\
1997 & 133,5140 & 132,8430 & 136,0230 & 137,1530 & 140,7110 & 144,0570 \\
1998 & 143,3240 & 143,8300 & 145,0040 & 144,4380 & 144,2880 & 151,1490 \\
\hline Precos & 14030 & & & & &
\end{tabular}

'Treços por atacado - oferta global.

Fonte: Dados básicos da Conjuntura Econômica (1991/1999). 
TABELA 9.- Índice de Preços de Produtos Industriais ${ }^{1}$, Brasil, 1990-98.

(Base Ago. $94=100$ )

\begin{tabular}{lcccccc}
\hline Ano & Jan. & Fev. & Mar. & Abr. & Maio & Jun. \\
\hline 1990 & 0,0007 & 0,0011 & 0,0021 & 0,0022 & 0,0023 & 0,0024 \\
1991 & 0,0062 & 0,0074 & 0,0075 & 0,0078 & 0,0082 & 0,0091 \\
1992 & 0,0376 & 0,0475 & 0,0579 & 0,0692 & 0,0848 & 0,1027 \\
1993 & 0,4817 & 0,6152 & 0,7806 & 1,0083 & 1,3269 & 1,7321 \\
1994 & 14,4684 & 20,5783 & 29,2094 & 41,4963 & 58,0191 & 84,4385 \\
1995 & 103,2460 & 104,1430 & 105,2010 & 107,2480 & 108,5500 & 110,2030 \\
1996 & 115,6860 & 115,7220 & 115,5500 & 115,9800 & 116,2460 & 116,7050 \\
1997 & 120,3670 & 120,7860 & 120,9720 & 121,4550 & 121,6550 & 122,0290 \\
1998 & 124,0060 & 124,1180 & 124,2270 & 124,1290 & 124,2790 & 124,5020 \\
\hline Ano & Jul. & Ago. & Set. & 0 Out. & Nov. & Dez. \\
\hline 1990 & 0,0026 & 0,0029 & 0,0032 & 0,0037 & 0,0044 & 0,0052 \\
1991 & 0,0104 & 0,0122 & 0,0143 & 0,0182 & 0,0236 & 0,0296 \\
1992 & 0,1250 & 0,1579 & 0,1968 & 0,2461 & 0,3078 & 0,3830 \\
1993 & 2,2929 & 3,0543 & 4,1049 & 5,5977 & 7,6410 & 10,3555 \\
1994 & 100,0190 & 100,0000 & 99,8730 & 100,0720 & 101,0160 & 102,1110 \\
1995 & 111,6150 & 112,1710 & 113,9320 & 114,6620 & 115,0790 & 115,4480 \\
1996 & 116,8550 & 117,3660 & 117,7480 & 117,9810 & 118,4000 & 119,9320 \\
1997 & 122,6820 & 122,7140 & 122,9320 & 123,1790 & 123,5550 & 123,6820 \\
1998 & 124,2280 & 123,9460 & 123,5610 & 123,4560 & 123,1450 & 123,4310 \\
\hline Precos pos & 1920 & & & & &
\end{tabular}

'Preços por atacado - oferta global.

Fonte: Dados básicos da Conjuntura Econômica (1991/1999). 


\section{2 - Método}

Basicamente, a metodologia empregada nesse estudo pode ser dividida em três partes. A primeira delas inclui a utilização da metodologia proposta inicialmente nos trabalhos de FULLER (1996), DICKEY e FULLER (1979) e DICKEY e FULLER (1981), a qual foi posteriormente completada pelo trabalho de PHILLIPS e PERRON (1988) para testar a presença ou não de raiz unitária nas séries temporais. A segunda parte é composta pelos testes de co-integração entre as variáveis, cujo trabalho pioneiro nessa área coube a ENGLE e GRANGER (1991), o qual foi aperfeiçoado por JOHANSEN e JUSELIUS (1990). A terceira parte envolve a utilizaçăo da metodologia de séries temporais relativa aos modelos Autoregressivos Vetoriais (VAR) conforme estabelecido em SIMS (1980 e 1986).

\subsection{1 - Testes de raiz unitária}

Segundo ENGLE e GRANGER (1991, p. 83) a ordem de integração de uma variável é definida como: "Uma série sem componente determinístico com representação ARMA, estacionária, inversível depois de ser diferenciada $d$ vezes, é dita ser integrada de ordem $d, e$ denotada por $x_{t} \sim l(d)$. Portanto, a ordem de integração de uma variável representa o número de vezes que uma série necessita ser diferenciada para se tornar estacionária, ou seja, se uma variável é integrada de ordem 1, ela precisa ser diferenciada uma vez para se atingir a estacionariedade ${ }^{16}$.

O primeiro tipo de teste de raiz unitária foi desenvolvido por DICKEY e FULLER (1979 e 1981). Esses autores consideraram um processo auto-regressivo de ordem $1(A R(1))$, conforme descrito a seguir:

$$
y_{t}=\rho y_{t-1}+e_{t}, t=1,2, \ldots
$$

onde $y_{0}$ é um valor inicial fixo enquanto que $e_{t}$ é uma seqüência de variáveis aleatórias identicamente $\mathrm{e}$ independentemente distribuídas (IID). A hipótese nula é que $y_{t}$ é não estacionária, ou seja, é uma variável aleatória sem intercepto, contra a hipótese alternativa de que $y_{t}$ é um processo AR(1). Portanto, tem-se que: $H_{0}: \rho=1$ contra $H_{A}: \rho<1$. Para a realização deste teste de hipótese utiliza-se como processo de estimação o modelo de mínimos quadrados ordinários. No entanto, os testes para detecção de raiz unitária e/ou de

\footnotetext{
${ }^{16}$ Em outras palavras, segundo KASSOUF (1988, p.23) o conceito de que uma variável é estacionária "significa que a série se desenvolve no tempo aleatoriamente em torno de uma média constante, refletindo alguma forma de equilibrio estável".
} 
estacionariedade, não utilizam a distribuição padrão de $t$ de Student, e sim, os valores das distribuiçőes denominadas $\tau$ e que foram tabuladas por FULLER (1996, p. 642).

Conforme HOLDEN e PERMAN (1994, p. 57) na "prática não se justifica o uso de $\tau$ de maneira isolada pois os valores críticos tem como base a distribuição limite que são derivadas de fortes hipóteses sobre $e_{t}$. Pressupōe-se que não há drift (isto é, sem intercepto) nem tendência na equação original. Contudo, a distribuição limite e os correspondentes valores críticos não são corretos se estas hipóteses são falsas". Sendo assim, foram incorporados termos relacionados com a presença de intercepto $(\alpha)$ e tendência $(\beta t)$ quando o termo de resíduo é independente e identicamente distribuído (IID). Logo, o modelo contendo intercepto fica representado como:

$$
y_{t}=\rho y_{t-1}+\alpha+e_{t}, t=1,2, \ldots
$$

enquanto que o modelo contendo intercepto e tendência assume o seguinte formato:

$$
y_{t}=\rho y_{t-1}+\alpha+\beta t+e_{t}, t=1,2, \ldots
$$

No caso da existência de intercepto a estatística utilizada é denominada de $\tau_{\mu}$ e para se testar a presença de intercepto e tendência a estatística utilizada é a $\tau_{\tau}$ Os valores críticos para essas distribuições estão tabuladas em DICKEY e FULLER (1981, p. 1062). Ainda nesse mesmo artigo encontra-se os valores críticos para testar de maneira conjunta a presença de um termo de intercepto e/ou tendência e de raiz unitária. Esses testes são denominados de teste $\phi$ e correspondem ao teste $F$ padrão. No caso do teste denominado de $\phi_{1}$, testa-se a hipótese de que $(\alpha, \rho)=(0,1)$ contra a hipótese de que $(\alpha, \rho) \neq(0,1)$. O teste $\phi_{2}$ tem como hipótese nula que $(\alpha, \beta, \rho)=(0,0,1)$ contra a hipótese alternativa de que $(\alpha, \beta, \rho) \neq(0,0,1)$. Finalmente, a estatística $\phi_{3}$, onde a hipótese nula é de que $(\alpha, \beta, \rho)=(\alpha, 0,1)$ versus a hipótese alternativa de que $(\alpha, \beta, \rho) \neq(\alpha, 0,1)$.

DICKEY e FULLER (1981), também, demonstraram que a distribuição limite e os valores críticos tabulados sob a hipótese de que o termo de resíduo (o qual é representado por $\left.e_{t}\right)$, é um processo IID, são válidos, mesmo quando o resíduo é estacionário e representado por um polinômio auto-regressivo ${ }^{17}$ de ordem p. Segundo MILLS $(1993$, p. 53) "para testar a presença de uma ou mais raízes unitárias no modelo polinomial auto-regressivo $(\phi(B))$ de ordem $p^{n}$ utiliza-se a seguinte expressão:

$$
\phi(B) y_{t}=\alpha+\theta(B) e_{t}
$$


sendo que, pressupõe-se que $\alpha=\phi(1)$ e $\mu$ é fixo, enquanto que, $\mu$ representa a média de $y_{\text {t }}$. Nesse caso, o teste de raiz unitária é denominado como Teste Dickey-Fuller Aumentado (ADF) e tem como base a seguinte regressão:

$$
y_{t}=\alpha+\beta t+\rho_{1} y_{t-1}-\sum_{j=1}^{p-1} \rho_{j+1} \nabla y_{t-j}+e_{t}
$$

onde

$$
\rho_{i}=\sum_{j=1}^{p} \phi_{j}, i=1, \ldots, p
$$

Ainda de acordo com MILLS (1993, p. 53) "desde que $\phi(B)$ conterá uma raiz unitária se $\sum_{1}^{p} \phi_{j}=1$, a presença dessa raiz é formalmente equivalente a testar a hipótese de que $\rho_{1}=$ $1^{\pi}$.Outro aspecto a ser observado é de que o símbolo $\nabla$ denota o operador de diferença, o qual pode ser representado como: $\nabla_{t}=Y_{t}-Y_{t-1}$.

A equação (5) pode ser redigida de maneira mais conveniente para se efetuar o teste para detecçåo de raiz unitária, ao se substituir o parâmetro $\rho_{1}$ do regressor $y_{t-1}$ por $(\rho,-1)$. Logo a regressão assume o seguinte aspecto:

$$
y_{t}=\alpha+\beta t+\left(\rho_{1}-1\right) y_{t-1}-\sum_{j=1}^{p-1} \rho_{j+1} \nabla y_{t-j}+e_{t}
$$

SAID e DICKEY (1984) ampliaram o campo para a utilização desses testes de raiz unitária ao incorporá-los aos modelos ARMA. Mais especificamente, segundo BANERJEE et al. (1993, p. 107) a técnica proposta por "Said - Dickey representa uma generalização do procedimento Dickey - Fuller, e produz testes estatísticos com os mesmos valores críticos tabulados por Dickey e Fuller. A principal vantagem desse teste é que ele pode ser aplicado não somente em modelos com erros de Médias Móveis (MA), mas também, em modelos para os quais (como é o caso típico) as ordens dos polinômios Auto-regressivos (AR) e de Médias Móveis (MA) são desconhecidas. O método envolve uma aproximação do verdadeiro processo através de uma auto-regressão na qual o número de defasagens (lags) aumentam com o tamanho da amostra". Nesse caso, admite-se que o termo de erro da auto-regressão é gerado por um processo ARMA de ordem $(p, q)$, o qual, presume-se ser estacionário e inversível. Portanto, o modelo pode ser re-escrito como:

$$
y_{t}=\alpha+\beta t+\left(\rho_{1}-1\right) y_{t-1}-\sum_{j=1}^{p-1} \rho_{j+1} \nabla y_{t-j}+a_{t}-\sum_{j=1}^{q} \theta_{j} a_{t-j}
$$

\footnotetext{
${ }^{17}$ Nesse caso, a estrutura de resíduo é representada como: $\theta_{t}=\theta_{1} \theta_{t-1}+\theta_{2} \theta_{t-2}+\ldots+\theta_{p} \theta_{t-p}+\varepsilon_{t}$.
} 
Conforme MILLS (1993), ao se aumentar simultaneamente o tamanho da amostra e o número de defasagens, isso tem efeito direto sobre a estrutura de correlação dos resíduos, alterando-se dessa forma o contomo da distribuição $\tau_{\mu}$, tomando-a mais precisa.

Para finalizar a apresentação sobre os diversos tipos de testes propostos para se detectar a presença de raiz unitária em séries de tempo, será comentado o teste elaborado por PHILLIPS e PERRON (1988). Basicamente, esse teste foi inicialmente desenvolvido por PHILLIPS (1987), o qual parte de uma análise não paramétrica, isto é, relaxa a hipótese de que a estrutura de erro $\left(e_{\ell}\right)$ é um processo IID. Esse autor demonstrou que esse teste de caráter não paramétrico e denominado de estatísticas $Z\left(Z(\alpha)\right.$ e $\left.Z\left(t_{a}\right)\right)$ possuem o mesmo poder assintótico diante de uma estrutura geral de erros, ou seja, é equivalente ao teste estatístico paramétrico $\tau_{\mu}$. Nas palavras de PHILLIPS e PERRON (1988, p. 336) um "procedimento alternativo para testar a presença de raiz unitária em séries de tempo foi recentemente proposto por PHILLIPS (1987). Este é um procedimento nåo paramétrico com relação a parâmetros incômodos (nuisance parameters) que estão presentes em diversas classes de séries de tempo em que exista raiz unitária. Inclui modelos ARIMA heterogêneos assim como inovações identicamente distribuidas. Esse método aparentemente tem significativas vantagens quando há componentes de médias móveis nas séries temporais e ao menos com relação a esse respeito, oferece uma alternativa promissora aos procedimentos Dickey-Fuller e Said-Dickey". No entanto, HOLDEN e PERMAN (1994), ressaltam que, quando o termo de ruído tem componentes de médias móveis positivos o poder do teste ADF é baixo comparativamente ao teste de Phillips-Perron, sendo assim, é melhor utilizar esse último. Por outro lado, quando há componentes de médias móveis com sinal negativo, as evidências indicam que a estatística $Z$ apresenta distorções no caso de amostras de tamanho finito.

De maneira resumida, PHILLIPS e PERRON (1988) assumem que a estrutura de erros $\left(e_{t}\right)$ em (5) tem um processo gerador representado por um modelo de médias móveis de ordem 1, conforme a equação abaixo:

$$
e_{t}=\varepsilon_{t}+\theta \varepsilon_{t-1}
$$

onde pressupõe-se que $\varepsilon_{t}$ seja IID. Contudo, deve-se enfatizar que, contrariamente ao que ocorre no teste ADF onde assume-se que $e$, é um processo gerador IID e conseqüentemente que a verdadeira variåncia populacional $\left(\sigma^{2}\right)$ a qual é representada por:

$$
\sigma^{2}=\lim _{T \rightarrow \infty} \frac{E\left[\sum_{t=1}^{t=T} e_{t}\right]^{2}}{T}
$$

é semelhante à variância dos residuos do modelo de regressão relativo à equação (5), a qual é representada como: 


$$
\sigma_{e}^{2}=\lim _{T \rightarrow \infty}\left[\frac{\sum_{t=1}^{t=T} E\left(e_{t}^{2}\right)}{T}\right]
$$

o teste de Phillips-Perron permite analisar a presença de raiz unitária naqueles casos em que essas duas variâncias não são semelhantes, como ocorre na maioria das vezes, fato esse que introduz viéses nos resultados dos testes ADF. Quando $\sigma^{2}$ é semelhante a $\sigma_{e}{ }^{2}$ o teste PhillipsPerron converge para os mesmos resultados obtidos pelos testes ADF.

Os estimadores consistentes de $\sigma^{2}$ e $\sigma_{e}^{2}$ sảo respectivamente:

$$
\begin{gathered}
S_{T \ell}{ }^{2}=\frac{1}{T} \sum_{t=1}^{T}\left(e_{t}{ }^{2}\right)+\frac{2}{T} \sum_{s=1}^{\ell} \omega_{s \ell} \sum_{t=s+1}^{T} e_{t} e_{t-s} \\
S_{e}{ }^{2}=\frac{1}{T} \sum_{t=1}^{T}\left(e_{t}{ }^{2}\right)
\end{gathered}
$$

onde $\omega_{s \ell}=\frac{1-s}{(\ell+1)}$ e e são os resíduos da regressão, enquanto que $\ell$ é o parâmetro para especificar a truncagem da defasagem necessária para garantir que a autocorrelação dos resíduos esteja completamente capturada. Quando não há presença de autocorrelação nos resíduos o segundo termo da expressão (12) é igual a zero, ou seja, nesse caso, tem-se que $\sigma^{2}$ é igual a $\sigma_{e}^{2}$.

Resumidamente, a estratégia para realizar os testes de raiz unitária é a seguinte:

1) Estimar uma auto-regressão completa, isto é contendo um intercepto $\left(\alpha_{0}\right)$ e uma variável tendência $(\beta t)$, ou seja:

$$
\nabla y_{t}=\alpha_{0}+\beta t+\rho y_{t-1}+\sum_{i=1}^{k} \rho_{i} \nabla y_{t-i}+\varepsilon_{t}
$$

onde $\nabla$ é o operador diferença já definido anteriormente. A escolha do número de defasagens (k) objetiva remover a autocorrelação dos resíduos e é determinado pelo menor valor obtido pelo critério A/C e/ou SBC;

2) Inicialmente, deve-se testar a hipótese que $\rho=0$ utilizando a estatística $\tau_{\tau}$;

3) Se a hipótese acima não pode ser rejeitada, então deve-se testar a hipótese conjunta $\rho=\beta=0$ utilizando a estatística $\phi_{3}$. Se esta estatística não pode ser rejeitada, então conclui-se que há uma raiz unitária e segue-se para a próxima etapa; 
4) Testar a hipótese conjunta $\rho=\alpha_{0}=\beta=0$ tendo-se como base a estatística $\phi_{2}$. Se esta hipótese não pode ser rejeitada, então conclui-se que o processo gerador da série é provavelmente uma random walk sem um intercepto fixo. Se esta hipótese é aceita nos procedimentos anteriores, mas é rejeitada nesse caso, então conclui-se que provavelmente o processo é uma random walk com intercepto fixo;

5) A seguir, deve-se estimar a seguinte auto-regressão sem a variável tendência, mas com intercepto:

$$
\nabla y_{t}=\alpha_{0}+\rho y_{t-1}+\sum_{i=1}^{k} \rho_{i} \nabla y_{t-i}+\varepsilon_{t}
$$

6) Tendo-se como base a auto-regressão anterior, deve-se testar a hipótese de que $\rho=0$ utilizando a estatística $\tau_{\mu}$;

7) Se esta hipótese não pode ser rejeitada, então deve-se testar a hipótese conjunta de que $\rho=\alpha_{0}=0$ utilizando a estatística $\phi_{1}$. Se esta hipótese conjunta não pode ser rejeitada conclui-se que há uma raiz unitária sem intercepto. Se a hipótese de que $\rho=0$ não pode ser rejeitada, ainda que a hipótese conjunta possa ser rejeitada, então o processo é uma random walk sem intercepto, sendo assim parte-se para a próxima etapa;

8) Estimar uma auto-regressão sem intercepto e tendência:

$$
\nabla y_{t}=\rho y_{t-1}+\sum_{i=1}^{k} \rho_{i} \nabla y_{t-i}+\varepsilon_{t}
$$

9) Deve-se testar se $\rho=0$ utilizando a estatística $\tau$. Se esta hipótese não pode ser rejeitada, então conclui-se que esse processo gerador possui raiz unitária. Portanto, deve-se trabalhar com a variável diferenciada e não em nível.

Nesse estudo, para a realização dos testes de raiz unitária foram utilizados os valores críticos tabulados por MACKINNON (1991), ao invés dos valores correspondentes às estatísticas $\tau, \tau_{\mu}$ e $\tau_{\tau}$ construídas e tabeladas por DICKEY e FULLER (1979 e 1981) e FULLER (1996). A justificativa para se utilizar os valores calculados por MACKINNON (1991) reside no fato de que os valores são obtidos de forma direta e sem a necessidade de cálculos adicionais. Os valores críticos elaborados por MACKINNON (1991) tem como base simulações, e são suficientemente exatos para os propósitos práticos. "Os resultados dos experimentos de simulação são sumarizados por meio de superfície de resposta de regressões, nas quais os valores críticos estão relacionados com o tamanho da amostra. Os coeficientes de resposta das superfícies de regressão são tabulados de maneira que os valores críticos assintóticos podem 
ser lidos diretamente, e os valores críticos para qualquer amostra de tamanho finito possa ser facilmente computado com calculadora manual". (MACKINNON, 1991, p. 268).

Para finalizar esse item, HARRIS (1995, p. 39) destaca às limitações proporcionadas pelos testes de raiz unitária, uma vez que, escolher "a forma correta do modelo ADF é problemática e ao utilizar diferentes extensões de defasagens freqüentemente obtém-se diferentes resultados com respeito à rejeição da hipótese nula de não estacionariedade. Esses problemas são complexos pelo fato de que há várias questões relacionadas com o tamanho e poder dos testes de raiz unitária, especialmente no que concerne as propriedades de pequenas amostras desses testes". Portanto, os resultados desses testes devem ser analisados com cautela, pois quando os valores calculados dos testes de raiz unitária estão muito próximos dos valores tabelados, os resultados podem indicar que a série é estacionária quando na verdade isso não acontece.

\subsection{2 - Análise de intervenção ${ }^{18}$}

As séries contendo variáveis econômicas normalmente são afetadas não só por alteraçōes no direcionamento dos instrumentos de política econômica, como também, por eventos de caráter exógeno como, por exemplo, bruscas variações climáticas. Logo, ao se realizar a modelagem econométrica de variáveis econômicas, esses eventos devem ser levados em consideração, pois caso contrário, corre-se o risco de se obter modelos estruturais viesados com a conseqüente perda de seu poder de previsão. "Eventos desse tipo, cujo timing é conhecido, têm sido denominados intervenções, por BOX e TIAO (1975), e podem ser incorporados ao modelo univariado estendendo-o para incluir variáveis de entrada deterministicas (ou dummy) "(MILLS, 1990, p. 235). A questão é que nem sempre o exato momento das intervençōes exógenas pode ser estabelecido a priori, fato esse que acarreta efeitos indesejáveis sobre o modelo, causando a ampliação de sua variância. O termo usado para a presença de observaçőes consideradas discrepantes no interior de séries de tempo é outliers. Entre os vários efeitos provocados pela existência de outliers nas séries de tempo, destacam-se a mudança em seu nivel, a qual pode ser abrupta ou suave, e/ou até mesmo alterações na trajetória de sua tendência.

Basicamente, duas são as estruturas no caso da análise de intervenção. A primeira delas é denominada pulse, a qual é representada por $P^{T}$ e assume valor igual a um no momento da ocorrência de determinado evento e valor igual a zero fora do tempo de ocorrência

${ }^{18}$ Esse item tem como base MARGARIDO (1994). 
do evento ${ }^{19}$. A segunda classe de outlier é conhecida com step e é representada por $S^{\top}$. Nesse caso, a dummy assume valor igual a zero antes da ocorrência do evento e valor igual a um no período posterior à ocorrência do evento.

Chamando-se de $I_{t}$ a variável de intervenção, em termos matemáticos os dois tipos de intervenção mencionados acima podem ser representados da seguinte forma:

1) variável de intervenção do tipo Pulse

$$
I_{t}=P^{T}{ }_{t}, \operatorname{com} P^{T}{ }_{t}=\left\{\begin{array}{l}
1, t=T \\
0, t \neq T
\end{array}\right.
$$

2) variável de intervençåo do tipo Step

$$
I_{t}=S^{T}{ }_{t}, \operatorname{com} S^{T}{ }_{t}=\left\{\begin{array}{l}
0, t<\mathrm{T} \\
1, \mathrm{t} \geq T
\end{array}\right.
$$

De maneira resumida, existem quatro categorias de impactos: a) o início é abrupto e o efeito de duração da intervenção é permanente; b) o início é gradual e o efeito de duração da intervenção é permanente; c) o início é abrupto e o efeito de duração da intenvenção é temporário; e d) o inicio é gradual e o efeito de duração da intervenção é temporário.

Até agora, em relação ao processo de construção dos modelos contendo análise de intervenção foi suposto que o momento exato para a aplicação da intervenção fosse conhecido. Entretanto, isso nem sempre acontece, pois em determinadas situações o exato momento da intervenção não é conhecido a priori. Quando ocorre essa situação, esses eventos exógenos desconhecidos podem provocar o surgimento de observações discrepantes, também chamadas de outliers. Conforme MARGARIDO (1994, p. 65), "o principal efeito provocado pelo aparecimento de outliers reside no fato de que a identificação do modelo fica prejudicada, pois os outliers podem mascarar a verdadeira identificação do modelo. Seguindo o caminho contrário, um modelo que não seja bem especificado pode conduzir ao aparecimento de outliers". Portanto, a não inclusão do modelo de intervenção em séries que apresentam valores aberrantes pode levar tanto à superespecificação quanto à subespecificação dos modelos, prejudicando não somente o trabalho de análise estrutural, mas empobrecendo o poder de previsão do modelo que está sendo elaborado.

Ao se detectar a presença de outliers, determinados procedimentos necessitam ser estabelecidos para o seu adequado tratamento. Em primeiro lugar, é necessário definir qual a sua categoria para posteriormente aplicar a análise de intervenção. Conforme descrito em MILLS (1990), há quatro categorias de outliers. O tipo de outlier considerado o mais simples é o additive outlier (AO), o qual é definido como:

\footnotetext{
$19 \mathrm{Em}$ relaçåo à notação utilizada, é necessário destacar que $t$ representa o tempo, enquanto que $T$ corresponde ao exato momento da introdução da dummy ou dummies na(s) série(s) de tempo.
} 


$$
x_{t}=\varepsilon_{t}+\omega I^{T}
$$

onde $\varepsilon_{l}$ representa o modelo de ruído composto por parâmetros auto-regressivos e de médias móveis. $O$ additive outlier pode ser corrigido com intervenção do tipo pulse.

Outra categoria de outlier corresponde ao innovational outlier (1O), a qual é representada matematicamente como:

$$
x_{t}=\varepsilon_{t}+\frac{\theta(B)}{\phi(B)} \omega I^{T}{ }_{t}
$$

A principal característica do innovational outlier é que os resíduos são afetados pelo processo gerador da série, ou seja, o seu efeito sobre a série de tempo não se esgota totalmente no mesmo momento em função da presença do modelo de ruído. Nas palavras de MILLS (1990, p.241-242), a fundamental diferença entre 0 innovational outlier e 0 additive outlier consiste no fato de que $O$ "caso $A O$ pode ser chamado de um modelo de 'erro grosseiro', desde que somente a t-ésima observação é afetada. De outra maneira, um 10 representa um choque extraordinário em $T$ influenciando $x_{T}, x_{T+1}$, ...através da memória do modelo dada por $\theta(B) /$ $\phi(B)^{n}$.

Finalmente, a terceira categoria de outlier é denominada de level shift (LS), o qual pode ser subdividido em termos do seu efeito ser transitório ou permanente. O tipo de $L S$ com efeito permanente pode ser representado como:

$$
x_{t}=\varepsilon_{t}+\frac{\omega}{(1-B)} I^{T}{ }_{t}
$$

Nesse caso, a magnitude da mudança de nivel, a qual é dada pelo parâmetro $\omega$, corresponde ao período de tempo em que $t=T$. Quando o efeito do $L S$ é temporário, ou seja, se a mudança de nivel é apenas transitória, o LS assume o seguinte formato:

$$
x_{t}=\varepsilon_{t}+\frac{\omega}{(1-\delta B)} I_{t}^{T}
$$

Nesse caso, a mudança de nivel ocorre a partir do período em que $t \geq T$, sendo que seu efeito declina exponencialmente a taxa dada por $\delta$, após o impacto inicial de $\omega$, ou seja, nesse caso existe uma "memória" a qual está relacionada com a presença do parâmetro $\delta$. Isto quer dizer que após a incidência de um choque, demora um certo período de tempo até que seu efeito se esgote totalmente. 


\subsection{3 - Teste de raiz unitária com quebra estrutural}

Segundo PERRON (1994) os testes de raiz unitária com quebras estruturais ${ }^{20}$ têm como base a análise de intervenção desenvolvida por BOX e TIAO (1975). Basicamente, de acordo com a metodologia de análise de intervenção eventos discrepantes (aberrantes) podem ser separados da função de ruído e ser modeladas como mudanças ou intervençőes na parte deterministica do modelo de série de tempo, isto é, pode-se utilizar dummies como variáveis de entrada no modelo que está sendo estimado. Utilizando tal estratégia é possível separar o que pode e o que não pode ser explicado pelo modelo de ruído. Outro aspecto importante, é que se pressupõe que as intervenções são exógenas e que ocorrem em datas conhecidas.

De acordo com PERRON (1994, p. 117) "são considerados três diferentes tipos de modelos, sendo que para cada um as hipóteses nulas são: uma que permite mudança exógena no nível das séries, uma que permite mudança exógena na taxa de crescimento e uma que concebe as duas mudanças conjuntamente".

Tendo como base o trabalho de BOX e TIAO (1975), PERRON (1994) elaborou dois tipos de modelos, os quais são posteriormente subdivididos. O modelo Additive Outlier (AO) caracteriza-se pelo fato de que a mudança na função tendência ocorre instantaneamente, enquanto que no modelo Innovational Outlier (IO) a mudança na função tendência é gradual.

\subsubsection{1 - Modelo additive outlier (AO)}

O modelo AO é subdividido em três modelos diferentes:

a) Modelo 1:

$$
y_{t}=\mu_{1}+\beta t+\theta D U_{t}+v_{t}
$$

onde: $D U_{t}=1$ se $t>T_{b}$ e zero caso contrário, sendo que $t$ representa o tempo e $T_{b}$ é o momento no tempo em que ocorreu a quebra estrutural. Nesse caso, a variável $D U_{t}$ é uma variável dummy do tipo step, isto é representa a mudança abrupta de nível (intercepto) da função tendência da série e $v_{t}$ é o modelo de ruído. Em relação ao modelo de ruído é necessário observar que $v_{t}$ é representado por um modelo ARMA tal que $A(L) v_{t}=B(L) e_{t}, 0$

\footnotetext{
${ }^{20}$ Segundo BANERJEE e URGA (1995) a terminologia quebras estruturais não é a mais adequada, no entanto, foi a que prevaleceu na literatura econométrica, a partir do trabalho de PERRON (1989), relativamente aos testes de raiz unitária e modelos de co-integração. Basicamente, os denominados testes de raiz unitária objetivam distinguir quebras deterministicas na tendência ou na média em séries de tempo de genuínos processos com raiz unitária.
} 
qual é IID $\left(0, \sigma^{2}\right)$, enquanto que $A(L)$ e $B(L)$ representam polinômios de ordem $p$ e $q$ respectivamente e $L$ é o operador de defasagem.

b) Modelo 2:

$$
y_{t}=\mu_{1}+\beta t+\theta D U_{t}+\gamma D T_{t}^{*}+v_{t}
$$

onde: $D T^{*}{ }_{t}=t-T_{b}$ se $t>T_{b}$ e zero caso contrário, ou seja $D T^{*}{ }_{t}$ representa uma variável dummy que capta a mudança na inclinação da função tendência. Portanto, esse modelo incorpora simultaneamente a mudança no intercepto e na inclinação da função tendência, ou seja uma abrupta mudança no nivel seguida de mudança na taxa de crescimento da série.

c) Modelo 3:

$$
y_{t}=\mu_{1}+\beta t+\gamma D T_{t}^{*}+v_{t}
$$

Esse modelo incorpora mudanças na taxa de crescimento da função tendência, isto é capta alteraçőes na inclinação da função tendência, mas sem mudanças abruptas no nível da série a partir do ponto da quebra estrutural.

No caso do modelo $A O$ a estratégia para a detecção de raiz unitária consiste em dois passos. O primeiro passo é eliminar a função tendência da série original, sendo que esse procedimento é o mesmo para os três modelos. Portanto, deve-se estimar cada um dos três modelos apresentados e guardar os respectivos resíduos. A partir daí, estima-se uma autoregressão com os resíduos para cada caso, isto eqüivale a realizar um teste de raiz unitária ADF sobre o parâmetro $\alpha$. No entanto, a estimação da regressão contendo os resíduos não é a mesma para os três casos. De acordo com PERRON (1994), para os modelos 1 e 2, a equação estimada é a seguinte:

$$
\tilde{v}_{t}=\alpha \tilde{v}_{t-1}+\sum_{j=0}^{k} d_{j} D\left(T_{b}\right)_{t-j}+\sum_{i=1}^{k} a_{i} \nabla \tilde{v}_{t-i}+e_{t}
$$

onde $\tilde{v}_{t}$ representam os resíduos estimados dos modelos 1 e 2.

Em relação ao modelo 3, dado que não há mudança de nivel envolvendo os dois segmentos da tendência a partir do ponto de quebra estrutural, não é necessário a introdução de variáveis dummies na regressão dos resíduos no segundo passo. Sendo assim, a autoregressão para os resíduos estimados no primeiro passo é a seguinte:

$$
\tilde{v}_{t}=\alpha \tilde{v}_{t-1}+\sum_{i=1}^{k} a_{i} \nabla \tilde{v}_{t-i}+e_{t}
$$


Outro ponto levantado por PERRON (1994, p. 134) é que este "procedimento em dois passos permite o teste de raiz unitária, que é assintóticamente invariante em relação a $\gamma$ (a magnitude de mudança na inclinação) sob a hipótese nula”.

\subsubsection{2 - Modelo innovational outlier (10)}

a) Modelo 1:

$$
y_{t}=\mu+\theta D U_{t}+\beta t+\delta D(T B)_{t}+\alpha y_{t-1}+\sum_{i=1}^{\infty} c_{i} \nabla y_{t-i}+e_{t}
$$

onde: $D\left(T_{b}\right)_{t}=1$ se $t=T_{D}+1$ e igual a zero caso contrário.

b) Modelo 2:

$$
y_{t}=\mu+\theta D U_{t}+\beta t+\gamma D T^{*}+\delta D(T B)_{t}+\alpha y_{t-1}+\sum_{i=1}^{\infty} c_{i} \nabla y_{t-i}+e_{t}
$$

Segundo PERRON (1994), a hipótese nula impõe as seguintes restrições sobre os coeficientes. No caso do modelo 25, a hipótese nula é de que $\alpha=1$ (tenha raiz unitária), $\theta=\beta=0$ (não há variação abrupta no nivel da série, isto é, no intercepto, e também, não tem tendência) e $\delta \neq 0$, isto é, há mudança de intercepto a partir do ponto de quebra estrutural. Para o modelo 26, a hipótese nula é de que $\alpha=1$ (tenha raiz unitária) e que $\beta=\gamma=0$ (não tem termo de tendência e que não há mudança na inclinação da função tendência) e $\delta \neq 0$. A hipótese altemativa, a qual é válida para ambos modelos é que $|\alpha|<1$ (não tem raiz unitária) e que $\delta=0$ (não há mudança de intercepto a partir do ponto de quebra estrutural).

Os valores críticos para os testes de raiz unitária com quebra estrutural podem ser encontrados em PERRON (1989) Tabelas IV.B e VI.B e são os mesmos tanto para os modelos $1 O$ (1 e 2), quanto $A O$ (1 e 2), e em PERRON (1993) para o modelo 3 AO.

PERRON (1994) chama a atenção para o fato de que os valores críticos dependem da posição relativa ocupada pela quebra estrutural na série $(\lambda)$, os quais são obtidos a partir da seguinte fómula: $\lambda=\frac{T_{b}}{T}$, onde $T_{b}$ representa 0 instante de tempo onde ocorreu a quebra estrutural na série e $T$ é o total de observações da série. Entretanto, segundo PERRON (1994) a menos que a quebra estrutural ocorra muito perto do início ou do fim da série, as variações 
nos valores críticos são irrelevantes. Portanto, na maioria da vezes pode-se utilizar o valor crítico correspondente à quebra estrutural no meio da série, isto é com $\lambda=0,5$.

\subsection{4 - Modelo Auto-regressivo Vetorial (VAR)}

Em meados dos anos 60 , a ciência econômica estava voltada no sentido de desenvolver novas técnicas econométricas que fossem capazes de superar os problemas decorrentes de viéses criados pela estimação de modelos com equações simultâneas, também denominados de modelos estruturais ${ }^{21}$. Esse tipo de modelo era utilizado principalmente para realizar análise e previsões de comportamento de variáveis macroeconômicas, e caracterizavase por conter um grande número de variáveis endógenas. No entanto conforme enfatizado por PINDYCK e RUBIFELD (1998) vários fatores podem impedir a correta estimação dos modelos, pois nem sempre a teoria econômica é suficiente para essa tarefa, ou seja a teoria pode ser tão complexa que muitas vezes é necessária a imposição de restrições sobre os parâmetros, ou então a teoria pode ser coerente com diversas estruturas de defasagens, que no entanto podem resultar em modelos com diferentes comportamentos dinâmicos e finalmente, pode não haver consenso de qual seja a correta teoria a ser utilizada. Em função desses problemas, na década de 70 , esses modelos passaram a ser criticados, especialmente no que se refere à necessidade de imposição de restrições, através do uso de variáveis assumindo valor igual a zero para possibilitar obter a sua identificação, além do que, havia a questão relativa à distinção do que deveria ser considerada como variável endógena ou exógena no interior do modelo.

Basicamente, a principal característica dos Modelos Auto-regressivos Vetoriais (VAR), desenvolvido a partir do trabalho de SIMS (1980), consiste em tratar todas as variáveis de forma simétrica, ou seja a questão relativa a quais variáveis devem ser consideradas dependentes ou independentes deixa de existir. Sendo assim, caso exista simultaneidade entre um conjunto de variáveis, todas elas devem ser tratadas em bases iguais. Outros dois aspectos relevantes característicos dos modelos VAR, é que não é necessário impor restrições com valor igual a zero, como ocorria na construção dos modelos estruturais, além do que, não há necessidade de uma teoria econômica específica que possa ser refletida pelo modelo, ou seja esse tipo de modelo tem a vantagem de se trabalhar com uma teoria de caráter mais amplo, pois contrariamente aos modelos de equações simultâneas, o modelo VAR "utiliza somente regularidades e padrões passados de dados históricos como base para previsão. Não se constrói nenhum modelo estrutural". (HILL, GRIFFITHS e JUDGE, 1999, p. 378). 
Reforçando o que foi dito no início desse item, outro ponto relevante com relação aos aspectos teóricos envolvidos, observa-se que a correta especificação de modelos teóricos está diretamente relacionada com a própria dinâmica do modelo, uma vez que as teorias são condizentes com diversas estruturas de defasagens das vanáveis, onde cada uma delas está associada a diferentes comportamentos dinâmicos. Uma das vantagens de se utilizar os modelos VAR é que esse tipo de modelo econométrico exige um grau reduzido de restrições teóricas sobre a sua estrutura. Para a utilização dos modelos VAR é necessário determinar somente duas coisas: 1) especificar o conjunto de variáveis que se acredita que interagem dentro do sistema; 2) determinar o maior número de defasagens necessárias para captar a dinâmica da interação entre as variáveis do modelo, sendo que a extensão das defasagens é realizada por testes que serăo delineados mais adiante.

Para captar a inter-relação entre variáveis econômicas os modelos VAR utilizam-se os seguintes instrumentos: função de resposta de impulso e decomposição da variância dos erros de previsão.

\subsection{5 - Processos auto-regressivos vetoriais}

Tendo como ponto de partida os modelos univariados de séries temporais conforme apresentados em BOX, JENKINS e REINSEL (1994) um processo auto-regressivo de ordem $p$ $(A R(p))$ pode ser representado como:

$$
y_{t}=\phi_{1} y_{t-1}+\phi_{2} y_{t-2}+\ldots+\phi_{p} y_{t-p}+\varepsilon_{t}
$$

ou seja, o valor da variável escalar $\left(y_{t}\right)$ no periodo $t$ é função de seus próprios valores passados.

Ao invés de se considerar esse processo em termos de escalar, mas sim na forma

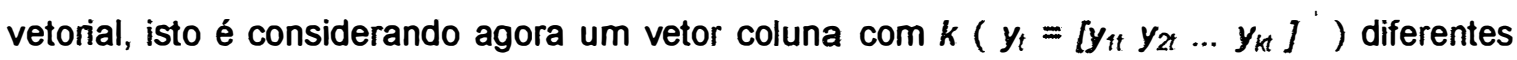
variáveis, obtém-se um vetor auto-regressivo, também conhecido como VAR, o qual algébricamente assume a seguinte forma:

$$
y_{t}=\Phi_{1} y_{t-1}+\Phi_{2} y_{t-2}+\ldots+\Phi_{p} y_{t-p}+\varepsilon_{t}
$$

onde $\Phi_{i}$ é uma matriz de coeficientes de ordem $k X k$, e $\varepsilon_{t}$ é um vetor coluna de erros contendo um processo ruído branco (white noise) com as seguintes propriedades: $E\left(\varepsilon_{t}\right)=0$ para todo $t$ e $E\left(\varepsilon_{t} \varepsilon_{s}^{\prime}\right)=\left\{\begin{array}{l}\sum s=t \\ 0 s \neq t\end{array}\right.$

${ }^{21}$ Por modelo estrutural entende-se que "relacionamentos especificos entre variáveis têm como base (formal ou informalmente) uma teoria econômica". (PINDYCK e RUBINFELD, 1998, p. 399). 
onde $\sum$ é a matriz de covariância a qual pressupõe-se ser definida como positiva definida, enquanto que os termos $\varepsilon$ são serialmente não correlacionados, mas podem ser contemporaneamente correlacionados.

Segundo MILLS (1990, p.67) um "teorema fundamental da análise de séries temporais, conhecido como decomposição de Wold (WOLD, 1938), estabelece que todo processo estocástico $\left(x_{t}-\mu\right)$ fracamente estacionário, puramente não determinístico pode ser escrito como uma combinação linear (ou filtro linear) de um seqüência de variáveis aleatórias não correlacionadas. Por puramente não determinístico significa que qualquer componente lineamente determinístico seja subtraído de $x_{t}$. De modo que um componente possa ser perfeitamente previsto a partir de seus próprios valores passados, sendo que os exemplos mais comuns são a (constante) média, implicando em escrever o processo como $\left(x_{t}-\mu\right)$, seqüências periódicas, e polinomial ou seqüências em $t$. Portanto, pelo que está estabelecido pelo teorema de Wold, todo processo estacionário não determinístico (centrado em relação à sua média $\left(x_{t}-\mu\right)$ ) possuí uma representação de médias móveis. Em termos matemáticos tem-se:

$$
y_{t}=\varepsilon_{t}+\Theta_{1} \varepsilon_{t-1}+\Theta_{2} \varepsilon_{t-2}+\ldots
$$

onde $\varepsilon_{t}$ é um ruído branco, isto é possuí todas as propriedades enumeradas para a equação 28.

A expressão 29 pode ser escrita de forma mais compacta, ou seja:

$$
y_{t}=\Theta(B) \varepsilon_{t}
$$

sendo que, $B$ é o operador de atraso (ou defasagem), tal que $B X_{t}=X_{t-1}$ que generalizando implica que $B^{k} X_{t}=X_{t-k}$. Expandindo o primeiro termo do lado direito de 30 , tem-se:

$$
\Theta(B)=\Theta_{0}+\Theta_{1} B+\Theta_{2} B^{2}+\ldots
$$

onde $\Theta_{i}$ são matrizes de ordem $k X k$ para todo $i$ e $\Theta_{0}=I$, sendo que $l$ é uma matriz identidade.

Conforme observado por BRANDÃO (1985) o termo $\varepsilon_{t}$ em 30 é denominado de erro de previsão para um determinado período específico, o qual é definido como:

$$
\varepsilon_{t}=y_{t}-E\left(\varepsilon_{t} \mid y_{t-1}, y_{t-2}, \ldots\right)
$$


logo, o erro de previsão, também chamado de inovação do processo $y_{t}$ corresponde a diferença entre o valor dessa variável no periodo $t$ relativamente ao seu próprio valor esperado em $t$ dado seus valores para os períodos passados, isto é $t-1, t-2, \ldots$.

Quando as raízes do polinômio $\Theta(B)$ caírem fora do círculo unitário, ou seja forem maiores que a unidade em módulo, o processo representado por $y_{t}$ poderá ser escrito na forma auto-regressiva, a qual assume o seguinte formato:

$$
\Phi(B) y_{t}=\varepsilon_{t}
$$

onde $\Phi(B)$ é um polinômio com operador de defasagem com coeficiente $\Phi_{i}$ e $\Phi_{0}=I$. Portanto, quando um modelo de médias móveis pode ser escrito na forma auto-regressiva, isso implica que satisfaz a seguinte relação: $\Phi(B) \Theta^{-1}(B)=I$, onde $l$ é a matriz identidade.

\subsection{4 - Teste da razão de verossimilhança}

O polinômio $\Phi(B)$ na equação 33 contém um número infinito de parâmetros, isto é de defasagens, sendo assim, toma-se necessário determinar o número de defasagens ( $p$ ) considerado ideal que possa captar da melhor forma possivel a relação dinâmica entre as variáveis. Segundo PONGIBOVE (1996, p. 58) no modelo VAR "toda variável pode experimentar choques autônomos, por exemplo, antecipando mudanças em outras variáveis e adicionalmente, qualquer variável pode ser afetada por efeitos retardados de qualquer outra variável do modelo, por exemplo, pelos processos de formação de expectativas ou por rigidez nas respostas. A estrutura de defasagens do modelo permite estabelecer estes efeitos retardados". Portanto, no caso dos modelos VAR a questão da determinação do número de defasagens assume grande relevância, dado que a introdução de um número reduzido de defasagens leva a uma especificação incorreta do modelo, enquanto que a inclusão de defasagens em excesso conduz a significativa perda dos graus de liberdade. Por exemplo, num modelo com $m$ variáveis endógenas, tem-se $m$ interceptos e $\mathrm{km}^{2}$ coeficientes variáveis, sendo que o total de parâmetros a serem estimados é igual a $m+k m^{2}$.

Para solucionar o problema relativo à determinação do número de defasagens (ordem dos parâmetros auto-regressivos) a serem incluidos no modelo, o método a ser utilizado consiste em fazer um teste de razão de verossimilhança, onde são comparados um conjunto de equaçőes irrestrito (com maior número de defasagens) contra um sistema de equaçőes restrito, isto é com menor número de defasagens comparativamente ao modelo irrestrito. De acordo com ENDERS (1995) o teste de razão de verossimilhança assume o seguinte aspecto: 


$$
(T-c)\left(\log \left|\Sigma_{r}\right|-\log \left|\Sigma_{u}\right|\right)
$$

onde: $T$ é o número de observações utilizadas; $c$ é o número de parâmetros estimados em cada equação do modelo irrestrito; $\Sigma_{u}$ e $\Sigma_{r}$ correspondem às matrizes de variância e covariância dos modelos irrestrito e restrito respectivamente e os termos $\log \left|\Sigma_{u}\right|$ e $\log \left|\Sigma_{r}\right|$ representam o logaritmo natural dos determinantes das estimativas das matrizes de variância e covariância para os sistemas irrestrito e restrito respectivamente. O teste de razão de verossimilhança em 34 possui distribuição $\chi^{2}$ com graus de liberdade equivalentes ao número de restrições do sistema. O critério para a escolha do número de defasagens implica que ao se rejeitar a hipótese de que as defasagens de ordem $m+1, m+2 \ldots M$ são capazes de melhorar 0 poder explicativo da regressão, então pode-se concluir que o número de defasagens adequado corresponde a $m$.

Ainda segundo ENDERS (1995) o teste de razão de verossimilhança baseia-se na teoria assintótica, fato esse que o toma pouco útil para ser aplicado quando se tem pequenas amostras. A altemativa apresentada em ENDERS (1995) para a determinação do número de defasagens diante de uma situação com pequenas amostras, corresponde à generalização dos critérios univariados de Akaike (AIC)

$$
A I C=T \log |\Sigma|+2 N
$$

e de Schwarz (SBC)

$$
S B C=T \log |\Sigma|+N \log (T)
$$

onde: $|\Sigma|=$ determinante da matriz de variância e covariância dos resíduos e $N=$ número total de parâmetros estimados em todas equações do sistema. No caso de um modelo VAR com $p$ defasagens contendo $n$ variáveis mais intercepto o número total de parâmetros estimados em todas equações corresponde a: $N=n^{2} p+n$, sendo que cada uma das $n$ equações contém $n p$ defasagens mais intercepto. O critério para escolha do número de defasagens, seja pelo critério de Akaike, seja pelo de Schwarz reside em escolher o valor que minimiza cada um desses dois critérios.

\subsection{5 - Função de resposta de impulso}

De acordo com ENDERS (1995) assim como um modelo univariado auto-regressivo tem uma representação de médias móveis, o mesmo acontece com o vetor auto-regressivo, 0 qual pode ser escrito em termos de um vetor de médias móveis (VMA). "A representação VMA 
é um aspecto essencial da metodologia proposta por SIMS (1980), dado que permite acompanhar, através de uma trilha temporal, os efeitos que os vários choques tem sobre as variáveis contidas no sistema VAR" (ENDERS, 1995, p. 305).

Tendo como base a equação 30 , tem-se que:

$$
\Theta_{k}=\left[\begin{array}{ccc}
a^{k}{ }_{11} & \ldots & a^{k}{ }_{1 n} \\
\vdots & & \vdots \\
a^{k}{ }_{n 1} & \ldots & a^{k}{ }_{n n}
\end{array}\right] ; \quad e_{t}=\left[\begin{array}{c}
e_{1 t} \\
e_{2 t} \\
\vdots \\
e_{n t}
\end{array}\right] \quad \text { e } \quad y_{t}=\left[\begin{array}{c}
y_{1 t} \\
y_{2 t} \\
\vdots \\
y_{n t}
\end{array}\right]
$$

onde a $i$ '-ésima coluna de $\Theta_{k}$ "mede o efeito de um choque unitário no i'-ésimo componente do vetor de inovações no período $(t-k)$ sobre $y_{i}$ no período $t$ (BRANDÃO, 1985, p. 39). Portanto, conhecendo-se a equação 30 , pode-se descrever o comportamento dinâmico das variáveis em resposta a choques, também denominados de inovaçőes, em qualquer dos parâmetros que compőem o sistema.

Dado que ao utilizar os modelos VAR um dos principais objetivos é examinar os efeitos de choques individuais sobre a dinâmica do sistema, torna-se necessário efetuar alguns ajustes em relação a matriz de variância-covariância dos resíduos $(\Sigma)$, pois geralmente essa não é uma matriz diagonal, 0 que implica que os choques $e_{1 t}, e_{2 t}, \ldots, e_{n t}$, podem ocorrer simultaneamente com probabilidade diferente de zero, ou seja podem estar contemporaneamente correlacionados, sendo assim, torna-se necessário diagonalizar a matriz de variância-covariância para evitar que choques sobre determinada variável contamine todo o sistema, impedindo dessa maneira que se possa analisar somente o efeito individual desse choque sobre o comportamento da variável de interesse.

O procedimento mais utilizado para diagonalizar essa matriz consiste em efetuar a decomposição de Cholesky ${ }^{22}$. Admitindo que a matriz de variância-covariância é não singular, então, existe uma matriz $C$, triangular inferior e não singular, tal que $\Sigma=C C^{\prime}$ onde $C^{\prime}$ é a matriz transposta de $C$. Portanto tem-se a seguinte relação: $C^{-1} \Sigma\left(C^{\prime}\right)^{-1}=I$. A seguir, define-se que: $n_{t}=C^{-1} e_{t}$, e obtém-se a seguinte expressão: $E\left[n_{t} n_{t}\right]=l$.

Continuando o processo de diagonalização da matriz de variância-covariância, multiplica-se os dois lados da equação 33 por $D=\left(C^{-1}\right)$, o que resulta na seguinte equação:

$$
H(B) y_{t}=n_{t}
$$

\footnotetext{
22 Para demonstrar o processo de diagonalizaçảo da matriz de variância-covariância será utilizado como referência o texto de BRANDÃO (1985).
} 
sendo $H(B)=D \Phi(B)$. BRANDÃO (1985) realça o fato de que a equação 37 pode ser escrita através da sua correspondente representação de médias móveis, ou seja:

$$
y_{t}=G(B) n_{t}
$$

sendo $G(B)=\Phi(B) C$ e $n_{t}$ é um ruido branco (white noise). Portanto, tendo como base a equação 38 "é possivel medir o efeito, período a periodo, de um choque unitário de um desvio padrão, em só uma das variáveis do modelo, sobre todas as variáveis do mesmo. Assim, por exemplo, os coeficientes da i-ésima coluna de $G_{j}$ mostram o efeito de um choque de um desvio padrão na variável $i$, em $t-j$, sobre todo o vetor $y$, no período $t$ " (PONGIBOVE, 1996, p. 60). No entanto, é importante frisar que apesar da ortogonalização dos erros pela decomposição de Cholesky resultar em uma matriz de variância-covariância de inovações diagonal, isto é não apresentar correlação serial entre os termos de erro, ainda assim, a decomposição de Cholesky é um método arbitrário pois atribui efeitos comuns, ou seja mudando a ordem das equações pode levar a mudanças na função de resposta de impulso, fato esse que exige muito cuidado na interpretação das funções de resposta de impulso. Em outras palavras, de acordo com BLISKA (1990, p. 46) uma "das principais vantagens das inovações ortogonalizadas sobre as demais é a de serem não correlacionadas. No entanto, há uma decomposiçâo diferente para cada ordenação das variáveis, sendo que a direção do efeito captado decorre da seleção arbitrária da ordem das variáveis no vetor analisado. Logo, quanto menor a covariância contemporânea (menor correlação entre os residuos) menor é a importância da ordem selecionada”. Portanto, mesmo não havendo sentido de causalidade entre duas variáveis, ainda assim pode haver efeito de um choque em uma delas sobre a outra em função da presença da covariância entre seus respectivos erros.

\subsection{6 - Decomposição da variância dos erros de previsão}

Outra maneira para caracterizar o inter-relacionamento dinâmico entre as variáveis do modelo é dado pela decomposição da variância dos erros de previsão para $k$ períodos a frente, distribuindo esses erros de previsão para cada uma das variáveis em componentes que podem ser atribuídos a cada uma das variáveis de saída do sistema.

Tendo-se como base a expressão 32, representada por $\varepsilon_{t}=y_{t}-E\left(\varepsilon_{t} \mid y_{t-1}, y_{t-2}, \ldots\right)$ e lembrando que $E\left[e_{t} e_{t}^{\prime}\right]=\Sigma=C C$ tem-se que a diagonal principal é uma soma de quadrados. No caso de um modelo com duas variáveis resulta que: 


$$
C=\left[\begin{array}{ll}
c_{11} & 0 \\
c_{21} & c_{22}
\end{array}\right]
$$

Logo:

$$
E\left[e_{t} e_{t}^{\prime}\right]=\left[\begin{array}{cc}
c_{11}^{2} & c_{11} c_{21} \\
c_{11} c_{21} & c_{22}^{2}+c_{21}^{2}
\end{array}\right]
$$

Implicando que $100 \%$ da variância do erro de previsão de um período relativa a variável $y_{1 t}$ refere-se às suas próprias inovações no período $t$ e somente uma percentagem da variância do erro de previsão da variável $y_{2 y}$ deve-se a inovação em $y_{11}$, sendo que essa parcela, ou reflexo da inovação de $y_{1 t}$ sobre $y_{2 y}$ é calculada pela seguinte fórmula:

$$
\left(\frac{c_{21}^{2}}{c^{2}{ }_{22}}+c_{21}^{2}\right) \cdot 100 \%
$$

Generalizando, tem-se que a variância do erro de previsão para $k$-periodos pode ser escrita como:

$$
y_{t+k}=G_{0} n_{t+k}+G_{1} n_{t+k-1}+\ldots+G_{k-1} n_{t+1}+G_{k} n_{t}+G_{k+1} n_{t-1}+\ldots
$$

Logo, a variância do erro de previsão para a variável $y_{t}$ para $k$-períodos a frente é dada pela diferença entre o valor efetivo dessa variável no período $t+k$ e a sua respectiva esperança matemática no mesmo período, dado seus respectivos valores nos períodos anteriores $t, t-1$, ....Portanto, tem-se que:

$$
y_{t+k}-E\left[y_{t+k} \mid y_{t}, y_{t-1}, \ldots\right]=\sum_{j=0}^{k-1} G_{j} n_{t+k-j}
$$

enquanto que a matriz de variância-covariância de $k$-períodos para frente é dada por:

$$
\sum_{j=0}^{k-1} \Phi_{j} \Sigma \Phi_{{ }_{j}}=\sum_{j=0}^{k-1}\left(\Phi_{j} C\right)\left(\Phi_{j} C\right) .
$$

Em relação a expressão 39 , verifica-se que a diagonal principal de cada matriz é uma soma de quadrados, fato esse que permite identificar a respectiva variância de cada choque unitário, também denominado de inovações, a parcela correspondente ao próprio choque e as demais parcelas cuja origem é proveniente dos demais choques.

PONGIBOVE (1996, p. 61) citando AGUIAR (1994) e PHILLIPS e BEWLEY (1991), ressalta que a "estrutura da matriz $C$ depende da ordem em que as variáveis sejam consideradas pelo sistema na medida em que choques numa variável só afetam contemporaneamente aquelas variáveis que seguem-Ihe na ordem não sendo afetada por elas”. 


\subsection{7 - Modelo VAR identificável}

Segundo BARROS (1991, p. 521), foram desenvolvidos "vários procedimentos para identificar os modelos VAR (BLANCHARD e WATSON (1984); BERNANKE (1986); SIMS (1986); MASON (1985); FACKLER (1988). A escolha do procedimento mais apropriado dependerá principalmente das hipóteses específicas assumidas sobre o modelo estrutural a ser estimado".

Uma das formas para realizar o procedimento de identificação dos modelos VAR foi desenvolvido por ORDEN e FACKLER (1989). A justificativa para seguir o caminho proposto por esses dois autores decorre do fato de que o processo de identificação dos modelos VAR deve concentrar-se somente em impor restrições sobre as matrizes de interações contemporâneas, uma vez que a própria teoria econômica sozinha é capaz de fornecer elementos para captar essas relações, além do que não é necessária a imposição de restrições sobre as realizações passadas (defasadas) das variáveis, as quais já são de conhecimento dos agentes econômicos, e consequentemente, já estão incorporadas na formação das expectativas desses agentes no que se refere aos respectivos valores presentes das variáveis analisadas.

O ponto de partida é a representação geral do modelo VAR, o qual assume os seguinte aspecto:

$$
\Phi_{0} y_{t}=\sum_{s=1}^{n} \Phi_{s} y_{t-s}+\mathrm{B}_{0} \varepsilon_{t}
$$

onde: $y_{t}$ corresponde ao vetor de variáveis consideradas no modelo; $\Phi$ „é a matriz de coeficientes de relações contemporâneas de ordem $n \times n$, na qual serão impostas as restrições, objetivando dessa maneira obter a forma reduzida do modelo; $\Phi_{s}$ são matrizes de ordem $n \times n$ contendo coeficientes de relações defasadas de ordem $s$ entre as variáveis; $\varepsilon_{t}$ é um vetor de choques ortogonais com média zero e não correlacionados e $\mathrm{B}_{0}=I$.

Para obter-se a forma reduzida (41), multiplicam-se os dois lados de 40 pela inversa da matriz de coeficientes de interações contemporâneas:

$$
y_{t}=\sum_{s=1}^{n} \Phi_{0}^{-1} \Phi_{s} y_{t-s}+\Phi_{0}^{-1} \mathrm{~B}_{0} \varepsilon_{t}
$$

A estimação da forma reduzida é realizada por mínimos quadrados ordinários, obtendose assim os seus correspondentes resíduos:

$$
u_{t}=\Phi_{0}^{-1} \varepsilon_{t}
$$

cuja matriz de covariância $\left(\operatorname{Cov}\left[u_{t}\right]=\sum\right.$ ) será utilizada para estimar $\Phi_{0}^{-1}$. 
Dado que $\sum$ tem $k(k+1) / 2$ parâmetros livres, este corresponde ao número de coeficientes que podem ser estimados em $\Phi_{0}$. Portanto, o número mínimo de restrições que necessitam ser impostas para se obter um modelo perfeitamente identificado é igual a $k(k+1)$ /2, logo um modelo contendo um número maior, ou menor que este de restrições será super ou subidentificado respectivamente.

O segundo passo na estimação do modelo VAR consiste na maximização da função logarítmica de verossimilhança de $\varepsilon_{t}$ em 42 , o qual é distribuido multinomalmente, enquanto que $D$ é a diagonal da matriz de covariância dos erros do modelo $\left(D=\operatorname{Cov}\left[\varepsilon_{t}\right]\right)$. Matematicamente, essa função logaritmica de verossimilhança tem o seguinte aspecto:

$$
\ln L=-T\left(\frac{k}{2}\right) \ln (2 \pi)+T\left[\left|\ln \Phi_{0}\right|-\left(\frac{1}{2}\right) \ln |D|\right]-\left(\frac{T}{2}\right) \operatorname{tr}\left(D \Phi_{0} \Sigma \Phi_{0}^{\prime}\right)
$$

Para obter-se a maximização dessa função logaritmica de verossimilhança, aplica-se o método de Newton.

Após estimar as matrizes $\Phi$ e $D$, pode-se proceder a análise da função de resposta de impulso e da decomposição da variância dos erros de previsão para cada variável. De acordo com BARROS (1991) o modelo de vetor auto-regressivo pode ser resolvido de forma que:

$$
y_{t}=\sum_{s=0}^{\infty} C_{s} u_{t-s}
$$

e utilizando a expressão 41, tem-se que:

$$
y_{t}=\sum_{s=0}^{\infty} C_{s} \Phi_{0}^{-1} D^{\frac{1}{2}} \varepsilon_{t}
$$

onde $C_{s}$ são as matrizes que medem os impactos do vetor de erros. Portanto a equação 44 "pode ser utilizada para obter os efeitos de choques unitários em $\varepsilon_{t}$, os quais multiplicados por $D$ são equivalentes a choques nas disturbâncias com um desvio padrão" (BARROS, 1991, p. 523).

\section{3 - Co-integração}

Basicamente, o conceito de co-integração procura identificar se duas ou mais variáveis integradas de mesma ordem possuem uma relação de equilíbrio no longo prazo. Especificamente no caso de duas variáveis, se $x_{t}$ e $y_{t}$ são integradas de ordem 1 (I(1)), então, é verdadeiro que a sua combinação linear dada por: 


$$
z_{t}=y_{t}-\alpha x_{t}
$$

também será I (1). No entanto, naqueles casos em que ambas variáveis forem $I(1)$ e $z$ for $I(0)$ isto quer dizer que $y_{t}$ e $\alpha x$, devem ter componentes de longo prazo que praticamente se cancelam para produzir $z_{\text {i }}$. Nessas circunstâncias diz-se que $x_{t}$ e $y_{t}$ são co-integradas e $\alpha$ é 0 parâmetro de co-integração, ou então, é denominado de vetor de co-integração, sendo representado como $(1,-\alpha)$. $O$ relacionamento entre co-integração e o conceito de equilíbrio de longo prazo, parte do princípio de que esse equilíbrio é representado como:

$$
y_{t}=\alpha x_{t} \text { ou } y_{t}-\alpha x_{t}=0
$$

onde $z$, na expressão (45) é o modelo de erro de equilibrio, ou seja, mede quanto o sistema representado por $(x, y$,$) se encontra distante do ponto de equilíbrio. Se duas variáveis são co-$ integradas, isso significa que elas convergem para uma condição de equilíbrio no longo prazo, no entanto, no curto prazo, pode ser que essas duas variáveis não consigam atingir uma situação de equilíbrio em função de algum fator que impeça essa convergência. Entretanto, a presença do modelo de correção de erro tende a fazer com que essas duas variáveis possam convergir para uma situação de equilibrio no longo prazo. Outro aspecto relevante em relação a interface entre co-integração e modelo de correção de erro, segundo ENGLE e GRANGER (1991, p. 10) é que "co-integração implica que o sistema segue uma representação de correção de erro e reciprocamente um sistema de correção de erro têm variáveis co-integradas".

ENGLE e GRANGER (1991, p. 84) definiram a co-integração de um processo da seguinte forma: "Os componentes de um vetor $x$, é dito ser co-integrado de ordem $d, b$, denotado por $x_{t} \sim C l(d, b)$, se (i) todos os componentes de $x_{t}$ são l (d); (ii) existe um vetor $\alpha$ ( $\neq$ o) tal que $z_{t}=\alpha^{\prime} x_{t} \sim l(d, b), b>0$. O vetor $\alpha$ é chamado de vetor de co-integraçăon. Em outras palavras, se ao ajustar um modelo de regressão entre duas variáveis e ambas forem integradas de ordem 1, isto quer dizer que essas variáveis apresentam uma combinação linear $(d=b=1)$ e como resultado os resíduos dessa regressão são $/(0)$, isto é, são estacionários e conseqüentemente, essas duas variáveis são co-integradas.

Portanto, partindo-se das definições dadas acima, testar a presença de co-integração pelo método desenvolvido por ENGLE e GRANGER (1991) significa verificar se as variáveis $y_{\text {t }}$ e $x_{t}$ derivam de um processo gerador estacionário $(I(0))$ ou não estacionário $(I(1))$. Portanto, 0 procedimento inicial reside em verificar se tanto $y_{t}$ quanto $x_{t}$ contém ou não raiz unitária. Se ambas forem caracterizadas por um processo I (1), então para testar se essas variáveis são cointegradas ou não, deve-se estimar a seguinte equação de co-integração:

$$
y_{t}=\alpha+\beta x_{t}+u_{t} \text { ou } y_{t}-\alpha-\beta x_{t}=u_{t}
$$

e testar posteriormente se o resíduo estimado (u $)$ é estacionário $(I(0)$ ) ou não, através da aplicação de teste de raiz unitária. Os valores críticos para os testes de raiz unitária sobre os 
resíduos da equação de co-integração podem ser encontrados em ENGLE e GRANGER (1991), PHILLIPS e OULIARIS (1990) e MACKINNON (1991).

Assim como no caso dos testes de raiz unitária, os testes de co-integração admitem as hipóteses de que o modelo não tenha constante nem tendência; ou tenha somente constante; ou tenha constante e tendência. Outra analogia em relação aos testes de raiz unitária, é que os testes de co-integração podem ser ampliados para verificar se há presença de correlação serial nos resíduos. Nesse caso, incorpora-se defasagens contendo a variável dependente diferenciada para se obter um ruido white noise. Enquanto que esse procedimento, para a aplicação de testes de raiz unitária denomina-se Dickey-Fuller Aumentado (ADF), no caso do teste de co-integração passa a ser denominado de Engle-Granger Aumentado (AEG). Outra semelhança com testes de raiz unitária, diz respeito aos testes não paramétricos propostos por PHILLIPS (1987). Segundo MACKINNON (1991, p. 270-271), um "procedimento diferente para obter os testes de raiz unitária que é assintóticamente válido na presença de correlação serial e/ou heterocedasticidade de forma desconhecida foi sugerida por PHILLIPS (1987) e estendida para o caso de co-integração por PHILLIPS e OULIARIS (1990). A distribuição assintótica a qual Phillips e Ouliaris chamam de estatistica $Z$, são idênticas àquelas correspondentes aos testes DF, ADF, EG e AEG. Phillips e Ouliaris tabularam valores críticos para duas fomas de suas estatísticas (correspondendo as versỏes sem tendência e com tendência das estatísticas DF e EG) para vários valores de $\mathcal{N}^{*}$. No entanto, segundo MACKINNON (1991), os valores críticos elaborados por Phillips e Ouliaris sofrem de considerável erro experimental, ou seja, dependendo do tamanho da amostra adotado, seus valores são viesados, isto é não convergem para as estimativas dos verdadeiros valores críticos assintóticos.

Portanto, dado que o teste de co-integração envolve a realização de teste de raiz unitária do tipo Dickey-Fuller Aumentado (ADF), sobre os resíduos da equação de cointegração, esse teste deve ser efetuado sobre a seguinte equação de resíduos:

$$
\nabla \hat{u}_{t}=\rho \hat{u}_{t-1}+\sum_{i=1}^{p} \gamma_{i} \nabla \hat{u}_{t-i}+e_{t}
$$

Nesse caso, o termo $\nabla \hat{u}_{t}$ representa a primeira diferença da variável $\hat{u}_{t}$ enquanto que, $\nabla \hat{\boldsymbol{u}}_{t-i}$ é a primeira diferença defasada da variável $\hat{\boldsymbol{u}}_{t}$, sendo que, 0 número total de defasagens corresponde a $i$ periodos. Quando o termo $\gamma_{i}$ é igual a zero para todos os is , ao invés do teste Dickey-Fuller Aumentado (ADF), tem-se o teste Dickey-Fuller (DF).

O procedimento de verificação de presença ou não de raiz unitária, tendo como base os resíduos da equação de co-integração testa a hipótese nula de que a série de resíduo têm raiz unitária $(\rho=0)$ contra a hipótese alternativa de que os resíduos são estacionários $(\rho \neq 0)$, ou 
seja, testa a hipótese nula de que não há co-integração versus a hipótese altemativa de que existe co-integração entre as variáveis $y_{t}$ e $x_{t}$.

Conforme BACCHI (1994, p. 96), citando LÜTKEPOHL (1991), se "as variáveis são cointegradas a relação entre elas deve ser especificada de forma a incluir a variável que mede 0 desvio em relação ao equilíbrio de longo prazo (defasada de um período), sem o que a equação não é corretamente especificada". Continuando, BACCHI (1994, p. 96) afirma que o "modelo de correção de erro permite que componentes de longo prazo obedeçam restrições de equilíbrio enquanto que componentes de curto prazo tenham uma especificação dinâmica flexivel".

Detectada a relação de co-integração entre as variáveis, o próximo passo consiste na inclusão do modelo de correção de erro. ENGLE e GRANGER (1991) mostraram que se $y_{t}$ e $x_{t}$ são ambas integradas de ordem um (I (1)) e são também co-integradas, então, existe uma representação de modelo de correção de erro, onde $z_{t}=y_{t}-\alpha x_{t}$, da seguinte forma:

$$
\nabla y_{t}=\omega_{0}+\omega_{1} \nabla x_{t}-\gamma\left(y_{t-1}-x_{t-1}\right)+\varepsilon_{t}
$$

A metodologia para a estimação de um sistema co-integrado, conforme descrito em ENGLE e GRANGER (1991) envolve duas etapas. Na primeira etapa, estima-se a equação (47), obtendo-se dessa forma os seus resíduos, e testa-se a presença ou não de co-integração entre as variáveis. Caso a hipótese de que as variáveis não são co-integradas seja rejeitada, procede-se a segunda etapa, a qual consiste na estimação do modelo de correção de erro.

O modelo de correção de erro toma-se importante pelo fato de permitir a ligação entre aspectos relacionados com a dinâmica de curto prazo com os de longo prazo. Os "mecanismos de correção de erro pretendem fomecer um caminho para combinar as vantagens de se modelar tanto em nível quanto nas diferenças. Em um modelo de correção de erro tanto a dinâmica do processo de ajustamento de curto prazo (variações), quanto de longo prazo (niveis) são modelados simultaneamente" (BANERJEE, et al., 1993, p. 139). Utilizando como exemplo a equação (47), se duas séries em nível, $y$, $e x$, são integradas de ordem 1 (I(1)) e se as suas respectivas diferenças, representadas por $\nabla y_{t}$ e $\nabla x_{t}$, são estacionárias, isto é I(0), então, a equação (49) mostra a dinâmica de curto prazo entre essas duas séries, enquanto que, o termo entre parênteses capta a relação de longo prazo entre elas.

Segundo BACCHI (1996, p.16-17), a "utilização da metodologia uni-equacional proposta por ENGLE e GRANGER não é indicada para testar co-integração quando se considera a possibilidade de existir mais de um vetor de co-integração ou quando existe endogeneidade do regressor (relação causal no sentido da variável dependente para a(s) explicativa(s)n . Sendo assim, quando da presença de mais de um vetor de co-integração e/ou quando da existência de feedback entre a variável dependente e a(s) variável(is) independente(s), sugere-se a aplicação do método desenvolvido por JOHANSEN e JUSELIUS (1990). 
O procedimento de Johansen têm como ponto de partida o modelo auto-regressivo vetorial (VAR). De acordo com HARRIS (1995, p.77), definindo "um vetor $z$ t com $n$ variáveis endógenas potenciais, é possível especificar o seguinte processo gerador e modelar $z$, como um vetor auto-regressivo (VAR) sem restrição envolvendo $k$ defasagens de $z_{i}{ }^{n}$. Logo o modelo VAR pode ser representado como:

$$
z_{t}=A_{1} z_{t-1}+\ldots+A_{k} z_{t-k}+\Phi D_{t}+u_{t}
$$

sendo que, $u_{\imath} \sim \mathbb{N}(0,2), z_{i}$ é um vetor $(n \times 1)$ e cada elemento $A_{i}$ é uma matriz de parâmetros de ordem $(n \times n)$ e $D_{l}$ representa termos determinísticos, tais como, constante, tendência linear, dummies sazonais, dummies de intervenção, ou qualquer outro tipo de regressor que são considerados fixos e não estocásticos. Ainda segundo HARRIS (1995, p.77) este "tipo de modelo VAR foi defendido principalmente por SIMS (1980) como uma forma de estimar relacionamentos dinâmicos entre variáveis endógenas conjuntas sem a necessidade de impor a priori fortes restrições (tais como relacionamentos estruturais particulares e/ou a exogeneidade de algumas das variáveis)". Assim como acontece nos testes de raiz unitária do tipo DickeyFuller Aumentado (ADF), no caso da metodologia de Johansen também torna-se necessário determinar $a(s)$ ordem(ns) da(s) defasagem(ns) de $z_{i}$, pois esse procedimento têm como base a hipótese de que ao se introduzir um número suficiente de defasagens é possível se obter uma estrutura de resíduos bem comportados, isto é, estacionários. Para a tomada de decisão em relação ao número de defasagens que devem ser aplicadas para se obter uma estrutura de ruido white noise, utiliza-se os critérios AIC (AKAIKE Information Criterion) ou então o SBC (SCHWARZ Bayesian Criterion).

A equação (50) pode ser modificada em temos de um modelo de vetor de correção de erro (VECM) cujo formato é o seguinte:

$$
\nabla z_{t}=\Gamma_{1} \nabla z_{t-1}+\ldots+\Gamma_{k-1} \nabla z_{t-k+1}+\Pi z_{t-k}+\Phi D_{t}+u_{t}
$$

onde, $\Gamma_{i}=-\left(I-A_{1}-\ldots-A_{i}\right),(i=1, \ldots, k-1)$, e $\Pi=-\left(I-A_{1}-\ldots-A_{k}\right)$. Segundo HARRIS (1995), a principal vantagem de se escrever o sistema em termos do modelo de correção de erro está relacionado ao fato de que nesse formato são incorporadas informações tanto de curto quanto de longo prazo via ajustes nas variações em $z_{\mathfrak{l}}$, as quais são dadas pelas estimativas dos parâmetros $\Gamma_{i}$ e $\Pi$. Visto com maior nível de detalhes, o termo $\Pi$ é representado como:

$$
\Pi=\alpha \beta^{\prime}
$$

sendo que, $\alpha$ representa a velocidade de ajustamento dos parâmetros da matriz no curto prazo, enquanto que, $\beta$ é uma matriz de coeficientes de co-integração de longo prazo, onde o termo $\beta^{\prime} z_{t \cdot k} 0$ qual está embutido na equação (52), representa as $n-1$ relações de co-integração 
no modelo multivariado, assegurando dessa forma que $z$, converge para uma solução de equilíbrio no longo prazo.

Resumidamente, a metodologia de co-integração de Johansen apresenta três situações distintas. Conforme descrito em HARRIS (1995, p.79), se "o posto de $\Pi$ é completo (isto é, há $r$ $=n$ colunas linearmente independentes) então as variáveis em $z$ são $I(0)$, enquanto que, se 0 posto de $\Pi$ é zero então não há relacionamento de co-integração. Nenhum desses dois casos são particularmente interessantes. Mais importante, é quando $\Pi$ tem posto reduzido; isto é, há $r$ $\leq(n-1)$ vetores de co-integração presentes". Portanto, quando $r=n$, isto significa que $z$, é estacionário, e nesse caso o ajuste do modelo deve ser efetuado com as variáveis em nível. Quando $r=0$, implica que $\nabla z_{t}$ é estacionário e conseqüentemente o modelo deve ser ajustado com as variáveis diferenciadas. Finalmente, quando $0<r<n$ isto eqüivale a testar quais colunas de $\alpha$ são iguais a zero, ou seja, dado que $\Pi$ pode ser formulado como $\Pi=\alpha \beta^{\prime}$ onde $\alpha$ e $\beta$ correspondem a matrizes de dimensão $(n X r)$, isto implica que $\beta^{\prime} z_{t}$ é estacionário, o que leva a conclusão de que existem $r$ vetores de co-integração, que são exatamente as $r$ colunas de $\beta$.

Dois são os testes propostos por JOHANSEN e JUSELIUS (1990), para testar a hipótese nula de que existem pelo menos $r$ vetores de co-integração. A hipótese nula é representada matematicamente como:

$$
H_{0}: \lambda_{i}=0 \quad i=r+1, \ldots, n
$$

ou seja, somente os primeiros $r$ autovalores $(\lambda)$ são diferentes de zero. Essa restrição pode ser imposta para diferentes valores de $r$. O próximo passo, consiste na comparação do valor do logarítmo da função de verossimilhança do modelo com restrição relativamente ao logarítmo da função de verossimilhança do modelo sem restrição. Esse teste é denominado de estatística traço e é representada em termos algébricos como:

$$
\lambda_{\text {trace }}=-2 \log (Q)=-T \sum_{i=r+1}^{n} \log \left(1-\hat{\lambda}_{i}\right) \quad r=0,1,2, \ldots, n-2, n-1 .
$$

onde $Q=$ (funçăo de verossimilhança restrita maximizada $\div$ funçăo de verossimithança sem restriçăo maximizada). Os valores críticos dessa estatística encontram-se em JOHANSEN e JUSELIUS (1990). Enquanto que, os valores tabelados para modelos contendo intercepto encontram-se em OSTERWALD-LENUM (1992).

O segundo teste de significância é a estatística $\lambda_{\text {max }}$, também denominada de máximo autovalor, a qual é representada como:

$$
\lambda_{M S X}=-T \log \left(1-\hat{\lambda}_{r+1}\right) \quad r=0,1,2, \ldots, n-2, n-1
$$


onde $\hat{\lambda}_{i}$ são os valores estimados dos autovalores. Nesse caso, a hipótese nula é de que existem $r$ vetores de co-integração enquanto que, a hipótese alternativa é de que existern $r+1$ vetores de co-integração. Conforme $\mathrm{BACCHI}(1996, \mathrm{p} .18)$ o teste $\lambda$ MAX é a diferença entre as

estatísticas-traço consecutivas. "Se $\hat{\lambda}_{i}=0$ ou $\ln \left(1-\hat{\lambda}_{i}\right)=0$ a $i$ - ésima combinação linear das variáveis não é estacionária. Valores dos testes significativos indicam relação estacionária". Quando os valores calculados de $\lambda_{\text {MAX }}$ são maiores que os respectivos valores tabelados, isto quer dizer que a hipótese nula de não co-integração é rejeitada. Para se determinar o número de vetores de co-integração, esse teste deve ser realizado até o momento em que a hipótese nula passa a ser aceita.

Para finalizar este item, JOHANSEN (1995) chama a tenção para o fato de que os componentes do processo vetorial não necessariamente precisam ter a mesma ordem, ou seja, na construção do modelo pode-se utilizar variáveis com diferentes ordens de integração. " $A$ razão para isto é ao analisar modelos económicos as variáveis são escolhidas por sua importância econômica e não por suas propriedades estatísticas. Consequentemente, somos capazes, por exemplo, de analisar variáveis $I(0)$ como $I(1)$ no mesmo modelo, de forma que possibilite descrever relacionamentos de longo prazo, assim como, ajustamentos de curto prazo" (JOHANSEN, 1995, p.34).

\section{6 - ANÁLISE DE RESULTADOS}

A análise de resultados está dividida em três itens. O primeiro apresenta os resultados dos testes de raiz unitária. A identificação da ordem de integração das variáveis assume grande relevância não só pelo fato de permitir determinar se a série possuí raiz unitária ou se é estacionária, evitando assim a possibilidade de se obter um relacionamento espúrio entre as variáveis, como também por permitir verificar se as variáveis podem ser utilizadas para a realização dos testes de co-integração. O segundo item consiste na apresentação e discussão dos resultados dos testes de co-integração. Finalmente, no terceiro item são apresentados e analisados os modelos Auto-regressivos Vetoriais (VAR) e/ou modelos Vetoriais de Correção de Erro (VEC) e seus respectivos resultados. 


\section{1 - Testes de Raiz Unitária}

Neste estudo foram utilizados os testes de raiz unitária do tipo proposto por DICKEY e FULLER (1979 e 1981) também denominado teste Dickey-Fuller Aumentado (ADF), o teste desenvolvido por PHILLIPS-PERRON (1988) denominado (PP), o teste de raiz unitána com quebra estrutural elaborado por PERRON (1989 e 1994) e FRANSES e HALDRUP (1993). A justificativa para a utilização de mais de um tipo de teste de raiz unitária está relacionado ao fato de que os resultados desses testes para deteç̧ão de raiz unitária possuem baixo poder, ou seja, são muito sensíveis, não somente no que refere-se ao número de defasagens necessárias a serem incluídas na auto-regressão para eliminar a autocorrelação dos resíduos ${ }^{23}$ nos casos dos testes ADF e PP, como também, quanto a introduçăo de paråmetros como intercepto e tendência na estimação do modelo, e em relação a possível presença de quebras estruturais nas séries temporais. A correta especificação da ordem de integração das variáveis reveste-se de suma importância para a realização dos testes de co-integração.

Naqueles casos em que houve conflito entre os resultados dos testes ADF e PP, utilizou-se como balizamento para a tomada de decisão em relação ao grau de integração de cada variável o comportamento da sua respectiva função de autocorrelação. Além dos testes de raiz unitária e da função de autocorrelação, também foram estimados modelos Auto-regressivos Integrados de Médias (ARIMA) para todas as variáveis. Dado que, as séries utilizadas neste estudo referem-se a preços, então há predominância de componentes auto-regressivos relativamente aos parâmetros de médias móveis nos modelos ARIMAs. Sendo assim, uma forma alternativa de se confirmar a presença de raiz unitária reside em analisar a magnitude da estimativa do parâmetro do termo auto-regressivo de ordem um. Como os testes de raiz unitária não são capazes de distinguir um processo com raiz unitária de outro com raiz muito próximo de um em função de seu baixo poder, então, naqueles casos em que o teste de raiz unitária sinalizou para a rejeição da hipótese nula de raiz unitária em favor da hipótese alternativa de estacionariedade, principalmente em nivel de $10,0 \%$, mas o valor da estimativa do paråmetro auto-regressivo de ordem um estava contido no intervalo entre $1 \leq \phi_{1} \leq 0,93^{24}$, e a função de autocorrelação comportava-se de maneira a apresentar queda lenta e contínua, então a série foi considerada não estacionária.

\footnotetext{
${ }^{23}$ Conforme SAS INSTITUTE $(1996$, p. 5) a versão 6.12 do SAS também permite a execução do teste de raiz Phillips-Perron Aumentado.

${ }_{24}^{4}$ De acordo com HATANAKA (1998) quando as raizes características estão contidas no intervalo entre 0,9 e 1,0 o teste Dickey-Fuller não consegue distinguir um processo diferença estacionánio (DS), ou seja que contém raiz unitária, de outro tendência estacionário (TS) para uma amostra pequena, neste caso contendo apenas cem observações. Portanto, o teste DF tem baixo poder diante de pequenas amostras.
} 
O primeiro passo residiu em verificar o comportamento de cada variável através de sua respectiva visualização gráfica. Este procedimento objetiva determinar se a variável que está sendo analisada apresenta algum problema que possa ter reflexos sobre os resultados dos testes de raiz unitária.

A análise gráfica ${ }^{25}$ mostrou que as variáveis LIFI (Figura 1), LIRMI (Figura 2), LPET (Figura 3), LIPPUS (Figura 4) e LRT (Figura 7) não apresentam problemas no que se refere à presença de quebras estruturais, sendo assim, os testes ADF e PP podem ser aplicados diretamente sobre cada uma dessas variáveis.

No entanto, para a variável LM2 (Figura 5) a visualizaçăo gráfica mostrou que essa variável apresenta problema, mais especificamente, sua trajetória foi dramaticamente alterada a partir da implementação do Plano Real em julho de 1994. Portanto, dado que essa variável possui quebra estrutural, os testes ADF e PP não podem ser utilizados diretamente, pois conforme ENDERS (1995) quando as variáveis tem quebras estruturais as estatísticas ADF são viesadas no sentido de não rejeitar a hipótese nula de raiz unitária, quando na verdade a série é estacionária. Na presença de quebras estruturais deve-se utilizar o teste de raiz unitária proposto por PERRON (1989 e 1994).

Em relação à variável LTCR (Figura 6), ela apresenta mais de uma quebra estrutural, contudo, nesse caso, dado que essas quebras caracterizam-se por ser do tipo AO, FRANSES e HALDRUP (1993) sugerem uma forma simples e prática para realizar o teste de raiz unitána $A D F$, a qual consiste na inclusão de variáveis dummies. De acordo com esses autores, esse procedimento via inclusão de variáveis de intervenção do tipo pulse não afeta a distribuição limite do teste ADF. O teste de raiz unitária ADF, segundo FRANSES e HALDRUP (1993) deve ser conduzido levando-se em consideração a seguinte regressão:

$$
\nabla z_{t}=(\alpha-1) z_{t-1}+\sum_{i=0}^{p} \sum_{j=1}^{k} \omega_{i j} D^{j}{ }_{t-i}+\sum_{i=1}^{p} \psi_{i} \nabla z_{t-1}+e_{i}
$$

onde, testa-se se o termo $\alpha-1$ é igual a zero utilizando o teste convencional ADF. Um termo de tendência também pode ser incluído na estimação da regressão. É importante observar que cada variável dummy do tipo pulse (D') incluída na estimação do modelo, assume valor igual a um no tempo $j$, e também que, a inclusão de $p$ defasagens representadas pela presença dos termos com diferenças defasadas, necessariamente corresponde a igual ordem de defasagem em relação à cada variável dummy utilizada no teste ADF. Em relação à variável LTCR, a visualização gráfica sugere a inclusão de variáveis de intervenção nas seguintes datas: março de 1990, novembro de 1990, janeiro de 1994 e fevereiro de 1995.

\footnotetext{
${ }^{25}$ As figuras 5, 6, 7 encontram-se no Anexo 1.
} 
Dado que no caso das variáveis domésticas existem dois períodos temporais distintos, um caracterizado pela elevada taxa de inflação, o qual corresponde a janeiro de 1990 até junho de 1994, e outro com maior estabilidade de preços após a implementação do Plano Real em julho de 1994 até dezembro de 1998, a análise relativa aos testes de raiz unitária foi conduzida em três etapas. Inicialmente, foram realizados os testes de raiz unitária convencionais do tipo ADF e PP para o período de janeiro de 1990 até junho de 1994. A seguir, utilizou-se os testes ADF e PP compreendendo o período de julho de 1994 até dezembro de 1998. Finalmente, na terceira fase, foram executados os testes de raiz unitária com quebra estrutural para a série completa, ou seja envolvendo conjuntamente os dois períodos.

Visando harmonizar a análise da ordem de integração das variáveis, no caso das variáveis externas também foram realizados testes de raiz unitária do tipo ADF e PP para os dois periodos citados acima conjuntamente. A diferença é que nesse caso, uma vez que essas variáveis năo apresentam quebras estruturais, ao invés de utilizar os testes de raiz unitária com quebra estrutural para o período completo, utilizou-se somente os testes do tipo ADF e PP.

A análise iniciar-se-á pelas variáveis que não apresentam quebras estruturais, sendo assim, a primeira etapa para a aplicação do teste de raiz unitária reside em determinar 0 número de defasagens a serem utilizadas na estimação de cada variável, visando dessa forma eliminar a autocorrelação dos resíduos.

Para a determinaçăo do número de defasagens (lags) de cada série utilizou-se o Critério de Informaçăo de Schwarz (Schwarz's Bayesian Criterion (SBC)) conforme apresentado na equação 36. Através da implementação da opção Minic do Procedimento ARIMA (proc ARIMA) do SAS versão 6.12, conforme descrito em SAS INSTITUTE (1996) foi possivel identificar a ordem do processo auto-regressivo de médias móveis (ARMA) estacionário e inversível que minimiza o valor do Critério de Informação. Uma das vantagens em se utilizar 0 procedimento ARIMA ${ }^{26}$, é que a partir das funções de autocorrelação (ACF) e de autocorrelação parcial (PACF) ${ }^{27}$ de cada variável permite verificar se a variável tem raiz unitária ou é estacionária, além de possibilitar observar a possível presença de parâmetros sazonais nas séries. No caso específico desse estudo, não foi detectada a presença de componentes sazonais em nenhuma das séries analisadas via observação das respectivas ACF e PACF de

\footnotetext{
${ }^{26}$ Para a deteç̧ão de possiveis parâmetros sazonais, o procedimento ARIMA foi implementado em todas as variáveis, independentemente do fato das séries apresentarem quebra estrutural ou não.

27 Como a utilização de modelos Auto-regressivos Integrados de Médias Móveis (ARIMA) para a estimação direta dos modelos encontra-se fora do escopo desse estudo não serão apresentados detalhes sobre esse tema. No entanto, para aqueles interessados em estudos de aplicação desse método recomenda-se consultar os seguinte trabalhos: SANTIAGO, CAMARGO e MARGARIDO (1997), MARGARIDO et al. (1996), MARGARIDO (1994) e MARGARIDO, KATO e UENO (1994) entre outros.
} 
cada série, sendo assim, não houve necessidade de se realizar testes de raiz unitária sazonais $^{28}$.

\subsection{1 - Testes de raiz unitária ADF e PP, periodo de janeiro de 1990 a junho de 1994}

$\mathrm{A}(\mathrm{s})$ ordem(ns) da(s) defasagem(ns) de todas as variáveis (externas e domésticas) para o período de janeiro de 1990 a junho de 1994 encontram-se na Tabela 10.

Para as variáveis LIFI, LIRMI e LPET em nível, o Critério de Informação de Schwarz apresentou o menor valor na primeira defasagem correspondendo a um modelo auto-regressivo de ordem 1 (AR 1), sendo assim, os testes de raiz unitária para essas variáveis utilizaram apenas uma defasagem. Já em relação à variável LRT em nível o modelo que apresentou o menor valor do Critério de Informação foi um auto-regressivo de ordem 2 (AR 2), logo o teste de raiz unitária para essa variável utilizou duas defasagens. No caso das variáveis LIPPUS e LM2 em nivel o Critério de Informação atingiu seu valor mínimo para um modelo auto-regressivo de ordem 3 (AR 3) e conseqüentemente o teste de raiz unitária para cada uma dessas duas variáveis teve um total de três defasagens (Tabela 10).

Apesar do Critério de Informação sinalizar que no caso da variável LTCR em nivel o modelo mais adequado seria um auto-regressivo de ordem 2 (AR 2) implicando na utilização de duas defasagens na realização dos testes de raiz unitária convencionais, a análise gráfica revelou que esta variável tem pelo menos três quebras estruturais do tipo $A O$, relativas as datas de março de 1990 (DM90), novembro de 1990 (DN90) e janeiro de 1994 (DJ94), sendo assim, ao invés dos testes ADF e PP, utilizou-se o procedimento proposto por FRANSES e HALDRUP (1993), o qual consiste na utilização do teste ADF, mas com a inclusão de variáveis de intervenção do tipo tipo pulse para cada data que apresentou quebra estrutural. Para se determinar a escolha do número de defasagem(ns) a ser(em) incluida(s) no teste de raiz unitária foi utilizado o método data-dependent $t^{29}$. Por se tratar de variável com dados mensais, 0

\footnotetext{
${ }^{28}$ Maiores detalhes sobre os testes de raiz unitária sazonais podem ser encontrados em DICKEY, HASZA e FULLER (1984), e também, em HYLLEBERG, ENGLE, GRANGER e YOO (1990).

${ }_{29}$ Para se determinar o número de defasagens necessárias para o teste de raiz unitária utilizou-se o método data-dependent conforme implementado originalmente em PERRON (1994, p.138). Basicamente, este método parte de um "procedimento recursivo geral para um específico, o qual baseia-se no valor da estatística $t$ em relação ao coeficiente associado à última defasagem na autoregressão estimada. Mais especificamente, este procedimento seleciona o valor de $k$, chamado de $k^{*}$, tal que o coeficiente da última defasagem de ordem $k^{*}$ na auta-regressão é significativo e o coeficiente da última defasagem de ordem maior do que $k^{*}$ não é significativo, de tal maneira o proporcionar a escolha da ordem máxima da defasagem (kmax) é feita à prior ". Como a variável utilizada tem periodicidade mensal adotou-se inicialmente um modelo auto-regressivo de ordem 12. Tanto para o teste ADF, como para o teste PP todas as doze defasagens mostraram-se significativas, sendo assim, adotou-se um total de doze defasagens na execução dos referidos testes (Tabela 14).
} 
número de defasagens inicialmente estabelecido correspondeu a doze. Aquelas defasagens com o valor do teste $t$ não significativo foram sendo eliminadas uma a uma. No final desse processo, verificou-se não ser necessária a inclusão de nenhuma defasagem (Tabela 10).

Para as variáveis externas LIFI, LIRMI e LPET diferenciadas ${ }^{30}$ o Critério de Informação apresentou seu valor mínimo para defasagem de ordem $z^{2}{ }^{31}$, sendo assim, os testes de raiz unitária para essas variáveis não utilizaram nenhuma defasagem. Para as variáveis diferenciadas LIPPUS e LRT o Critério de Informação forneceu valor mínimo para um modelo contendo somente componente de médias móveis de ordem $5^{32}$. Portanto, para essas duas variáveis utilizou-se o método data-dependent ${ }^{33}$ para a determinação do número de defasagens. Utilizou-se inicialmente um total de doze defasagens. Em relação à variável LIPPUS, as defasagens de ordem 12 até 2 mostraram-se não significativas, logo na execução do teste ADF foi incluída somente uma defasagem, enquanto que, as doze defasagens mostram-se significativas em relação ao teste de raiz unitária do tipo $P P$, sendo assim nesse caso, foram utilizadas um total de doze defasagens. A variável LRT apresentou comportamento semelhante para os testes ADF e PP. Das doze defasagens iniciais, apenas três apresentaramse significativas para o teste ADF, consequentemente, para cada variável o teste ADF utilizou apenas três defasagens. Já para o teste PP as doze defasagens foram consideradas significativas, sendo assim, para cada variável o teste PP incorporou doze defasagens (Tabela 10).

Enquanto que, para a variável diferenciada LM2 o Critério de Informação obteve valor mínimo para um modelo auto-regressivo de ordem 2 (AR 2), sendo assim, os testes de raiz unitária para essa variável utilizou duas defasagens (Tabela 10).

Finalmente, para a variável LTCR diferenciada, o Critério de Informação indicou a presença de um modelo de médias móveis de ordem 3 (MA 3), logo para se determinar o número de defasagens partiu-se de um modelo auto-regressivo de ordem 12 (AR 12). O método data-dependent sinalizou que não há necessidade de inclusão de defasagens para a aplicação do teste de raiz unitária (Tabela 10).

\footnotetext{
${ }^{30}$ Foram utilizadas diferenças de ordem 1 para todas as variáveis envolvidas na análise.

31 Modelo ARMA $(0,0)$.

32 Modelo ARMA $(0,5)$.

33 Neste caso, dada a presença de um parâmetro de médias móveis de ordem 5 , então este modelo pode ser rescrito em forma de um modelo auto-regressivo de elevada ordem.
} 
TABELA 10. - Determinação do número de defasagens segundo o Critério de Informação de Schwarz (SBC) para executar o teste de raiz unitária do tipo ADF e PP para as variáveis LIFI, LIRMI, LPET, LIPPUS, LM2, LTCR e LRT, Janeiro de 1990 a Junho de 1994.

\begin{tabular}{cc}
\hline Variável & $\begin{array}{c}\text { Defasagem(ns) utilizada(s) no modelo ARMA e } \\
\text { valor mínimo do Critério de Informação SBC }\end{array}$ \\
\hline LIFI $^{1}$ & $\operatorname{SBC}(1,0)=-8,94723$ \\
$\nabla$ LIFI $^{2}$ & $\operatorname{SBC}(0,0)=-8,92905$ \\
LIRMI $^{1}$ & $\operatorname{SBC}(1,0)=-9,51903$ \\
$\nabla$ LIRMI $^{2}$ & $\operatorname{SBC}(0,0)=-9,57504$ \\
LPET $^{1}$ & $\operatorname{SBC}(1,0)=-7,39462$ \\
$\nabla$ LPET $^{2}$ & $\operatorname{SBC}(0,0)=-7,23514$ \\
LIPPUS $^{1}$ & $\operatorname{SBC}(3,0)=-11,4006$ \\
$\nabla$ LIPPUS $^{2}$ & $\operatorname{SBC}(0,5)=-11,9551^{3}$ \\
LM2 $^{1}$ & $\operatorname{SBC}(3,0)=-7,38513$ \\
$\nabla$ LM2 $^{2}$ & $\operatorname{SBC}(2,0)=-7,45378$ \\
LTCR $^{1}$ & $\operatorname{SBC}(2,0)=-8,42504^{5}$ \\
$\nabla$ LTCR $^{2}$ & $\operatorname{SBC}(0,3)=-8,46688^{5}$ \\
LRT $^{1}$ & $\operatorname{SBC}(2,0)=-7,68737$ \\
$\nabla$ LRT $^{2}$ & $\operatorname{SBC}(0,5)=-8,04236^{4}$
\end{tabular}

Variável em nivel, ${ }^{2}$ Variável diferenciada, ${ }^{3}$ Método data-dependent utilizando uma defasagem para 0 teste ADF e doze defasagens para o teste $P P,{ }^{4}$ Método data-dependent utilizando três defasagens para o teste $A D F$ e doze defasagens para o teste $P P,{ }^{5}$ Método data-dependent utilizando defasagem de ordem zero para o teste de raiz unitária proposto por FRANSES e HALDRUP (1993).

Fonte: Dados básicos da International Financial Statistics (1990/1999), Conjuntura Econômica (1991/1999) e U.S. Department of Labor, Bureau of Labor Statistics.

Os testes de raiz unitária mostraram que as variáveis externas LIFI e LIRMI (testes ADF e PP), LPET (teste PP) e a variável doméstica LM2 (teste PP) são integradas de ordem 1 (I(1)), ou seja possuem raiz unitária. Em relação a variável LPET, o resultado do teste ADF mostrou que a hipótese nula de raiz unitária foi rejeitada em nível de $5,0 \%$ para a estatística $\tau_{\tau}$ e em nível de $10,0 \%$ para a estatística $\phi_{3}$. Contudo, o teste PP obteve resultado contrário para todos os testes, ou seja, a hipótese nula de raiz unitária não pode ser rejeitada para nenhuma das três estatísticas (Tabelas 11 e 12). Outro aspecto a ser realçado é que a função de autocorrelação para LPET em nivel caracterizou-se por apresentar um comportamento com queda lenta e contínua, enquanto que ao se diferenciar esta variável, a sua função de autocorrelação apresentou queda rápida e abrupta, configurando uma situação de estacionariedade para LPET somente nas diferenças. A variável LM2 em nível também apresentou resultados conflitantes 
entre os testes ADF e PP. Somente a estatística $\phi_{3}$ rejeitou a hipótese nula de raiz unitária, porém em nivel de apenas $10,0 \%$, enquanto que, para as demais estatísticas do teste ADF a hipótese nula de raiz unitária não pode ser rejeitada, fato que se repetiu para todas as estatísticas do teste PP (Tabelas 11 e 12). A função de autocorrelação para LM2 apresentou comportamento semelhante, seja em nivel, e também, nas diferenças relativamente a função de autocorrelação de LPET. Sendo assim, para evitar o surgimento de relacionamento espúrio entre as variáveis analisadas tornou-se necessário trabalhar com as séries diferenciadas e não em nivel. Para torná-las estacionárias foi aplicada uma diferença de ordem um sobre cada uma delas (Tabelas 11 e 12). Logo, pode-se concluir que essas quatro séries são estacionárias nas diferenças (diferença estacionária (DS)).

A variável externa LIPPUS em nível também apresentou comportamento discrepante em relação aos resultados dos testes de raiz unitária ADF e PP, e também, quanto ao comportamento da função de autocorrelação. A hipótese nula de raiz unitária foi rejeitada somente para as estatísticas $\tau_{\tau}$ e $\phi_{3}$ ambas em nivel de 5,0\% (Tabela 11). Para o teste PP, a hipótese nula de raiz unitária somente foi rejeitada para a estatística $\tau_{\tau}$, mas em nível de $10,0 \%$. No caso do teste PP, como o valor calculado está muito próximo do tabelado torna-se muito complicado, analisando-se apenas o resultado da estatística $\tau_{\tau}$, afirmar que LIPPUS em nivel é estacionária (Tabela 12), pois os testes de raiz unitária possuem baixo poder. Sendo assim, o próximo passo consistiu na análise do comportamento da função de autocorrelação com a variável em nível e diferenciada. Para a variável em nível a função de autocorrelação decai lenta e continuamente, enquanto que ao ser diferenciada o seu comportamento alterou-se completamente passando a cair de maneira rápida e abrupta, indicando que ao ser diferenciada esta variável toma-se estacionária, fato esse confirmado pelos testes de raiz unitária ADF e PP (Tabelas 11 e 12). Logo, essa variável também foi considerada como sendo integrada de ordem um.

O caso mais complicado envolveu a variável LRT em nível, uma vez que, todas as estatísticas do teste ADF, mais as estatísticas $\tau_{\mu}$ e $\tau$ do teste PP mostraram que essa variável em nível é estacionária (Tabelas 11 e 12), entretanto, os resultados da função de autocorrelação caminharam no sentido contrário, ou seja, esta variável não é estacionária quando considerada em nível. Sendo assim, os testes de raiz unitária foram reformulados, só que desta vez, foi utilizada a variável diferenciada. Os resultados obtidos mostraram que ao se aplicar uma diferença sobre a variável LRT todas as estatísticas dos testes ADF e PP rejeitaram a hipótese nula de raiz unitária (Tabelas 11 e 12), além do que os resultados da função de autocorrelação mostraram que neste caso, houve mudança no comportamento dessa função, a 
qual passou de queda lenta e contínua para um decréscimo rápido e abrupto, indicando que ao se diferenciar está variável ela torna-se estacionária. Portanto, a variável LRT pode ser considerada como sendo integrada de ordem 1.

Em relação à variável LTCR em nivel, a visualização gráfica mostrou a presença de três quebras estruturais do tipo $A O$ relativas às datas de março de 1990 (DM90), novembro de 1990 (DN90) e janeiro de 1994 (DJ94), sendo assim, ao invés dos testes de raiz unitária convencionais, foi utilizado o teste ADF com a inclusão de variáveis de intervenção do tipo pulse conforme sugerido por FRANSES e HALDRUP (1993). O teste de raiz unitária mostrou que essa variável pode ser considerada estacionária em nível (LTCR $\left.t_{-1}\right)$, pois o seu valor calculado $(-2,002)$ relativo ao teste $\tau$ é superior em módulo ao valor tabelado $(-1,94667)$ em nível de 5,0\%, porém em nível de $1,0 \%$ verifica-se um resultado contrário, dado que 0 valor calculado em módulo é inferior ao respectivo valor tabelado $(-2,60554)$ indicando que essa variável tem raiz unitária. Diante desse conflito de resultados, para se determinar a ordem de integração dessa variável utilizou-se da visualização gráfica. A Figura 6 revela que essa variável em nível não é estacionária, sendo assim, adotou-se que ela possuí raiz unitária (Tabela 13).

Para finalizar este item torna-se necessário tecer alguns comentários sobre os resultados conflitantes dos testes de raiz unitária envolvendo as variáveis. Em primeiro lugar, os testes de raiz unitária tem baixo poder, ou seja, a inclusão de termos determinísticos, como por exemplo, tendência linear e intercepto, e também, a inclusão do número de defasagens podem conduzir a resultados viesados, isto é, pode levar o pesquisador a rejeitar (aceitar) a hipótese nula de raiz unitária quando ela é verdadeira (falsa). Também, em função do baixo poder dos testes de raiz unitária, eles não são capazes de distinguir um processo com raiz unitária de outro processo com raiz quase unitária ${ }^{34}$, fato este que pode induzir o pesquisador a tomar a decisão errada em relação à ordem de integração da variável. Outro fator que influi nos resultados dos testes de raiz unitária é o número de obsenvações. Para pequenas amostras estes testes tem baixo poder. No caso analisado neste item, o periodo abrangido vai de janeiro de janeiro de 1990 até junho de 1994 totalizando 54 observações, configurando dessa forma uma amostra pequena, dado que, ao se trabalhar com séries temporais o recomendável é utilizar pelo menos 60 observações.

Deixando-se de lado a questão estatística, outro fator que possivelmente contribuiu para as discrepâncias encontradas nos testes de raiz unitária tem origem econômica, uma vez que, nesse período, a economia brasileira caracterizou-se pela elevada instabilidade do nível de

${ }^{34}$ Tomando-se como exemplo a equação 1 do teste Dickey-Fuller, quando o valor do parâmetro $\rho$ for igual a um, então a variável possuí raiz unitária, no entanto, quando o valor deste parâmetro estiver muito próximo de 1, como por exemplo, entre 0,99 e 0,90, então o teste de raiz unitária não é capaz de distinguir precisamente se a variável possuí ou não raiz unitária, isto é, se ela é diferença estacionária ou estacionária. 
preços. Este fato pode ter influenciado o comportamento das variáveis domésticas analisadas aqui neste estudo, refletindo-se sobre os resultados dos testes de raiz unitária, gerando assim esses resultados conflituosos, uma vez que, a instabilidade de preços provoca distorçōes nos preços relativos da economia. Numa situação de inflação acelerada as séries temporais de preços e indices de preços tendem a apresentar um comportamento explosivo, e sua modelagem toma-se muito mais complexa, sendo assim, os resultados dos testes de raiz unitária podem ser contaminados pela inflação, devendo ser analisados com muito mais cuidado do que numa situação com preços estáveis, pois como já foi dito anteriormente, estes testes possuem baixo poder, os quais podem conduzir o pesquisador a encontrar resultados viesados. 
TABELA 11. - Resultados dos Testes de Raiz Unitária Dickey-Fuller Aumentado (ADF) ${ }^{1}$ para as variáveis LIFI, LIRMI, LPET, LIPPUS, LM2 e LRT, Janeiro de 1990 a Junho de 1994.

\begin{tabular}{cccccc}
\hline Variável & $\tau_{\tau}$ & $\phi_{3}$ & $\tau_{\mu}$ & $\phi_{1}$ & $\tau$ \\
\hline LIFI $^{2}$ & $-2,6748$ & $3,6676^{2}$ & $-2,4923$ & 3,1114 & $-0,1224$ \\
$\nabla$ LIFI $^{3}$ & $-6,7459^{4}$ & $22,7538^{4}$ & $-6,7913^{4}$ & $23,0865^{4}$ & $-6,8608^{4}$ \\
\hline LIRMI $^{2}$ & $-2,0552$ & 2,9090 & $-1,3346$ & 1,0984 & 0,6314 \\
$\nabla$ LIRMI $^{3}$ & $-7,6097^{4}$ & $28,9545^{4}$ & $-7,4739^{4}$ & $27,9297^{4}$ & $-7,5483^{4}$ \\
\hline LPET $^{2}$ & $-3,5737^{5}$ & $6,4788^{6}$ & $-2,4503$ & 3,0034 & $-0,1986$ \\
$\nabla$ LPET $^{3}$ & $-5,2755^{4}$ & $13,9568^{4}$ & $-5,3144^{4}$ & $14,1528^{4}$ & $-5,3661^{4}$ \\
\hline LIPPUS $^{2}$ & $-3,8919^{5}$ & $7,7006^{5}$ & $-1,9543$ & 2,6093 & 1,1400 \\
$\nabla$ LIPPUS $^{3}$ & $-5,0640^{4}$ & $12,8285^{4}$ & $-5,0955^{4}$ & $12,9818^{4}$ & $-5,1480^{4}$ \\
\hline LM2 $^{2}$ & $-1,1807^{4}$ & $5,6749^{6}$ & $2,5881^{4}$ & 3,4882 & 1,9001 \\
$\nabla$ LM2 $^{3}$ & $-2,7463$ & 4,9432 & $-0,1202^{4}$ & 0,5252 & $-0,2124$ \\
\hline LRT $^{2}$ & $-4,0323^{5}$ & $8,5913^{4}$ & $-3,6598^{4}$ & $6,8765^{5}$ & $-2,1344^{5}$ \\
$\nabla$ LRT $^{3}$ & $-4,8090^{4}$ & $13,5205^{4}$ & $-5,2452^{4}$ & $14,3474^{4}$ & $-5,1955^{4}$ \\
\hline
\end{tabular}

1 Valores criticos para $\tau_{\tau}, \tau_{\mu}$ e $\tau$ obtidos conforme descrito em MACKINNON (1991) e correspondem respectivamente a , $-3,17528,-2,59527$ e $-1,61895$ em nivel de $10,0 \%$, e $-3,49351,-2,91567$ e $-1,94667$ em nivel de $5,0 \%$ e $-4,13475,-3,55472$ e $-2,60554$ em nivel de $1,0 \%$, enquanto que os valores criticos para $\phi_{3}$ e $\phi_{1}$ foram obtidos diretamente de DICKEY e FULLER (1981) e são iguais respectivamente a 5,61 e 3,94 em nivel de $10,0 \%$, e 6,73 e 4,86 em nivel de 5,0\%, e 9,31 e 7,06 em nível de $1,0 \%{ }^{2}$ Variável em nivel, ${ }^{3}$ Variável diferenciada, ${ }^{4}$ Significativo em nível de $1,0 \%,{ }^{5}$ Significativo em nivel de $5,0 \%,{ }^{6}$ Significativo em nivel de $10,0 \%$.

Fonte: Dados básicos da International Financial Statistics (1990/1999), Conjuntura Econômica (1991/1999) e U.S. Department of Labor, Bureau of Labor Statistics. 
TABELA 12. - Resultados dos Testes de Raiz Unitária Phillips-Perron (PP) ${ }^{1}$ para as variáveis LIFI, LIRMI, LPET, LIPPUS, LM2 e LRT, Janeiro de 1990 a Junho de 1994.

\begin{tabular}{cccc}
\hline Variável & $\tau_{\tau}$ & $\tau_{\mu}$ & $\tau$ \\
\hline LIFI $^{2}$ & $-2,7115$ & $-2,5420$ & $-0,2468$ \\
$\nabla$ LIFI $^{3}$ & $-6,7459^{4}$ & $-6,7913^{4}$ & $-6,8608^{4}$ \\
\hline LIRMI $^{2}$ & $-2,1504$ & $-1,4425$ & 0,6223 \\
$\nabla$ LIRMI $^{3}$ & $-7,6097^{4}$ & $-7,4739^{4}$ & $-7,5483^{4}$ \\
\hline LPET $^{2}$ & $-2,5611^{4}$ & $-2,0230$ & $-0,4530$ \\
$\nabla$ LPET $^{3}$ & $-5,2755^{4}$ & $-5,3144^{4}$ & $-5,3661^{4}$ \\
\hline LIPPUS $^{2}$ & $-3,2121^{6}$ & $-1,7132^{4}$ & 1,1755 \\
$\nabla$ LIPPUS $^{3}$ & $-9,4954^{4}$ & $-9,2294^{4}$ & $-9,3820^{4}$ \\
\hline LM2 $^{2}$ & 0,5536 & 5,7945 & $8,3495^{4}$ \\
$\nabla$ LM2 $^{3}$ & $-10,4901^{4}$ & $-5,8767^{4}$ & $-5,9158^{4}$ \\
\hline LRT $^{2}$ & $-2,9696^{4}$ & $-2,9178^{5}$ & $-2,2610^{5}$ \\
$\nabla$ LRT $^{3}$ & $-4,2301^{4}$ & $-4,1531^{4}$ & $-4,2127^{4}$ \\
\hline
\end{tabular}

1 Valores criticos para $\tau_{\tau}, \tau_{\mu}$ e $\tau$ obtidos conforme descrito em MACKINNON (1991) e correspondem respectivamente a , $-3,17528,-2,59527$ e $-1,61895$ em nivel de $10,0 \%$ e $-3,49351,-2,91567$ e $-1,94667$ em nível de $5,0 \%$ e $-4,13475,-3,55472$ e $-2,60554$ em nível de $1,0 \%,{ }^{2}$ Variável em nivel, ${ }^{3}$ Variável diferenciada, ${ }^{4}$ Significativo em nivel de $1,0 \%,{ }^{5}$ Significativo em nivel de $5,0 \%$, ${ }^{6}$ Significativo em nível de $10,0 \%$.

Fonte: Dados básicos da International Financial Statistics (1990/1999), Conjuntura Econômica (1991/1999) e U.S. Department of Labor, Bureau of Labor Statistics.

TABELA 13.- Estimativas dos Parâmetros do Teste de Raiz Unitária ADF com Variáveis de Intervenção do tipo Pulse, para a Variável LTCR, Janeiro de 1990 a Junho de 1994.

\begin{tabular}{cccc}
\hline Variável & Parâmetro & Estimativa & Teste $\tau^{3}$ \\
\hline LTCR $^{1}{ }^{2}$ & $(\alpha-1)$ & $-0,080332$ & $-2,002^{4}$ \\
\hline Variável & Parâmetro & Estimativa & \\
\hline DM90 $t$ & $\omega_{01}$ & $-0,065623$ & Teste $t$ \\
DN90 & $\omega_{02}$ & $(0,01727427)$ & $-3,799^{5}$ \\
DJ94 & $\omega_{03}$ & 0,047590 & $2,785^{5}$ \\
& & $(0,01708691)$ & $-4,008^{5}$ \\
\hline
\end{tabular}

Tariável em nivel, ${ }^{2}$ Erro padrāo da estimativa entre parênteses, ${ }^{3}$ Valores críticos para $\tau$ obtidos conforme descrito em MACKINNON (1991) e correspondem respectivamente a $-1,61895$ em nivel de $10,0 \%,-1,94667$ em nivel de $5,0 \%$ e $-2,60554$ em nível de $1,0 \%,{ }^{4}$ Significativo em nivel de $5,0 \%,{ }^{5}$ Significativo em nivel de $1,0 \%$

Fonte: Dados básicos da Conjuntura Econômica (1991/1999) e U.S. Department of Labor, Bureau of Labor Statistics. 


\subsection{2 - Testes de raiz unitária ADF, período de julho de 1994 a dezembro de 1998}

Para as variáveis internacionais LIFI, LIRMI, LIPPUS mais a variável doméstica LRT todas consideradas em nivel, o Critério de Informação de Schwarz (SBC) apresentou valor mínimo para um modelo auto-regressivo de ordem 1 (AR 1), sendo assim, para essas quatro variáveis o teste de raiz unitária para cada uma delas levou em consideração a utilização de apenas uma defasagem (Tabela 14). Já para a variável LTCR em nível o Critério de Informação obteve valor mínimo para um modelo auto-regressivo e de médias móveis (ARMA) de ordem (1, 1). Em função da presença do parâmetro de médias móveis, para proceder a identificação do número de defasagens nesse caso utilizou-se um modelo auto-regressivo de ordem elevada. Dado que essa variável tem periodicidade mensal, inicialmente partiu-se de um modelo autoregressivo de ordem 12 (AR 12). A aplicação do método data-dependent para a escolha do número de defasagens mostrou que a estatística $t$ para as defasagens de ordem doze até quatro não são significativas, logo para a realização do teste de raiz unitária com a inclusão de uma variável de intervenção em fevereiro de 1995 conforme proposto por FRANSES e HALDRUP (1993) foi necessária a inclusão de três defasagens (Tabela 14).

No caso da variável LPET houve a necessidade da inclusão de dois termos defasados e diferenciados na realização dos testes de raiz unitária, pois o Critério de Informação com valor mínimo ocorreu para um modelo auto-regressivo de ordem dois (AR 2) (Tabela 14).

Em relação à variável LM2 em nível, o Critério de Informação atingiu valor mínimo para um modelo auto-regressivo de ordem 5 (AR 5) e consequentemente, foram adotadas cinco defasagens na estimação dos testes de raiz unitária (Tabela 14).

Relativamente à variável LIRMI diferenciada, o Critério de Informação atingiu valor minimo para a defasagem de ordem zero, sendo assim, para a realização dos testes de raiz unitária ADF e PP não foi necessária a inclusão de defasagens (Tabela 14).

Já para as variáveis LPET e LIPPUS diferenciadas, o Critério de Informação obteve valor mínimo para um modelo auto-regressivo de ordem 1 (AR 1) para a primeira e de ordem 2 (AR 2) para a segunda, logo, os testes de raiz unitária ADF e PP foram conduzidos com a aplicação de uma defasagem para LPET e com duas defasagens para LIPPUS (Tabela 14).

Para todas as demais variáveis, o Critério de Informação registrou a presença de componentes de médias móveis, em função deste fato, para a determinação do número de defasagens deve-se partir de um modelo auto-regressivo de ordem elevada, e através da aplicação do método data-dependent aquelas defasagens não significativas foram eliminadas até que se encontrou o número correto de defasagens a serem utilizadas nos testes de raiz unitária. Para a variáveI LIFI diferenciada, o número de defasagens utilizadas no teste ADF caiu de doze para apenas uma, enquanto que para o teste PP as doze defasagens iniciais foram 
mantidas. Para a variável LRT diferenciadas, na execução do teste ADF foram utilizadas três defasagens e para o teste PP todas as doze defasagens foram incluídas. Quanto à variável LM2 diferenciada não foi necessária a inclusão de nenhuma defasagem para o teste ADF, enquanto que, para a execução do teste PP foram incorporadas todas as doze defasagens utilizadas inicialmente (Tabela 14).

Finalmente, em função da presença de uma quebra estrutural do tipo $A O$, para a variável LTCR diferenciada, foi executado apenas o teste de raiz unitária do tipo ADF com a inclusão de uma variável de intervenção do tipo pulse em fevereiro de 1995. Partindo-se inicialmente de um total de doze defasagens, o método data-dependent sinalizou a necessidade de incluir apenas duas defasagens para a realização do teste de raiz unitária (Tabela 14). 
TABELA 14. - Determinação do número de defasagens segundo o Critério de Informação de Schwarz (SBC) para executar o teste de raiz unitária do tipo ADF para as variáveis LIFI, LIRMI, LPET, LIPPUS, LM2, LTCR e LRT, Julho de 1994 a Dezembro de 1998.

\begin{tabular}{cc}
\hline Variável & $\begin{array}{c}\text { Defasagem(ns) utilizada(s) no modelo ARMA e } \\
\text { valor mínimo do Critério de Informação SBC }\end{array}$ \\
\hline LIFI $^{1}$ & $\operatorname{SBC}(1,0)=-8,49875$ \\
$\nabla$ LIFI $^{2}$ & $\operatorname{SBC}(0,1)=-8,64027^{4}$ \\
LIRMI $^{1}$ & $\operatorname{SBC}(1,0)=-8,77$ \\
$\nabla$ LIRMI $^{2}$ & $\operatorname{SBC}(0,0)=-8,84753$ \\
LPET $^{1}$ & $\operatorname{SBC}(2,0)=-7,06968$ \\
$\nabla$ LPET $^{2}$ & $\operatorname{SBC}(1,0)=-7,13038$ \\
LIPPUS $^{1}$ & $\operatorname{SBC}(1,0)=-11,1858$ \\
$\nabla$ LIPPUS $^{2}$ & $\operatorname{SBC}(2,0)=-11,3539$ \\
LM2 $^{1}$ & $\operatorname{SBC}(5,0)=-8,89121$ \\
$\nabla$ LM2 $^{2}$ & $\operatorname{SBC}(0,5)=-9,05992$ \\
LTCR $^{1}$ & $\operatorname{SBC}(1,1)=-10,4205^{3}$ \\
$\nabla$ LTCR $^{2}$ & $\operatorname{SBC}(0,1)=-10,4235^{6}$ \\
LRT $^{1}$ & $\operatorname{SBC}(1,0)=-8,70468$ \\
$\nabla$ LRT $^{2}$ & $\operatorname{SBC}(0,5)=-9,85022^{5}$
\end{tabular}

Tariável em nivel, ${ }^{2}$ Variável diferenciada, ${ }^{3}$ Método data-dependent utilizando defasagem de ordem três para o teste de raiz unitária proposto por FRANSES e HALDRUP (1993), ${ }^{4}$ Método data-dependent utilizando uma defasagem para o teste ADF e doze defasagens para o teste PP, ${ }^{5}$ Método data-dependent utilizando três defasagens para o teste ADF e doze defasagens para o teste PP. ${ }^{6}$ Método data-dependent utilizando defasagem de ordem dois para o teste de raiz unitária proposto por FRANSES e HALDRUP (1993)

Fonte: Dados básicos da International Financial Statistics (1990/1999), Conjuntura Econômica (1991/1999) e U.S. Department of Labor, Bureau of Labor Statistics.

Os testes de raiz unitária relativos a este segundo período não apresentaram resultados conflituosos entre os testes ADF e PP. Para todas as variáveis internacionais (LIFI, LIRMI, LPET e LIPPUS) em nivel mais as variáveis domésticas LM2 e LRT também em nível, ambos testes de raiz unitária sinalizaram no sentido de não rejeitar a hipótese nula de raiz unitária para todas essas variáveis, enquanto que ao adotá-las nas diferenças, os resultados dos testes ADF e PP rejeitaram a hipótese nula de raiz unitária, ou seja, aceitaram a hipótese alternativa de que essas variáveis são estacionárias nas diferenças, e portanto, podem ser consideradas como sendo integradas de ordem um, dado que foi necessária a aplicação de uma diferença de ordem um para torná-las estacionárias (Tabelas 15 e 16). 
Em relação a variável LTCR foi utilizado o teste de raiz unitánia proposto por FRANSES e HALDRUP (1993), uma vez que, foi detectada a presença de uma quebra estrutural do tipo $A O$ relativa à data de fevereiro de 1995 (DF95). Os resultados do teste ADF mostraram que a hipótese nula de raiz unitária não pode ser rejeitada ao se considerar LTCR em nível, pois o valor calculado $(0,781)$ para a estatística $\tau$ revelou-se ser inferior em módulo ao respectivo valor tabelado para todos os niveis de significância adotados. Logo, essa variável pode ser considerada como sendo integrada de ordem 1 (Tabela 17).

TABELA 15. - Resultados dos Testes de Raiz Unitária Dickey-Fuller Aumentado (ADF) ${ }^{1}$ para as variáveis LIFI, LIRMI, LPET, LIPPUS, LM2 e LRT, Julho de 1994 a Dezembro de 1998.

\begin{tabular}{cccccc}
\hline Variável & $\tau_{\tau}$ & $\phi_{3}$ & $\tau_{\mu}$ & $\phi_{1}$ & $\tau$ \\
\hline LIFI $^{2}$ & $-1,6952$ & 3,0541 & $-1,1099$ & 0,6350 & $-0,2192$ \\
$\nabla$ LIFI $^{3}$ & $-5,1272^{4}$ & $13,1543^{4}$ & $-4,6730^{4}$ & $10,9372^{4}$ & $-4,7194^{4}$ \\
\hline LIRMI $^{2}$ & $-2,6552$ & 4,6735 & $-0,8922$ & 0,4592 & $-0,3725$ \\
$\nabla$ LIRMI $^{3}$ & $-6,2112^{4}$ & $19,2904^{4}$ & $-5,9823^{4}$ & $17,9109^{4}$ & $-6,0433^{4}$ \\
\hline LPET $^{2}$ & $-1,1805$ & 2,1029 & $-0,5461$ & 0,4017 & $-0,7456$ \\
$\nabla$ LPET $^{3}$ & $-4,4021^{4}$ & $10,0932^{4}$ & $-4,0954^{4}$ & $8,4195^{4}$ & $-4,1445^{4}$ \\
\hline LIPPUS $^{2}$ & $-2,1684$ & 2,5026 & $-1,9827$ & 2,4008 & 0,8999 \\
$\nabla$ LIPPUS $^{3}$ & $-4,5284^{4}$ & 10,2970 & $-4,5000^{4}$ & $10,1547^{4}$ & $-4,5537^{4}$ \\
\hline LM2 $^{2}$ & $-1,5848$ & $1,7311^{4}$ & $-1,2565$ & 2,8283 & 1,9255 \\
$\nabla$ LM2 $^{3}$ & $-6,0913^{4}$ & $18,5635^{4}$ & $-6,1476^{4}$ & $18,9011^{4}$ & $-6,2095^{4}$ \\
\hline LRT $^{2}$ & $-2,2041$ & $2,6704^{4}$ & $-1,1963$ & 0,9756 & $-0,5021$ \\
$\nabla$ LRT $^{3}$ & $-4,6144^{4}$ & $11,2188^{4}$ & $-4,2645^{4}$ & $9,1061^{4}$ & $-4,1066^{4}$
\end{tabular}

${ }^{1}$ Valores críticos para $\tau_{\tau}, \tau_{\mu}$ e $\tau$ obtidos conforme descrito em MACKINNON (1991) e correspondem respectivamente a , $-3,17528,-2,59527$ e $-1,61895$ em nivel de $10,0 \%$, e $-3,49351,-2,91567$ e $-1,94667$ em nivel de $5,0 \%$ e $-4,13475,-3,55472$ e $-2,60554$ em nivel de $1,0 \%$, enquanto que os valores criticos para $\phi_{3}$ e $\phi_{1}$ foram obtidos diretamente de DICKEY e FULLER (1981) e são iguais respectivamente a 5,61 e 3,94 em nivel de $10,0 \%$, e 6,73 e 4,86 em nivel de $5,0 \%$, e 9,31 e 7,06 em nível de $1,0 \%{ }^{2}$ Variável em nivel, ${ }^{3}$ Variável diferenciada, ${ }^{4}$ Significativo em nível de $1,0 \%,{ }^{5}$ Significativo em nível de $5,0 \%,{ }^{6}$ Significativo em nivel de $10,0 \%$.

Fonte: Dados básicos da International Financial Statistics (1990/1999), Conjuntura Econômica (1991/1999) e U.S. Department of Labor, Bureau of Labor Statistics. 
TABELA 16. - Resultados dos Testes de Raiz Unitária Phillips-Perron (PP) para as variáveis LIFI, LIRMI, LPET, LIPPUS, LM2 e LRT, Julho de 1994 a Dezembro de 1998.

\begin{tabular}{cccc}
\hline Variável & $\tau_{\tau}$ & $\tau_{\mu}$ & $\tau$ \\
\hline LIFI $^{2}$ & $-1,6702$ & $-1,1005$ & $-0,1119$ \\
$\nabla$ LIFI $^{3}$ & $-6,1071^{4}$ & $-5,7977^{4}$ & $-5,8582^{4}$ \\
\hline LIRMI $^{2}$ & $-2,1521$ & $-0,6879$ & $-0,5218$ \\
$\nabla$ LIRMI $^{3}$ & $-6,2112^{4}$ & $-5,9823^{4}$ & $-6,0433^{4}$ \\
\hline LPET $^{2}$ & $-1,0091^{4}$ & $-0,5384$ & $-0,9578$ \\
$\nabla$ LPET $^{3}$ & $-5,2131^{4}$ & $-4,9956^{4}$ & $-5,0486^{4}$ \\
\hline LIPPUS $^{2}$ & $-2,5493^{4}$ & $-2,1405^{4}$ & $0,8119^{4}$ \\
$\nabla$ LIPPUS $^{3}$ & $-9,8684^{4}$ & $-9,8894^{4}$ & $-10,0016^{4}$ \\
\hline LM2 $^{2}$ & $-1,4996$ & $-0,5209^{4}$ & 4,0141 \\
$\nabla$ LM2 $^{3}$ & $-6,3371^{4}$ & $-6,4257^{4}$ & $-6,4790^{4}$ \\
\hline LRT $^{2}$ & $-2,4440$ & $-1,9593$ & $-0,8668$ \\
$\nabla$ LRT $^{3}$ & $-7,2919^{4}$ & $-7,0520^{4}$ & $-6,9881^{4}$ \\
\hline
\end{tabular}

1 Valores críticos para $\tau_{\tau}, \tau_{\mu}$ e $\tau$ obtidos conforme descrito em MACKINNON (1991) e correspondem respectivamente a , $-3,17528,-2,59527$ e $-1,61895$ em nivel de $10,0 \%$, e $-3,49351,-2,91567$ e $-1,94667$ em nivel de $5,0 \%$ e $-4,13475,-3,55472$ e $-2,60554$ em nivel de $1,0 \%,{ }^{2}$ Variável em nivel, ${ }^{3}$ Variável diferenciada, ${ }^{4}$ Significativo em nivel de $1,0 \%,{ }^{5}$ Significativo em nivel de $5,0 \%,{ }^{6}$ Significativo em nivel de $10,0 \%$.

Fonte: Dados básicos da International Financial Statistics (1990/1999), Conjuntura Econômica (1991/1999) e U.S. Department of Labor, Bureau of Labor Statistics. 
TABELA 17.- Estimativas dos Parâmetros do Teste de Raiz Unitária ADF com Variáveis de Intervenção do tipo Pulse, para a Variável LTCR, Julho de 1994 a Dezembro de 1998.

\begin{tabular}{|c|c|c|c|}
\hline Variável & Parâmetro & Estimativa $^{3}$ & Teste $\tau^{4}$ \\
\hline LTCR $^{\prime}{ }^{\prime}+1$ & $(\alpha-1)$ & $\begin{array}{c}0,091894 \\
(0,11761130)\end{array}$ & 0,781 \\
\hline Variável & Parâmetro & Estimativa $^{3}$ & Teste $t$ \\
\hline$\nabla$ LTCR $^{2} 1-1$ & $\psi_{1}$ & $\begin{array}{c}-0,304478 \\
(0,28001774)\end{array}$ & $-1,087$ \\
\hline$\nabla$ LTCR $^{2}{ }_{t-2}$ & $\psi_{2}$ & $\begin{array}{c}-0,286332 \\
(0,26169107)\end{array}$ & $-1,094$ \\
\hline$\nabla$ LTCR $^{2} 1-3$ & $\psi_{3}$ & $\begin{array}{c}0,198814 \\
(0,10162185)\end{array}$ & $1,956^{5}$ \\
\hline DF95 t & $\omega \cdot 1$ & $\begin{array}{c}-0,009952 \\
(0,00583124)\end{array}$ & $-1,707^{7}$ \\
\hline DF95 $t .1$ & $\omega_{02}$ & $\begin{array}{c}0,015059 \\
(0,00598775)\end{array}$ & $2,515^{6}$ \\
\hline DF95 $t-2$ & $\omega_{03}$ & $\begin{array}{c}0,004981 \\
(0,00639909)\end{array}$ & 0,778 \\
\hline DF95 t-3 & $\omega_{04}$ & $\begin{array}{c}0,008016 \\
(0,00638261) \\
\end{array}$ & 1,256 \\
\hline
\end{tabular}

Variável em nível, ${ }^{2}$ Variável diferenciada, ${ }^{3}$ Erro padrāo da estimativa entre parênteses, ${ }^{4}$ Valores criticos para $\tau$ obtidos conforme descrito em MACKINNON (1991) e correspondem respectivamente a $-1,61895$ em nivel de $10,0 \%,-1,94667$ em nivel de $5,0 \%$ e $-2,60554$ em nível de $1,0 \%,{ }^{5}$ Significativo em nivel de $5,0 \%,{ }^{6}$ Significativo em nivel de $1,0 \%,{ }^{7}$ Significativo em nivel de $10,0 \%$.

Fonte: Dados básicos da Conjuntura Econômica (1991/1999) e U.S. Department of Labor, Bureau of Labor Statistics.

\subsection{3 - Testes de raiz unitária ADF, periodo de janeiro de 1990 a dezembro de 1998}

Os resultados obtidos a partir do Critério de Informação de Schwarz mostram que para as variáveis externas LIFI e LIRMI em nivel o valor mínimo ocorreu na primeira defasagem do modelo auto-regressivo (AR 1), sendo assim, os testes ADF e PP para essas duas variáveis foram realizados adotando-se apenas uma defasagem. Já para as variáveis LPET e LIPPUS em nivel, segundo os resultados do Critério de Informação, o modelo que melhor se ajustou para a primeira variável foi um modelo auto-regressivo de ordem dois (AR 2) e para a segunda um modelo auto-regressivo de ordem três (AR 3), logo foram utilizadas duas e três defasagens respectivamente na realização dos testes de raiz unitária (Tabela 18).

Para as variáveis LIFI e LIRMI diferenciadas, o Critério de Informação obteve valor mínimo para um modelo ARMA de ordem zero, ou seja, não houve necessidade de se incluir defasagens nos testes de raiz unitária relativos a essas duas variáveis. Em relação a LPET 
diferenciada, o Critério de Infonnação sinalizou para um modelo auto-regressivo de ordem um (AR 1), conseqëntemente, foi utilizada somente uma defasagem nos testes de raiz unitária relativos a esta variável. Ao considerar-se LIPPUS diferenciada, o Critério de Informação obteve valor mínimo para um modelo de médias móveis de ordem cinco (MA 5). Em função das presença deste componente de médias móveis, foi necessário utilizar o método data-dependent para se determinar o número de defasagens necessárias para a realização dos testes de raiz unitánia para a referida variável. Por se tratar de observações com periodicidade mensal, partiuse inicialmente de um modelo auto-regressivo de ordem doze (AR 12). Todas as doze defasagens mostraram-se significativas em relação às respectivas estatísticas $t$, seja para 0 teste ADF, seja para PP, sendo assim, para ambos testes de raiz unitária foram utilizadas um total de doze defasagens (Tabela 18). Para a variável doméstica LRT em nivel, o Critério de Informação apresentou valor mínimo para um modelo auto-regressivo de ordem 2 (AR 2), sendo assim, nos testes de raiz unitária foram incorporadas duas defasagens. Finalmente, para LRT diferenciada, o Critério de Informação indicou valor mínimo para um modelo de médias móveis de ordem cinco (MA 5), logo, adotou-se também, o método data-dependent para a determinação do número de defasagens. Somente as seis primeiras defasagens das doze defasagens introduzidas inicialmente mostraram-se significativas em termos de seus respectivos teste $t$, sendo assim, no caso da variável LRT foram utilizadas seis defasagens para a execução dos testes ADF e PP. 
TABELA 18. - Determinação do número de defasagens segundo o Critério de Informação de Schwarz (SBC) para executar o teste de raiz unitária do tipo ADF e PP para as variáveis LIFI, LIRMI, LPET, LIPPUS e LRT, Janeiro de 1990 a Dezembro de 1998.

\begin{tabular}{cc}
\hline Variável & $\begin{array}{c}\text { Defasagem(ns) utilizada(s) no modelo ARMAe } \\
\text { valor minimo do Critério de Informação SBC }\end{array}$ \\
\hline LIFI $^{1}$ & $\operatorname{SBC}(1,0)=-8,66543$ \\
$\nabla$ LIFI $^{2}$ & $\operatorname{SBC}(0,0)=-8,674$ \\
LIRMI $^{1}$ & $\operatorname{SBC}(1,0)=-8,79916$ \\
$\nabla$ LIRMI $^{2}$ & $\operatorname{SBC}(0,0)=-8,82076$ \\
LPET $^{1}$ & $\operatorname{SBC}(2,0)=-7,19882$ \\
$\nabla$ LPET $^{2}$ & $\operatorname{SBC}(1,0)=-7,19454$ \\
LIPPUS $^{1}$ & $\operatorname{SBC}(3,0)=-11,2546$ \\
$\nabla$ LIPPUS $^{2}$ & $\operatorname{SBC}(0,5)=-11,3878^{3}$ \\
LRT & $\operatorname{SBC}(2,0)=-7,82861$ \\
L LRT $^{2}$ & $\operatorname{SBC}(0,5)=-7,99639^{4}$
\end{tabular}

TVariável em nível, ${ }^{2}$ Variável diferenciada, ${ }^{3}$ Método data-dependent utilizando doze defasagens para os testes ADF e PP, ${ }^{4}$ Método data-dependent utilizando seis defasagens para os testes ADF e PP.

Fonte: Dados básicos da International Financial Statistics (1990/1999), Conjuntura Econômica (1991/1999) e U.S. Department of Labor, Bureau of Labor Statistics.

Os testes de raiz unitária $A D F$ e PP relativos às variáveis LIFI e LIRMI não apresentaram discordâncias, uma vez que, todas as estatísticas não rejeitaram a hipótese nula de raiz unitária, quando consideradas em nível. Ao serem diferenciadas, todas as estatísticas rejeitaram a hipótese nula de raiz unitária em favor da hipótese alternativa, em nível de 1,0\%, de que ambas são estacionárias. Portanto, essas duas variáveis são integradas de ordem um (Tabelas 19 e 20).

No caso de LPET, apenas as estatísticas $\tau_{\tau}$ e $\phi_{3}$ do teste ADF rejeitaram a hipótese nula de raiz unitária, porém, somente em nível de 10,0\%. Agora, analisando-se os resultados dos testes PP, nenhuma das três estatísticas rejeitaram a hipótese nula de raiz unitária, sinalizando assim, que esta variável possuí raiz unitária (Tabelas 19 e 20). Para a tomada de decisão em relação a ordem de integração de LPET em nivel utilizou-se o comportamento da função de autocorrelação, o qual, apresentou um comportamento de queda lenta e contínua, indicando que esta variável tem raiz unitária. No entanto, ao ser diferenciada, o comportamento da função de autocorrelação alterou-se, passando a apresentar uma queda rápida e abrupta, sinalizando que nesse caso essa variável é estacionária. Em função desse conjunto de resultados, a variável LPET foi adotada como sendo integrada de ordem um. 
A variável LIPPUS apresentou resultados semelhantes a LPET e também foi considerada como sendo integrada de ordem um (Tabelas 19 e 20).

Finalmente, a variável LRT em nivel também apresentou conflitos em relação aos testes de raiz unitária $A D F$ e PP. No caso do teste ADF, a hipótese nula de raiz unitária foi rejeitada em nivel de 5,0\% para as estatisticas $\tau_{\tau}, \phi_{3}, \tau_{\mu}, \phi_{1}$ e em nivel de 1,0\% para a estatistica $\tau$. Em relação ao teste $P P$, verificou-se que a hipótese nula de raiz unitária não pode ser rejeitada para a estatistica $\tau_{\tau}$, enquanto que, para as estatísticas $\tau_{\mu}$ e $\tau$ a hipótese de raiz unitária foi rejeitada em nivel de 10,0\% para a primeira e 1,0\% para a segunda (Tabelas 19 e 20). Em função dessas discrepâncias entre os testes, optou-se em analisar o comportamento da função de autocorrelação de LRT em nivel. A visualização do seu correlograma mostrou que a sua função de correlação apresentava comportamento de queda lenta e contínua, indicando a presença de forte memória, isto é, captando a presença de raiz unitánia. Diante desta constatação, optou-se em aplicar uma diferença de ordem um sobre a variável e repetir o teste de raiz unitária, só que desta vez, com a variável diferenciada. Os resultado obtidos mostram que ao se diferenciar LRT a hipótese de raiz unitária é rejeitada para todas as estatísticas dos testes ADF e PP, ou seja, a variável torna-se estacionária. Sendo assim, assumiu-se que LRT é integrada de ordem um, dado que, foi necessária a implementação de uma diferença de ordem um para torná-la estacionária. 
TABELA 19. - Resultados dos Testes de Raiz Unitária Dickey-Fuller Aumentado (ADF) ${ }^{1}$ para as variáveis LIFI, LIRMI, LPET, LIPPUS e LRT Janeiro de 1990 a Dezembro de 1998.

\begin{tabular}{cccccc}
\hline Variável & $\tau_{\tau}$ & $\phi_{3}$ & $\tau_{\mu}$ & $\phi_{1}$ & $\tau$ \\
\hline LIFI $^{2}$ & $-1,5007$ & 1,3370 & $-1,6403$ & 1,3796 & $-0,2931$ \\
$\nabla$ LIFI $^{3}$ & $-9,1056^{4}$ & $41,4855^{4}$ & $-9,1115^{4}$ & $41,5098^{4}$ & $-9,1548^{4}$ \\
\hline LIRMI $^{2}$ & $-1,0396$ & 0,9561 & $-1,3542$ & 0,9189 & $-0,0957$ \\
$\nabla$ LIRMI $^{3}$ & $-9,1869^{4}$ & $42,2094^{4}$ & $-9,1501^{4}$ & $41,8651^{4}$ & $-9,1943^{4}$ \\
\hline LPET $^{2}$ & $-3,2977^{6}$ & $6,0001^{6}$ & $-1,8917$ & 1,9457 & $-0,6716$ \\
$\nabla$ LPET $^{3}$ & $-6,3312^{4}$ & $20,2410^{4}$ & $-6,2807^{4}$ & $19,7283^{4}$ & $-6,3097^{4}$ \\
\hline LIPPUS $^{2}$ & $-3,4357^{6}$ & $6,1389^{6}$ & $-1,6548$ & 2,7021 & 1,6060 \\
$\nabla$ LIPPUS $^{3}$ & $-3,6199^{5}$ & $6,6168^{5}$ & $-3,4583^{5}$ & $5,9809^{5}$ & $-3,4298^{4}$ \\
\hline LRT $^{2}$ & $-3,7483^{5}$ & $7,2136^{5}$ & $-2,9418^{5}$ & $4,8803^{5}$ & $-3,0928^{4}$ \\
$\nabla$ LRT $^{3}$ & $-4,9677^{4}$ & $12,6385^{4}$ & $-5,0287^{4}$ & $12,6837^{4}$ & $-4,9478^{4}$ \\
\hline
\end{tabular}

Valores criticos para $\tau_{\tau}, \tau_{\mu}$ e $\tau$ obtidos conforme descrito em MACKINNON (1991) e correspondem respectivamente a $,-3.15094,-2.5808$ e -1.61728 em nivel de $10,0 \%$, e $-3.45153,-2.88817$ e -1.94299 em nivel de $5,0 \%$ e $-4.04521,-3.49165$ e -2.58481 em nivel de $1,0 \%$, enquanto que os valores criticos para $\phi_{3}$ e $\phi_{1}$ foram obtidos diretamente de DICKEY e FULLER (1981) e são iguais respectivamente a 5,47 e 3,86 em nível de $10,0 \%$, e 6,49 e 4,71 em nivel de $5,0 \%$, e 8,73 e 6,70 em nível de $1,0 \%{ }^{2}$ Variável em nivel, ${ }^{3}$ Variável diferenciada, ${ }^{4}$ Significativo em nivel de $1,0 \%,{ }^{5}$ Significativo em nível de $5,0 \%,{ }^{6}$ Significativo em nivel de $10,0 \%$.

Fonte: Dados básicos da International Financial Statistics (1990/1999), Conjuntura Econômica (1991/1999) e U.S. Department of Labor, Bureau of Labor Statistics. 
TABELA 20. - Resultados dos Testes de Raiz Unitána Phillips-Perron (PP) ${ }^{1}$ para as variáveis LIFI, LIRMI, LPET, LIPPUS e LRT Janeiro de 1990 a Dezembro de 1998.

\begin{tabular}{cccc}
\hline Variável & $\tau_{\tau}$ & $\tau_{\mu}$ & $\tau$ \\
\hline LIFI $^{2}$ & $-1,4391$ & $-1,5350$ & $-0,3769$ \\
$\nabla$ LIFI $^{3}$ & $-9,1056^{4}$ & $-9,1115^{4}$ & $-9,1548^{4}$ \\
\hline LIRMI $^{2}$ & $-0,9230$ & $-1,2723$ & $-0,1063$ \\
$\nabla$ LIRMI $^{3}$ & $-9,1869^{4}$ & $-9,1501^{4}$ & $-9,1943^{4}$ \\
\hline LPET $^{2}$ & $-2,7542$ & $-1,8421$ & $-0,8893$ \\
$\nabla$ LPET $^{3}$ & $-7,5302^{4}$ & $-7,5052^{4}$ & $-7,5399^{4}$ \\
\hline LIPPUS $^{2}$ & $-3,7018^{5}$ & $-1,5912^{4}$ & 1,5550 \\
$\nabla$ LIPPUS $^{3}$ & $-15,0990^{4}$ & $-14,4969^{4}$ & $-14,5963^{4}$ \\
\hline LRT $^{2}$ & $-3,0972$ & $-2,8124^{6}$ & $-3,1603^{4}$ \\
$\nabla$ LRT $^{3}$ & $-6,3159^{4}$ & $-6,3109^{4}$ & $-6,3459^{4}$
\end{tabular}

1 Valores criticos para $\tau_{\tau}, \tau_{\mu}$ e $\tau$ obtidos conforme descrito em MACKINNON (1991) e correspondem respectivamente a , $-3.15094,-2.5808$ e -1.61728 em nivel de $10,0 \%$ e e $-3.45153,-2.88817$ e -1.94299 em nível de $5,0 \%$ e $-4.04521,-3.49165$ e -2.58481 em nível de $1,0 \%,{ }^{2}$ Variável em nivel, ${ }^{3}$ Variável diferenciada, ${ }^{4}$ Significativo em nivel de $1,0 \%,{ }^{5}$ Significativo em nível de $5,0 \%,{ }^{6}$ Significativo em nivel de $10,0 \%$

Fonte: Dados básicos da International Financial Statistics (1990/1999), Conjuntura Econômica (1991/1999) e U.S. Department of Labor, Bureau of Labor Statistics.

\subsection{4 - Testes de raiz unitária com quebra estrutural, período de janeiro de 1990 a dezembro de 1998}

Como as demais variáveis apresentaram quebra estrutural os seus respectivos testes de raiz unitária necessitaram levar em consideração esse fato, logo, foram utilizados os testes de raiz unitária proposto em PERRON (1989 e 1994) para a variável LM2, pois ela apresentou apenas uma quebra estrutural, relativa ao Plano Real, implementado em julho de 1994 (Figura 5). Em contrapartida, a análise gráfica (Figura 6 ) mostrou que variável LTCR possuí quatro quebras estruturais do tipo $A O$ cujas datas correspondem respectivamente a março de 1990 (DM90), novembro de 1990 (DN90) e janeiro de 1994 (DJ94) e fevereiro de 1995 (DF95). Em função da presença de mais de uma quebra estrutural e também, pelo fato de todas elas poderem ser corrigidas por variáveis de intervenção do tipo Pulse, ao invés do teste proposto por PERRON (1989 e 1994) foi utilizado o teste de raiz unitária desenvolvido por FRANSES e HALDRUP (1993) em relação a variável LTCR. 
O primeiro passo, residiu na escolha do modelo ( $A O$ ou 10 ) para a variável LM2. PERRON (1994) sugere a utilização do modelo 2 do caso 10 , pois este modelo é o de caráter mais geral.

Para a escolha dos modelos a serem utilizados nesse estudo, foi estimado um modelo 10 (caso 2), e também, um modelo $A O$ (caso 3) para a variável LM2. A visualização gráfica da série mostra que a variável LM2 apresenta mudança na inclinação da tendência, justificando dessa forma a escolha do caso 3 do modelo AO (Figura 5). Dado que a quebra estrutura na função tendência da variável ocorreu de maneira abrupta optou-se em utilizar unicamente o modelo do caso $A O$, pois o modelo do tipo 10 é mais adequado quando a quebra acontece de maneira mais suave.

Como já mencionado, ao se trabalhar com os modelos $A O$ são necessários dois passos. Em primeiro lugar é necessário estimar uma regressão contendo apenas o intercepto, uma variável tendência e uma variável dummy que capta a mudança de inclinação da função tendência (Caso 3) conforme a equação 22. Este procedimento inicial visa eliminar a tendência da série. Estimada essa regressão aplica-se o teste de raiz unitária sobre os respectivos residuos, utilizando-se a equação 24 para o caso três. $O$ valor calculado dos testes de raiz unitária devem então ser comparados com os valores críticos da Tabela 1 (caso 3) em PERRON (1993), ou então, com os valores tabulados na Tabela 4.6 contidos em PERRON (1994).

Para a estimação da regressão utilizou-se o procedimento Autoreg (Proc Autoreg) do SAS versão 6.12 como apresentado em SAS INSTITUTE (1993), enquanto que para os testes de raiz unitária do tipo ADF foi utilizada a opção STATIONARITY do procedimento ARIMA (Proc ARIMA) do SAS conforme exposto em SAS INSTITUTE (1996).

Os resultados da regressão e do teste de raiz unitária com quebra estrutural para o modelo $A O$ caso 3 referente à variável LM2 encontra-se na Tabela 21.

Para a determinação do número de defasagens utilizadas na realização dos testes de raiz unitária optou-se em usar o método data-dependent apresentado em PERRON (1994). Inicialmente, foram inseridas um total de doze defasagens no modelo auto-regressivo. A seguir, verificou-se o nivel de significância para cada defasagem em termos do teste $t$ de student. As doze defasagens mostram-se significativas em nivel de $1,0 \%$ e $5,0 \%$. Portanto, diante desses resultados, no teste de raiz unitária para LM2 foram utilizadas doze defasagens.

O resultado do teste de raiz unitária mostrou que no caso da variável LM2 (modelo AO caso 3) possui raiz unitária, uma vez que o valore calculado de $t(\alpha)$ dessa variável é maior do que os respectivos valores criticos tabelados da estatistica $t(\alpha)$. Especificamente, o valor calculado para estatística $t(\alpha)$ é igual a $-2,4360$, enquanto que, os valores tabelados 
correspondem a -3,65, -3,93 e -4,49 respectivamente em nivel de $10,0 \%, 5,0 \%$ e $1,0 \%$ com $\lambda=0,5$ (Tabela 21). Dado que o valor calculado é menor em módulo que os valores criticos tabalados, isto significa que a hipótese nula de que existe raiz unitária é aceita, em contrapartida, rejeita-se a hipótese alternativa de que há flutuação estacionária ao redor de uma função tendência determinística.

TABELA 21.- Estimativas dos Parâmetros do Modelo de Regressão com Variável de Intervenção e do Teste de Raiz Unitária Dickey-Fuller Aumentado para a Variável LM2, Modelo Additive Outlier (AO) caso 3, Janeiro de 1990 a Dezembro de 1998.

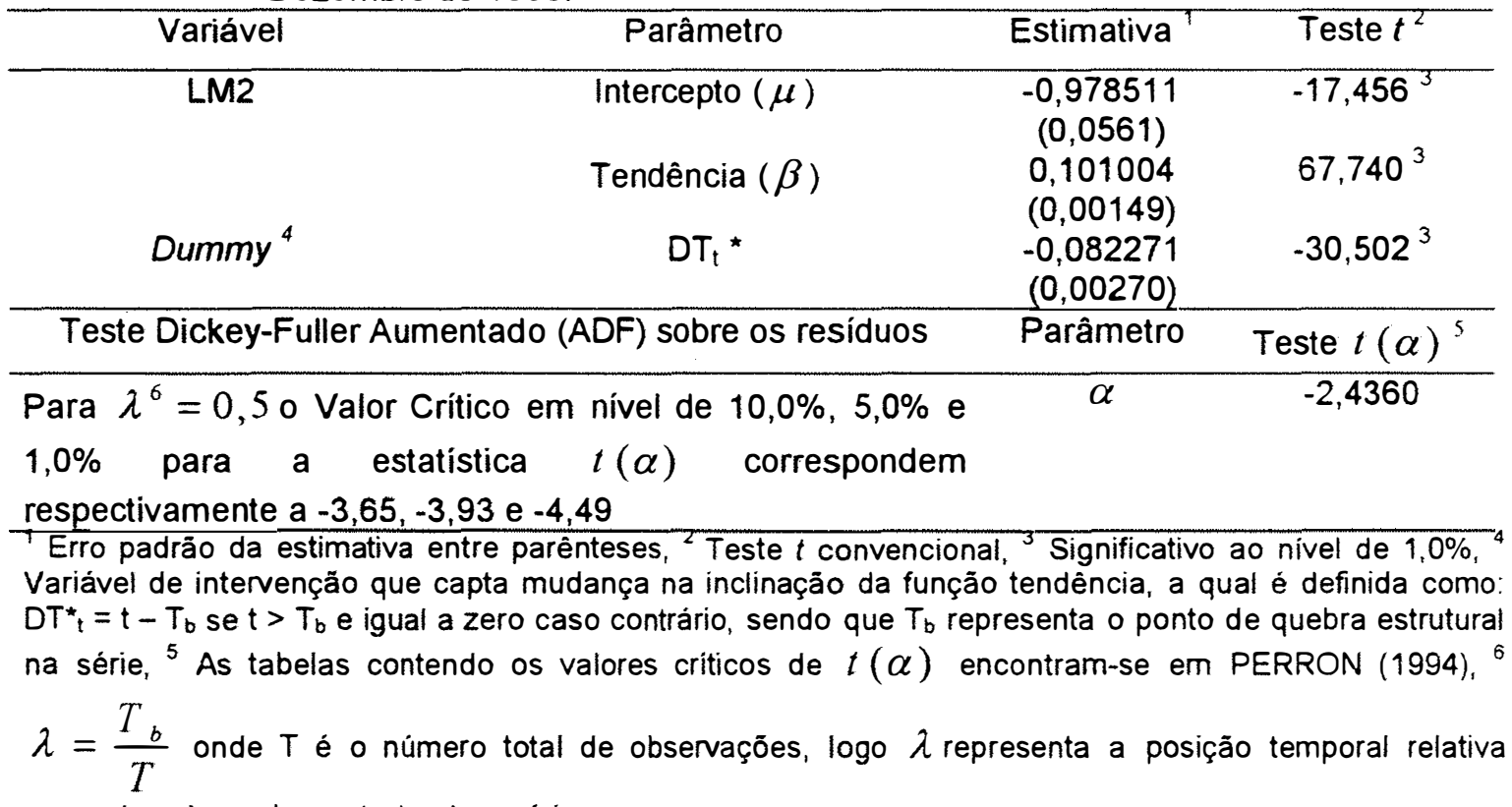
ocupada pela quebra estrutural na série.

Fonte: Dados Básicos da Conjuntura Econômica (1991/1999).

O teste de raiz unitária ADF para a variável LTCR foi conduzido conforme apresentado por FRANSES e HALDRUP (1993). Foram introduzidas quatro variáveis de intervenção do tipo Pulse relativas a março de 1990 (DM90), novembro de 1990 (DN90), janeiro de 1994 (DJ94) e fevereiro de 1995 (DF95). Todas as variáveis de intervenção apresentaram-se significativas em relação aos seus respectivos testes $t$, com exceção de DF95, sendo assim, essa variável foi removida da estimação da auto-regressão. Para a determinação do número de defasagens a serem utilizadas no teste ADF adotou-se o método data-dependent, onde partiu-se inicialmente de um modelo auto-regressivo de ordem doze. As defasagens não significativas foram removidas. No final, não foi necessária a inclusão de nenhuma defasagem. O resultado obtido pelo teste ADF mostrou que o valor calculado do teste $\tau$ é superior em módulo comparado ao seu respectivo valor tabelado em nivel de $5,0 \%$, indicando que esta variável pode ser 
considerada como sendo integrada de ordem zero, uma vez que, o teste ADF rejeitou a hipótese nula de raiz unitária para a variável em nivel. No entanto, ao utilizar-se como referência o nivel de significância de 1,0\% conclui-se que essa variável é integrada de ordem um, dado que, o valor calculado $(-1,982)$ é inferior em módulo ao seu respectivo valor tabelado $(-2,60554)$, ou seja, a esse nível de significância a hipótese nula de raiz unitária não pode ser rejeitada (Tabela 22). Em função desse conflito de resultados, e também, pelo fato do valor calculado estar muito próximo do valor tabelado em nivel de $5,0 \%$, optou-se em utilizar a visualização gráfica dessa variável para a tomada de decisão em relação à sua ordem de integração. Analisando-se graficamente o comportamento da variável LTCR (Figura 6) verificase que ela não se desloca ao longo do tempo de maneira estacionária, isto é, não fica oscilando aleatoriamente ao redor de uma média, sendo assim, essa variável também foi considerada como sendo integrada de ordem um.

TABELA 22.- Estimativas dos Parâmetros do Teste de Raiz Unitária ADF com Variáveis de Intervenção do tipo Pulse, para a Variável LTCR, Janeiro de 1990 a Dezembro de 1998.

\begin{tabular}{|c|c|c|c|}
\hline Variável & Parâmetro & Estimativa $^{2}$ & Teste $\tau^{3}$ \\
\hline LTCR $^{1}-1$ & $(\alpha-1)$ & $\begin{array}{c}-0,043640 \\
(0,02201456)\end{array}$ & $-1,982^{4}$ \\
\hline Variável & Parâmetro & Estimativa $^{2}$ & Teste $t$ \\
\hline DM90 & $\omega_{01}$ & $\begin{array}{c}-0,063055 \\
(0,01406522)\end{array}$ & $-4,483^{5}$ \\
\hline DN90 t & $\omega_{02}$ & $\begin{array}{c}0,048691 \\
(0,01399614)\end{array}$ & $3,479^{5}$ \\
\hline DJ94 t & $\omega_{03}$ & $\begin{array}{c}-0,069127 \\
(0,01398748)\end{array}$ & $-4,942^{5}$ \\
\hline
\end{tabular}

Variavel em nivel, Erro padrâo da estimativa entre parênteses, Valores criticos para $\tau$ obtidos conforme descrito em MACKINNON (1991) e correspondem respectivamente a -1,61895 em nivel de $10,0 \%,-1,94667$ em nivel de $5,0 \%$ e $-2,60554$ em nível de $1,0 \%$, ${ }^{4}$ Significativo em nivel de $5,0 \%,{ }^{5}$ Significativo em nível de $1,0 \%$.

Fonte: Dados básicos da Conjuntura Econômica (1991/1999) e U.S. Department of Labor, Bureau of Labor Statistics.

\section{2. - Testes de Co-integração}

Em relação aos testes de co-integração, é necessário frisar que, assim como aconteceu com os testes de raiz unitária, na realização dos testes de co-integração foram analisados três períodos distintos. O primeiro inicia-se em janeiro de 1990 e termina em junho de 1994, englobando um período em que a economia brasileira caracterizou-se por apresentar elevada taxa de inflação e menor grau de abertura em relação ao comércio internacional comparativamente ao segundo periodo de análise, o qual inicia-se a partir de Plano Real em 
julho de 1994 e estende-se até dezembro de 1998, onde predominou maior estabilidade do nivel de preços com um nivel de abertura da economia mais acentuado relativamente ao periodo anterior. Finalmente, um terceiro período, o qual envolve conjuntamente os dois períodos citados anteriormente. Diferentemente dos testes de co-integração dos dois períodos separados, para o período conjunto, o teste de co-integração necessitou a inclusão de uma variável de intervenção em função da presença de uma quebra estrutural em relação à variável doméstica LM2, proporcionada pela implementação do Plano Real (Figura 5).

Antes da realização dos testes de co-integração foi necessário determinar o número de defasagens para cada um dos períodos isoladamente. Para a determinação do número de defasagens (lags) de cada teste de co-integração foi utilizado o Critério de Informação de Akaike (Akaike Information Criterion $(A / C)$ ) através da implementação do Procedimento de Espaço de Estado (proc STATESPACE) do SAS conforme descrito em SAS INSTITUTE (1993). A justificativa para a utilização da proc STATESPACE é que o referido procedimento, tem como base o trabalho de AKAIKE (1976), o qual inicialmente ajusta um modelo VAR sem restrição e posteriormente fornece os valores para o Critério de Informação de AKAIKE (AIC). A ordem do modelo VAR (número de defasagens) a ser escolhida será aquela que tiver o menor valor para o AIC.

Os resultados dos testes de raiz unitária mostraram que todas as variáveis utilizadas são integradas de mesma ordem ${ }^{35}$, nesse caso especifico, de ordem um (I(1)), ou seja essas variáveis possuem raiz unitária, sendo assim pode-se partir para o próximo passo o qual consiste na realização dos testes de co-integração.

Neste trabalho foi utilizado o teste de co-integração proposto por JOHANSEN (1991), o qual baseia-se em testes de razão de máxima verossimilhança, enquanto que o pacote econométrico utilizado foi Econometric Views (Eviews) versão 2.0 conforme descrito em EVIEWS (1994-95).

Quando as variáveis do modelo VAR são integradas de ordem igual ou maior a um, a estimação do modelo VAR sem restrição envolvendo variáveis não estacionárias pode conduzir a regressōes viesadas. No entanto, conforme JOHNSTON e DiNARDO (1997) a presença de variáveis com raiz unitária permitem o obtenção de relações de co-integração.

Como já mencionado anteriomente, duas são as estatísticas disponiveis para testar a hipótese nula de que o rank de co-integração é pelo menos $r$, sendo que $r<n$, ou seja testa-se

\footnotetext{
${ }^{35}$ ENDERS (1995) chama a atenção para o fato de que mesmo que as variáveis sejam integradas de ordem diferentes, ainda assim é possivel fazer o teste de co-integração. Utilizando o próprio exemplo apresentado em ENDERS (1995, p.411) suponha que " $x_{1 t}$ e $x_{2 t}$ sãol(2) e que $x_{3 t}$ seja I(1). Se $x_{1 t}$ e $x_{2 t}$ são $\mathrm{C}(2,1)$, existe uma combinação linear da forma $\beta_{1} x_{1 t}+\beta_{2} x_{2 t}$ que é I(1). Então é possivel que esta
} 
a hipótese de que existam pelo menos $r$ vetores de co-integração (colunas linearmente independentes). Naqueles casos em que a hipótese alternativa é de que existam $n$ colunas linearmente independentes, a estatistica a ser utilizada corresponde à estatística $\lambda_{\text {traco }}$. Quando a hipótese alternativa é de existam $r+1$ colunas linearmente independentes, a estatística utilizada é a estatística $\lambda_{\max }$. Os valores críticos para esses testes para os modelos VAR contendo até onze variáveis encontram-se em OSTERWALD-LENUM (1992). Ao todo são cinco tabelas contendo os valores críticos, os quais dependem do comportamento das caracteristicas de cada série que está sendo analisada, ou seja as tabelas diferem em função da inclusão ou não de termos como intercepto e tendência tanto nas equações do modelo VAR, quanto das equações de co-integração.

O critério para a escolha de qual opção de teste de co-integração a ser utilizado nesse estudo, teve como base os resultados dos testes de raiz unitária, os quais, mostraram que todas as nove variáveis (LIFI, LIRMI, LPET, LIPPUS, LM2, LTCR e LRT) são integradas de ordem 1 , isto é possuem raiz unitária, além do que, a visualização gráfica das variáveis em nível sugere a presença de tendência determinística nos dados ${ }^{36}$.

\subsection{1 - Teste de co-integração, periodo de janeiro de 1990 a junho de 1994}

O primeiro passo na condução do teste de co-integração residiu em determinar o número de defasagens a ser utilizada no modelo VAR. Nesse estudo foi empregado o critério de Akaike univariado generalizado conforme a equação 34.

De acordo com os resultados apresentados na Tabela 23, o critério de Akaike atinge o valor mínimo na defasagem de ordem 6 , a qual corresponde a $-2849,32448$, sinalizando para implementar um modelo VAR com seis defasagens no teste de co-integração. No entanto, em função do grande número de variáveis aliado ao pequeno tamanho do número de observações, não foi possivel efetuar o teste de co-integração com seis defasagens. A opção foi implementar o teste de co-integração utilizando somente uma defasagem, correspondendo dessa forma ao segundo menor valor para o Critério de Informação de Akaike $(-2756,1858)$, conforme apresentado na Tabela 23.

combinação de $x_{1 t}$ e $x_{2 t}$ seja integrada com $x_{3 t}$ tal que a combinação $\beta_{1} x_{1 t}+\beta_{2} x_{2 t}+\beta_{3} x_{3 t}$ è estacionária".

${ }^{36}$ Uma descrição detalhada sobre cada uma das opções relativas ao teste de co-integração e modelos VAR pode ser encontrada em LUTKEPOHL (1999). 
TABELA 23.- Critério de Informação de Akaike para o Modelo Auto-regressivo Vetorial (VAR), variáveis LPET, LIRMI, LIFI, LIPPUS, LTCR, LM2 e LRT, Janeiro de 1990 a Junho de 1994.

\begin{tabular}{cc}
\hline Defasagem $(\mathrm{Lag})$ & Valor do Critério de Informação de Akaike \\
\hline 0 & $-2381,55296$ \\
1 & $-2756,1858^{2}$ \\
2 & $-2718,28306$ \\
3 & $-2682,98474$ \\
4 & $-2708,94822$ \\
5 & $-2745,87121$ \\
6 & $-2849,32448$
\end{tabular}

Menor valor para o Critério de Informaçāo de Akaike, ${ }^{2}$ Defasagem efetivamente adotada.

Fonte: Dados Básicos da International Financial Statistics (1990/1999), Conjuntura Econômica (1991/1999) e U.S. Department of Labor, Bureau of Labor Statistics.

Os valores de todos eigenvalues encontram-se dentro do círculo unitário (Tabela 28). Segundo JOHANSEN (1995), estes resultados indicam que o tipo de não estacionariedade apresentada pelas variáveis analisadas pode ser facilmente removida através da aplicação do operador de diferenças, ou seja, as variáveis são diferença estacionárias.

O teste de co-integração relativo à estatística $\lambda_{\text {traço }}$ mostrou que a hipótese nula de que não há nenhum vetor de co-integração $(r \leq 0)$ contra a hipótese alternativa de que há pelo menos um vetor de co-integração $(r>0)$ foi rejeitada, uma vez que, o valor calculado da estatística $\lambda$ trạ̧o $(201,9172)$ excede o seu respectivo valor tabelado em nível de $1,0 \%$ $(133,57)$. A seguir, foi testada a hipótese nula de que há somente um vetor de co-integração $(r \leq 1)$ contra a hipótese alternativa de que há mais de um vetor de co-integração $(r>1)$. Os resultados obtidos mostraram que a hipótese nula foi rejeitada, dado que, o valor calculado da estatística $\lambda_{\text {trąo }}(115,5038)$ foi novamente superior ao seu respectivo valor tabelado em nível de 1,0\% $(103,18)$. Logo, deve-se dar continuidade ao teste, só que desta vez, a hipótese nula é de que existam somente dois vetores de co-integração $(r \leq 2)$ contra a hipótese alternativa de que existam mais de dois vetores de co-integração $(r>2)$. Novamente, a hipótese nula pode ser rejeitada em nível de 1,0\%, uma vez que, o valor calculado da estatística $\lambda_{\text {traço }}$ é maior que o seu respectivo valor tabelado a esse nível de significância $(76,30283>$ $76,07)$. O próximo passo consistiu em contrastar a hipótese nula de há somente três vetores de co-integração $(r \leq 3)$ contra a hipótese alternativa de que existam pelo menos quatro vetores 
de co-integração $(r>3)$. Verificou-se que mais uma vez a hipótese nula foi rejeitada, porém, em nivel de 5,0\%, dado que o valor calculado excede o valor tabelado somente a esse nivel de significância $(52,29674>47,21)$. O teste foi então repetido, sendo que, adotou-se a hipótese nula de que existam somente quatro vetores de co-integração $(r \leq 4)$ versus a hipótese alternativa da presença de pelo menos cinco vetores $(r>4)$. A hipótese nula foi novamente rejeitada em nivel de 5,0\%, uma vez que, o valor calculado $(30,64138)$ mostrou-se superior ao respectivo valore tabelado $(29,68)$. A seguir confrontou-se a hipótese nula de que há pelo menos cinco vetores de co-integração $(r \leq 5)$ em relação a hipótese alternativa de que existem mais de cinco vetores $(r>5)$. Os resultados indicam que nesse caso, a hipótese nula não pode ser rejeitada, seja em nivel de $1,0 \%$, quanto de $5,0 \%$, dado que o valor calculado $(13,664)$ é inferior aos respectivos valores tabelados a esse niveis de significância. Em função deste resultado, pode-se inferir a presença de cinco vetores de co-integração (Tabela 24). Portanto, não há mais necessidade de se prosseguir com o teste de co-integração, uma vez que o número de vetores de co-integração foi identificado.

Dado que existem pelo menos cinco equações de co-integração entre as variáveis analisadas, isto quer dizer que o número de colunas linearmente independentes é reduzido $(0<$ $r<n$ ), o que implica que as variáveis são co-integradas e consequentemente existe um modelo Vetorial de Correção de Erro (VEC). A partir dessa constatação, o modelo VAR deve incorporar - VEC para analisar os aspectos relativos tanto de curto, quanto de longo prazo entre as variáveis envolvidas no modelo. 
TABELA 24.- Resultados do Teste de Co-integração de Johansen, variáveis LRT, LPET, LIRMI, LIFI, LIPPUS, LTCR e LM2, Janeiro de 1990 a Junho de 1994

\begin{tabular}{|c|c|c|c|c|c|}
\hline Eigenvalue & $\begin{array}{l}\text { Hipótese } \\
\text { Nula }\end{array}$ & $\begin{array}{l}\text { Hipótese } \\
\text { Alternativa }\end{array}$ & $\begin{array}{c}\text { Estatística } \\
\lambda_{\text {traço }} \text { Calculada }\end{array}$ & $\begin{array}{l}\text { Estatistica } \lambda \text { traço } \\
\text { Valor Crítico em } \\
\text { Nivel de } 5,0 \%{ }^{1}\end{array}$ & $\begin{array}{l}\text { Estatística } \lambda \text { traço } \\
\text { Valor Crítico em } \\
\text { Nivel de } 1,0 \%\end{array}$ \\
\hline 0,810202 & $r=0$ & $r>0$ & 201,9172 & 124,24 & 133,57 \\
\hline 0,529456 & $r \leq 1$ & $r>1$ & $115,5038^{2}$ & 94,15 & 103,18 \\
\hline 0,369761 & $r \leq 2$ & $r>2$ & $76,30283^{2}$ & 68,52 & 76,07 \\
\hline 0,340616 & $r \leq 3$ & $r>3$ & $52,29674^{3}$ & 47,21 & 54,46 \\
\hline 0,278547 & $r \leq 4$ & $r>4$ & $30,64138^{3}$ & 29,68 & 35,65 \\
\hline 0,166669 & $r \leq 5$ & $r>5$ & 13,664 & 15,41 & 20,04 \\
\hline 0,077294 & $r \leq 6$ & $r>6$ & $4,183105^{3}$ & 3,76 & 6,65 \\
\hline
\end{tabular}

Talores críticos obtidos diretamente do Eviews, ${ }^{2}$ Significativo em nivel de $1,0 \%,{ }^{3}$ Significativo em nivel de $5,0 \%$.

Fonte: Dados Básicos da International Financial Statistics (1990/1999), Conjuntura Econômica (1991/1999) e U.S. Department of Labor, Bureau of Labor Statistics.

A partir dos resultados do teste de co-integração também é possivel verificar se os sinais dos coeficientes das variáveis analisadas estão coerentes com a teoria econômica. Isto é feito através da análise dos coeficientes das variáveis relativas à primeira equação de cointegração normalizada.

Neste caso a normalização foi efetuada tendo-se como base o valor da estimativa do coeficiente da variável LRT, logo o valor dessa estimativa assumiu valor igual a um. Portanto, LRT representa a variável de saída (endógena) do sistema enquanto que as demais variáveis são consideradas de entrada (exógenas). Sendo assim, a análise das estimativas dos coeficientes deve ser conduzida com os respectivos sinais invertidos, exceto no caso da variável LRT, uma vez que, na equação de co-integração normalizada todas as variáveis permanecem do mesmo lado. Consequentemente, os sinais dos coeficientes estimados das variáveis de entrada na Tabela 25 devem ser analisados com seus respectivos sinais trocados.

A expectativa era de que os sinais relativos a LIFI, LIRMI e LIPPUS fossem todos positivos (relação direta) e o sinal de LPET fosse negativo (relação inversa). No entanto, ao analisar a Tabela 25 verifica-se que somente o sinal relativo a variável LIFI está trocado, enquanto que, os sinais de LPET, LIFI e LIPPUS estão corretos.

Esperava-se que elevações nos preços de alimentos e matérias-primas agrícolas no mercado internacional, os quais são representados pelos índices internacionais de preços de 
alimentos (LIFI) e de matérias-primas agrícolas (LIRMI), decorrentes de excesso de demanda no mercado internacional por tais produtos, levassem ao aumento do índice de relação de troca (LRT), uma vez que, na maior parte dos casos, o Brasil é tomador de preços no mercado mundial de produtos agrícolas, favorecendo dessa forma o setor agrícola brasileiro.

Já elevações no preço internacional do preço do petróleo (LPET) teriam efeito negativo sobre LRT, dado que, choques de oferta, como aqueles ocorridos em 1974 e 1979, são capazes de elevar os custos de produção, principalmente de produtos industriais, uma vez que, o petróleo é um importante insumo utilizado por esse setor, refletindo-se dessa maneira sobre os preços industriais, e consequentemente, tende a reduzir a relação de troca entre agricultura e industria, pois normalmente os preços industriais variam mais que proporcionalmente em relação aos preços agrícolas diante de variações nos preços do petróleo.

Uma elevação no índice de preços ao produtor nos Estados Unidos (LIPPUS) agiria no sentido contrário de variações negativas em LPET, pois o aumento da inflação nos EUA representa uma proxy da utilização da capacidade instalada naqueles país. Mais especificamente, uma vez que, a economia americana é maior e mais importante individualmente em nivel mundial, e também, em função do fato de que os EUA vem experimentando um crescimento sustentado deste 1984, isto implica na necessidade de importação de insumos e matérias-primas agricolas para atender a sua demanda doméstica. Sendo assim, a variação de preços nos EUA pode ser interpretada como sendo a própria demanda internacional, e como resultado, isso teria um efeito positivo sobre a relação de troca entre agricultura e indústria no Brasil, pois agiria no sentido de pressionar os preços agrícolas no Brasil, e consequentemente, favoreceria o setor agricola em detrimento do setor industrial. Também, não se pode esquecer de que as cotações internacionais dos principais produtos agricolas tem como referência as Bolsas americanas (Chicago e New York) e que o geralmente Brasil é tomador de preços no mercado mundial de commodities agrícolas conforme comprovado em diversos estudos, entre os quais, pode-se citar AGUIAR e BARROS (1989), BARROS (1992), PINO e ROCHA (1994), MARGARIDO (1994), MARGARIDO e SOUSA (1998), MARGARIDO et al. (1999) entre outros.

Quanto as variáveis domésticas, observou-se que a oferta de moeda (LM2) não apresentou consistência em relação ao seu respectivo sinal, dado que, a expectativa era de relação direta, pois o aumento da oferta de moeda tende a diminuir a taxa de juros, resultando na transferência de recursos do setor financeiro para a aplicação em commodities agrícolas. Esse aumento na demanda por commodities agricolas tende a contribuir para elevar os preços dos produtos agrícolas, conforme modelo teórico proposto por FRANKEL (1986), favorecendo o setor agricola relativamente ao setor industrial (Tabela 25 ). 
A variável taxa de câmbio real (LTCR), apresentou sinal coerente, pois uma desvalorização real da moeda doméstica (R\$) frente a moeda estrangeira (US\$) tende a elevar a taxa de câmbio real e consequentemente estimular as exportações principalmente de produtos industriais, pelo menos no curto prazo, tendo efeito positivo sobre os preços industriais domésticos em nivel de atacado e piorando a relação de troca entre agricultura e indústria (Tabela 25). Em função de suas próprias características, o processo produtivo no âmbito agrícola apresenta forte sazonalidade, sendo assim, variações na taxa de câmbio não tem muito impacto sobre os preços agrícolas no curto prazo, pois é necessário esperar o próximo ciclo produtivo para ampliar a oferta do produto. Já em relação aos produtos industriais, a produção não é tão afetada pela sazonalidade, ou seja, a produção é mais constante ao longo do ano. Portanto, os preços industriais tendem a responder mais rapidamente relativamente aos preços agrícolas diante de choques na taxa de câmbio real. Geralmente, os preços agrícolas tendem a ser mais sensiveis às variações nas condições de demanda no mercado internacional do que em função de variações na taxa real de câmbio conforme apresentado em CARVALHO e NEGRI (2000).

TABELA 25.- Coeficientes da primeira equação de co-integração normalizada, variáveis LPET, LIRMI, LIFI, LIPPUS, LTCR, LM2 e LRT, Janeiro de 1990 a Junho de 1994.

\begin{tabular}{cc}
\hline Variável & Estimativas dos Coeficientes do primeiro vetor \\
\hline LRT & 1.000000 \\
LPET & $12.62767^{1}$ \\
LIRMI & $-131.1355^{1}$ \\
LIFI & $303.3214^{1}$ \\
LIPPUS & $-28.67744^{1}$ \\
LTCR & $30.86353^{1}$ \\
LM2 & $9.698394^{1}$ \\
Constante & $-327.5878^{1}$
\end{tabular}

\footnotetext{
A análise dos sinais dos coeficientes é realizada com os sinais invertidos em relação ao que aparecem na Tabela.

Fonte: Dados Básicos da International Financial Statistics (1990/1999), Conjuntura Econômica (1991/1999) e U.S. Department of Labor, Bureau of Labor Statistics.
} 


\subsection{2 - Teste de co-integração, periodo de julho de 1994 a dezembro de 1998}

O Critério de Informação apresentou valor minimo para a defasagem de ordem um, logo, para a realização do teste de co-integração utilizou-se apenas uma defasagem (Tabela 26).

TABELA 26.- Critério de Informação de Akaike para o Modelo Auto-regressivo Vetorial (VAR), variáveis LPET, LIRMI, LIFI, LIPPUS, LTCR, LM2 e LRT, Julho de 1994 a dezembro de 1998

\begin{tabular}{cc}
\hline Defasagem (Lag) & Valor do Critério de Informação de Akaike \\
\hline 0 & $-2757,23425$ \\
1 & $-3208,97936^{1}$ \\
2 & $-3170,07005$ \\
3 & $-3129,48375$ \\
4 & $-3104,40686$ \\
5 & $-3103,00295$ \\
6 & $-3109,53174$
\end{tabular}

TMenor valor para o Critério de Informação de Akaike.

Fonte: Dados Básicos da International Financial Statistics (1990/1999), Conjuntura Econômica (1991/1999) e U.S. Department of Labor, Bureau of Labor Statistics.

Contrariamente ao que ocorreu em relação ao primeiro período analisado, os valores dos eigenvalues para o segundo periodo não encontram-se tão próximos de um como no caso anterior, porém estão todos dentro do círculo unitário, logo para eliminar a não estacionariedade é necessário utilizar diferenças para tornar as variáveis estacionárias.

Os resultados do teste de co-integração mostraram que a hipótese nula de não cointegração foi rejeitada, uma vez que, o valor calculado da estatística $\lambda$ traço é igual a 152,9633, o qual é superior ao seu respectivo valor crítico que nesse caso vale 133,57 em nível de 1,0\%. Portanto, esse resultado indica que há pelo menos um vetor de co-integração, logo, o teste deve continuar, só que desta vez, a hipótese nula é de que exista somente um vetor de cointegração $(r \leq 1)$ contra a hipótese alternativa de que exista mais de um vetor de cointegração $(r>1)$. Novamente, a hipótese nula é rejeitada, pois a estatística calculada é superior ao valor crítico ao nível de $1,0 \%(111,9036>103,18)$. Sendo assim, deve-se dar prosseguimento ao teste de co-integração. Agora, a hipótese nula é de que há pelo menos dois vetores de co-integração $(r \leq 2)$ versus a hipótese alternativa de que há mais de dois vetores de co-integração $(r>2)$. Os resultados obtidos, indicam mais uma vez que a hipótese nula 
não pode ser rejeitada ao nivel de $1,0 \%$, dado que o valor calculado para a estatística $\lambda_{\text {traço }}$ é igual a 76,11615, enquanto que, o valor crítico a esse nível de significância vale 76,07. Logo, o teste necessita ser efetuado mais uma vez. A hipótese nula nessa etapa é de que existam pelo menos três vetores de co-integração $(r \leq 3)$ contra a hipótese alternativa de que existam mais de três vetores de co-integração $(r>3)$. O valor para a estatística $\lambda_{\text {trạ̧o }}$ calculada é igual a 46,73511, enquanto que, os valores críticos são iguais a 54,46 e 47,21 em nível de $1,0 \%$ e $5,0 \%$ respectivamente, isto é, a esses niveis de significância a hipótese nula não pode ser rejeitada (Tabela 27). Portanto, conclui-se que existem apenas três vetores de co-integração, sendo assim, como o número de vetores não é pleno, deve-se utilizar o modelo Vetorial de Correção de Erro (VEC), o qual é uma forma restrita do modelo Vetorial Auto-regressivo (VAR) .

TABELA 27.- Resultados do Teste de Co-integração de Johansen, variáveis LPET, LIRMI, LIFI, LIPPUS, LTCR, LM2 e LRT, Julho de 1994 a Dezembro de 1998

\begin{tabular}{cccccc}
\hline Eigenvalue & Hipótese & Hipótese & Estatística & Estatística $\lambda$ traço & Estatística $\lambda$ traço \\
& Nula & Alternativa & $\lambda_{\text {traco }}$ Calculada & Valor Crítico em & Valor Crítico em \\
& & & Nível de $5,0 \%$ & Nível de $1,0 \%{ }^{1}$
\end{tabular}

\begin{tabular}{llllll}
\hline 0,545979 & $r=0$ & $r>0$ & $152,9633^{2}$ & 124,24 & 133,57 \\
0,49753 & $r \leq 1$ & $r>1$ & $111,9036^{2}$ & 94,15 & 103,18 \\
0,431651 & $r \leq 2$ & $r>2$ & $76,11615^{2}$ & 68,52 & 76,07 \\
0,345045 & $r \leq 3$ & $r>3$ & 46,73511 & 47,21 & 54,46 \\
0,30394 & $r \leq 4$ & $r>4$ & 24,72926 & 29,68 & 35,65 \\
0,106606 & $r \leq 5$ & $r>5$ & 5,88867 & 15,41 & 20,04 \\
0,000516 & $r \leq 6$ & $r>6$ & 0,026843 & 3,76 & 6,65 \\
\hline
\end{tabular}

Valores críticos obtidos diretamente do Eviews, ${ }^{2}$ Significativo em nivel de $1,0 \%$.

Fonte: Dados Básicos da International Financial Statistics (1990/1999), Conjuntura Econômica (1991/1999) e U.S. Department of Labor, Bureau of Labor Statistics.

Nesse caso, em relação ao sinal das variáveis, verificou-se que do total de sete variáveis, apenas uma apresentou sinal trocado. Assim como aconteceu no primeiro modelo, as variáveis internacionais indice de preços de matérias-primas agricolas, indice de preços nos Estados Unidos e preço internacional do petróleo apresentaram sinal consistente com o esperado, somente a variável indice internacional de preços de alimentos teve seu sinal alterado relativamente ao que se esperava.

No tocante as variáveis domésticas, tanto a taxa de câmbio real, quanto a oferta de moeda apresentaram-se com o sinal condizente com o esperado (Tabela 28). 
Detalhando um pouco mais a análise, obsenva-se que variações nos preços internacionais do petróleo (LPET) em magnitude de 10,0\% tendem a deteriorar a relação de troca entre o setor agrícola e industrial (LRT) em torno de 2,37\%. Já variações de 10,0 nos preços internacionais de matérias-primas agrícolas (LIRMI) proporcionam uma melhoria da relação de troca em cerca de $1,27 \%$, enquanto que, variações de $10,0 \%$ nos preços internacionais de alimentos (LIFI) provocam queda da relação de troca de $3,33 \%$. No caso de variações do índice de preços nos Estados Unidos de 10,0\% tendem a elevar a relação de troca em $28,85 \%$ (Tabela 28).

Quanto ao comportamento de LRT diante de alterações nas variáveis domésticas, verifica-se que variações de $10,0 \%$ na taxa de câmbio real (LTCR) reduzem a relação de troca em 19,48\%. Para a variável oferta de moeda (LM2) uma expansão de 10,0\% na quantidade de moeda na economia leva a um aumento na relação de troca entre os setores agrícola e industrial em $1,54 \%$ (Tabela 28).

TABELA 28.- Coeficientes da primeira equação de co-integração normalizada, variáveis LPET, LIRMI, LIFI, LIPPUS, LTCR, LM2 e LRT, Julho de 1994 a Dezembro de 1998.

\begin{tabular}{cc}
\hline Variável & Estimativas dos Coeficientes do primeiro vetor \\
\hline LRT & 1,000000 \\
LPET & $0,237423^{1}$ \\
LIRMI & $-0,127976^{1}$ \\
LIFI & $0,333419^{1}$ \\
LIPPUS & $-2,885560^{1}$ \\
LTCR & $1,948248^{1}$ \\
LM2 & $-0,154339^{1}$ \\
Constante & $5,986053^{1}$
\end{tabular}

T análise dos sinais dos coeficientes é realizada com os sinais invertidos em relação ao que aparecem na Tabela.

Fonte: Dados Básicos da International Financial Statistics (1990/1999), Conjuntura Econômica (1991/1999) e U.S. Department of Labor, Bureau of Labor Statistics.

Finalmente, em relação aos sinais dos coeficientes das equações de co-integração, torna-se relevante mencionar que esses sinais devem ser analisados com muito cuidado, uma vez que, para algumas variáveis, eles refletem o comportamento de mercado dessas variáveis, como por exemplo, no caso do preço internacional do petróleo, cujas variações têm efeitos diretos sobre o conjunto das demais variáveis. Enquanto que, outras espelham os efeitos indiretos, ou seja, decorrentes das respostas das medidas de política econômica como reação aos choques exógenos, visando dessa forma, minimizar os efeitos destes últimos. Neste caso, pode-se citar como exemplo os efeitos de variaçōes no nivel de preços nos Estados Unidos 
sobre o comportamento da taxa de câmbio real no Brasil.

JOHNSTON e DiNARDO (1997) também chamam a atenção para o fato de que a presença de dois ou mais vetores de co-integração pode conduzir a resultados ambíguos em relação aos coeficientes estimados nas equações de co-integração. Portanto, pode-se concluir que os valores dos coeficientes estimados devem ser analisados com cautela.

\subsection{3 - Teste de co-integração, período de janeiro de 1990 a dezembro de 1998}

O Critério de Informação de Akaike obteve valor minimo $(-7577,93287)$ na defasagem de ordem dez, indicando a necessidade de se incluir um total de dez defasagens na realização do teste de co-integração (Tabela 29).

TABELA 29.- Critério de Informação de Akaike para o Modelo Auto-regressivo Vetorial (VAR), variáveis LPET, LIRMI, LIFI, LIPPUS, LTCR, LM2 e LRT, Janeiro de 1990 a Dezembro de 1998

\begin{tabular}{cc}
\hline Defasagem (Lag) & Valor do Critério de Informação de Akaike \\
\hline 0 & $-4281,26535$ \\
1 & $-5638,25064$ \\
3 & $-5628,34971$ \\
4 & $-5606,3502$ \\
5 & $-5601,47314$ \\
6 & $-5612,43125$ \\
7 & $-5595,62969$ \\
8 & $-5577,15137$ \\
9 & $-5539,63112$ \\
10 & $-5542,2575$ \\
\hline
\end{tabular}

\footnotetext{
Menor valor para o Critério de Informação de Akaike.

Fonte: Dados Básicos da Intemational Financial Statistics (1990/1999), Conjuntura Econômica (1991/1999) e U.S. Department of Labor, Bureau of Labor Statistics.
}

O fato dos eigenvalues estarem contidos dentro do círculo unitário, indica que a estacionariedade para cada variável pode ser obtida a partir da aplicação do operador de diferenças.

Em relação ao teste de co-integração relativo a este periodo, é necessário realçar que foi incluída uma variável de intervenção (dummy) do tipo step a partir de julho de 1994 (Plano Real). Essa variável assume valor igual a zero no intervalo de janeiro de 1990 até junho de 1994 e valor igual a um a partir de julho de 1994 até dezembro de 1998. Outro aspecto a ser 
frisado, é que em função da inclusão da variável de intervenção, o Eviews não fornece diretamente os respectivos valores críticos, sendo assim, os valores críticos tabelados em nível de $1,0 \%$ e $5,0 \%$ foram obtidos do trabalho de OSTERWALD-LENUM (1992).

Os resultados dos testes de co-integração indicaram a presença de quatro vetores de co-integração (Tabela 30). Assim como aconteceu com os testes de co-integração para os dois períodos anteriores, o número de colunas linearmente independentes não é plena, dado que o número total de variáveis corresponde a sete e somente existem quatro colunas linearmente independentes $(0<r=4<p=7)$ então, ao invés do modelo VAR é necessário utilizar o modelo Vetorial de Correção de Erro (VEC) para captar as relações de curto e longo prazo existentes entre as variáveis envolvidas na análise.

TABELA 30.- Resultados do Teste de Co-integração de Johansen, variáveis LPET, LIRMI, LIFI, LIPPUS, LTCR, LM2 e LRT, Janeiro de 1990 a Dezembro de 1998

\begin{tabular}{|c|c|c|c|c|c|}
\hline \multirow[t]{3}{*}{ Eigenvalue } & \multirow{3}{*}{$\begin{array}{l}\text { Hipótese } \\
\text { Nula }\end{array}$} & \multirow{3}{*}{$\begin{array}{l}\text { Hipótese } \\
\text { Alternativa }\end{array}$} & \multirow{3}{*}{$\begin{array}{c}\text { Estatistica } \lambda_{\text {trạ̧o }} \\
\text { Calculada }\end{array}$} & Estatística & Estatística \\
\hline & & & & $\lambda_{\text {traço }}$ Valor & $\lambda_{\text {tracoo }}$ Valor \\
\hline & & & & $\begin{array}{l}\text { Critico em Nivel } \\
\text { de } 5.0 \%\end{array}$ & $\begin{array}{l}\text { Crítico em Nível } \\
\text { de } 1,0 \%\end{array}$ \\
\hline 0,841594 & $r=0$ & $r>0$ & $520,7536^{2}$ & 202,92 & 215,74 \\
\hline 0,763859 & $r \leq 1$ & $r>1$ & $342,0221^{2}$ & 165,58 & 177,20 \\
\hline 0,50832 & $r \leq 2$ & $r>2$ & $202,0194^{2}$ & 131,70 & 143,09 \\
\hline 0,488114 & $r \leq 3$ & $r>3$ & $133,1564^{2}$ & 102,14 & 111,01 \\
\hline 0,362961 & $r \leq 4$ & $r>4$ & 68,20002 & 76,07 & 84,45 \\
\hline 0,222588 & $r \leq 5$ & $r>5$ & 24,46028 & 53,12 & 60,16 \\
\hline 0,000383 & $r \leq 6$ & $r>6$ & 0,037133 & 34,91 & 41,07 \\
\hline
\end{tabular}

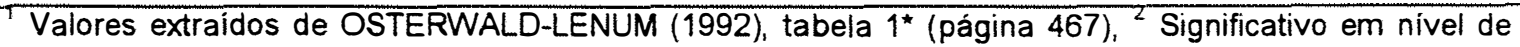
$1,0 \%$.

Fonte: Dados Básicos da International Financial Statistics (1990/1999), Conjuntura Econômica (1991/1999) e U.S. Department of Labor, Bureau of Labor Statistics.

Comparativamente aos resultados obtidos nos dois periodos anteriores, este periodo foi o que apresentou resultados menos consistentes em relação aos sinais das variáveis. Do total de seis variáveis de entrada, cerca de três variáveis apresentaram sinais não coerentes com a teoria econômica, sendo todas externas, quais sejam, LIRMI, LPET e LIPPUS. Somente as variáveis LIFI (externa), e as duas domésticas LTCR e LM2 mantiveram os sinais consistentes com o que era esperado (Tabela 31). 
TABELA 31.- Coeficientes da primeira equação de co-integração normalizada, variáveis LPET, LIRMI, LIFI, LIPPUS, LTCR, LM2 e LRT, Janeiro de 1990 a Dezembro de 1998.

\begin{tabular}{cc}
\hline Variável & Estimativas dos Coeficientes do primeiro vetor \\
\hline LRT & 1,000000 \\
LPET & $-0.699344^{1}$ \\
LIRMI & $3.693273^{1}$ \\
LIFI & $-3.204773^{1}$ \\
LIPPUS & $2.567542^{1}$ \\
LTCR & $1.086123^{1}$ \\
LM2 & $-0.035270^{1}$ \\
Constante & $-4.944294^{1}$ \\
\hline
\end{tabular}

T análise dos sinais dos coeficientes é realizada com os sinais invertidos em relação ao que aparecem na Tabela.

Fonte: Dados Básicos da International Financial Statistics (1990/1999), Conjuntura Econômica (1991/1999) e U.S. Department of Labor, Bureau of Labor Statistics.

\section{3.- Modelo vetorial de correção de erro (VEC)}

De acordo com ALVES, FAVA e SILBER (1999) os coeficientes dos vetores de cointegração "não devem ser interpretados diretamente como uma medida dos impactos das inovações para cada variável isolada do resto. Segundo LUTKEPOHL (1991), estes coeficientes não levam em conta os relacionamentos entre as variáveis, expressa no modelo VAR. Então, o caminho mais apropriado para avaliar os impactos da inovações é dado pela função de resposta de impulso". Portanto, para analisar os efeitos dos choques das variáveis internacionais e domésticas sobre os preços agricolas em nível de atacado no Brasil, o mais indicado é utilizar o modelo Vetorial de Correção de Erro (VEC). Para a obtenção da decomposição da variância e da função de resposta de impulso para cada período foi utilizado o software Eviews 2.0.

O próximo passo consistiu na escolha do modelo mais apropriado para dar continuidade à análise. Todos os três modelos apresentaram um número de vetores de co-integração inferior ao número de variáveis envolvidas em cada modelo. Portanto, em nenhum dos três casos pode-se utilizar o VAR, seja em nivel, ou nas diferenças. De acordo com o referencial teórico apresentado em JOHANSEN (1995), o mais indicado é utilizar o VEC de maneira a captar, tanto os aspectos de curto, quanto de longo prazo entre as variáveis.

O modelo para o periodo de janeiro de 1990 até junho de 1994 apresentou um total de cinco vetores de co-integração num sistema com sete variáveis, sendo que, apenas cinco variáveis apresentaram-se com seus respectivos sinais consistentes com a teoria econômica. 
Já o modelo abrangendo julho de 1994 até dezembro de 1998 apresentou três vetores de cointegração e seis variáveis com os sinais coerentes. Finalmente, o terceiro modelo que vai de janeiro de 1990 até dezembro de 1998 apresentou quatro vetores de co-integração e apenas quatro variáveis com os sinais de acordo com o que se esperava. Em função desses resultados, optou-se em utilizar o modelo 2, dado que foi esse modelo que apresentou o maior número de variáveis com sinal consistente com a teoria econômica comparativamente aos demais modelos, além do que, não houve muitos conflitos em relação a determinação da ordem de integração das variáveis nesse período. Outros fatores que contribuiram para a escolha desse modelo, refere-se ao fato de que a determinação da ordem de integração das variáveis no modelo 1 apresentou resultados conflitantes entre os testes de raiz unitária, talvez, em função da instabilidade de preços da economia brasileira no período que antecedeu a implementação do Plano Real, podendo assim, prejudicar a seqüência da análise. Quanto ao modelo 3, dado que, foi necessária a inclusão de uma variável de intervenção para captar mudança ocorrida nas variáveis após a implementação do Plano Real, isto pode complicar a análise, uma vez que, a questão do uso de variáveis de intervenção nos testes de co-integração ainda não é uma área completamente sedimentada.

Uma vez que, o objetivo principal deste estudo consiste em verificar como variações em variáveis internacionais e domésticas se transferem para os preços agrícolas internos no caso de uma economia com maior grau de abertura ao comércio internacional, como aconteceu com - Brasil, principalmente após a implementação do Plano Real, visando assim, fazer uma análise comparativa com o trabalho de PONGIBOVE (1996), o qual explorou esse mesmo tema, só que, numa situação em que a economia brasileira era mais fechada em relação ao comércio internacional, aparentemente torna-se mais interessante utilizar o modelo abrangendo julho de 1994 até dezembro de 1998, pois após o Plano Real a abertura comercial foi intensificada, enquanto que no modelo completo estão incorporados dois periodos distintos seja em termos de grau de abertura em relação ao exterior, seja em relação a questão da estabilidade de preços, fatos que tornam a utilização deste modelo mais complexa, pois é necessária a inclusão de variáveis de intervenção. Mais especificamente, conforme ALVES, FAVA e SILBER (1999, p. 26) é importante realçar que "os valores críticos para os testes de co-integração podem não ser completamente válidos quando o modelo contém variáveis deterministicas outras que não sejam o intercepto e tendência". 


\subsection{1 - Modelo Auto-regressivo Vetorial (VAR) Identificável}

Para calcular os coeficientes da matriz $A_{0}$ do modelo VAR identificável utilizou-se o pacote econométrico WINRATS versão 4.3. Adotou-se o procedimento especificado em ENDERS (1995) para a estimação desse modelo no RATS. Quanto à ordem em que as variáveis foram introduzidas no modelo é necessário observar que, em primeiro lugar entram as variáveis internacionais, as quais devem influenciar o comportamento das variáveis domésticas e não o contrário. Ainda, em relação às variáveis internacionais, o mais sensato é colocar os insumos antes dos produtos, ou seja, preço do petróleo antecedendo preços de matériasprimas agrícolas e alimentos, logo a ordem a ser seguida consiste em colocar os produtos antes dos índices de preços que por eles é afetado. Quanto às variáveis domésticas, as variáveis macroeconômicas devem aparecer antes das variáveis setoriais, isto é, a taxa de câmbio real e a oferta de moeda devem vir antes do indice de relação de trocas entre os setores agrícolas e industrial. Ainda assim, falta determinar se os preços das matérias-primas agricolas devem anteceder os preços dos alimentos ou deve ser o contrário no caso das variáveis internacionais e se a taxa de câmbio deve vir antes ou depois da oferta de moeda em relação às variáveis domésticas macroeconômicas.

Foram realizadas simulações em relação a ordem de estimação das variáveis no modelo VAR identificável, e os resultados mostraram que o modelo mais adequado foi aquele utilizado por PONGIBOVE (1996), sendo assim, a ordem das variáveis neste estudo é a mesma utilizada por esse autor.

É importante frisar que as estimativas dos coeficientes da matriz de inter-relações contemporâneas $\left(A_{0}\right)$ mostram os efeitos imediatos e parciais a partir de uma determinada variação de alguma variável sobre as demais variáveis levando em consideração a estrutura de restrições que são impostas sobre o sistema. Mais especificamente, os valores estimados dos coeficientes representam os efeitos instantâneos, pois não levam em consideração os impactos de choques acontecidos no passado, logo capta apenas os efeitos de choques contemporâneos, e também, são parciais, dado que, não levam em consideração os impactos derivados, ou seja, captam somente os impactos diretos sofridos pela variável e não os impactos indiretos proporcionados por outras variáveis do sistema.

Os sinais dos elementos fora da diagonal principal foram devidamente trocados. De maneira geral os sinais dos coeficientes estão alinhados com o que era esperado conforme apresentado na Tabela 32.

No caso de LPET, verificou-se que variações nos preços internacionais do petróleo praticamente não tem influência sobre o comportamento dos preços internacionais de matériasprimas agricolas. Em relação ao índice de preços de alimentos no mercado internacional, 
verificou-se que variações nos preços internacionais do petróleo conduzem a uma redução desse indice. Já, quanto ao comportamento do indice de preços nos Estados Unidos, variações nos preços internacionais do petróleo também praticamente não tem efeito sobre esse indice (Tabela 32).

Quanto às variáveis domésticas, o maior impacto de variações nos preços do petróleo incide sobre a taxa de câmbio real, produzindo uma valorização da respectiva taxa, enquanto que, os efeitos de variações nos preços internacionais do petróleo têm impactos reduzidos sobre o comportamento da oferta de moeda da relação de troca entre agricultura e indústria no Brasil (Tabela 32).

Em relação às variações nos preços internacionais de matérias-primas agricolas, seu efeito sobre o conjunto de variáveis externas indice internacional de preços de alimentos e indice de preços nos EUA é reduzido. O impacto maior incide sobre a variável doméstica relação de troca agricultura e indústria, seguida da taxa de câmbio real e em menor escala sobre a oferta de moeda (Tabela 32 ).

O efeito de variações nos preços internacionais de alimentos foi a que apresentou maior equilibrio em relação a distribuição de seu seus efeitos sobre o grupo de variáveis domésticas, enquanto que, no âmbito internacional, suas variaçōes têm efeitos despreziveis sobre o indice de preços nos EUA (Tabela 32).

Quanto à variável nivel de preços nos EUA, observou-se que variações nessa variável têm efeitos principalmente sobre o comportamento da taxa de câmbio real, seguida da oferta de moeda e da relação de troca agricultura indústria (Tabela 32 ).

O efeito de variações na taxa de câmbio real tem forte impacto sobre a relação de troca e praticamente impacto nulo sobre a oferta de moeda (Tabela 36). Este resultado mostra que variações na taxa de câmbio real tendem a reduzir a relação de troca entre o setor agricola e industrial, ou seja, os preços agricolas são menos sensiveis às variações na taxa de câmbio do que os preços industriais conforme resultado obtido por CARVALHO e NEGRI (2000).

Finalmente, choques na oferta de moeda tem impacto positivo sobre o comportamento da variável relação de troca (Tabela 32). 
TABELA 32.- Estimativas dos coeficientes da matriz $A_{0}$

\begin{tabular}{|c|c|c|c|c|c|c|c|}
\hline Variáveis & LPET & LIRMI & LIFI & LIPPUS & LTCR & LM2 & LRT \\
\hline LPET & 1 & 0 & 0 & 0 & 0 & 0 & 0 \\
\hline LIRMI & $\begin{array}{c}0,054447 \\
(0,07800)\end{array}$ & 1 & 0 & 0 & 0 & 0 & 0 \\
\hline LIFI & $\begin{array}{l}-0,11407 \\
(0,06461)\end{array}$ & $\begin{array}{c}0,04060 \\
(0,11434)\end{array}$ & 1 & 0 & 0 & 0 & 0 \\
\hline LIPPUS & $\begin{array}{c}0,04163 \\
(0,01478)\end{array}$ & $\begin{array}{l}-0,04177 \\
(0,02544)\end{array}$ & $\begin{array}{c}0,09465 \\
(0,03081)\end{array}$ & 1 & 0 & 0 & 0 \\
\hline LTCR & $\begin{array}{c}-0,13449 \\
(-)\end{array}$ & $\begin{array}{c}0,14967 \\
(-)\end{array}$ & $\begin{array}{c}0,19411 \\
(-)\end{array}$ & $\begin{array}{c}2,14721 \\
(-)\end{array}$ & 1 & 0 & $\begin{array}{c}1,61604 \\
(-)\end{array}$ \\
\hline LM2 & $\begin{array}{c}-0,01997 \\
(-)\end{array}$ & $\begin{array}{c}0,04345 \\
(-)\end{array}$ & $\begin{array}{c}0,14545 \\
(-)\end{array}$ & $\begin{array}{c}1,89065 \\
(-)\end{array}$ & $\begin{array}{c}-0,60761 \\
(-)\end{array}$ & 1 & 0 \\
\hline LRT & $\begin{array}{c}-0,03381 \\
(-) \\
\end{array}$ & $\begin{array}{c}-0,41430 \\
(-) \\
\end{array}$ & $\begin{array}{c}-0,45397 \\
(-)\end{array}$ & $\begin{array}{c}0,79977 \\
(-)\end{array}$ & $\begin{array}{c}-2,98053 \\
(-)\end{array}$ & $\begin{array}{c}0,30095 \\
(-)\end{array}$ & 1 \\
\hline
\end{tabular}

\subsection{2.- Modelo Vetorial de Correção de Erro (VEC) julho de 1994 a dezembro de1998}

A Tabela 37 apresenta as estimativas dos coeficientes das equações de co-integração e do modelo Vetorial de Correção de Erro. Pode-se observar que o sentido de causalidade, levando-se em consideração a correção de erro, mostra que as variáveis que mais influenciam LRT além dela própria no período anterior é o índice internacional de preços de alimentos defasado de um período ambos com teste $t$ igual a $-2,04$ (Tabela 33). Em ordem decrescente, as demais variáveis que exercem influência sobre o comportamento de LRT são: preço internacional do petróleo (teste $t$ igual a-1,63; indice de preços nos EUA (teste $t$ igual a -1,60; indice internacional de preços de alimentos (teste $t$ igual a -1,49); taxa de câmbio real (teste $t$ igual a $-1,24$ ) e finalmente, a oferta de moeda (teste $t$ igual a $-1,16$ ) todas defasadas de um período. 
TABELA 33.- Coeficientes das equações de co-integração e do modelo Vetorial de Correção de Erro (VEC), variáveis LPET, LIRMI, LIFI, LIPPUS, LTCR, LM2 e LRT, Julho de 1994 a Dezembro de 1998.

\begin{tabular}{|c|c|c|c|c|c|c|c|}
\hline $\begin{array}{c}\text { Correção de } \\
\text { Erro }\end{array}$ & $\mathrm{D}(\mathrm{LPET})$ & $\mathrm{D(LIRMI)}$ & $\mathrm{D}(\mathrm{LIFI})$ & $\overline{D(\text { LIPPUS) }}$ & $\mathrm{D}(\mathrm{LTCR})$ & $\overline{\mathrm{D}(\mathrm{LM} 2)}$ & $\overline{\mathrm{D}(\mathrm{LRT})}$ \\
\hline \multicolumn{8}{|l|}{ Co-integração } \\
\hline Equação 1 & $-0,245$ & 0,021 & 0,078 & $-0,007$ & $-0,064$ & $-0,074$ & 0,038 \\
\hline Teste $t$ & $(-3,04)^{3}$ & $(-0,41)$ & $(-1,82)^{4}$ & $(-0,62)$ & $(-3,15)^{3}$ & $(-1,65)^{4}$ & $(-0,90)$ \\
\hline Equação 2 & 0,416 & 0,062 & $-0,133$ & 0,043 & 0,059 & 0,130 & $-0,170$ \\
\hline Teste $t$ & $(-2,94)^{3}$ & $(-0,68)$ & $(-1,77)^{4}$ & $(-2,17)^{3}$ & $(-1,66)^{4}$ & $(-1,64)^{5}$ & $(-2,33)^{3}$ \\
\hline Equação 3 & $-0,082$ & 0,102 & $-0,160$ & 0,030 & $-0,018$ & $-0,018$ & $-0,195$ \\
\hline Teste $t$ & $(-0,52)$ & $(-1,03)$ & $(-1,94)^{4}$ & $(-1,36)^{5}$ & $(-0,45)$ & $(-0,21)$ & $(-2,44)^{3}$ \\
\hline$\overline{\mathrm{D}(\mathrm{LPET}(-1))^{2}}$ & 0,140 & 0,006 & $-0,042$ & $-0,007$ & 0,035 & $-0,106$ & $-0,124$ \\
\hline Teste $t$ & $(-0,95)$ & $(-0,06)$ & $(-0,54)$ & $(-0,32)$ & $(-0,95)$ & $(-1,28)$ & $(-1,63)^{5}$ \\
\hline$\overline{D(L I R M I(-1))^{2}}$ & $-0,214$ & 0,073 & 0,163 & 0,010 & 0,118 & $-0,392$ & 0,256 \\
\hline Teste $t$ & $(-0,64)$ & $(-0,34)$ & $(-0,92)$ & $(-0,21)$ & $(-1,40)^{5}$ & $(-2,11)^{3}$ & $(-1,49)^{5}$ \\
\hline$\overline{\mathrm{D}(\mathrm{LIFI}(-1))^{2}}$ & $-0,586$ & $-0,014$ & 0,030 & $-0,001$ & $-0,052$ & 0,145 & 0,310 \\
\hline Teste $t$ & $(-1,99)^{4}$ & $(-0,07)$ & $(-0,19)$ & $(-0,01)$ & $(-0,69)$ & $(-0,87)$ & $(-2,04)^{3}$ \\
\hline$\overline{D(L I P P U S(-1))^{2}}$ & 1,539 & $-0,283$ & 0,117 & $-0,126$ & $-0,186$ & 0,388 & $-0,912$ \\
\hline Teste $t$ & $(-1,40)^{5}$ & $(-0,40)$ & $(-0,20)$ & $(-0,82)$ & $(-0,67)$ & $(-0,62)$ & $(-1,60)^{5}$ \\
\hline$\overline{\mathrm{D}(\mathrm{LTCR}(-1))^{2}}$ & $-0,171$ & 0,202 & 0,348 & 0,072 & $-0,053$ & 0,246 & 0,380 \\
\hline Teste $t$ & $(-0,29)$ & $(-0,53)$ & $(-1,10)$ & $(-0,86)$ & $(-0,35)$ & $(-0,74)$ & $(-1,24)$ \\
\hline$\overline{D(L M 2(-1))^{2}}$ & $-0,462$ & 0,002 & $-0,064$ & $-0,067$ & 0,030 & $-0,107$ & $-0,197$ \\
\hline Teste $t$ & $(-1,41)^{5}$ & $(-0,01)$ & $(-0,37)$ & $(-1,46)^{5}$ & $(-0,36)$ & $(-0,58)$ & $(-1,16)$ \\
\hline$\overline{\mathrm{D}(\mathrm{LRT}(-1))^{2}}$ & 0,562 & 0,124 & 0,120 & 0,033 & $-0,002$ & 0,045 & 0,423 \\
\hline Teste $t$ & $(-1,40)^{5}$ & $(-0,48)$ & $(-0,56)$ & $(-0,58)$ & $(-0,02)$ & $(-0,20)$ & $(-2,04)^{3}$ \\
\hline Constante & $-0,001$ & $-0,001$ & 0,000 & 0,001 & 0,000 & 0,010 & 0,003 \\
\hline Teste $t$ & $(-0,20)$ & $(-0,33)$ & $(-0,07)$ & $(-1,66)^{4}$ & $(-0,35)$ & $(-4,09)^{3}$ & $(-1,36)^{5}$ \\
\hline
\end{tabular}

'Variável diferenciada, ${ }^{2}$ Variável diferenciada e defasada, ${ }^{3}$ Significativo em nivel de 5,0\%, ${ }^{4}$ Significativo em nivel de $10,0 \% e^{5}$ Significativo em nivel de $20,0 \%$.

Fonte: Dados básicos da International Financial Statistics (1990/1999), Conjuntura Econômica (1991/1999) e U.S. Department of Labor, Bureau of Labor Statistics.

\subsubsection{1 - Análise da decomposição da variância dos erros de previsão}

A Tabela 34, apresenta os resultados relativos à decomposição da variância dos erros de previsão para as variáveis internacionais e domésticas. Em outras palavras, a decomposição da variância dos erros de previsão mostra o comportamento dinâmico apresentado pelas 
variáveis econômicas. Mais especificamente, este instrumental permite separar a variância do erro de previsão para cada variável em componentes que podem ser atribuidos pelas demais variáveis endógenas isoladamente, ou seja, revela em termos percentuais qual o efeito que um choque não antecipado sobre determinada variável tem sobre as demais variáveis pertencentes ao sistema.

A primeira coluna da Tabela 34 apresenta os periodos, que nesse caso estão expressos em números de meses. Neste estudo, admite-se que um choque sobre qualquer uma das variáveis analisadas perdure no máximo vinte e quatro meses. A segunda coluna apresenta o erro-padrão da previsão para os horizontes de um até vinte quatro meses em função de choques exógenos sobre cada variável individualmente. A tendência é de que o erro-padrão da previsão aumente conforme avance o horizonte temporal relativamente à data de ocorrência do choque inicial. Isto deve-se ao fato de que as incertezas que permeiam os diversos mercados tornam as previsões menos precisas no médio e longo prazo.

Ainda com relação à Tabela 34, tomando como exemplo o caso da variável LPET, a terceira coluna capta o percentual da variância do erro de previsão em função de choques sobre essa variável, ou seja, mede qual o efeito que um choque sobre LPET tem sobre ela mesma ao longo do tempo. Enquanto que, por exemplo, a quarta coluna mostra o percentual da variância de previsão de LPET que é atribuida à variações em LIRMI.

Tomado-se o grupo das variáveis internacionais, verifica-se que, expressiva parcela da variância dos erros de previsão é atribuida por choques das variáveis pertencentes a este grupo. No caso da variância dos erros de previsão de LPET, decorridos 24 meses, choques na própria variável $(6,46 \%)$ somados aos choques sobre LIRMI $(41,48 \%)$, LIFI $(2,31 \%)$ e LIPPUS $(36,17 \%)$ são responsáveis por $86,42 \%$ da variância erros de previsão de LPET (Tabela 34 ).

Em relação a LIRMI a maior parte de seu próprio erro de previsão também é explicada pelas variáveis externas, decorridos 24 meses, o seu erro de previsão totalizou cerca de $98,30 \%$. Sendo que, desse total, cerca de $91,73 \%$ refere-se a variância da própria LIRMI, enquanto que LIFI, LPET e LIPPUS são responsáveis por $1,08 \%, 0,34 \%$ e $5,15 \%$ respectivamente (Tabela 35 ).

A variável internacional LIFI foi a que apresentou menor consistência em relação ao bloco de variáveis internacionais, pois ao final de 24 meses, as variáveis internacionais respondem por apenas $60,11 \%$ do total da variância dos erros de previsão dela própria, cuja distribuição ficou determinada da seguinte maneira: LPET $(9,15 \%)$, LIRMI $(6,76 \%)$, LIFI $(21,58 \%)$ e LIPPUS $(22,62 \%)$ conforme apresentado na Tabela 36.

Para LIPPUS o grupo de variáveis externas também é o principal responsável pela variância do seu erro de previsão, em torno de $87,76 \%$, e a distribuição é a seguinte: LPET 
(7,83\%), LIRMI (57,38\%), LIFI (10,76\%) e LIPPUS (11,79\%). Neste caso, após 24 meses, a maior parte da variância de LIPPUS deve-se a LIRMI (Tabela 37).

Contrariamente ao comportamento de LIRMI e LIFI, onde choques sobre cada uma delas tendem a se dissipar lentamente ao longo do tempo, nos casos de LPET e LIPPUS, choques sobre essas duas últimas variáveis diluem-se rapidamente, pois ao final de 12 meses as suas respectivas decomposição da variância dos erros de previsão decresceram para $18,40 \%$ e $13,77 \%$ respectivamente (Tabela 34 e 37 ) e ao final de 24 meses decaíram ainda mais, chegando a $6,46 \%$ para LPET e $11,79 \%$ para LIPPUS, enquanto que, em relação às outras duas variáveis internacionais as suas respectivas decomposição da variância dos erros de previsão permaneceram acima de $20,0 \%$ ao considerar-se os períodos relativos a 12 e 24 meses respectivamente, sendo igual a $92,70 \%$ e $91,73 \%$ para LIRMI, e $34,78 \%$ e $21,58 \%$ para LIFI (Tabela 35 e 36).

Com exceção de LPET, os resultados encontrados para as demais variáveis externas apresentaram comportamento relativamente próximo àqueles obtidos por PONGIBOVE (1996), pois em relação ao conjunto de variáveis internacionais, ao final de 24 meses, esse autor encontrou um valor relativo a decomposição da variância dos erros de previsão igual a 73,0\%, onde $44,0 \%$ da variância do erro de previsão devia-se ao próprio preço internacional do petróleo e os restantes $29,0 \%$ distribuíram-se da seguinte forma: indice internacional de preços de matérias-primas $(13,0 \%)$, indice internacional de preços de alimentos $(14,0 \%)$ e índice de preços no atacado nos EUA (2,0\%). Enquanto que, neste estudo, ao final de 24 meses, a variância da decomposição da variância dos erros de previsão de LPET somou $86,42 \%$ (Tabela 35). Deste total, ao longo do vigésimo quarto mês, apenas $6,46 \%$ da variância da decomposição dos erros de previsão de LPET deve-se a ela própria, sendo que, os restantes $79,96 \%$ está diretamente relacionada com as demais variáveis, onde em ordem decrescente, LIRMI responde por $41,48 \%$, LIPPUS $36,17 \%$ e LIFI $2,31 \%$.

Possivelmente a discrepância em relação aos resultados obtidos para a variância dos erros de previsão do preço internacional do petróleo entre este estudo e o de PONGIBOVE (1996) está diretamente ligada ao fato de que o periodo de análise abrangido em cada caso é distinto um do outro, refletindo assim os acontecimentos relativos a cada período de análise respectivamente.

Os resultados obtidos por PONGIBOVE (1996), aparentemente captaram os acontecimentos relacionados com as décadas de 70 e 80 , período no qual ocorreram os dois choques do petróleo (1973 e 1979). Em função destes dois choques de oferta, os paises passaram por um profundo processo de ajuste econômico, onde a economia mundial enfrentou uma forte recessão que perdurou até a metade da década de 80 . Este quadro somente começou a reverter-se com a recuperação da economia dos EUA em 1984/85. Esta 
necessidade de se adequar a este tipo de choque de oferta implicou na mudança da matriz energética de vários países, objetivando com isso reduzir a dependência do petróleo.

Em relação ao primeiro choque do petróleo, diferentemente de outro países, os quais optaram em fazer em processo de ajuste econômico via recessão, no caso do Brasil, a opção consistiu em realizar um processo de financiamento. Mais especificamente, com a radical mudança do cenário internacional em 1973 decorrente do choque de oferta proporcionado pela quadruplicação dos preços internacionais do petróleo ${ }^{37}$, o déficit em Conta Corrente do país deteriorou-se ainda mais com a instabilidade dos preços mundiais de matérias-primas e de produtos agrícolas. Com isto, o Governo tinha duas opções para enfrentar essa nova situação. A primeira, a qual foi rejeitada, inclusive em função de problemas políticos, seria fazer uma política de ajustamento ortodoxo da economia, como foi realizada pelos demais paises, ou seja, para reduzir o expressivo déficit do Balanço de Pagamentos seria necessário desaquecer a economia, diminuindo sua taxa de crescimento, de tal forma, que a queda na demanda agregada conduziria a uma contração das importações e, simultaneamente, seria capaz de elevar o excedente exportável, e, consequentemente, atenuar o déficit externo ${ }^{38}$.

A segunda opção, que foi adotada, consistiu em realizar o equacionamento da questão externa através de uma política de financiamento. Em 1974, a política do Governo buscou manter a taxa de crescimento econômico próxima àquelas do período do "milagre". Portanto, tendo como referência o primeiro choque do petróleo, os rumos da política econômica foram completamente reformulados, surgindo então o II Plano Nacional de Desenvolvimento (II PND), que objetivou alterar o perfil da estrutura produtiva do país, estimulando projetos nas áreas de insumos básicos e de bens de capital, visando dessa forma reduzir a vulnerabilidade do país com relação aos choques externos ${ }^{39}$. Dada a necessidade de se acumular divisas e arrumar recursos para desenvolver os projetos propostos pelo II PND, foi utilizada a politica monetária, com taxas de juros internas superiores àquelas praticadas no mercado internacional, encarecendo o crédito interno, o que forçou os tomadores de empréstimos, sejam eles estatais ou privados, a obterem recursos no exterior. 0 financiamento do $\| P^{4} D^{40}$ se deu através do

\footnotetext{
${ }^{37}$ Para se ter uma idèia da intensidade da elevação dos preços do petróleo em 1973 sobre a economia brasileira, as importações totais do país que em 1973 foram da ordem de US $\$ 6,0$ bilhões, simplesmente duplicou para US\$12,0 bilhões em 1974.

${ }^{38}$ Não se pode esquecer que antes do choque do petróleo a economia brasileira apresentava elevadas taxas de crescimento, sendo assim, colocar a economia num processo recessivo seria extremamente complicado politicamente para o regime militar, dado que, um dos principais pilares da política econômica então vigente, consistia numa política salarial contracionista. Portanto, a adoção de um regime recessivo provocaria perdas ainda mais acentuadas no nivel de renda dos trabalhadores, os quais já eram demasiadamente baixos, fato esse que seria insustentável em termos politicos.

39 Basicamente, partiu-se para uma última etapa do Programa de Substituição de Importaçōes, voltado para aqueles setores que não conseguiram ser completados no processo de substituição de importaçōes da década de 50, como por exemplo, fertilizantes, defensivos agrícolas, minerais não metálicos, etc.

${ }^{40}$ Maiores detalhes sobre o II PND podem ser encontrados em CASTRO e SOUZA (1985).
} 
endividamento externo e, além disso, os investimentos foram realizados basicamente pelo setor público após 1976. Mais especificamente, conforme BIER, PAULANI e MESSENBERG (1987), a concentração dos investimentos do II PND, principalmente por empresas estatais, gerou acentuado desequilibrio no setor externo, abalando a confiança dos capitalistas com relação à taxa de câmbio, que, somada à "ciranda financeira", se refletiram negativamente sobre os investimentos do setor privado ${ }^{41}$.

Em 1979, ocorreu o segundo choque do petróleo, que agravado pela elevação das taxas de juros internacionais, encareceu não somente os gastos com importação de bens e matérias-primas, como também, a captação de recursos externos.

A partir de 1981, tendo com base o receituário proposto pelo Fundo Monetário Internacional (FMI), objetivou-se incrementar o nivel das exportações. Portanto, através da redução do dispêndio doméstico, conjugado com a modificação da relação câmbio/salário para cima, pretendeu-se modificar a rentabilidade relativa dos setores tradeables e nontradeables, de modo a contrair o nivel de renda, o consumo interno, e consequentemente, as importações, possibilitando dessa forma, incrementar o excedente exportável. O resultado no período 1981 a 1983 foi positivo no que concerne às contas externas, mas às custas de mergulhar o país numa profunda recessão, sendo que, os ganhos obtidos com a implementação da ortodoxia foi muito pequeno pelo menos em 1983 no que se refere ao superávit comercial ${ }^{42}$.

A recuperação do crescimento da economia brasileira iniciou-se a partir de 1984 liderada pela componente externa da demanda agregada, em função da reversão do cenário mundial. Mais especificamente, o reaquecimento da economia americana, juntamente com a queda do preço petróleo e das taxas de juros no mercado internacional, aliadas a fatores de ordem interna, como o amadurecimento dos projetos oriundos do II PND, além da "purificação" industrial aplicada através do receituário ortodoxo (recessivo) do início da década de 80 , contribuiram de maneira significativa para alterar a estrutura econômica do país, tornando-a mais madura e integrada, possibilitando, simultaneamente a contração do coeficiente de importações e a expansão das exportações.

Assim como aconteceu em relação ao trabalho de PONGIBOVE (1996), os resultados obtidos neste estudo, também captaram as mudanças no ambiente econômico na década de 90 , as quais são derivadas do processo de ajuste ocorrido nas duas décadas anteriores. Em

\footnotetext{
${ }^{41}$ Dado o elevado diferencial entre as taxas de juros doméstica e internacional tornou-se negócio muito mais atraente pegar empréstimos no exterior e aplicar esses recursos em ativos financeiros aqui no Brasil, do que aplicá-los em ativos reais, pois os retornos oferecidos pelos primeiros eram superiores comparativamente aos ativos reais, além do que, proporcionavam menores riscos.

${ }^{42}$ Segundo CASTRO e SOUZA (1985), a recessão só não foi mais acentuada, em função dos diversos investimentos de projetos dos setores de matérias-primas e de bens de capital que tiveram seu inicio dentro do II PND nos anos 70 estavam maturando nos primeiros anos da década de oitenta, fato esse, que
} 
função dos choques do petróleo, os países procuraram fontes alternativas de energia para diminuir sua dependência do petróleo, e consequentemente, o petróleo passou a influenciar em menor escala as demais variáveis internacionais, fato esse que se refletiu sobre 0 comportamento da decomposição da variância dos erros de previsão de LPET para a década de 90.

Outra variável internacional que apresentou comportamento relativamente daquele obtido em PONGIBOVE (1996) em relação ao grupo de variáveis externas foi o indice internacional de preços de matérias-primas agrícolas, dado que, este autor obteve como resultado da decomposição da variância dos erros de previsão para esta variável um valor igual a $61,00 \%$ decorridos 24 meses, sendo que, desse total, cerca de $37,00 \%$ deve-se à própria variável e os restantes $24,00 \%$ devem-se às demais variáveis. Já neste trabalho, a decomposição da vanância dos erros de previsão para LIRMI após 24 meses totalizou 98,30\%, onde $91,73 \%$ da decomposição da variância deve-se à própria variável ao final deste período, sendo que, as demais variáveis assumiram pequena relevância na explicação de LIRMI com apenas $6,57 \%$. Novamente, possivelmente isto reflita os aspectos conjunturais de cada época de análise. No caso de PONGIBOVE (1996) o periodo analisado correspondeu aos anos 70 e 80 , período esse marcado por choques reais (choques de oferta proporcionados pelos dois choques do petróleo em 1973 e 1979) e monetário (choque internacional dos juros em 1979) com conseqüente redução do nivel de atividade econômica em nível mundial, deprimindo os preços das commodities internacionais, uma vez que, esses choques conduziram a um processo recessivo em nível mundial. Já, o periodo de análise neste estudo envolve a segunda metade dos anos noventa, período este que se caracterizou pelo crescimento da economia mundial de maneira geral (apesar da crise dos países do sudeste asiático no final de 1997) e em especial pelo vigoroso crescimento da economia dos Estados Unidos, sendo assim, pode-se afirmar que esses fatores contribuiram para que a importância da decomposição da variância dos erros de previsão do índice internacional de preços de matérias-primas agrícolas ganhasse relevância comparativamente ao que foi obtido em PONGIBOVE (1996).

Também, em relação às demais variáveis do bloco internacional, a decomposição da variância de LIRMI também têm papel de destaque na decomposição da variância dos preços internacionais do petróleo e do índice de preços nos EUA.

A parcela da decomposição da variância dos erros de previsão relativa a variável LTCR mostrou que, ao final de 24 meses, também é o grupo de variáveis externas que tem maior influência sobre o comportamento da taxa de câmbio real. Este grupo de variáveis é responsável por 79,33\% da decomposição da variância de LTCR (Tabela 38). No final de 24

permitiu a redução nas importaçōes de algumas matérias-primas e bens de capital durante o periodo recessivo, além de ter contribuído também, para a elevação do saldo comercial no periodo 1984/85. 
meses, as variáveis que demonstraram ter maior peso da decomposição da variância de LTCR em ordem decrescente foram: LPET $(24,09 \%)$, LIPPUS $(23,74 \%)$, LIRMI $(15,98 \%)$, LIFI $(15,52)$ e a própria LTCR com 17,41\%. Portanto, isto quer dizer que, 24 meses após a ocorrência de algum choque não antecipado sobre LTCR o comportamento desta variável é fortemente influenciado por ela mesma e principalmente pelas variações de preços no mercado internacional de petróleo, índice de preços nos Estados Unidos, preços internacionais de matérias-primas agrícolas e de alimentos.

Para a variável LM2, verificou-se um comportamento diferenciado em relação às demais variáveis, dado que, a sua decomposição da variância dos erros de previsão decorridos 24 meses é pesadamente influenciada somente por duas variáveis, quais sejam, por ela própria $(43,97 \%)$ e por LPET com $38,24 \%$. Somente essas duas variáveis são responsáveis por $82,21 \%$ da decomposição da variância de LM2 (Tabela 39). Outro aspecto relevante em relação a decomposição da variância de LM2 é que existe um equilíbrio entre o grupo de variáveis externas e domésticas. Levando-se em consideração somente o bloco de variáveis internacionais, decorridos 24 meses, esse conjunto de variáveis responderam por $48,55 \%$ da decomposição da variância da oferta de moeda, enquanto que, as variáveis internas foram responsáveis pelos restantes $51,45 \%$.

A análise do bloco de variáveis domésticas revelou que a decomposição da variância dos erros de previsão da variável LRT é mais influenciada pelo conjunto de variáveis externas, relativamente às variáveis domésticas, pois $65,66 \%$ da sua variância é atribuída a esse grupo de variáveis ao final de 24 meses, sendo assim distribuida: LPET (15,40\%), LIRMI $(25,65 \%)$, LIFI $(17,41 \%)$ e LIPPUS $(7,20 \%)$, enquanto que, as variáveis domésticas LTCR e LM2 são responsáveis por apenas $34,34 \%$ no total, sendo que, desse total $15,83 \%$ diz respeito a sua própria decomposição da variância, e os restantes 18,51\% dividem-se em 14,82\% para LTCR e apenas 3,69 para LM2 (Tabela 40). Logo, estes resultados provavelmente confirmam, de maneira geral, que o Brasil é um tomador de preços no mercado agricola internacional, pois os preços agrícolas internos são relativamente aderentes aos preços externos, pois individualmente, a variável que tem maior peso na decomposição da variância da relação de troca entre agricultura e indústria é o indice internacional de preços de matérias-primas agrícolas, o qual sozinho responde por pouco mais de $25,00 \%$ da decomposição da variância de LRT.

Outro aspecto a ser realçado é que está sendo utilizado uma relação de preços entre os setores agrícolas e industrial, sendo que, esse dois setores tem características distintas em termos do conjunto da economia brasileira. Foram realizadas simulações com estas duas variáveis desagregadas, e os resultados mostraram que a decomposição da variância dos erros de previsão dos preços do setor agricola é fortemente influenciada pelo conjunto de variáveis 
internacionais em detrimento do grupo de variáveis domésticas. Possivelmente, este resultado reflete o fato do Brasil ser um importante exportador de produtos agrícolas em nivel mundial, e dessa maneira os preços domésticos estarem atrelados aos respectivos preços internacionais. Por outro lado, a decomposição da variância dos erros de previsão dos preços industriais domésticos mostrou que há tendência para esses preços apresentarem certo equilíbrio diante do conjunto de variáveis internacionais e domésticas, dado que, em função dos programas de substituição de importações colocados em prática nas décadas de 50 e 70, mais o processo recessivo do início dos anos 80 , tornaram a estrutura industrial brasileira muito mais integrada, ou seja, foram capazes de reduzir a dependência do país em relação a importação de insumos básicos, intermediários e de bens de capital, pois diversas matérias-primas e máquinas passaram a ser produzidas internamente. Portanto, apesar do Brasil, ainda depender da importação de vários insumos e de bens de capital, pode-se inferir que essa dependência nos anos 90 foi reduzida em comparação às décadas anteriores. Também, é necessário enfatizar que a ampliação do grau de abertura da economia brasileira ao comércio internacional a partir do início dos anos 90 , pois em decorrência do processo de globalização há tendência para uma maior divisão internacional do processo produtivo, uma vez que, em muitos casos, o produtos deixaram de ser produzidos inteiramente num único pais e passaram a ser manufaturados em partes em diferentes paises. Sendo assim, aparentemente, estes dois fatores justificam esse relativo equilibrio apresentado pelo comportamento da decomposição da variância do erros de previsão atribuivel às variáveis internacionais e domésticas sobre os preços industriais no Brasil para a década de 90.

Para o indice de preços relativos entre agricultura e industria, PONGIBOVE (1996) verificou que a sua decomposição da variância dos erros de previsão, após 24 meses é atribuida principalmente pelo conjunto de variáveis domésticas, totalizando $78,00 \%$, sendo que, destacaram-se a variância da taxa de câmbio com 35,00\% e a variância da própria variável com $34,00 \%$, fato este que mostra o menor grau de inserção da economia brasileira no comércio mundial nas décadas de 70 e 80 . Em contrapartida, neste estudo, verificou-se que decorrido 0 periodo de 24 meses, a decomposição da variância dos erros de previsão de LRT é atribuída a principalmente ao indice internacional de preços de matérias-primas agrícolas com $25,65 \%$, seguida pela variância do índice internacional de preços com $17,41 \%$, pela sua própria variância com 15,82\%, e pela variância do preço internacional do petróleo com $15,40 \%$, as quais totalizam $89,10 \%$ (Tabela 34). Somando-se a decomposição da variância dos erros de previsão decorridos 24 meses após um choque inicial sobre LRT, observa-se que o conjunto de variáveis internacionais respondem por $65,66 \%$ da explicação da decomposição da variância de LRT contra 23,00\% obtida em PONGIBOVE (1996). Portanto, comparativamente ao estudo de PONGIBOVE (1996), pode-se afimar que no periodo analisado neste estudo a economia 
brasileira apresenta um maior grau de inserção na economia mundial, uma vez que, a relação de troca agricultura/indústria passou a sofrer maior influência em relação ao grupo de variáveis internacionais.

TABELA 34.- Resultados da Decomposição da Variância dos Erros de Previsão em Porcentagem para as variáveis LPET, LIRMI. LIFI, LIPPUS, LTCR, LM2 e LRT, Julho de 1994 a Dezembro de 1998

\begin{tabular}{|c|c|c|c|c|c|c|c|c|}
\hline \multicolumn{9}{|c|}{ Decomposição da Variância dos Erro de Previsão: LPET } \\
\hline Período? & S.E. ${ }^{2}$ & LPET & LIRMI & LIFI & LIPPUS & LTCR & LM2 & LRT \\
\hline 1 & 0,022 & 100,00 & 0,00 & 0,00 & 0,00 & 0,00 & 0,00 & 0,00 \\
\hline 2 & 0,034 & 89,82 & 1,01 & 6,26 & 0,26 & 1,80 & 0,80 & 0,06 \\
\hline 3 & 0,042 & 77,77 & 6,00 & 8,38 & 3,57 & 3,24 & 0,63 & 0,41 \\
\hline 4 & 0,049 & 66,40 & 12,12 & 8,43 & 7,61 & 4,02 & 0,55 & 0,88 \\
\hline 5 & 0,055 & 55,79 & 18,09 & 7,86 & 11,93 & 4,24 & 0,77 & 1,31 \\
\hline 6 & 0,062 & 46,48 & 23,43 & 7,10 & 15,90 & 4,16 & 1,21 & 1,72 \\
\hline 7 & 0,069 & 38,89 & 27,66 & 6,37 & 19,27 & 3,94 & 1,74 & 2,13 \\
\hline 8 & 0,076 & 32,83 & 30,85 & 5,74 & 22,08 & 3,68 & 2,28 & 2,54 \\
\hline 9 & 0,082 & 28,00 & 33,23 & 5,22 & 24,41 & 3,41 & 2,80 & 2,93 \\
\hline 10 & 0,089 & 24,12 & 35,02 & 4,77 & 26,35 & 3,17 & 3,28 & 3,29 \\
\hline 11 & 0,096 & 20,97 & 36,39 & 4,39 & 27,98 & 2,95 & 3,72 & 3,61 \\
\hline 12 & 0,103 & 18,40 & 37,45 & 4,07 & 29,34 & 2,75 & 4,11 & 3,88 \\
\hline 13 & 0,109 & 16,28 & 38,28 & 3,79 & 30,49 & 2,58 & 4,47 & 4,11 \\
\hline 14 & 0,116 & 14,52 & 38,95 & 3,55 & 31,45 & 2,43 & 4,78 & 4,32 \\
\hline 15 & 0,122 & 13,06 & 39,48 & 3,34 & 32,27 & 2,29 & 5,06 & 4,49 \\
\hline 16 & 0,129 & 11,82 & 39,90 & 3,16 & 32,98 & 2,17 & 5,32 & 4,65 \\
\hline 17 & 0,135 & 10,77 & 40,25 & 3,01 & 33,58 & 2,07 & 5,54 & 4,78 \\
\hline 18 & 0,141 & 9,88 & 40,53 & 2,87 & 34,11 & 1,97 & 5,74 & 4,91 \\
\hline 19 & 0,147 & 9,10 & 40,76 & 2,75 & 34,57 & 1,89 & 5,92 & 5,01 \\
\hline 20 & 0,152 & 8,43 & 40,96 & 2,64 & 34,97 & 1,81 & 6,08 & 5,11 \\
\hline 21 & 0,158 & 7,84 & 41,12 & 2,54 & 35,32 & 1,75 & 6,23 & 5,20 \\
\hline 22 & 0,163 & 7,33 & 41,26 & 2,46 & 35,64 & 1,69 & 6,36 & 5,27 \\
\hline 23 & 0,169 & 6,87 & 41,38 & 2,38 & 35,92 & 1,63 & 6,48 & 5,34 \\
\hline 24 & 0,174 & 6,46 & 41,48 & 2,31 & 36,17 & 1,58 & 6,59 & 5,41 \\
\hline
\end{tabular}

Fonte: Dados Básicos da International Financial Statistics (1990/1999), Conjuntura Econômica (1991/1999) e U.S. Department of Labor, Bureau of Labor. 
TABELA 35.- Resultados da Decomposição da Variância dos Erros de Previsão em Porcentagem para as variáveis LPET, LIRMI. LIFI, LIPPUS, LTCR, LM2 e LRT, Julho de 1994 a Dezembro de 1998

\begin{tabular}{ccccccccc}
\hline \multicolumn{2}{c}{ Decomposição da Variância dos Erro de Previsão: LIRMI } & & & \\
\hline Período & S.E. & LPET & LIRMI & LIFI & LIPPUS & LTCR & LM2 & LRT \\
\hline 1 & 0,014 & 0,61 & 99,39 & 0,00 & 0,00 & 0,00 & 0,00 & 0,00 \\
2 & 0,022 & 0,69 & 95,52 & 0,51 & 1,42 & 0,25 & 0,00 & 1,60 \\
3 & 0,029 & 0,68 & 94,27 & 0,64 & 1,86 & 0,19 & 0,01 & 2,36 \\
4 & 0,034 & 0,66 & 93,78 & 0,69 & 2,09 & 0,23 & 0,01 & 2,53 \\
5 & 0,039 & 0,71 & 93,65 & 0,75 & 2,22 & 0,29 & 0,02 & 2,36 \\
6 & 0,043 & 0,79 & 93,52 & 0,83 & 2,35 & 0,35 & 0,02 & 2,13 \\
7 & 0,047 & 0,83 & 93,36 & 0,93 & 2,53 & 0,39 & 0,04 & 1,93 \\
8 & 0,050 & 0,82 & 93,21 & 1,00 & 2,75 & 0,41 & 0,05 & 1,76 \\
9 & 0,053 & 0,79 & 93,06 & 1,04 & 2,98 & 0,42 & 0,08 & 1,62 \\
10 & 0,057 & 0,74 & 92,93 & 1,07 & 3,22 & 0,43 & 0,10 & 1,51 \\
11 & 0,060 & 0,69 & 92,81 & 1,08 & 3,43 & 0,44 & 0,13 & 1,41 \\
12 & 0,063 & 0,65 & 92,70 & 1,09 & 3,63 & 0,45 & 0,16 & 1,33 \\
13 & 0,066 & 0,61 & 92,59 & 1,09 & 3,82 & 0,46 & 0,18 & 1,25 \\
14 & 0,068 & 0,57 & 92,49 & 1,09 & 3,99 & 0,47 & 0,21 & 1,18 \\
15 & 0,071 & 0,54 & 92,40 & 1,10 & 4,14 & 0,47 & 0,23 & 1,12 \\
16 & 0,074 & 0,51 & 92,30 & 1,10 & 4,29 & 0,48 & 0,26 & 1,06 \\
17 & 0,076 & 0,48 & 92,22 & 1,10 & 4,43 & 0,49 & 0,28 & 1,02 \\
18 & 0,079 & 0,45 & 92,13 & 1,10 & 4,56 & 0,49 & 0,30 & 0,97 \\
19 & 0,081 & 0,43 & 92,06 & 1,09 & 4,67 & 0,50 & 0,32 & 0,93 \\
20 & 0,084 & 0,41 & 91,98 & 1,09 & 4,78 & 0,50 & 0,34 & 0,90 \\
21 & 0,086 & 0,39 & 91,91 & 1,09 & 4,89 & 0,50 & 0,36 & 0,86 \\
22 & 0,088 & 0,37 & 91,85 & 1,09 & 4,98 & 0,51 & 0,37 & 0,83 \\
23 & 0,090 & 0,35 & 91,79 & 1,09 & 5,07 & 0,51 & 0,39 & 0,80 \\
24 & 0,092 & 0,34 & 91,73 & 1,08 & 5,15 & 0,51 & 0,40 & 0,78 \\
\hline
\end{tabular}

'Mês, ${ }^{2}$ Desvio-padrão.

Fonte: Dados Básicos da International Financial Statistics (1990/1999), Conjuntura Econômica (1991/1999) e U.S. Department of Labor, Bureau of Labor. 
TABELA 36.- Resultados da Decomposição da Variância dos Erros de Previsão em Porcentagem para as variáveis LPET, LIRMI. LIFI, LIPPUS, LTCR, LM2 e LRT Julho de 1994 a Dezembro de 1998

\begin{tabular}{cccccccccc}
\hline \multicolumn{2}{l}{ Decomposição da Variância dos Erro de Previsão: LIFI } & & & \\
\hline Período & S.E. & LPET & LIRMI & LIFI & LIPPUS & LTCR & LM2 & LRT \\
\hline 1 & 0,012 & 3,88 & 0,15 & 95,97 & 0,00 & 0,00 & 0,00 & 0,00 \\
2 & 0,017 & 3,07 & 0,19 & 90,19 & 0,00 & 4,66 & 0,17 & 1,71 \\
3 & 0,021 & 2,03 & 0,14 & 82,04 & 0,08 & 7,77 & 0,12 & 7,83 \\
4 & 0,024 & 1,49 & 0,30 & 72,94 & 0,48 & 9,34 & 0,19 & 15,27 \\
5 & 0,028 & 1,18 & 0,30 & 65,06 & 1,73 & 9,80 & 0,45 & 21,48 \\
6 & 0,031 & 1,26 & 0,26 & 58,50 & 3,86 & 9,71 & 0,96 & 25,44 \\
7 & 0,035 & 1,78 & 0,51 & 52,86 & 6,41 & 9,38 & 1,63 & 27,44 \\
8 & 0,038 & 2,55 & 1,05 & 47,97 & 8,88 & 8,97 & 2,34 & 28,24 \\
9 & 0,042 & 3,37 & 1,70 & 43,79 & 11,02 & 8,60 & 3,02 & 28,50 \\
10 & 0,046 & 4,12 & 2,33 & 40,27 & 12,81 & 8,26 & 3,63 & 28,58 \\
11 & 0,050 & 4,79 & 2,89 & 37,30 & 14,32 & 7,96 & 4,17 & 28,58 \\
12 & 0,054 & 5,38 & 3,38 & 34,78 & 15,61 & 7,69 & 4,64 & 28,52 \\
13 & 0,058 & 5,91 & 3,83 & 32,64 & 16,72 & 7,45 & 5,06 & 28,40 \\
14 & 0,062 & 6,39 & 4,24 & 30,80 & 17,68 & 7,22 & 5,42 & 28,24 \\
15 & 0,065 & 6,82 & 4,62 & 29,23 & 18,52 & 7,02 & 5,74 & 28,05 \\
16 & 0,069 & 7,21 & 4,97 & 27,87 & 19,24 & 6,84 & 6,02 & 27,85 \\
17 & 0,073 & 7,55 & 5,28 & 26,69 & 19,87 & 6,68 & 6,27 & 27,65 \\
18 & 0,076 & 7,86 & 5,56 & 25,67 & 20,42 & 6,54 & 6,49 & 27,46 \\
19 & 0,080 & 8,14 & 5,81 & 24,77 & 20,91 & 6,41 & 6,68 & 27,28 \\
20 & 0,083 & 8,38 & 6,04 & 23,98 & 21,33 & 6,30 & 6,85 & 27,12 \\
21 & 0,086 & 8,61 & 6,25 & 23,27 & 21,71 & 6,20 & 7,01 & 26,96 \\
22 & 0,090 & 8,81 & 6,43 & 22,65 & 22,05 & 6,10 & 7,14 & 26,81 \\
23 & 0,093 & 8,99 & 6,60 & 22,09 & 22,35 & 6,02 & 7,27 & 26,68 \\
24 & 0,096 & 9,15 & 6,76 & 21,58 & 22,62 & 5,95 & 7,38 & 26,55 \\
\hline
\end{tabular}

TMès, ${ }^{2}$ Desvio-padrão.

Fonte: Dados Básicos da International Financial Statistics (1990/1999), Conjuntura Econômica (1991/1999) e U.S. Department of Labor, Bureau of L.abor. 
TABELA 37.- Resultados da Decomposição da Variância dos Erros de Previsão em Porcentagem para as variáveis LPET, LIRMI. LIFI, LIPPUS, LTCR, LM2 e LRT Julho de 1994 a Dezembro de 1998

\begin{tabular}{cccccccccc}
\hline \multicolumn{2}{l}{ Decomposição da Variância dos Erro de Previsão: LIPPUS } \\
\hline Período & S.E. & LPET & LIRMI & LIFI & LIPPUS & LTCR & LM2 & LRT \\
\hline 1 & 0,003 & 0,70 & 5,54 & 18,05 & 75,70 & 0,00 & 0,00 & 0,00 \\
2 & 0,004 & 0,53 & 4,40 & 17,34 & 69,85 & 2,23 & 3,27 & 2,38 \\
3 & 0,004 & 0,42 & 12,59 & 16,57 & 60,99 & 2,49 & 2,86 & 4,10 \\
4 & 0,004 & 0,38 & 17,60 & 16,10 & 54,80 & 3,25 & 2,59 & 5,29 \\
5 & 0,005 & 0,39 & 22,54 & 15,80 & 49,72 & 3,99 & 2,27 & 5,29 \\
6 & 0,005 & 0,44 & 26,26 & 15,61 & 45,94 & 4,81 & 2,01 & 4,93 \\
7 & 0,005 & 0,56 & 29,61 & 15,40 & 42,59 & 5,52 & 1,82 & 4,51 \\
8 & 0,006 & 0,80 & 32,88 & 15,14 & 39,31 & 6,08 & 1,68 & 4,11 \\
9 & 0,006 & 1,18 & 36,12 & 14,83 & 36,02 & 6,50 & 1,62 & 3,73 \\
10 & 0,006 & 1,68 & 39,19 & 14,48 & 32,84 & 6,81 & 1,61 & 3,39 \\
11 & 0,007 & 2,24 & 41,97 & 14,13 & 29,89 & 7,04 & 1,65 & 3,07 \\
12 & 0,007 & 2,82 & 44,42 & 13,77 & 27,24 & 7,23 & 1,73 & 2,80 \\
13 & 0,007 & 3,39 & 46,53 & 13,43 & 24,89 & 7,37 & 1,83 & 2,57 \\
14 & 0,007 & 3,94 & 48,34 & 13,09 & 22,84 & 7,48 & 1,95 & 2,37 \\
15 & 0,008 & 4,46 & 49,90 & 12,78 & 21,03 & 7,56 & 2,07 & 2,20 \\
16 & 0,008 & 4,95 & 51,25 & 12,48 & 19,44 & 7,61 & 2,21 & 2,05 \\
17 & 0,008 & 5,41 & 52,42 & 12,21 & 18,04 & 7,65 & 2,34 & 1,93 \\
18 & 0,009 & 5,84 & 53,44 & 11,95 & 16,80 & 7,68 & 2,47 & 1,83 \\
19 & 0,009 & 6,24 & 54,32 & 11,71 & 15,71 & 7,69 & 2,59 & 1,73 \\
20 & 0,009 & 6,61 & 55,10 & 11,49 & 14,74 & 7,70 & 2,71 & 1,66 \\
21 & 0,010 & 6,95 & 55,77 & 11,28 & 13,88 & 7,70 & 2,82 & 1,59 \\
22 & 0,010 & 7,27 & 56,37 & 11,09 & 13,10 & 7,70 & 2,93 & 1,53 \\
23 & 0,010 & 7,56 & 56,90 & 10,92 & 12,41 & 7,69 & 3,03 & 1,48 \\
24 & 0,010 & 7,83 & 57,38 & 10,76 & 11,79 & 7,69 & 3,13 & 1,43 \\
\hline
\end{tabular}

Mês, ${ }^{2}$ Desvio-padrão.

Fonte: Dados Básicos da International Financial Statistics (1990/1999), Conjuntura Econômica (1991/1999) e U.S. Department of Labor, Bureau of Labor. 
TABELA 38.- Resultados da Decomposição da Variância dos Erros de Previsão em Porcentagem para as variáveis LPET, LIRMI. LIFI, LIPPUS, LTCR, LM2 e LRT Julho de 1994 a Dezembro de 1998

\begin{tabular}{ccccccccc}
\hline \multicolumn{7}{c}{ Decomposição da Variância dos Erro de Previsão: LTCR } \\
\hline Periodo & S.E. & LPET & LIRMI & LIFI & LIPPUS & LTCR & LM2 & LRT \\
\hline 1 & 0,006 & 2,38 & 4,48 & 5,32 & 13,21 & 74,62 & 0,00 & 0,00 \\
2 & 0,007 & 3,51 & 7,60 & 4,89 & 19,12 & 63,18 & 0,74 & 0,95 \\
3 & 0,008 & 9,84 & 9,16 & 5,78 & 19,52 & 53,78 & 1,12 & 0,79 \\
4 & 0,010 & 17,00 & 13,09 & 7,65 & 17,37 & 42,77 & 1,55 & 0,57 \\
5 & 0,012 & 21,95 & 16,08 & 9,42 & 15,41 & 34,75 & 1,74 & 0,65 \\
6 & 0,014 & 24,57 & 17,99 & 10,78 & 14,41 & 29,62 & 1,78 & 0,85 \\
7 & 0,015 & 25,81 & 18,87 & 11,79 & 14,27 & 26,52 & 1,73 & 1,02 \\
8 & 0,016 & 26,33 & 19,14 & 12,52 & 14,65 & 24,58 & 1,64 & 1,15 \\
9 & 0,018 & 26,51 & 19,08 & 13,06 & 15,30 & 23,27 & 1,55 & 1,24 \\
10 & 0,019 & 26,52 & 18,89 & 13,47 & 16,03 & 22,30 & 1,46 & 1,34 \\
11 & 0,020 & 26,45 & 18,66 & 13,80 & 16,76 & 21,53 & 1,37 & 1,43 \\
12 & 0,021 & 26,32 & 18,43 & 14,07 & 17,46 & 20,89 & 1,29 & 1,54 \\
13 & 0,022 & 26,16 & 18,19 & 14,30 & 18,14 & 20,34 & 1,21 & 1,65 \\
14 & 0,023 & 25,98 & 17,96 & 14,50 & 18,79 & 19,88 & 1,15 & 1,75 \\
15 & 0,023 & 25,78 & 17,72 & 14,67 & 19,41 & 19,48 & 1,08 & 1,85 \\
16 & 0,024 & 25,58 & 17,49 & 14,82 & 20,01 & 19,13 & 1,03 & 1,95 \\
17 & 0,025 & 25,37 & 17,27 & 14,94 & 20,57 & 18,83 & 0,97 & 2,04 \\
18 & 0,026 & 25,17 & 17,05 & 15,06 & 21,11 & 18,56 & 0,93 & 2,12 \\
19 & 0,026 & 24,97 & 16,85 & 15,16 & 21,62 & 18,32 & 0,88 & 2,20 \\
20 & 0,027 & 24,78 & 16,65 & 15,25 & 22,10 & 18,11 & 0,84 & 2,28 \\
21 & 0,028 & 24,59 & 16,47 & 15,33 & 22,54 & 17,91 & 0,81 & 2,35 \\
22 & 0,029 & 24,42 & 16,30 & 15,40 & 22,97 & 17,73 & 0,77 & 2,42 \\
23 & 0,029 & 24,25 & 16,13 & 15,46 & 23,36 & 17,57 & 0,74 & 2,48 \\
24 & 0,030 & 24,09 & 15,98 & 15,52 & 23,74 & 17,41 & 0,71 & 2,54 \\
\hline
\end{tabular}

Tès, ${ }^{2}$ Desvio-padrão.

Fonte: Dados Básicos da International Financial Statistics (1990/1999), Conjuntura Econômica (1991/1999) e U.S. Department of Labor, Bureau of Labor. 
TABELA 39.- Resultados da Decomposição da Variância dos Erros de Previsão em Porcentagem para as variáveis LPET, LIRMI. LIFI, LIPPUS, LTCR, LM2 e LRT Julho de 1994 a Dezembro de 1998

\begin{tabular}{cccccccccc}
\hline \multicolumn{2}{l}{ Decomposição da Variância dos Erro de Previsão: LM2 } & & & \\
\hline Periodo & S.E. & LPET & LIRMI & LIFI & LIPPUS & LTCR & LM2 & LRT \\
\hline 1 & 0,012 & 6,37 & 0,19 & 2,93 & 10,23 & 9,48 & 70,80 & 0,00 \\
2 & 0,019 & 19,13 & 2,59 & 5,90 & 8,34 & 6,81 & 56,84 & 0,39 \\
3 & 0,025 & 24,68 & 1,87 & 8,30 & 6,44 & 5,08 & 51,50 & 2,12 \\
4 & 0,030 & 27,26 & 1,68 & 9,15 & 5,16 & 4,04 & 49,27 & 3,45 \\
5 & 0,035 & 29,19 & 1,40 & 9,39 & 4,12 & 3,50 & 48,18 & 4,23 \\
6 & 0,040 & 30,90 & 1,11 & 9,48 & 3,31 & 3,15 & 47,45 & 4,59 \\
7 & 0,045 & 32,35 & 0,90 & 9,53 & 2,70 & 2,89 & 46,87 & 4,76 \\
8 & 0,049 & 33,49 & 0,77 & 9,56 & 2,25 & 2,67 & 46,40 & 4,87 \\
9 & 0,053 & 34,36 & 0,68 & 9,56 & 1,92 & 2,48 & 46,03 & 4,98 \\
10 & 0,057 & 35,02 & 0,63 & 9,53 & 1,67 & 2,32 & 45,74 & 5,09 \\
11 & 0,060 & 35,55 & 0,59 & 9,48 & 1,48 & 2,19 & 45,50 & 5,22 \\
12 & 0,064 & 35,98 & 0,57 & 9,42 & 1,33 & 2,08 & 45,30 & 5,33 \\
13 & 0,067 & 36,34 & 0,56 & 9,35 & 1,22 & 1,99 & 45,12 & 5,43 \\
14 & 0,071 & 36,65 & 0,56 & 9,29 & 1,13 & 1,91 & 44,96 & 5,52 \\
15 & 0,074 & 36,91 & 0,57 & 9,22 & 1,05 & 1,84 & 44,81 & 5,59 \\
16 & 0,077 & 37,15 & 0,58 & 9,17 & 1,00 & 1,77 & 44,68 & 5,66 \\
17 & 0,080 & 37,35 & 0,59 & 9,11 & 0,95 & 1,72 & 44,56 & 5,72 \\
18 & 0,083 & 37,52 & 0,60 & 9,06 & 0,92 & 1,67 & 44,45 & 5,78 \\
19 & 0,086 & 37,68 & 0,62 & 9,01 & 0,89 & 1,62 & 44,35 & 5,83 \\
20 & 0,089 & 37,82 & 0,63 & 8,96 & 0,87 & 1,58 & 44,26 & 5,88 \\
21 & 0,091 & 37,94 & 0,65 & 8,92 & 0,85 & 1,54 & 44,18 & 5,92 \\
22 & 0,094 & 38,05 & 0,67 & 8,88 & 0,83 & 1,51 & 44,10 & 5,96 \\
23 & 0,097 & 38,15 & 0,68 & 8,84 & 0,82 & 1,48 & 44,03 & 6,00 \\
24 & 0,099 & 38,24 & 0,69 & 8,81 & 0,81 & 1,45 & 43,97 & 6,03 \\
\hline
\end{tabular}

Tês, ${ }^{2}$ Desvio-padrão.

Fonte: Dados Básicos da International Financial Statistics (1990/1999), Conjuntura Econômica (1991/1999) e U.S. Department of Labor, Bureau of Labor. 
TABELA 40.- Resultados da Decomposição da Variância dos Erros de Previsão em Porcentagem para as variáveis LPET, LIRMI. LIFI, LIPPUS, LTCR, LM2 e LRT Julho de 1994 a Dezembro de 1998

\begin{tabular}{ccccccccc}
\hline \multicolumn{7}{c}{ Decomposição da Variância dos Erro de Previsão: LRT } & & \\
\hline Período & S.E. & LPET & LIRMI & LIFI & LIPPUS & LTCR & LM2 & LRT \\
\hline 1 & 0,011 & 3,43 & 0,49 & 13,85 & 0,39 & 26,25 & 0,00 & 55,59 \\
2 & 0,016 & 2,03 & 0,26 & 10,89 & 0,55 & 24,24 & 1,77 & 60,26 \\
3 & 0,018 & 3,32 & 1,01 & 10,14 & 2,92 & 22,59 & 2,67 & 57,36 \\
4 & 0,020 & 7,14 & 6,82 & 10,34 & 6,26 & 19,25 & 3,32 & 46,86 \\
5 & 0,023 & 10,61 & 13,41 & 11,17 & 7,93 & 16,47 & 3,64 & 36,77 \\
6 & 0,026 & 12,54 & 17,71 & 12,14 & 8,32 & 15,09 & 3,78 & 30,42 \\
7 & 0,028 & 13,43 & 19,94 & 12,99 & 8,26 & 14,65 & 3,84 & 26,88 \\
8 & 0,030 & 13,84 & 21,05 & 13,62 & 8,13 & 14,60 & 3,87 & 24,88 \\
9 & 0,032 & 14,07 & 21,68 & 14,10 & 8,03 & 14,64 & 3,89 & 23,59 \\
10 & 0,033 & 14,26 & 22,18 & 14,48 & 7,97 & 14,66 & 3,89 & 22,56 \\
11 & 0,034 & 14,45 & 22,64 & 14,81 & 7,92 & 14,64 & 3,89 & 21,64 \\
12 & 0,036 & 14,62 & 23,08 & 15,12 & 7,87 & 14,62 & 3,88 & 20,80 \\
13 & 0,037 & 14,77 & 23,49 & 15,40 & 7,82 & 14,60 & 3,87 & 20,05 \\
14 & 0,038 & 14,89 & 23,83 & 15,66 & 7,75 & 14,60 & 3,86 & 19,40 \\
15 & 0,039 & 14,98 & 24,13 & 15,91 & 7,69 & 14,61 & 3,84 & 18,84 \\
16 & 0,040 & 15,06 & 24,38 & 16,13 & 7,62 & 14,63 & 3,82 & 18,36 \\
17 & 0,041 & 15,13 & 24,60 & 16,33 & 7,56 & 14,66 & 3,80 & 17,93 \\
18 & 0,042 & 15,18 & 24,79 & 16,52 & 7,50 & 14,68 & 3,78 & 17,54 \\
19 & 0,043 & 15,23 & 24,97 & 16,70 & 7,44 & 14,71 & 3,77 & 17,19 \\
20 & 0,044 & 15,27 & 25,13 & 16,86 & 7,39 & 14,73 & 3,75 & 16,87 \\
21 & 0,045 & 15,31 & 25,28 & 17,01 & 7,34 & 14,75 & 3,73 & 16,58 \\
22 & 0,046 & 15,35 & 25,41 & 17,15 & 7,29 & 14,78 & 3,72 & 16,31 \\
23 & 0,047 & 15,38 & 25,54 & 17,29 & 7,24 & 14,80 & 3,70 & 16,06 \\
24 & 0,048 & 15,40 & 25,65 & 17,41 & 7,20 & 14,82 & 3,69 & 15,83 \\
\hline
\end{tabular}

Mês, ${ }^{2}$ Desvio-padrão.

Fonte: Dados Básicos da International Financial Statistics (1990/1999), Conjuntura Econômica (1991/1999) e U.S. Department of Labor, Bureau of Labor.

\subsubsection{2 - Análise da função de resposta de impulso}

\subsubsection{1 - Efeitos de choques em LPET sobre o bloco de variáveis domésticas}

O comportamento da taxa de câmbio real diante de um choque não antecipado nos preços internacionais do petróleo apresentou três fases distintas. Inicialmente, após a incidência de um choque não antecipado sobre os preços internacionais do petróleo, a taxa de câmbio real tende a valorizar-se continuamente até o sexto mês após esse choque. Isto, provavelmente reflete o fato de que os preços domésticos no Brasil são mais sensiveis as variações nos preços internacionais do petróleo do que os preços internos nos EUA, sendo assim, isso gera 
um processo de valorização da taxa de câmbio real. Após o sexto mês, a taxa de câmbio real assume um movimento de desvalorização continua, porém lenta, para então, estabilizar-se por volta do vigésimo quarto mês, mas num patamar inferior ao que encontrava-se antes desse choque (Figura 8). Portanto, pode-se inferir que um aumento no nivel de preços do petróleo no mercado internacional tende a provocar uma valorização da taxa de câmbio real relativamente ao periodo anterior ao choque nos preços do petróleo.

Um choque não antecipado sobre os preços do petróleo tem impacto bem definido sobre a oferta de moeda no Brasil. Dado que um choque nos preços do petróleo tende a elevar o nivel de preços domésticos no Brasil, após a incidência desse choque a oferta real de moeda decai continuamente, sendo que o efeito desse choque sobre a oferta de moeda tende a dissipar-se após vinte e quatro meses (Figura 8).

No caso da variável LPET, observou-se que um choque sobre essa variável inicialmente causa uma queda na relação de troca entre agricultura e indústria até o segundo mês após o choque inicial, uma vez que, os preços dos produtos industriais possivelmente são mais sensiveis às variações no preço do petróleo, o qual consiste no principal insumo utilizado por este setor. A partir deste ponto, a relação de troca cresce até o quinto mês após o choque inicial, onde atinge seu ponto de máximo. Em função deste choque, os preços agrícolas em nivel de atacado tendem a subir, provavelmente, em razão da expectativa de alta generalizada de preços, sendo assim, os preços agrícolas no atacado são elevados acentuadamente, descrevendo mecanismo semelhante ao do overshooting. No periodo do quinto, até aproximadamente o oitavo/nono mês a relação de troca volta a cair, aparentemente pelo fato dessa elevação dos preços causar uma redução da demanda, com a conseqüente queda do nivel de preços dos produtos agricolas em nivel de atacado, para então, se estabilizar em torno do décimo mês, porém, num patamar superior àquele que antecedeu ao choque nos preços do petróleo (Figura 8). Portanto, um choque do petróleo tem efeitos permanentes sobre a relação de troca, ou seja, tem "memória" longa. 


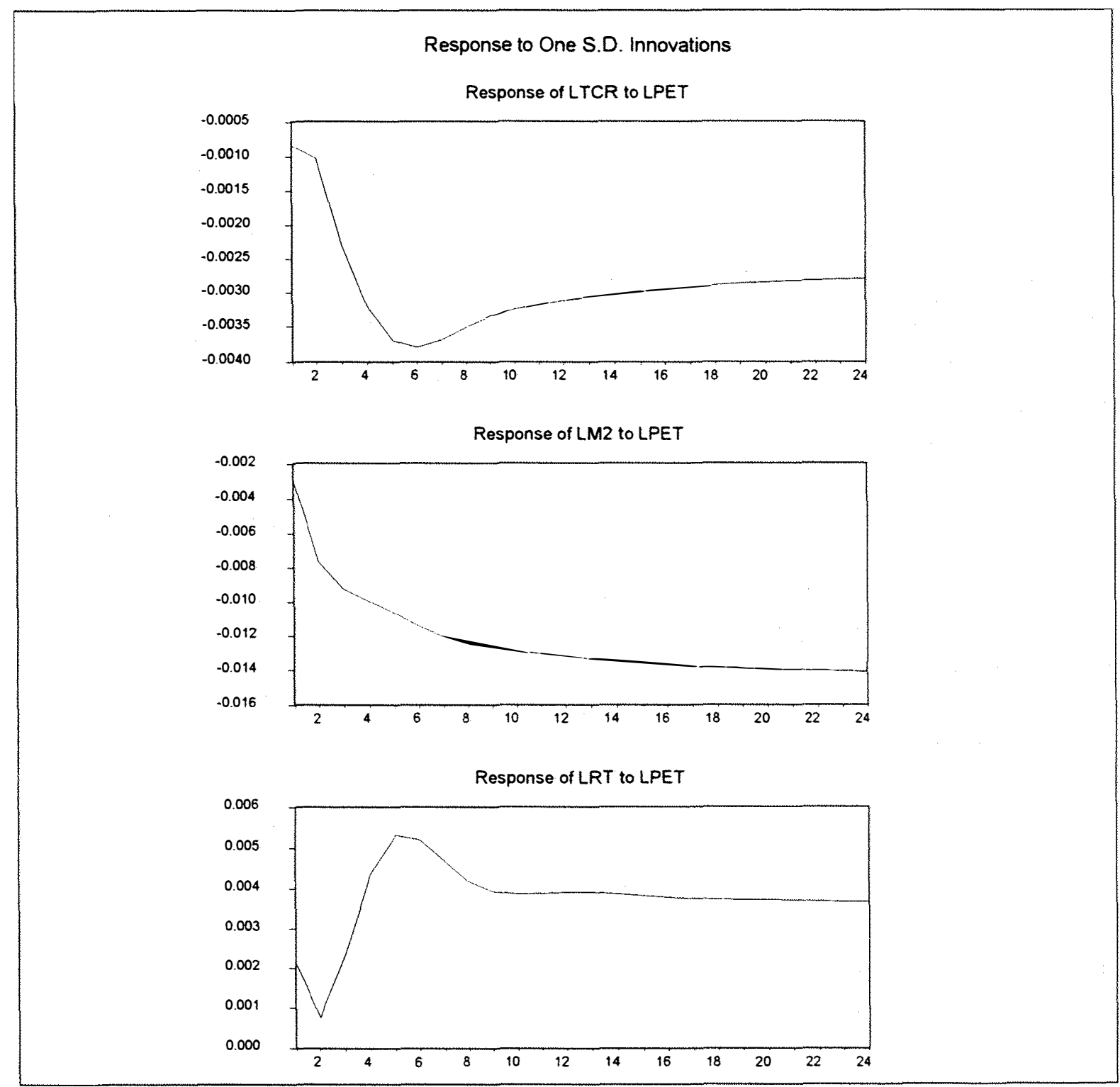

Figura 8: Elasticidades de função de resposta de impulso, efeitos de choques em LPET sobre LRT, LTCR e LM2.

Fonte: Dados Básicos da International Financial Statistics (1990/1999), Conjuntura Econômica (1991/1999) e U.S. Department of Labor, Bureau of Labor.

\subsubsection{2 - Efeitos de choques em LIRMI sobre o bloco de variáveis domésticas}

Quanto à taxa de câmbio real, inicialmente, observou-se que um choque não antecipado nos preços internacionais de matérias-primas agricolas causa um processo de rápida desvalorização cambial nos dois primeiros meses que se seguem a este choque. Esse processo de desvalorização tem continuidade no período que abrange o segundo até o quinto 
mês, porém, em menor intensidade, para em seguida a esse periodo, estabilizar-se, num nivel superior relativamente ao que a taxa de câmbio real encontrava-se situada antes da ocorrência desse choque (Figura 9). Sendo assim, pode-se afirmar que, choques nos preços internacionais de matérias-primas agrícolas funcionam como mecanismo de desvalorização da taxa de câmbio real, isto é, dado que, os preços internacionais sobem mais que proporcionalmente que os preços domésticos esse processo eqüivale a uma desvalorização da taxa de câmbio real.

Os efeitos de um choque não antecipado nos preços internacionais de matérias-primas agricolas sobre a oferta de moeda apresentou duas fases bem delineadas. A primeira fase caracterizou-se pela instabilidade na trajetória da oferta de moeda, enquanto que, na segunda fase, verificou-se que a trajetória de LM2 está devidamente definida. Na primeira fase, ou seja, após o choque inicial a oferta de moeda cai rapidamente até o segundo mês após a incidência desse choque, voltando a subir no intervalo compreendido entre o segundo e o terceiro mês, para voltar a decrescer entre o terceiro e quarto mês. A partir do quarto mês, a oferta de moeda volta a crescer, mas de forma lenta e gradual até estabilizar-se ao final de vinte e quatro meses relativamente ao choque inicial (Figura 9). Essa redução da oferta de moeda, provavelmente deve ao fato de que aumentos nos preços internacionais de matérias-primas agrícolas tem impacto sobre o nivel de preços domésticos como já foi analisado em relação à variável LRT.

Em relação a choques de preços originados na variável preço internacional de matériasprimas agricolas sobre a relação de troca entre agricultura e indústria, observou-se que a resposta desta última pode ser dividida em quatro fases distintas. Inicialmente, um choque não antecipado nos preços internacionais da matérias-primas agricolas conduz a uma pequena elevação da relação de troca entre o setor agricola e industrial até o segundo mês após a incidência desse choque. Possivelmente, num primeiro momento, uma elevação na demanda pelas matérias-primas agricolas conduz a um aumento nos preços dessas matérias-primas e consequentemente reflete-se sobre os preços agricolas praticados em nivel de atacado no Brasil, favorecendo a relação de troca em favor do setor agricola em detrimento do setor industrial. No segundo momento, o qual compreende o segundo e o sexto mês, a trajetória da relação de troca inverte-se, ou seja, ela torna-se rapidamente decrescente, indicando que, os preços industriais no atacado passam a incorporar esse aumento de custos proporcionado pela elevação dos preços das matérias-primas agricolas, e como resultado, elevam-se bruscamente.

Posteriormente, no periodo entre o sexto e o décimo mês, ocorre outra mudança na trajetória de LRT, isto é, a relação de troca passa a crescer, porém lentamente, até estabilizarse a partir do décimo segundo mês. Provavelmente, imediatamente, após o choque ocorrido sobre os preços das matérias-primas agricolas, os preços industriais são reajustados fortemente a partir do segundo mês após o choque em função da expectativa de elevação do nivel geral de preços, entretanto, como os preços foram reajustados de maneira muito intensa, 
isto causa uma queda da demanda por esses produto, obrigando aos agentes econômicos a rever esses reajustes, o que leva a uma redução dos preços dos produtos industriais em nível de atacado e a conseqüente elevação da relação de troca entre o sexto e o décimo período. Entretanto, deve-se observar que o patamar final relativo a estabilização de LRT é inferior ao que prevalecia no período anterior ao choque, indicando que, apesar da redução dos preços industriais, ainda assim essa redução é menos que proporcional ao aumento que foi imposto aos preços dos produtos industriais pós choque nos preços das matérias-primas agrícolas.

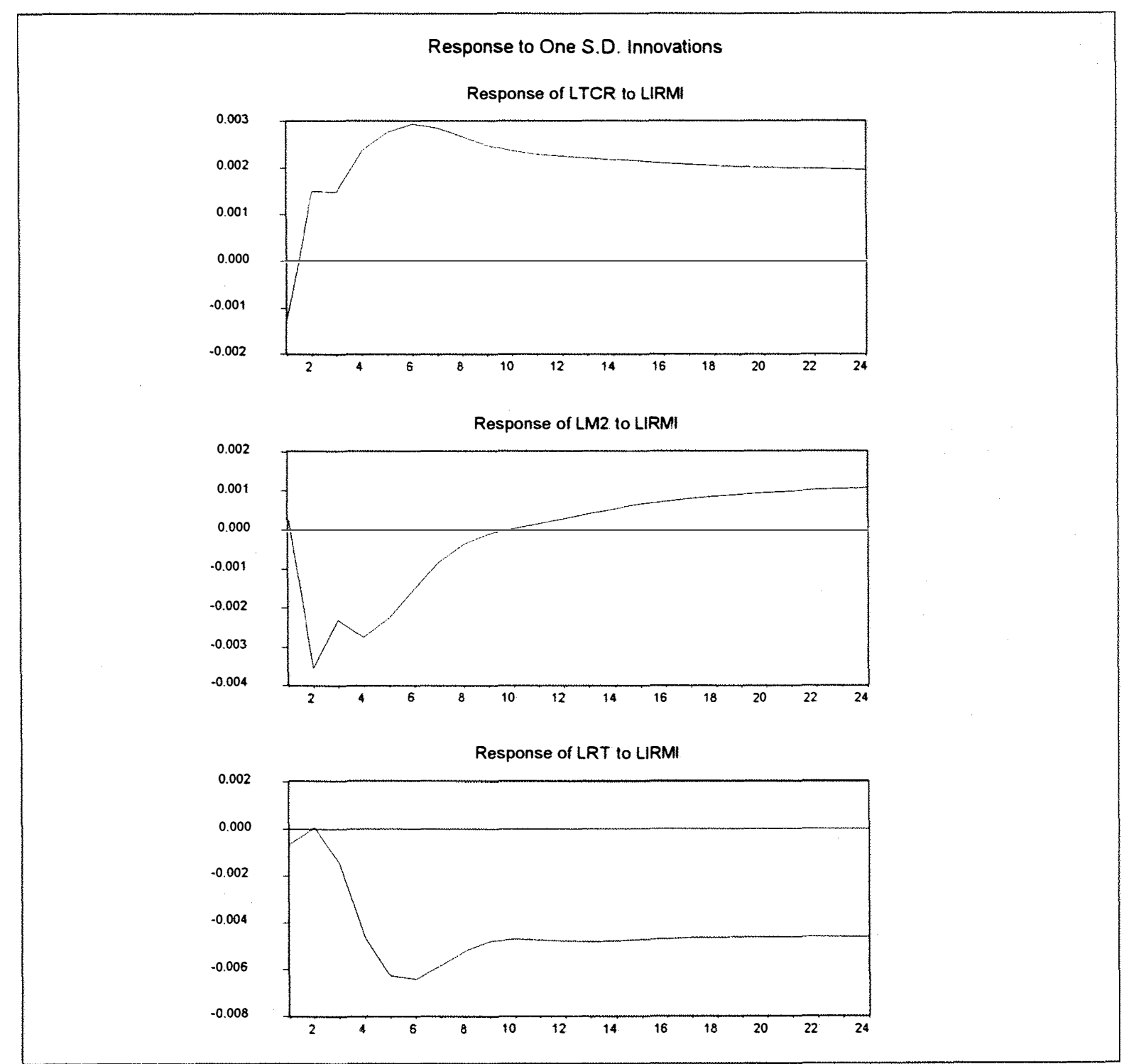

Figura 9: Elasticidades de função de resposta de impulso, efeitos de choques em LIRMI sobre LRT, LTCR e LM2.

Fonte: Dados Básicos da International Financial Statistics (1990/1999), Conjuntura Econômica (1991/1999) e U.S. Department of Labor, Bureau of Labor. 


\subsubsection{3 - Efeitos de choques em LIFI sobre o bloco de variáveis domésticas}

Em relação a choques não antecipados originados nos preços internacionais de alimentos LIFI, verificou-se que seus efeitos sobre a relação de troca envolvendo o setor agricola/industrial, e também, sobre a taxa de câmbio real, são semelhantes aos impactos que variações nos preços internacionais de matérias-primas agrícolas tem sobre essas duas variáveis (Figuras 10 e 9).

Já no caso da variável oferta de moeda, choques não antecipados nos preços internacionais de alimentos proporcionaram efeitos completamente contrários àqueles obtidos no caso em que se analisou os impactos que variações nos preços internacionais de preços de matérias-primas agricolas tem sobre a oferta de moeda, dado que, ao invés da oferta de moeda reduzir-se em função da elevação dos preços domésticos, neste último caso houve um aumento da oferta de moeda (Figura 10). 


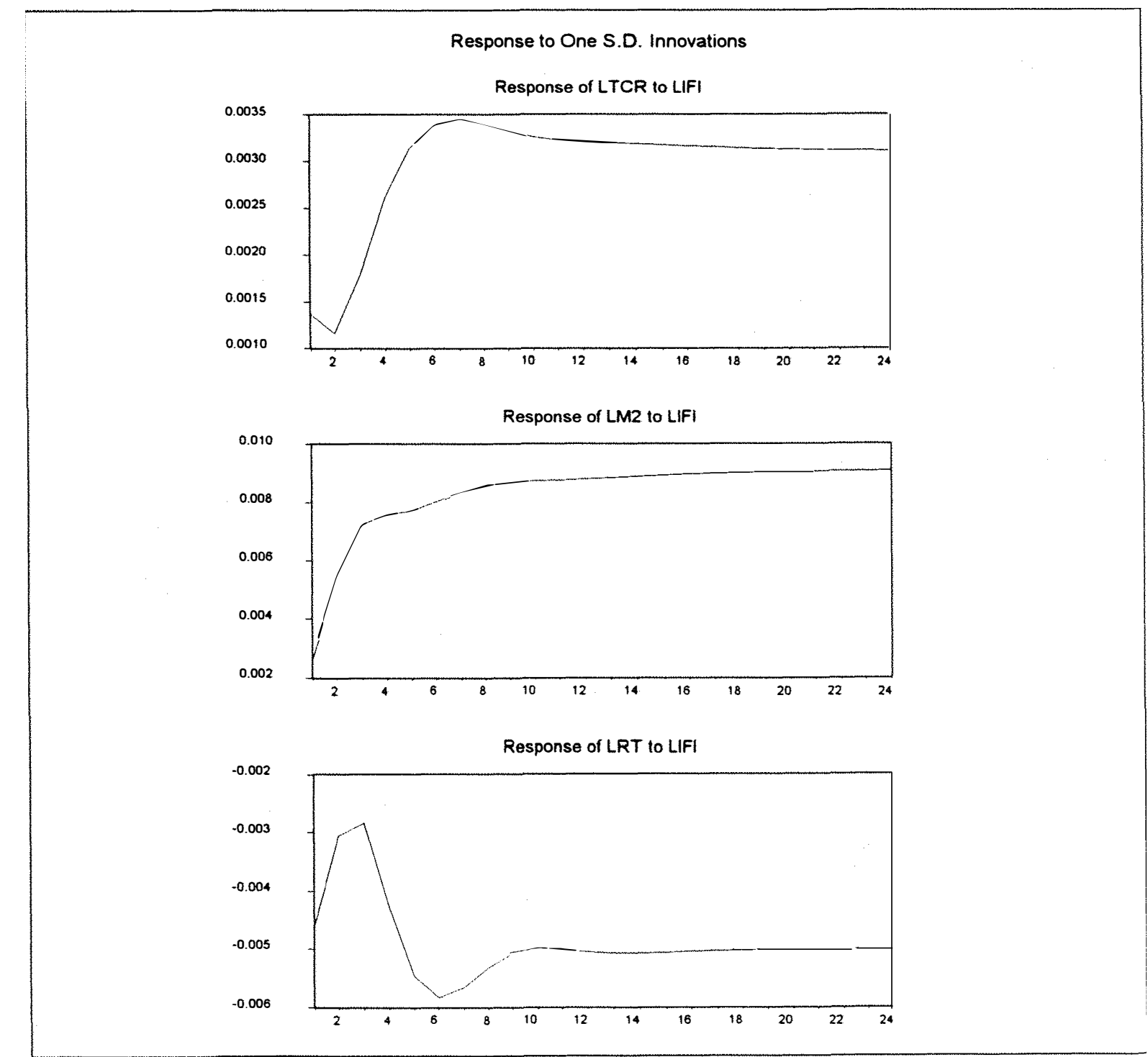

Figura 10: Elasticidades de função de resposta de impulso, efeitos de choques em LIFI sobre LRT, LTCR e LM2.

Fonte: Dados Básicos da International Financial Statistics (1990/1999), Conjuntura Econômica (1991/1999) e U.S. Department of Labor, Bureau of Labor.

\subsubsection{4 - Efeitos de choques em LIPPUS sobre o bloco de variáveis domésticas}

Os efeitos de um choque não antecipado em LIPPUS sobre LTCR, num primeiro momento causa uma valorização da taxa de câmbio real, sendo que, esse processo de apreciação estende-se até o quarto mês após o choque inicial. A partir do quarto mês a trajetória da taxa de câmbio é revertida, e observa-se que a taxa de câmbio real tende a desvalorizar-se continuamente até estabilizar-se em torno do vigésimo quarto mês, sendo que, 
do quarto mês até aproximadamente o décimo mês esse processo de desvalorização cresce a taxas crescentes, para posteriormente, continuar a se depreciar, porém à taxas decrecentes. Novamente, como por exemplo, aconteceu no caso anterior, o periodo mais critico parece ser entre a incidência do choque e o quinto mês, pois dentro desse intervalo de tempo ainda não é possivel determinar com precisão a trajetória da variável que sofreu o choque (Figura 11).

Choques não antecipados no nivel de preços nos EUA tendem a fazer com que a oferta de moeda no Brasil apresente trajetória ascendente desde o choque até o segundo mês após a sua incidência. A partir do segundo mês verifica-se que a oferta de moeda tende a decrescer lentamente até o quarto mês, para em seguida decrescer rapidamente até estabilizar-se num patamar inferior ao que encontrava-se antes do choque inicial em torno do vigésimo quarto mês (Figura 11). A possivel explicação para esse comportamento da oferta de moeda, aparentemente está relacionado ao fato de que a elevação dos preços domésticos nos EUA resulta no aumento da demanda por produtos, principalmente básicos, no mercado internacional, e consequentemente pressiona os preços desses produtos, refletindo sobre os preços domésticos no Brasil, ou seja, a elevação da taxa de inflação no Brasil faz com que a oferta de moeda tenda a cair.

O comportamento da relação de troca diante de um choque não antecipado nos preços domésticos nos EUA, tendeu numa primeira etapa, a elevar-se lentamente até o segundo mês após a incidência do choque em LIPPUS. Em seguida, a relação de troca eleva-se acentuadamente entre o segundo e o quinto mês onde atinge seu ponto de máximo, para então, cair lentamente até estabilizar-se por volta do décimo mês após o choque inicial. Aparentemente, dado que a economia norte americana representa papel de destaque no cenário mundial, o aumento na taxa de inflação nesse país indica que a economia está crescendo e como resultado, as importaçōes de matérias-primas entre as quais àquelas de origem agricola tendem a crescer, ou seja, esse aumento na demanda por produtos agricolas básicos resulta no aumento dos preços agricolas em nivel de atacado no Brasil, logo, a variação dos preços internos nos EUA funcionam de maneira semelhante àquele esperado em decorrência da elevação dos preços de matérias-primas agricolas e de alimentos no mercado internacional, favorecendo dessa fomia a relação de troca para o setor agricola. 

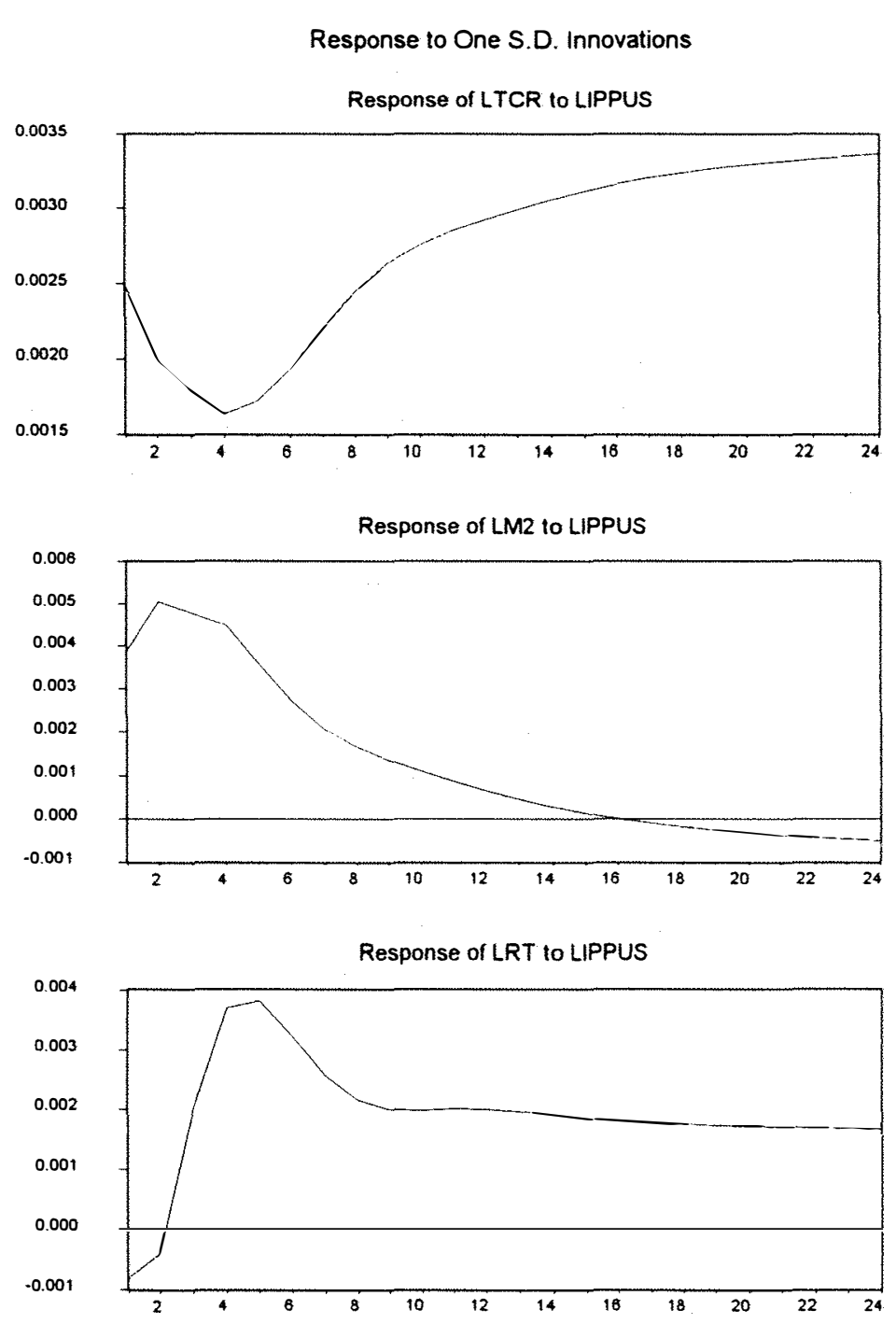

Figura 11: Elasticidades de funçāo de resposta de impulso, efeitos de choques em LIPPUS sobre LRT, LTCR e LM2.

Fonte: Dados Básicos da International Financial Statistics (1990/1999), Conjuntura Econômica (1991/1999) e U.S. Department of Labor, Bureau of Labor.

\subsubsection{5 - Efeitos de choques em LTCR sobre o bloco de variáveis domésticas}

Um choque não antecipado na taxa de câmbio real condicionou três fases distintas em relação ao comportamento da oferta de moeda. A primeira fase, inicia-se com o choque e estende-se até o segundo mês e caracterizou-se por uma rápida elevação na oferta de moeda. A segunda fase vai do segundo até o quarto mês, e também, apresenta crescimento na oferta de moeda, porém em menor velocidade comparativamente àquela da primeira fase, sendo que 
o ponto de máximo ocorreu no quarto mês após a ocorrência do choque inicial. A partir de então, a oferta de moeda tende a decrescer até estabilizar-se em torno do vigésimo quarto mês.

Uma desvalorização da taxa de câmbio real resulta no encarecimento dos produtos importados e com a conseqüente perda de renda real por parte dos agentes econômicos, deslocando demanda para os produtos domésticos. Logo, uma desvalorização real da taxa de câmbio encarece a importação de matérias-primas, produtos intermediários e finais, aumentando os custos domésticos de produção, os quais são repassados aos preços dos produtos, ou seja, os preços domésticos tendem a elevar-se gerando dessa forma uma redução na oferta de moeda. Portanto, espera-se que um choque em LTCR implique na redução da oferta doméstica de moeda. Diante de um choque cambial, a oferta de moeda tende a cair rapidamente a partir do quarto até o sexto mês após a incidência desse choque. A partir desta data, LM2 continua a ser reduzida, porém mais lentamente, para finalmente, estabilizar ao final do vigésimo quarto mês (Figura 12).

Numa primeira fase, o efeito de um choque não antecipado em LTCR ocasionou uma rápida elevação da relação de troca entre o setor agricola e industrial, sendo que, esse aumento perdurou pelo prazo de quatro meses após esse choque inicial, e caracterizou-se por ser de grande magnitude. A seguir, a trajetória de LRT foi revertida apresentando queda entre o quarto até o sétimo/oitavo mês onde atingiu seu ponto de mínimo, para em seguida começar um processo recuperação que se estende até o décimo quarto mês, para finalmente estabilizarse num patamar superior àquele que antecedeu ao choque em LTCR (Figura 12).

Aparentemente, um choque na taxa de câmbio real pode ser analisado como tendo impactos diferenciados sobre os preços agricolas e industriais em termos de seus respectivos horizontes temporais exatamente em função das características de cada mercado.

No curto prazo, após o choque sobre LTCR, os preços agrícolas respondem mais rapidamente que os preços industriais, dado que essa desvalorização cambial favorece as exportações de ambos produtos, pois os exportadores passam a receber mais unidades de moeda nacional por unidade de moeda estrangeira, isto estimula a exportação principalmente de produtos agrícolas que encontram-se estocados, pressionando os preços desses produtos para cima e eleva a relação de troca no curto prazo (dois primeiros meses), mas diante de uma oferta fixa, como é o caso de produtos agrícolas, cuja produção geralmente apresenta sazonalidade, esse processo não pode sustentar-se por muito tempo, ou seja, esgota-se rapidamente. Também, deve-se destacar que, de acordo com CARVALHO e NEGRI $(2000)^{43}$ as

\footnotetext{
43 Mais especificamente, em relação ao comportamento so setor agropecuário brasileiro deiante de variaçōes na taxa de câmbio real, segundo CARVALHO e NEGRI (2000, p.27) no "longo prazo, a desvalorização cambialde $1,00 \%$ ocasionaria alavancagem das exportações do setor em apenas $0,12 \%$, enquanto o aumento no produto mundial em $1,00 \%$ influenciaria positivamente as exportaçōes setoriais em $0,65 \%$. Isso demonstra que a recente desvalorização da moeda nacional provavelmente terá pouca
} 
exportações de produtos agrícolas são mais sensiveis às condiçōes de demanda no mercado mundial do que em função da variação da taxa de câmbio, pelo menos no curto prazo. Já no caso dos produtos industriais, diante de uma desvalorização da taxa de câmbio real, eles também tendem a responder rapidamente, só que neste caso, a exportação de produtos industriais é mais complexa, pois envolve a procura de novos mercado, além do fato de que a concretização de contratos ser mais demorada entre o exportador e o importador, retardando o efeito da variação cambial sobre esses produtos relativamente aos produtos agrícolas (até os quatro primeiros meses após o choque). No entanto, no longo prazo, conforme a nova produção agrícola entra no mercado, a relação de troca tende a diminuir, porém, menos que proporcionalmente, dado que os preços industriais são mais afetados pela variação cambial do que os preços agrícolas, justificando dessa forma as fases em que a relação de troca diminui rapidamente e o subsequente período de estabilidade, mas num patamar superior ao de antes do choque na taxa de câmbio real.

repercussão nas exportaçōes do setor, que vem sendo prejudicado pelo atual cenário de estagnação da economia mundial. Obviamente, esses impactos não se dão de maneira imediata, pois há um processo de ajustamento no curto prazo. O nivel de atividade mundial somente se reflete na decisão dos exportadores no trimestre seguinte, enquanto, no mesmo período, uma alteração positiva no càmbio real se reflete negativamente nas exportações, e esse movimento inicial é compensado no trimestre seguinte". 


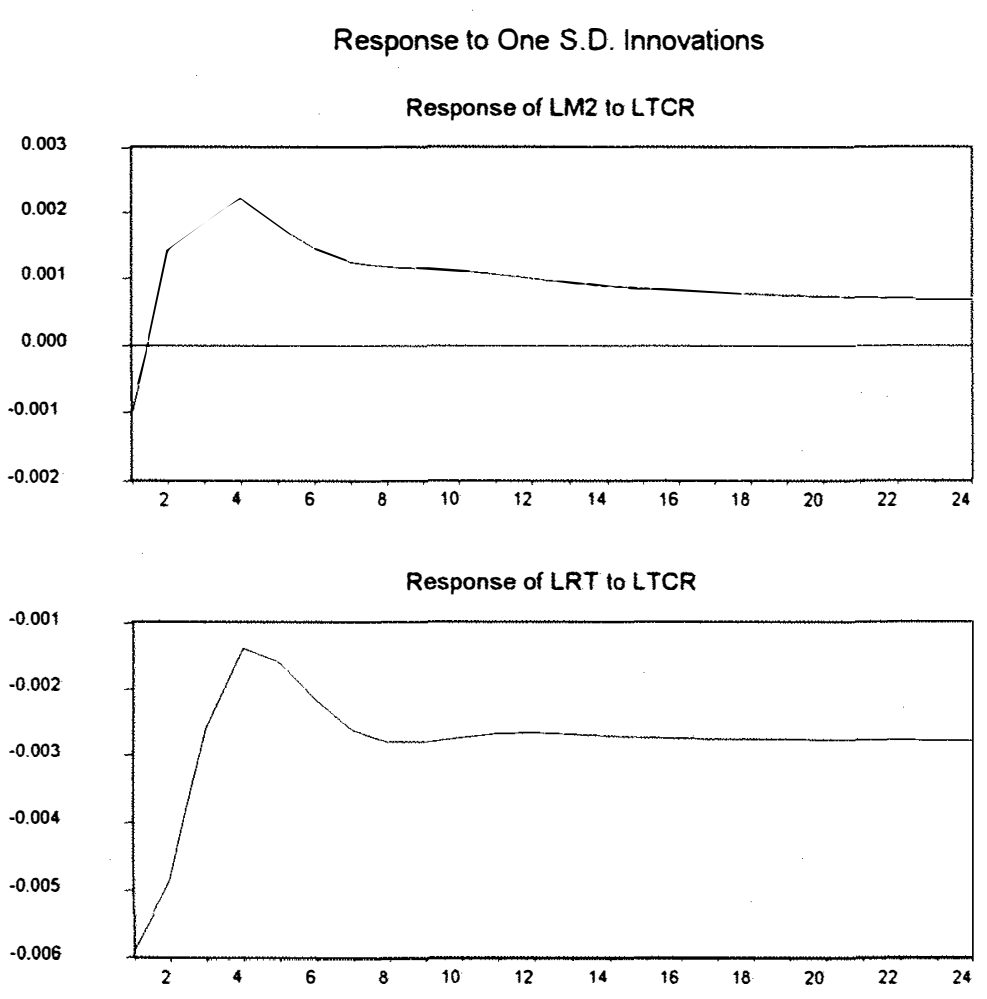

Figura 12: Elasticidades de função de resposta de impulso, efeitos de choques em LTCR sobre LRT e LM2.

Fonte: Dados Básicos da International Financial Statistics (1990/1999), Conjuntura Econômica (1991/1999) e U.S. Department of Labor, Bureau of Labor.

\subsubsection{6 - Efeitos de choques em LM2 sobre o bloco de variáveis domésticas}

A partir de um choque não antecipado em LM2 a relação de troca agricultura/indústria cai rapidamente até o segundo mês após a ocorrência desse choque monetário. Passada esta fase de queda abrupta, a relação de troca continua com tendência de queda, porém de forma menos intensa no periodo compreendido entre o segundo e o quinto mês, onde atingiu seu nivel mais baixo. A partir do quinto mês, inicia-se um período de lenta recuperação de LRT até estabilizar-se por volta do vigésimo segundo/vigésimo quarto mês depois da incidência do choque (Figura 13). Possivelmente, este comportamento de LRT esteja relacionado ao fato de que ao aumentar a oferta de moeda os juros tendem a cair e como resultado ocorre, pelo menos no primeiro momento, um aumento da demanda por produtos industriais pressionando os preços desses produtos e reduzindo a relação de troca nessa fase. Posteriomente, a demanda por produtos agrícolas eleva-se pressionando os preços, aumentando a relação de 
troca, porém, menos que proporcionalmente ao aumento dos preços industriais, justificando assim a estabilização de LRT num patamar inferior ao que se encontrava no periodo anterior ao choque.

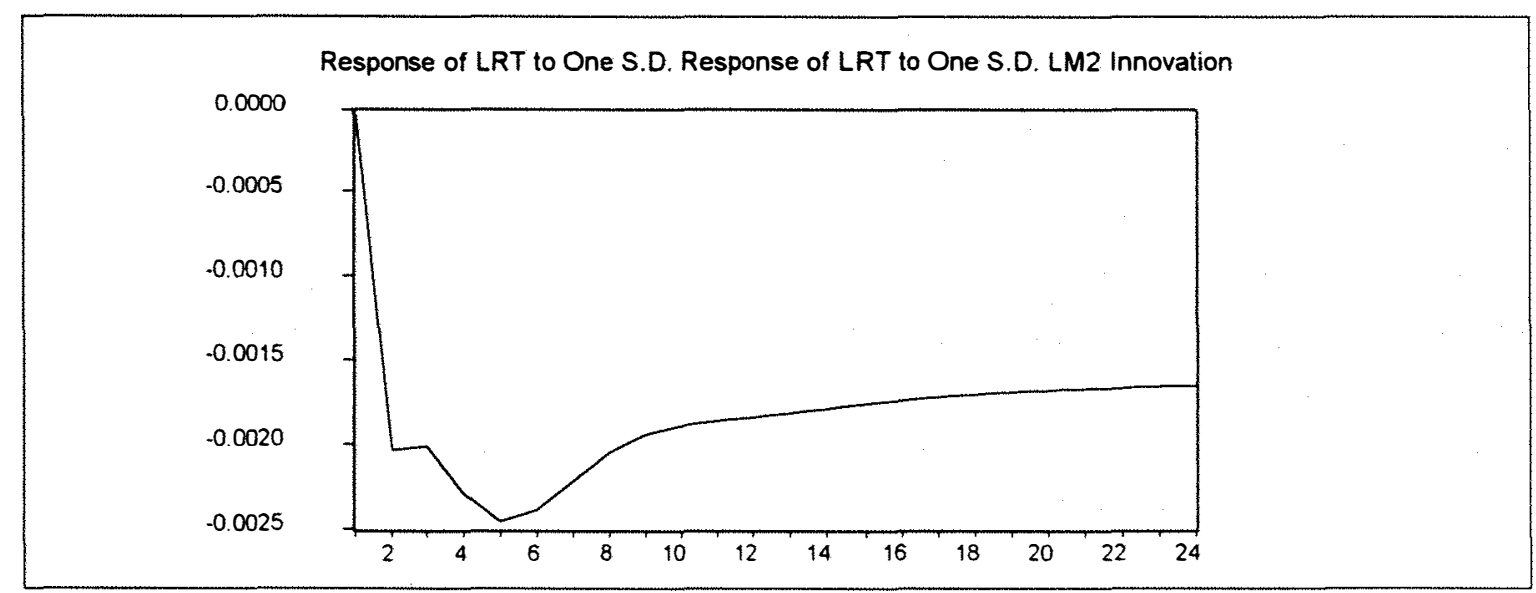

Figura 13: Elasticidades de função de resposta de impulso, efeitos de choques em LM2 sobre LRT.

Fonte: Dados Básicos da International Financial Statistics (1990/1999), Conjuntura Econômica (1991/1999) e U.S. Department of Labor, Bureau of Labor. 


\section{CONCLUSÕES}

Este trabalho analisou o comportamento dos preços agricolas no Brasil diante de choques em variáveis internacionais e domésticas para o período de janeiro de 1990 a dezembro de 1998 utilizando como base o modelo teórico desenvolvido por PONGIBOVE (1996).

Basicamente, foram utilizadas sete séries de tempo sendo quatro internacionais (índice internacional de preços de alimentos, índice internacional de preços de matérias-primas, preço internacional do petróleo e índice de preços em nivel de produtor nos Estados Unidos) e três domésticas (índice de relação de troca agricultura/indústria, taxa de câmbio real e oferta de moeda.

Para analisar o efeito deste conjunto de vaiáveis sobre a relação de troca no Brasil foram utilizados os testes de raiz unitária convencionais dos tipos Dickey-Fuller Aumentado, Phillips-Perron, além de testes de raiz unitária com quebra estrutural conforme apresentados em PERRON (1989 e 1994) e FRANSES e HALDRUP (1993), além de testes de co-integração de Johansen e modelos Vetoriais Auto-regressivos e de Correção de Erro (VEC).

Contrastando com diversos estudos realizados anteriormente abordando o mesmo tema, esse trabalho destaca-se pelo fato de que houve grande preocupação em relação à determinação da ordem de integração das variáveis envolvidas neste trabalho, dado que a ordem de integração das variáveis assume papel preponderante na utilização dos testes de cointegração, assim como, em relação à tomada de decisão sobre a utilização dos modelos VAR ou VEC para analisar as relaçőes dinâmicas entre as variáveis.

A principal crítica em relação aos diversos trabalhos anteriores consultados reside no fato de que esses estudos geralmente fizeram uma análise superficial da ordem de integração, ou seja, na maioria dos casos utilizaram somente um tipo de teste de raiz unitária, não comparando com outros tipos de testes dado que esses testes possuem baixo poder pode-se incorrer em resultados viesados, pois a introdução de parâmetros como constante e/ou tendência podem alterar radicalmente os resultados dos testes, além do que, a determinação do número de defasagens também pode influenciar os resultados dos testes. Outro aspecto ignorado pelos demais trabalhos estudos refere-se ao fato de que, principalmente os estudos 
envolvendo análises sobre a transmissão de preços no Brasil nas décadas de 70 e 80 , utilizaram-se dos convencionais testes de raiz unitárias, ou seja, não levaram em consideração os efeitos que os choques do petróleo nos anos 70 e os diversos planos de estabilização implementados no Brasil na década de 80 tiveram sobre as séries analisadas, podendo dessa forma comprometer os respectivos resultados obtidos sobre a ordem de integração dessas variáveis $^{44}$.

Segundo FRANSES e HALDRUP (1993), a presença de quebras estruturais nas séries tendem a produzir estacionariedade espúria nos modelos univariados, ou seja, os testes de raiz unitária tendem a obter resultados viesados ao mostrar que as séries são estacionárias, quando na verdade elas possuem raiz unitária, sendo que o mesmo raciocínio é válido para os testes de co-integração, dado que, as quebras estruturais podem provocar co-integração espúria, isto é, os resultados desses testes podem indicar que as variáveis são co-integradas (apresentam relacionamento de longo prazo) quando isso não é verdade.

Diante da presença de quebras estruturais nas séries em análise, ao invés dos testes de raiz unitária convencionais, o mais correto é utilizar testes de raiz unitária com quebra estrutural. Especificamente, neste estudo foi utilizado o teste de raiz unitária com quebra estrutural desenvolvido por PERRON (1989 e 1994), além do teste apresentado em FRANSES e HALDRUP (1993) para outliers do tipo aditivo. Ambos testes utilizam-se da escolha exógena do ponto de quebra estrutural, mais precisamente, a data onde deve ser colocada a variável dummy no caso do teste proposto por PERRON (1989 e 1994) e das variáveis dummies para o teste de FRANSES e HALDRUP (1993) é realizado através da visualização gráfica de cada série ao longo do tempo. De acordo com MADDALA e KIM (1996), não há necessidade de se pesquisar possíveis quebras sobre toda a série, uma vez que, geralmente há informação a priori sobre as respectivas datas relacionadas com os principais choques, seja no âmbito real, quanto financeiro, fato esse que sugere o local próximo de ocorrência efetiva da mudança estrutural.

Foram analisados modelos para três períodos distintos. $O$ primeiro, inicia-se em janeiro de 1990 e vai até junho de 1994, mês que antecedeu a implementação do Plano Real, sendo que, este período caracterizou-se por apresentar maior grau de abertura da economia brasileira

\footnotetext{
44 CUNHA e MARGARIDO (1999) utilizando a metodologia de série temporais desenvolvida por BOX, JENKINS e REINSEL (1994), analisaram o comportamento do Índice Geral de Preços (IGP) da Fundação Getúlio Vargas (FGV) para o período de 1971 até 1998. A conclusão deste estudo é que houve mudanças estruturais no comportamento do IGP no período de 1985 a 1998 comparativamente ao período de 1971 a 1984, como decorréncia do acirramento do processo inflacionário a partir da segunda metade da década de 80 . Em função das diversas tentativas fracassadas para debelar o processo inflacionário, via a implementação de vários planos econômicos de estabilização, exacerbaram-se ainda mais as expectativas dos agentes econômicos, proporcionando não somente maior dispersão dos preços como também, amplificando as suas respectivas variåncias. Essa conjunção de fatores conduziu a bruscas variaçōes do IGP exigindo a implementação de diversas variáveis de intervenção para modelar a série do IGP no período de 1985 a 1998, e conseqüentemente, obrigando a utilização de testes de raiz unitária com quebra estrutural ao invés dos testes convencionais.
} 
comparativamente à década de 80 , porém, ainda com elevada instabilidade dos preços domésticos. O segundo período analisado inicia-se em julho de 1994, mês de implementação do Plano Real, e estende-se até dezembro de 1998. Em relação ao período anterior, deve-se observar que este segundo período configurou-se por apresentar estabilidade do nível de preços domésticos conjugado com ampliação do raio de abertura da economia brasileira ao comércio internacional, dado que, para estabilizar os preços internos, o Plano Real utilizou como âncora a política cambial Finalmente, o terceiro período engloba janeiro de 1990 até dezembro de 1998, englobando, portanto, dois períodos distintos.

A justificativa para a divisão temporal dos períodos reside no fato de que procuro-se determinar o comportamento da transmissão de preços entre os diversos segmentos em conjunturas econômicas distintas, ou seja, menor grau de abertura da economia com instabilidade de preços internos (janeiro de 1990 a junho de 1994) contra um periodo com estabilidade de preços e maior grau de abertura da economia brasileira ao comércio internacional (julho de 1994 até dezembro de 1998) e também um periodo englobando os dois anteriores. Em relação a este último período, é necessário observar que a visualização gráfica mostrou uma quebra estrutural nas séries de tempo domésticas em julho de 1994 (mês de implementação do Plano Real) fato esse que obrigou a inclusão de uma variável de intervenção nesta data para possibilitar a sua efetiva modelagem.

Como mencionado inicialmente, em função de seu baixo poder, foram utilizados mais de um teste de raiz unitária. No caso do primeiro período, observou-se conflitos de resultados nos testes convencionais de raiz unitária (Dickey-Fuller Aumentado (ADF) e Phillips-Perron (PP)) para a maior parte das variáveis domésticas, sendo assim, para a tomada de decisão quanto a ordem de integração das variáveis foi necessário partir para a visualização das respectivas funções de autocorrelação de cada variável. Possivelmente, dois podem ser os fatores que explicam esses conflitos de resultados. O primeiro deles é de ordem estatística, uma vez que, os testes de raiz unitárias tem baixo poder, principalmente diante de pequenas amostras, pois neste caso foram utilizadas somente 54 observaçőes, quando normalmente ao se trabalhar com séries de tempo a "regra de bolso" indica utilizar pelo menos 60 observações, isto pode ter influenciado nos resultados dos testes de raiz unitária . No entanto, talvez o fator preponderante tenha sido o fato de que o período analisado caracterizou-se por apresentar elevada instabilidade dos preços internos, a qual provoca distorções nos preços relativos. Numa situação de instabilidade generalizada de preços, as séries econômicas tendem a apresentar um comportamento explosivo e conseqüentemente, a sua modelagem toma-se muito mais complexa, refletindo-se dessa forma sobre os próprios resultados dos testes de raiz unitánia, os quais devem ser analisados com muito mais cautela do que normalmente acontece. 
Em contrapartida, ao levar-se em consideração os resultados dos testes de raiz unitária convencionais para o segundo período e dos testes de raiz unitária com quebra estrutural para o periodo completo para as variáveis domésticas, verificou-se que praticamente não houve conflitos em relação aos resultados dos testes de raiz unitária.

Determinada a ordem de integração das variáveis, o próximo passo consistiu na construção dos testes de co-integração de Johansen para a verificação ou não da presença de equilibrio de longo prazo entre as variáveis analisadas. Para o primeiro periodo, os resultados do teste de co-integração mostrou que cinco variáveis são co-integradas, e sendo assim, não pode-se utilizar o modelo VAR e sim o modelo VEC, o qual capta o relacionamento, tanto de curto, quanto de longo prazo entre as variáveis. No entanto, a análise dos sinais revelou que somente cinco variáveis tinham sinais coerentes com o que era esperado. Portanto, esse modelo foi descartado e a atenção recaiu sobre o modelo relativo ao segundo período e ao modelo com período completo.

Os resultados dos testes de co-integração para ambos modelos mostraram que o número de vetores de co-integração não é pleno, indicando que as variáveis para cada modelo apresentam equilíbrio não somente de curto prazo, como também, de longo prazo entre si, e como resultado dessa situação ao invés do modelo VAR deve-se utilizar o modelo vetorial de correção de erro (VEC). Dado que ambos modelos apresentaram resultados semelhantes em relação a determinação do número de vetores de co-integração (três vetores no periodo dois contra quatro vetores no modelo completo), o próximo passo consistiu na análise dos sinais. Neste caso, os resultados obtidos para o modelo dois foram melhores comparativamente ao modelo completo, pois seis das sete variáveis apresentaram sinais coerentes ao que era esperado, enquanto que, no modelo para o período completo, o qual incorporou uma variável de intervenção em julho de 1994, apresentou somente quatro variáveis com sinal condizente ao que esperava-se. No entanto, é necessário frisar que a introdução de variáveis dummies nos testes de co-integração pode invalidar os valores críticos desses testes. Em função do fato de que incorporação de variáveis deterministicas nos testes de co-integração que não sejam constante e tendência ainda não se encontra totalmente sedimentado, optou-se em continuar a análise da transmissão de preços levando-se em consideração apenas o modelo relacionado com o segundo periodo. Também, uma vez que, ambos modelos apresentaram comportamento semelhantes relativamente aos testes de co-integração em termos estatísticos, ao se trabalhar com séries temporais, quando dois modelos tem desempenho muito próximo, normalmente escolhe-se aquele mais parcimonioso, que nesse caso é o modelo do periodo de julho de 1994 a dezembro de 1998, uma vez que, este modelo é menos complexo, dado que, não foi necessária a introdução de uma variável de intervenção. 
Tendo como base o segundo período, o próximo passo consistiu na utilização da decomposição da variância dos erros de previsão e das funções de repostas de impulso para analisar o comportamento de cada variável em relação à transmissão de preços, tanto em nível externo, quanto doméstico.

Em relação aos resultados da decomposição da variância dos erros de previsão, verificou-se que a maior parcela da decomposição da variância das variáveis extemas é função de choques ocorridos dentro do próprio conjunto de variáveis intemacionais. Ainda com relação ao grupo de variáveis internacionais, destaca-se que, individualmente, todas as variáveis são bastante influenciadas pela sua respectiva variância decorridos 24 meses após um choque não antecipado em cada uma delas, isto é, apresentaram uma "memória" longa, especialmente os preços intemacionais das matérias-primas agrícolas. A única exceção foi a variável relativa ao preço intemacional do petróleo, dado que após 24 meses após a incidência de um choque não antecipado sobre ela mesma, os efeitos desse choque praticamente desaparecem.

Os resultados obtidos em relação ao conjunto de variáveis extemas estão consistentes com os resultados obtidos por PONGIBOVE (1996), sendo que, a única exceção foi o preço internacional do petróleo, pois no trabalho deste último os preços internacionais do petróleo tem papel de destaque na variância dos erros de previsão do grupo de variáveis extemas, fato este que não se confirmou neste estudo.

Tanto os resultados obtidos por PONGIBOVE (1996), quanto os obtidos neste estudo apresentam coerência, uma vez que, o período de analisado por PONGIBOVE (1996) refere-se às décadas de 70 e 80 , períodos em que o petróleo tinha papel de destaque na matriz energética da maioria dos países, além do que, foi nos anos 70 que ocorreram os dois choques do petróleo, sendo assim, os resultados em PONGIBOVE (1996) captaram os acontecimentos relativos àqueles dois períodos. Já os resultados relativos à década de 90 contidos neste estudo, também refletem a conjuntura atual, pois, em função dos choques do petróleo, diversos países implementaram projetos de pesquisa na área de energia visando não somente 0 desenvolvimento de fontes de energia altemativas, como também, intensificar a produção doméstica de petróleo, com o intuito de reduzir sua dependência externa em relação ao petróleo importado. Sendo assim, a redução da participação do preço do petróleo em relação a variância dos erros de previsão do grupo de variáveis intemacionais também está coerente, uma vez que, que reflete a nova conjuntura intemacional.

Outra conclusão relevante refere-se ao comportamento da decomposição da variância dos erros de previsão da relação de troca entre agricultura e indústria diante de choques nas variáveis internacionais. Os resultados obtidos neste estudo mostraram que o termo de troca agricultura/indústria é influenciado principalmente pelos preços internacionais de matérias- 
primas agrícolas, preço do petróleo, preços intemacionais de alimentos e em menor escala pela inflação nos Estados Unidos.

Esses resultados contrastam com aqueles obtidos por PONGIBOVE (1996), o qual trabalhou com um índice de relações de troca entre os setores agrícola e industrial e concluiu que a decomposição da variância dos erros de previsão dessa variável, após 24 meses a incidência de um choque, é explicada somente pelas variáveis domésticas (própria variável e a taxa de câmbio), configurando dessa forma a menor inserção da economia brasileira nas décadas de 70 e 80, período este abrangido por aquele estudo. Já neste estudo, os resultados da decomposição da variância dos erros de previsão mostraram que o comportamento da relação de troca está condicionada principalmente pelo conjunto de variáveis extemas, configurando dessa forma que os preços setoriais no Brasil estão mais aderentes aos preços no mercado internacional.

Quanto aos resultados das funções de resposta de impulso, verificou-se que choques não antecipados tendem a gerar três fases distintas. De maneira geral, a primeira fase que compreende os dois primeiros meses tende a apresentar forte variabilidade dos preços, ou seja, ainda não é possível determinar a trajetória dos preços das variáveis que sofreram o choque. Entre o quinto mês e o décimo segundo mês após a incidência de um choque não antecipado, os preços continuam a variar, contudo, com menor intensidade, e inclusive, toma-se possível determinar quais são as suas respectivas trajetórias. Finalmente, a terceira fase, que vai aproximadamente do décimo segundo ao vigésimo quarto mês, caracteriza-se pela estabilidade dos preços, ou seja, nesse período, tanto a trajetória, quanto o novo patamar de preços estão praticamente definidos. Portanto, diante de choques não antecipados, o período crítico para que - Govemo possa intervir no mercado no sentido de atenuar os efeitos desses choques corresponde ao seis primeiros meses após a ocorrência do choque.

Para finalizar, a principal contribuição desse estudo foi no sentido de mostrar a dinâmica de transmissão de preços entre diversos mercados para a economia de um país em desenvolvimento com relativo grau de abertura ao comércio intemacional e com estabilidade de preços domésticos. A partir dos resultados obtidos neste estudo, posteriores trabalhos podem ser elaborados procurando incluir aspectos relacionados com o processo de globalização e a formação de blocos, sejam eles comerciais, ou econômicos. Também, podem ser desenvolvidos trabalhos que visem analisar setores específicos, ao invés de mercados agregados como foi realizada a análise neste estudo. 


\section{REFERÊNCIAS BIBLIOGRÁFICAS}

AGUIAR, Danilo R.D. Custo, risco e margem de comercialização de arroz e de feijão no Estado de São Paulo: análise dinâmica e teste de modelos alternativos. Piracicaba, 1994. 183p. Tese (Doutorado). Escola Superior de Agricultura Luiz de Queiroz, Universidade de São Paulo.

AGUIAR, Danilo R.D. ; BARROS, Geraldo S.A.C. Transmissão de preços de laranja entre os mercados externo e interno. Revista de Economia e Sociologia Rural, v.27, n. 1, p. 6170, jan./mar. 1989.

AKAIKE, H. Canonical correlations analysis of time series and the use of an information criterion. In: Advances and Case Studies in System Identification. New York: Academic Press, 1976. p.27-96.

ALVES, Denisard; FAVA, Vera L. ; SILBER, Simão D. Current account balance and the real exchange rate: the brazilian case in the last two decades. Economia Aplicada, v.3, $\mathrm{n}$. especial, p.15-33, mar. 1999.

BACCHI, Mirian R.P. Integração, co-integração e modelo de correção de erro: uma introdução. Piracicaba: ESALQ, 1996. 20 p.

BACCHI, Mirian R.P. Previsão de preços de bovino, suíno e frango com modelos de séries temporais. Piracicaba, 1994. 173p. Tese (Doutorado). Escola Superior de Agricultura Luiz de Queiroz, Universidade de São Paulo.

BANERJEE, Anindya ; URGA, Giovanni. Looking for structural breaks in cointegrated systems. London: London Business School, Centre for Economic Forecasting. Jun., 1995. 22p. (Discussion Paper n.18-95).

BANERJEE, Anindya et al. Co-integration, error-correction, and the econometric analysis of non-stationary data. New York: Oxford University Press, 1993. 329p. (Advanced Texts in Econometrics).

BARBOSA, F.H. Ensaios sobre inflação e indexação. Rio de Janeiro: Fundação Getúlio Vargas, 1987. $168 \mathrm{p}$.

BARROS, Geraldo S.A.C. Effects of intemational shocks and domestic macroeconomic policies upon Brazilian agriculture. Agricultural Economics, v. 7, n. 314, p. 317-329, Oct. 1992.

BARROS, Geraldo S.A.C. Impacts of monetary and real factors on the US dollar in identifiable VAR models. Revista Brasileira de Economia, v. 45, n. 4, p. 519-541, 1991.

BARROS, Geraldo S.A.C. Efeitos de políticas macroeconômicas sobre a agricultura brasileira. Piracicaba: Fundação de Estudos Agrários "Luiz de Queiroz" / Ministério da Economia, Fazenda e Planejamento, 1990a. 175 p.

BARROS, Geraldo S.A.C. Preços de commodities agrícolas e o câmbio flexível. Piracicaba: ESALQ, 1990b. 36p.

BERGMANN, Denis; BAUDIN, Pierre. Politicas do futuro para a Europa agrícola. Portugal: Publicaçőes Europa-América, 1989. 215p. 
BERNANKE, B.S. Altemative explanations of the money-income correlation. CarnegieRochester Conference Series on Public Policy, v. 25, p. 49-100, 1986.

BESSLER, David A. Relative prices and money: a vector autoregression on Brazilian data. American Journal of Agricultural Economics, v. 66, n.1, p. 25-30, Feb. 1984.

BIER, Amaury G. ; PAULANI, Leda M. ; MESSENBERG, Roberto. O heterodoxo e o pósmoderno: o Cruzado em conflito. Rio de Janeiro: Paz e Terra, 1987. 142p.

BLANCHARD, Oliver J. ; WATSON, M. Are the business cycles all alike? National Bureau of Economic Research Working Paper, n. 1.392, 1984.

BLISKA, Flávia M. de Mello. Formação de preços de carne bovina: uma aplicação do modelo de auto-regressão vetorial. Agricultura em São Paulo, v. 37, n. 3, p. 41-59, 1990.

BOX, George E.P. ; JENKINS, Gwilym M. ; REINSEL, Gregory C. Time series analysis: forecasting and control. 3. ed. New Jersey: Prentice Hall, 1994. 598p.

BOX, George E.P.; TIAO, George C. Intervention analysis with application to economic and environmental problems. Joumal of the American Statistical Association, v. 70, n.3, p.70-79, Mar. 1975.

BRANDÃO, Antonio S. P. Moeda e preços relativos: evidência empírica. Revista de Econometria, v. 5, n. 2, p. 33-80, nov. 1985.

CARVALHO, Alexandre ; NEGRI, João A. Estimação de equações de importação e exportação de produtos agropecuários para o Brasil (1977/1998). Brasília: Instituto de Pesquisa Econômica Aplicada. Texto para Discussão n. 698, jan. 2000. 30p.

CARVALHO, Maria A. e SILVA, César R.L. Políticas agrícolas dos países desenvolvidos. Informações Económicas, São Paulo, v. 25, Supl. 1, p. 1-112, 1995.

CARVALHO, Maria A. ; SILVA, César R.L. Políticas de ajustamento e preços agrícolas: um estudo de caso. Agricultura em São Paulo, v. 41, n. 2, p. 17-28, 1994.

CASTRO, Antonio B. ; SOUZA, Francisco E.P. A economia brasileira em marcha forçada. Rio de Janeiro: Paz e Terra, 1985. 217p.

COMUNIDADE ECONO̊MICA EUROPÉIA. Uma política agrícola comum para os anos noventa. Luxemburgo, 1989. 96p.

CONJUNTURA ECONO̊MICA. Rio de Janeiro: Fundação Getúlio Vargas, 1991-1999.

COSTA, Silvia M. L. Relações de longo prazo entre preços nos mercados internacionais de arroz e milho. In: CONGRESSO BRASILEIRO DE ECONOMIA E SOCIOLOGIA RURAL, 37., Foz do Iguaçu, 1999. Anais. Brasília: SOBER, 1999.

CUNHA, Marina S. ; MARGARIDO, Mario A. Avaliação dos impactos dos planos de estabilização pós-1986 sobre o indice geral de preços (IGP): uma aplicação da metodologia Box \& Jenkins. Agricultura em São Paulo, v. 46, n. 2, p. 1-18, 1999. 
DICKEY, David A. ; HASZA, D. P. ; FULLER, Wayne A. Testing for unit roots in seasonal time series. Joumal of the American Statistical Association, v. 79, n.386, p.355-367, Jun. 1984.

DICKEY, David A.; FULLER, Wayne A. Likelihood ratio statistics for autoregressive time series with a unit root. Econometrica, v. 49, n.4, p.1057-1072, jul., 1981.

DICKEY, David A.; FULLER, Wayne A. Distribution of the estimators for autoregressive time series with unit root. Joumal of The American Statistical Association, v. 74, n.366, p.427-431, Jun. 1979.

DORNUBUSCH, Rudiger. Expectations and exchange rate dynamics. Joumal of Political Economy, v. 84, p. 1161-1176. 1976.

ENDERS, Walter. Rats handbook for econometric time series. John Wiley \& Sons, Inc. 1996. 204 p.

ENDERS, Walter. Applied econometric time series. New York: John Wiley and Sons, 1995. 433p.

ENGLE, Robert F.; GRANGER, C.W.J. Long-run economic relationship: readings in cointegration. New York: Oxford University Press, 1991. 301p. (Advanced texts in econometrics).

EVIEWS user guide - Version 2.0. Califomia: QMS, 1994-95. 372p.

FACKLER, Paul L. Vector autoregressive techniques for structural analysis. Revista de Análisis Económico, v. 2, p.119-134, 1988.

FOCUS. NEWSLETTER. Switzeriand, 1990/98.

FRANKEL, Jeffrey A. Expectations and commodity price dynamics: the overshooting model. American Joumal of Agricultural Economics, v. 67, p.344-348, 1986.

FRANSES, Philip Hans ; HALDRUP, Niels. The effects of additive outliers on tests for unit roots and cointegration. Florence: European University Institute, 24p. 1993 (EUI Working Paper ECO, n. 93/16).

FREITAS FILHO, Floriano et al. Aspectos operacionais do mercado cambial brasileiro. Agricultura em São Paulo, v. 40, n.2, p.67-93, 1993.

FULLER, Wayne A. Introduction to statistical time series. 2. ed. New York: John Wiley \& Sons, 1996. 698p.

HAN, Doo B.; JANSEN, Dennis W. ; PENSON JR., John B. Variance of agricultural prices, industrial prices, and money. American Joumal of Agricultural Economics, v. 72, n. 4, p. 1066-1073, Jul. 1990.

HARRIS, Richard I.D. Cointegration analysis in econometric modelling. London: Prentice Hall, 1995. 176p.

HATANAKA, Michio. Time-series-based econometrics: unit roots and cointegration. New York: Oxford University Press, 1998. 294p. (Advanced Texts in Econometrics). 
HILL, R. Carter; GRIFFITHS, William E. ; JUDGE, George G. Econometria. São Paulo: Saraiva, 1999. 408p.

HOLDEN, Darryl ; PERMAN, Roger. Unit roots and cointegration for the economist. In: RAO, B. Bhaskara. Cointegration for the applied economist. New York: ST. Martin's Press, 1994. p.47-94.

HYLLEBERG, Svend; ENGLE, Robert; GRANGER, Clive ; YOO, B.S. Seasonal integration and cointegration. Journal of Econometrics, v. 44, p. 215-38, 1990.

INTERNATIONAL MONETARY FUND. International Financial Statistics Yearbook. Washington, 1990/1999.

JOHANSEN, Soren. Likelihood-based inference in cointegrated vector auto-regressive models. New York: Oxford University Press, 1995. 267p. (Advanced Texts in Econometrics).

JOHANSEN, Soren. Estimation and hypothesis testing of cointegration vectors in gaussian vector Autoregressive Models. Econometrica, v. 59, p.1551-1580, 1991.

JOHANSEN, Soren; JUSELIUS, Katarina. Maximum likelihood estimation and inference on cointegration with applications to the demand for money. Oxford Bulletin of Economics and Statistics, v. 52, n. 2, p. 169-210, 1990.

JOHNSTON, Jack ; DiNARDO, John. Econometric methods. 4.ed. Singapore: McGraw-Hill Intemational Editions, 1997. 531p.

KASSOUF, Ana L. Previsão de preços na pecuária de corte no Estado de São Paulo. Piracicaba, 1988. 102p. Dissertação (Mestrado). Escola Superior de Agricultura Luiz de Queiroz, Universidade de São Paulo.

KRUGMAN, Paul R.; OBSTFELD, Maurice. International economics: theory and policy. 4. ed., Massachusetts: Addison Wesley, 1997. 766p.

LAPP, John S. ; SMITH, Vincent H. Aggregate sources of relative price variability among agricultural commodities. American Journal of Agricultural Economics, v.74, n.1, p.1-9, feb. 1992.

LAPP, John S. Relative agricultural prices and monetary policy. American Journal of Agricultural Economics, v.72, n.3, p. 622-630, aug. 1990.

LOPES, Mauro R. Os efeitos das coalizões na política agrícola e o comércio exterior de produtos agrícolas no Brasil. Agricultura em São Paulo, v. 39, n. 2, p.23-41, 1992.

LUTKEPOHL, Helmut. Vector Autoregressions. http://ise.wiwi.hu-berlin.de/ (12 de jan. 1999).

LUTKEPOHL, Helmut. Introduction to multiple time series analysis. Berlin: Springer-Verlag, 1991. 545p.

MACKINNON, James G. Critical values for cointegration tests. In: ENGLE, R. F. ; GRANGER, W. J. Long-run economic relationships: readings in cointegration. New York: Oxford University Press, 1991. p.267-276. 
MADDALA, G.S. ; KIM, In-Moo. Structural change and unit roots. Joumal of Statistical Planning and Inference, v. 49, p. 73-103, 1996.

MARGARIDO, Mario A. ; SOUSA, Eduardo L.L. ; BARBOSA, Marisa Z. ; FREITAS, Silene M. Transmissão de preços no mercado intemacional do grão de soja: uma aplicação da metodologia de séries temporais. In: CONGRESSO BRASILEIRO DE ECONOMIA E SOCIOLOGIA RURAL, 37., Foz do Iguaçu, 1999. Anais. Brasília: SOBER, 1999.

MARGARIDO, Mario A. ; SOUSA, Eduardo L.L. Formação de preços da soja no Brasil. Agricultura em Såo Paulo, v 45, n. 2, p. 52-61, 1998.

MARGARIDO, Mario A. et al. Análise dos impactos das cotações do dólar paralelo e do índice pluviométrico sobre os preços do boi gordo no Estado de São Paulo. Revista Brasileira de Economia, v. 50, n. 2, p. 255-278, abr./ jun. 1996.

MARGARIDO, Mario A. ; CAMBON JUNIOR, Edison. A União Européia (UE) e a questão dos direitos niveladores e das restituiçőes às exportaçőes no interior do Acordo Geral de Tarifas e Comércio (GATT). Informações Econômicas, São Paulo, v. 25, n. 4, p. 9-23, abr. 1995.

MARGARIDO, Mario A. Transmissão de preços internacionais de suco de laranja para preços ao nível de produtor de laranja no estado de São Paulo. São Paulo, 1994. 96p. Dissertação (Mestrado). Escola de Administração de Empresas da Fundação Getúlio Vargas.

MARGARIDO, Mario A.; KATO, Heitor T. ; UENO, Lídia Hathue. Aplicação da metodologia BoxJenkins na análise de transmissão de preços no mercado de tomate no Estado de São Paulo. Estudos Econômicos, v.24, n. 3, p.405-432. 1994.

MARGARIDO, Mario A.; FREITAS FILHO, Floriano ; BIRAL, Gustavo L. A comunidade econômica européia e sua política agrícola comum. Informações Econômicas, São Paulo, v. 22 , n. 5 , p. 41-47, maio. 1992 b.

MASON, C. The impact of govemment policy on the US steel and cigarette industries. Minneapolis, 1985. Dissertation (Ph.D.). University of Minnesota

MILLS, Terence C. The econometric modelling of financial time series. New York: Cambridge University, 1993. 247p.

MILLS, Terence C. Time series techniques for economists. New York: Cambridge University, 1990. 377p.

MODIANO, E.M. Salários, preços e câmbio: os multiplicadores dos choques numa economia indexada. Pesquisa e Planejamento Econômico, v. 15, n. 1, p. 1-32. 1985

MUNDLACK, Yair ; LARSON, Donald F. On the transmission of world agricultural prices. The World Bank Economic Review, v. 6, n. 1, p. 399-422, 1992.

MUNDLACK, Yair ; CAVALLO, Domingo ; DOMENECH, Roberto. Effects of macroeconomics policies on setoral prices. The World Bank Economic Review, v.4, n.1, p.55-79.

ORDEN, David ; FACKLER, Paul L. Identifying monetary impacts on agricultural prices in VAR models. American Joumal of Agricultural Economics, v. 71, n. 2, p. 495-502, May 1989. 
OSTERWALD-LENUM, Michael. A note with quantiles of asymptotic distribution of the maximum likelihood cointegration rank test statistics, Oxford Bulletin of Economics and Statistics, v.54, n. 3, p.461-472. 1992.

PERRON, Pierre. Trend, unit root and structural change in macroeconomic time series. In RAO, B. Bhaskara. Cointegration for the applied economist. New York: ST. Martin's Press, 1994. p.113-146.

PERRON, Pierre. The great crash, the oil price shock and the unit root hypothesis: Erratum. Econometrica, v. 61, n. 1, p. 248-249, jan. 1993.

PERRON, Pierre. The great crash, the oil price shock and the unit root hypothesis. Econometrica, v. 57, n. 6, p. 1361-1401, nov. 1989.

PHILLIPS, S. ; BEWLEY, R. The effects of flexible exchange rates on australian wool prices. Autralian Joumal of Agricultural Economics, v. 36, n. 1, p. 49-76, April 1991.

PHILLIPS, Peter C.B. ; OULIARIS, S. Asymptotic properties of residual based tests for cointegration. Econometrica, v. 58, n. 1, p. 165-193, jan. 1990.

PHILLIPS, Peter C.B. ; PERRON, Pierre. Testing for a unit root in time series regression. Biometrika, v.75, n. 2, p. 335-346, 1988.

PHILLIPS, Peter C.B. Time series with a unit root. Econometrica, v. 55, n. 2, p. 277-301, Mar. 1987.

PINDYCK, Robert S. ; RUBINFELD, Daniel L. Econometric models and economic forecasts. 4 ed. Singapore: McGraw-Hill, 1998. 634p.

PINO, Francisco A. ; ROCHA, Marina B. Transmissão de preços de soja no Brasil. Revista de Economia e Sociologia Rural, v. 32, n. 4, p. 345-361, out./dez. 1994.

PONGIBOVE, Alfredo E.P. Políticas macroeconômicas, agricultura e comércio de produtos agrícolas: o caso do Brasil e Uruguai. Piracicaba, 1996. 181p. Tese (Doutorado). Escola Superior de Agricultura, Universidade de São Paulo.

ROBERTSON, John C. ; ORDEN, David. Monetary impacts on prices in the short and long run: some evidence from New Zealand. American Joumal of Agricultural Economics, v. 72, n. 1, p. 160-171, Feb. 1990.

SACHS, Jeffrey ; ZINI JUNIOR., Álvaro. A inflação brasileira e o "Plano Real". Revista de Economia Politica, v.15, n. 2, p. 26-49, abr.jjun. 1995.

SAID, Said E. ; DICKEY, David A. Testing for unit roots in autoregressive moving average models of unknow order. Biometrika, v. 71, n. 3, p.599-607, 1984.

SANTIAGO, Maura M.; CAMARGO, Maria L. ; MARGARIDO, Mario A. Detecção e análise de outliers em séries temporais de índices de preços agrícolas no Estado de São Paulo. Agricultura em São Paulo, v. 43, n. 2, p. 89-115. 1996.

SAS INSTITUTE Inc. SAS/ETS Sortware: Changes and Enhancements for Release 6.12. Cary: SAS Institute Inc., 1996. 112p.

SAS INSTITUTE Inc. User's Guide, Version 6, 2ed. Cary: SAS Institute Inc., 1993. 1022p. 
SAYAD, J. Inflação e agricultura. Pesquisa e Planejamento Económico, v. 9, n. 1, 1-31, abril. 1979.

SCHUH, Edward G. The exchange rate and U.S. agriculture. American Joumal Agricultural Economics, v. 56, n. 1, p. 1-13, Feb. 1974.

SILVA, César R.L. ; CARVALHO, Maria A. Taxa de câmbio e preços de commodities agrícolas. Informaçס̋es Econômicas, v.25, n. 5, p. 23-35, maio 1995.

SIMS, Christopher A. Are forecasting models usable for policy analysis? Quarterly ReviewFederal Reserve Bank of Minneapolis, Winter, 1986.

SIMS, Christopher A. Macroeconomics and reality. Econometrica, v. 48, p. 1-48, Jan. 1980.

THORSTENSEN, Vera. Comunidade Européia: líder do comércio intemacional. São Paulo: Aduaneiras, 1993. 318p.

VICENTE, José R. Choque agrícola, indexação e aceleração inflacionária: teste de um modelo pós-keynesiano. Agricultura em São Paulo, v. 41, n. 3, p. 39-60, 1994.

WOLD, H. A study in the analysis of stationary time series. Stockholm: Almqvist and Wiksell, 1938.

ZINI JÚNIOR, Álvaro A. Taxa de câmbio e política cambial no Brasil. São Paulo: EDUSP/BMF, 1993. 192p. 


\section{ANEXO 1}

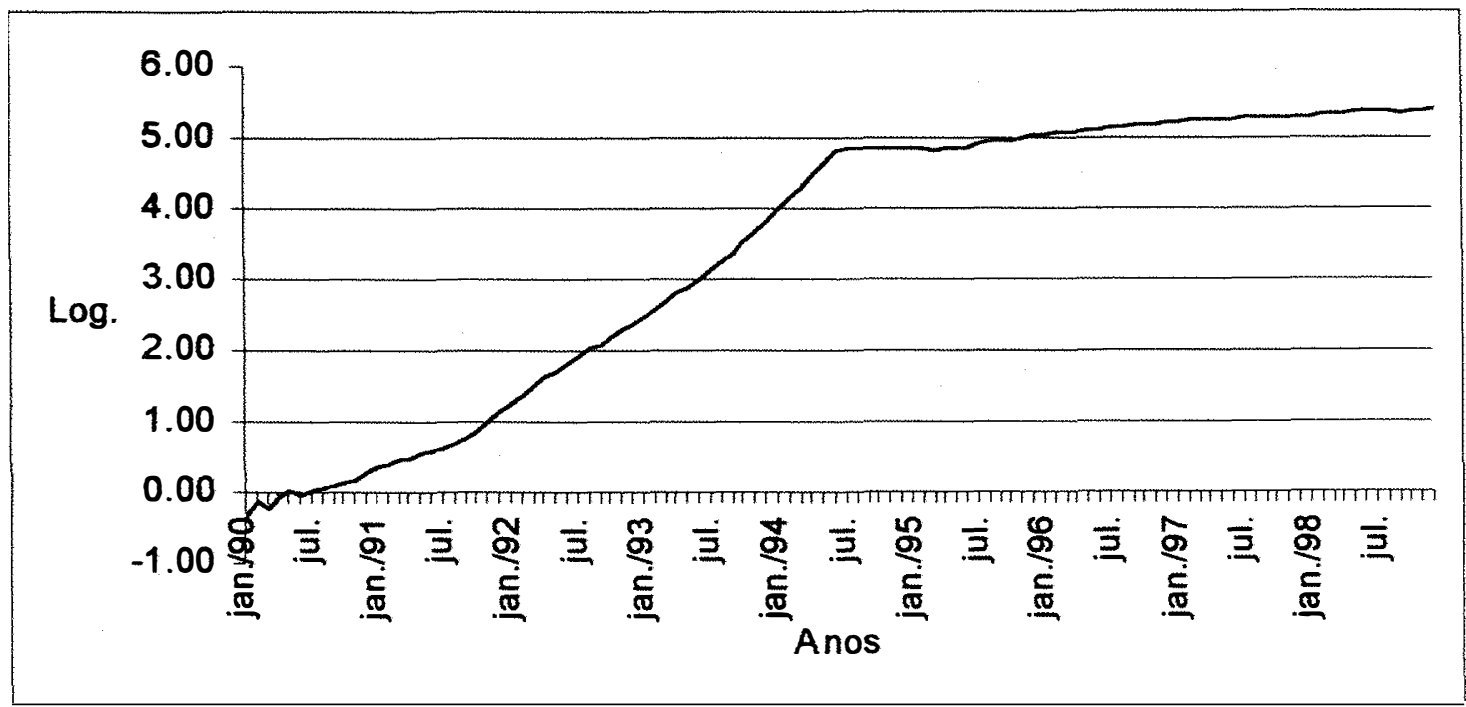

Figura 5 - Logaritmo da Oferta de Moeda (LM2), Brasil, Janeiro de 1990 a Dezembro de 1998. Fonte: Dados Básicos da Conjuntura Econômica (1991/1999).

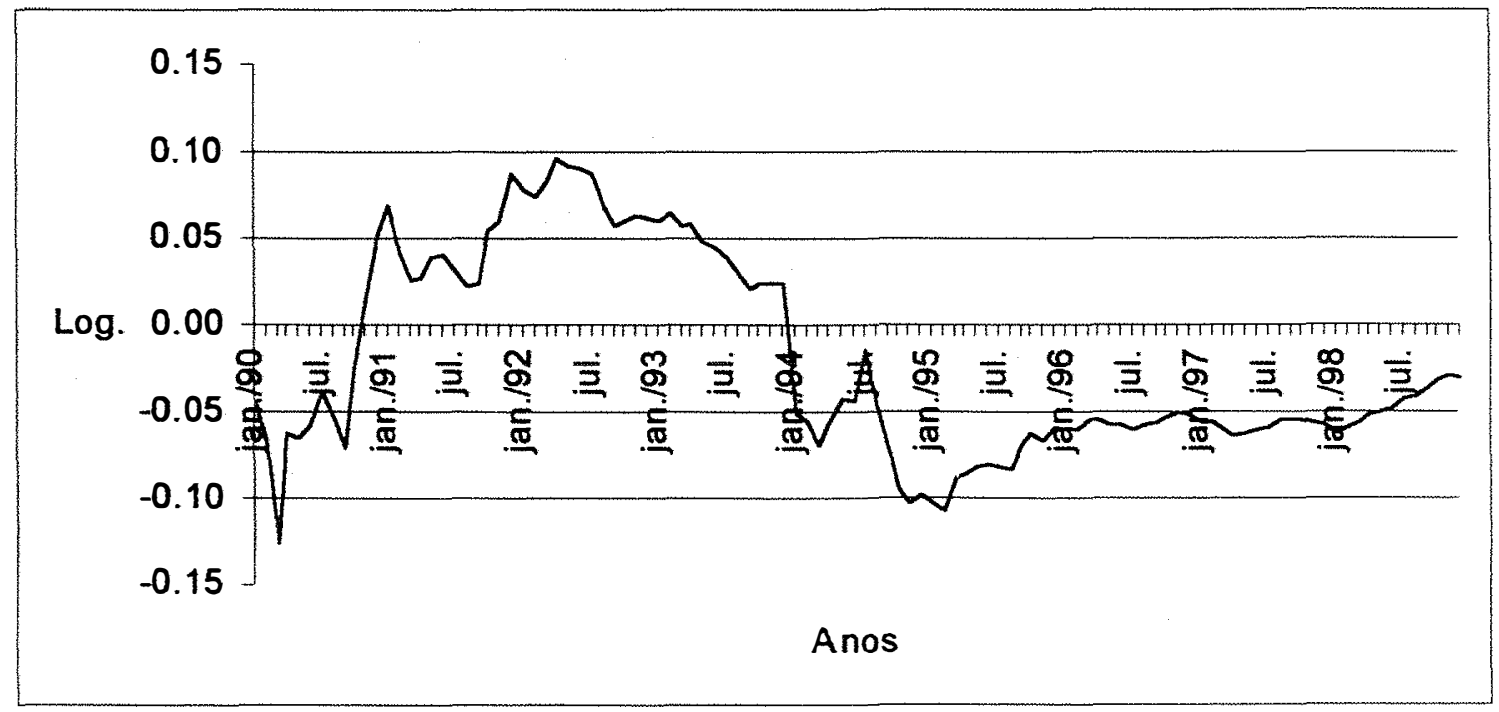

Figura 6 - Logaritmo da Taxa de Câmbio Real (LTCR), Brasil, Janeiro de 1990 a Dezembro de 1998.

Fonte: Dados Básicos da Conjuntura Econômica (1991/1999). 


\section{ANEXO 1}

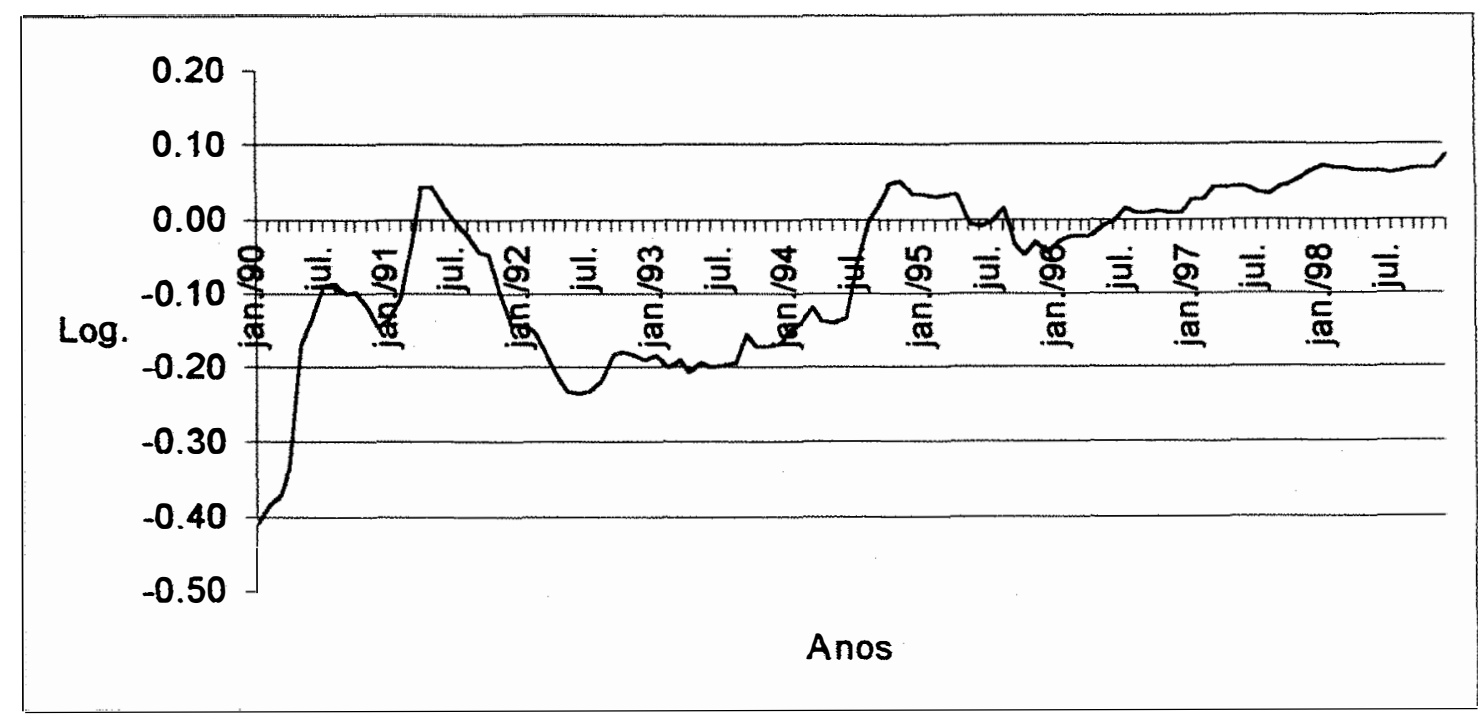

Figura 7 - Logaritmo da Relação de Troca entre Agricultura e Indústria (LRT), Brasil, Janeiro de 1990 a Dezembro de 1998.

Fonte: Dados Básicos da Conjuntura Económica (1991/1999). 